\title{
SYNTHESIS AND STRUCTURE-PROPERTY STUDIES OF ORGANIC DYES POSSESSING UNIQUE FUSED THIOPHENE $\pi$-SPACERS
}

\author{
by \\ Maryam Abdinejad \\ Masters in Science in Pharmaceutical Science \\ Greenwich University, London, UK 2011
}

A thesis presented to Ryerson University

in Partial Fulfillment of the

Requirements for the Degree of

Master of Science

in the Program of

Molecular Science 


\section{Author's Declaration}

I hereby declare that I am the sole author of this thesis. This is a true copy of the thesis, including any required final revisions, as accepted by my examiners.

I authorize Ryerson University to lend this thesis to other institutions or individuals for the purpose of scholarly research. I further authorize Ryerson University to reproduce this thesis by photocopying or by other means, in total or in part, at the request of other institutions or individuals for the purpose of scholarly research. I understand that my thesis may be made electronically available to the public.

Maryam Abdinejad

Sep. 11, 2014 


\title{
SYNTHESIS AND STRUCTURE-PROPERTY STUDIES OF ORGANIC DYES POSSESSING UNIQUE FUSED THIOPHENE $\pi$-SPACERS
}

\author{
Maryam Abdinejad \\ Master of Science, Molecular Science, \\ Ryerson University, 2014
}

\begin{abstract}
This thesis examines the synthesis of metal-free organic dyes for light-harvesting applications within the DSSC manifold. All DSSC organic dyes possess a similar donor- $\pi$-spacer-acceptor (D- $\pi-A)$ motif. Here, triphenylamine (TPA) is employed as a donor owing to its redox stability and cyanoacetic acid has been utilized as an acceptor due to its electron-withdrawing ability. Thiophenes are ubiquitous in organic materials chemistry owing to their exceptional charge transport behavior, and in this body of work, $\pi$-spacers incorporating benzodithiophene and thiophene-quinones have been incorporated into a DSSC dye and their utility explored. Fused thiophene cores are non-innocent $\pi$-spacers. Non-innocent, in this context, is defined as $\pi$ spacers that incorporate a secondary chromophore or redox active species (benzodithiophene or quinone).
\end{abstract}




\section{Acknowledgement}

First and foremost, I would like to thank my thesis supervisor Professor Bryan Koivisto for all his time, patience, advice and encouragement throughout my masters degree. His guidance led me to truly understand the topic at hand. Bryan's mentorship has provided me with nearly every opportunity to learn about interpreting, carrying out, and communicating science.

Many thanks also to Dr. Catherine Bonnier, Dr. Russell Viirre, Dr. Robert Gossage and Dr. Andrew McWilliams for this comments on my research in different stages that assisted in development of my thesis. I would like to thank Muhammad Yousaf, Omar Abdi, Benjamin Fischer and all my colleagues in the KHE 211 laboratory at the University of Ryerson for their conversations, friendship, and support during my M.Sc. research. I am eternally grateful for the support and encouragement of my family and friends, both here and afar, without whom life would be meaningless. A great many thanks are owed to my Mom and Dad. Without their tireless devotion to my happiness and education I would not be where I am today. Thank you! 


\section{Table of Contents}

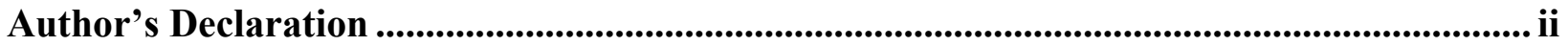

Abstract........................................................................................................................................ ii

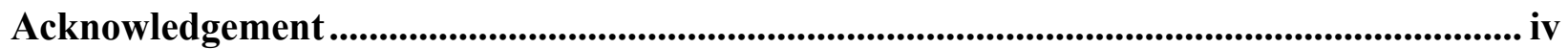

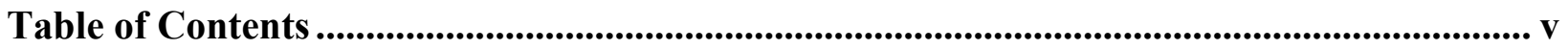

List of Figures...................................................................................................................................... viii

List of Schemes................................................................................................................. ix

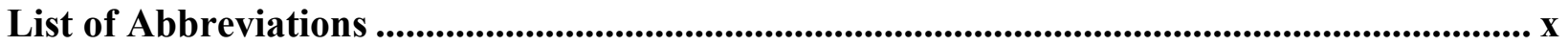

Chapter 1: Introduction ......................................................................................................................... 1

1.1. Energy and the environment: .............................................................................................................. 1

1.2. Dye sensitized solar cells (DSSC): .................................................................................................. 3

1.3. How molecules absorb light: ............................................................................................... 6

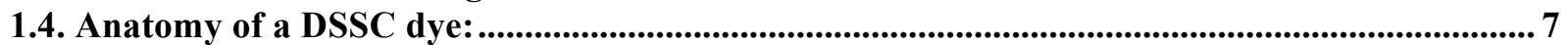

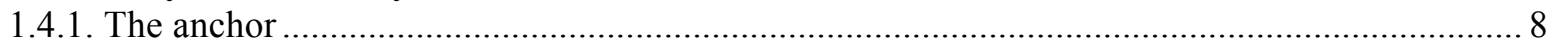

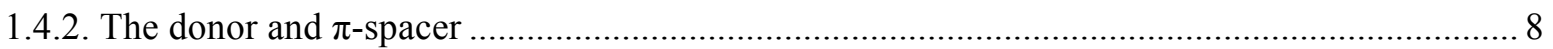

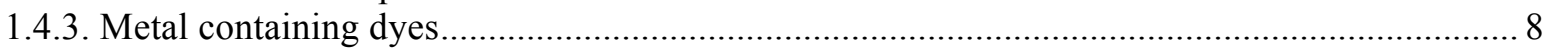

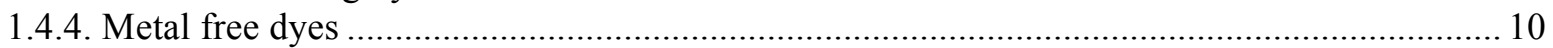

1.5. Physicochemical characterization: ..................................................................................................... 15

1.5.1. Electronic spectroscopy: Ultraviolet visible (UV-Vis) ....................................................... 16

1.5.2. Computational methods: Density functional theory (DFT) ……………………………........ 17

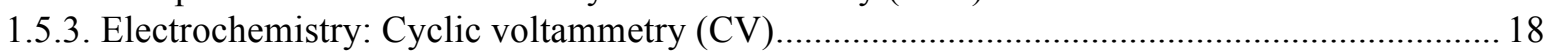

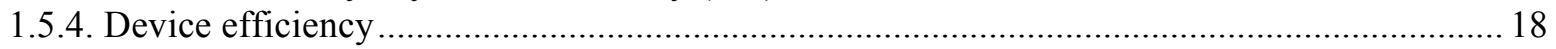

1.6. Thesis objectives: .................................................................................................................................... 20

Chapter 2: Synthesis of dyes containing fused thiophene $\pi$-spacers......................................... 23

2.1. Synthesis of electron donor (2.5): ..............................................................................................26

2.2. Synthesis of thiophene $\pi$-spacer building block (2.8): ............................................................... 27

2.3. Synthesis of the BDT-TPA-OMe dye (1.18): .............................................................................2

2.4. Synthesis of the thiophene-BDT-TPA-OMe dye (1.19): ...............................................................2 29

2.5. Synthesis of the BDT-OMe-TPA dye (1.20): ................................................................................31

2.6. Synthesis of the BDT-OMe-TPA thiophene dye (1.21): ................................................................32

2.7. Synthesis of quinone-thiophene-TPA-OMe dye (1.22):...................................................................34

2.8. Synthesis of the quinone-thiophene-TPA-OHex dye (1.23) and quinone-thiophene TPA dye

(1.24):...........................................................................................................................................35

Chapter 3: Results and discussion ............................................................................................... 37

3.1. Theoretical predictions using Density Functional Theory .............................................................37

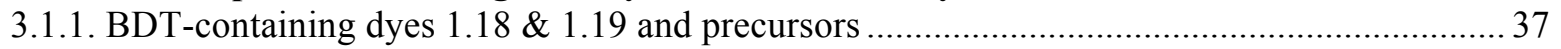

3.1.2. OMe-BDT containing dyes $1.20 \& 1.21$ and precursors ......................................................... 39

3.1.3. Quinone containing dyes $1.22,1.23 \& 1.24$ and precursors................................................... 41

3.2. Experimental Properties in Solution ........................................................................................... 44

3.2.1. Summary of results of the BDT dye family and precursors.................................................. 45

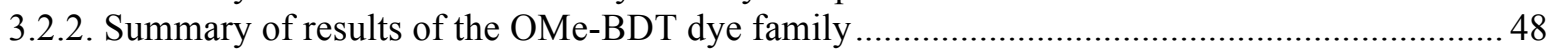


3.2.3. Summary of results of quinone dyes and precursors.

Chapter 4: Conclusions and future work ............................................................................... 56

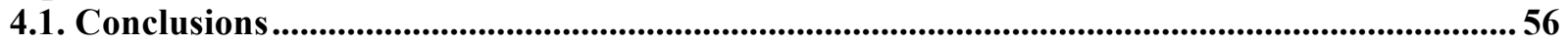

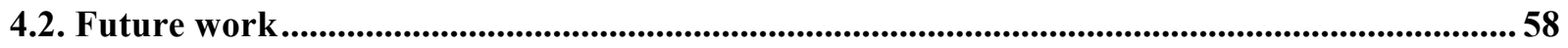

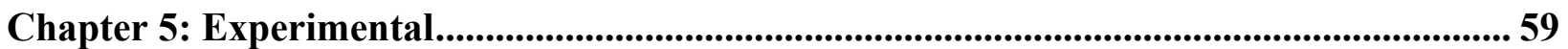

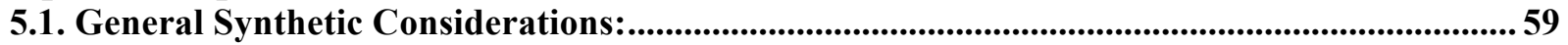

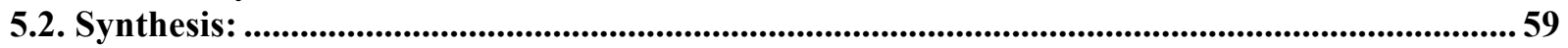

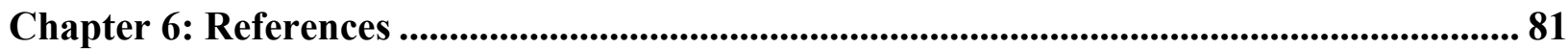

Appendix 1: Molecular index for chapter 1 ............................................................... 86

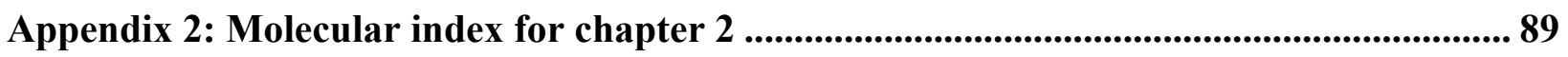




\section{List of Tables}

Table 1.1. Comparison of two of triphenylamine-based dyes ..................................................... 11

Table 1.2. Comparison of a number of dyes with similar electron donors and acceptors to the

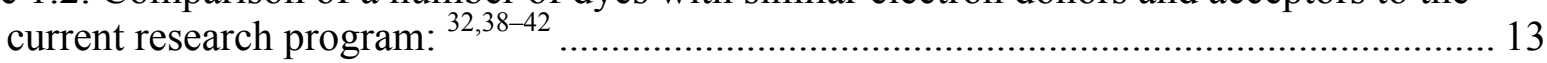

Table 1.3. Comparison of a number of BDT-based dyes. ........................................................ 14

Table 1.4. Halogenation's effect on BDT dye performance......................................................... 15

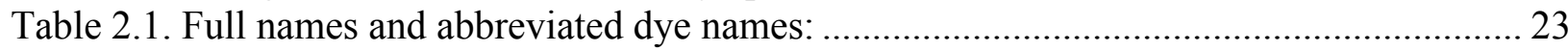

Table 2.2. Comparison of reactions used for the synthesis of 4,8-dimethoxy-benzo [1,2-b:4,5-b]

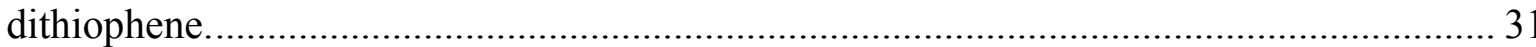

Table 3.1. Physicochemical characterization of the BDT dye family ......................................... 47

Table 3.2. Physicochemical characterization of the OMe-BDT dye family ..................................50

Table 3.3. Physicochemical characterization of the quinone dye family: Part A .......................... 54

Table 3.4. Physicochemical characterization of the BDT dye family: Part B .............................. 55 


\section{List of Figures}

Figure 1.1. Total primary energy demand from 1987 to 2011 and predicted demand 2011-2035 as sorted by source

Figure 1.2. Comparison of the annual energy gifted from the sun with total energy reserves and

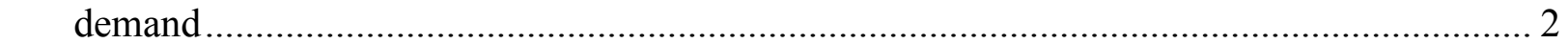

\section{1}

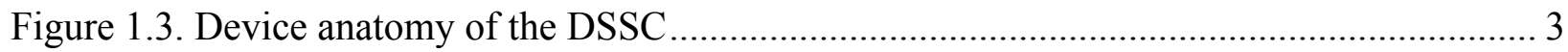

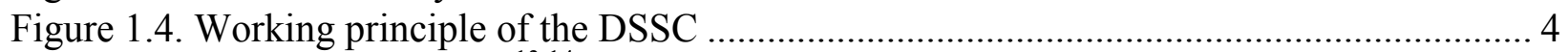

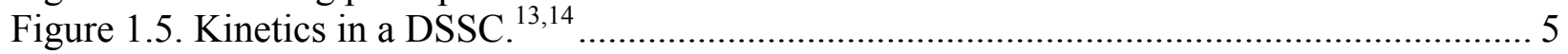

Figure 1.6. Things to consider when building a better chromophore ............................................ 6

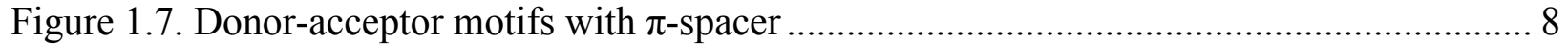

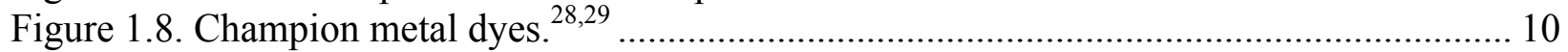

Figure 1.9. Comparing the affect of some different $\pi$-spacers ............................................. 11

Figure 1.10. Sun-like dye motifs comparing the affect of varied $\pi$-spacers ................................ 12

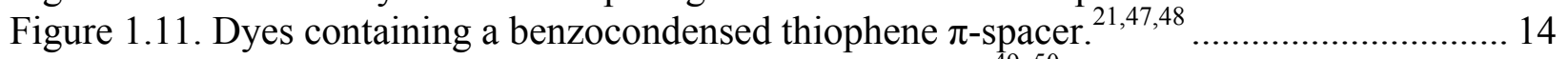

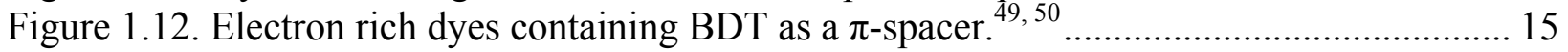

Figure 1.13. Different energy levels in DSSC applications..................................................... 16

Figure 1.14. Solar irradiance at terrestrial level. inset photon flux as a function of wavelength. ${ }^{54}$

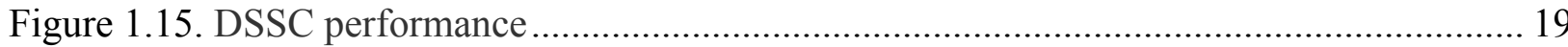

Figure 1.16. A variety of dyes with fused-thiophene $\pi$-spacers ................................................ 22

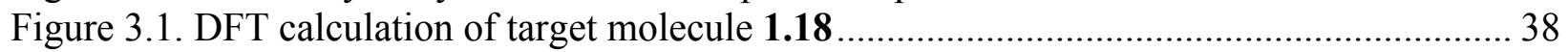

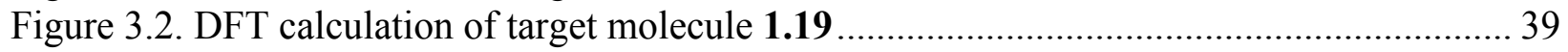

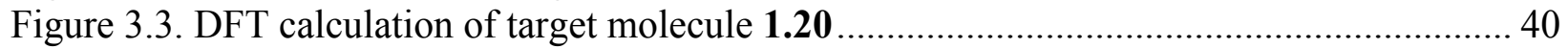

Figure 3.4. DFT calculation of target molecule 1.21 ............................................................... 41

Figure 3.5. DFT calculation of target molecule 1.22 ........................................................... 42

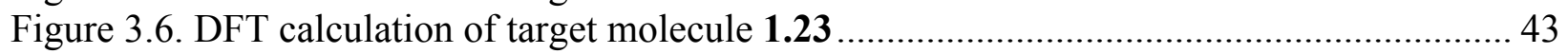

Figure 3.7. DFT calculation of the target molecule 1.24 ......................................................... 44

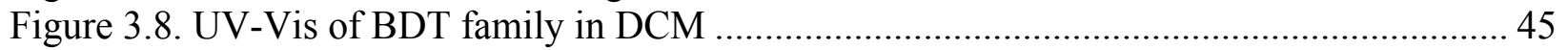

Figure 3.9. UV-Vis spectra in DCM for a select subset of the BDT-OMe dye family ................. 46

Figure 3.10. Comparison of cyclic voltammograms for dye $\mathbf{1 . 2 0}$ and molecule 2.26................. 48

Figure 3.11. Comparison of cyclic voltammograms for dye precursors $\mathbf{2 . 1 5}$ and 2.19............... 49

Figure 3.12. UV-Vis spectra in DCM for quinone-thiophene dye family .................................. 52

Figure 3.13. UV-Vis spectra in DCM for quinone- thiophene-TPA-OHex and thiophene TPA dye 


\section{List of Schemes}

Scheme 2.1. Synthesis of donor building blocks (2.5) ...................................................... 26

Scheme 2.2. Synthesis of thiophene spacer building block (2.8) ......................................... 27

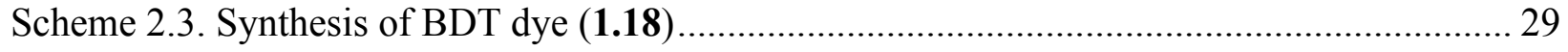

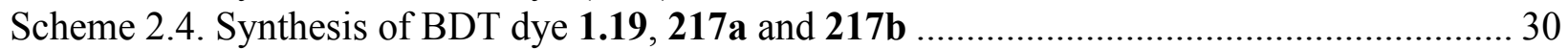

Scheme 2.5. Synthesis of MeO-BDT dye (1.20) .......................................................... 32

Scheme 2.6. Synthesis of MeOBDT-Thiophene dye (1.21) and by-product (2.28a and 2.28b) .. 33

Scheme 2.7. Synthesis of quinone-thiophene dye (1.22) ................................................ 35

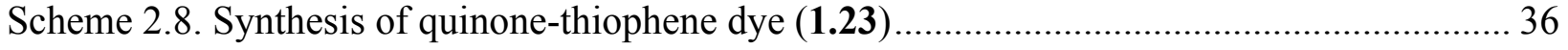

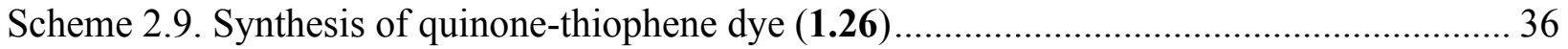




\section{List of Abbreviations}

$\delta \quad$ chemical shift

${ }^{\circ} \mathrm{C} \quad$ degree(s) Celsius

$\mathrm{AcOH}$ acetic acid

BDT benzodithiophene

$\mathrm{Bu} \quad$ butyl

CN cyanide

CV cyclic voltammetry

D- $\pi$-A donor-spacer-acceptor

DCM dichloromethane

DFT density functional theory

DIPEA $N, N$-diisopropylethylamine

DSSC dye sensitized solar cell

EI electron impact

eq equivalent

$\mathrm{EtOH}$ ethanol

g gram

h hour(s)

ICT intra-molecular charge-transfer

HOMO highest occupied molecular orbital

$\mathrm{Hz}$ hertz

Ipr- $\mathrm{B}_{\text {pin }}$ isopropoxy pin barone

LUMO lowest unoccupied molecular orbital

$\mathrm{m} / \mathrm{z} \quad$ mass/charge ratio

$\mathrm{mL} \quad$ milliliter

Mtoe million tonnes of oil equivalent

NBS $N$-bromosuccinimide

NHE normal hydrogen electrode 


$\begin{array}{ll}\text { NMP } & \text { N-methylpyrrolidone } \\ \text { NMR } & \text { nuclear magnetic resonance } \\ \text { OHex } & \text { hexoxy } \\ \text { OMe } & \text { methoxy } \\ \text { p } & \text { para } \\ \text { Phen } & \text { 1,10-phenanthroline } \\ \text { ppm } & \text { parts per million } \\ & \\ \text { PV } & \text { photovoltaic } \\ \text { s } & \text { singlet, strong, (NMR, IR descriptor) or standard } \\ \text { TBA } & \text { tetrabutylammonium } \\ \text { TDDFT } & \text { time- dependent DFT } \\ \text { THF } & \text { tetrahydrofuran } \\ \text { TiO } 2 & \text { titanium oxide } \\ \text { TLC } & \text { thin layer chromatography } \\ & \\ \text { TPA } & \text { triphenylamine } \\ \text { UV } & \text { ultraviolet } \\ & \text { molar absorptivity } \\ & \text { wavelength of strongest electronic absorption } \\ & \\ & \end{array}$




\section{Chapter 1: Introduction}

\subsection{Energy and the environment:}

From the beginning of the last century, our energy demand has grown quickly, and as a result of an increasing global population and higher standards of living, we are depleting our fossil fuel reserves. ${ }^{1}$ Fossil fuels are carbonaceous energy sources that are nonrenewable and produce $\mathrm{CO}_{2}$ upon combustion, leading to adverse effects on the environment. ${ }^{2,3}$ While 2009 saw a global reduction in primary energy consumption of $1.1 \%$ (owing to the global recession) the highest rate increase in consumption (since 1973) was observed in 2010 (+5.6\%). Energy-related emissions of $\mathrm{CO}_{2}$ will more than double by 2050 with unsustainable consequences economically, environmentally and socially (Figure 1.1). Therefore, the advancement of clean energy needs to be accelerated. ${ }^{4,5}$

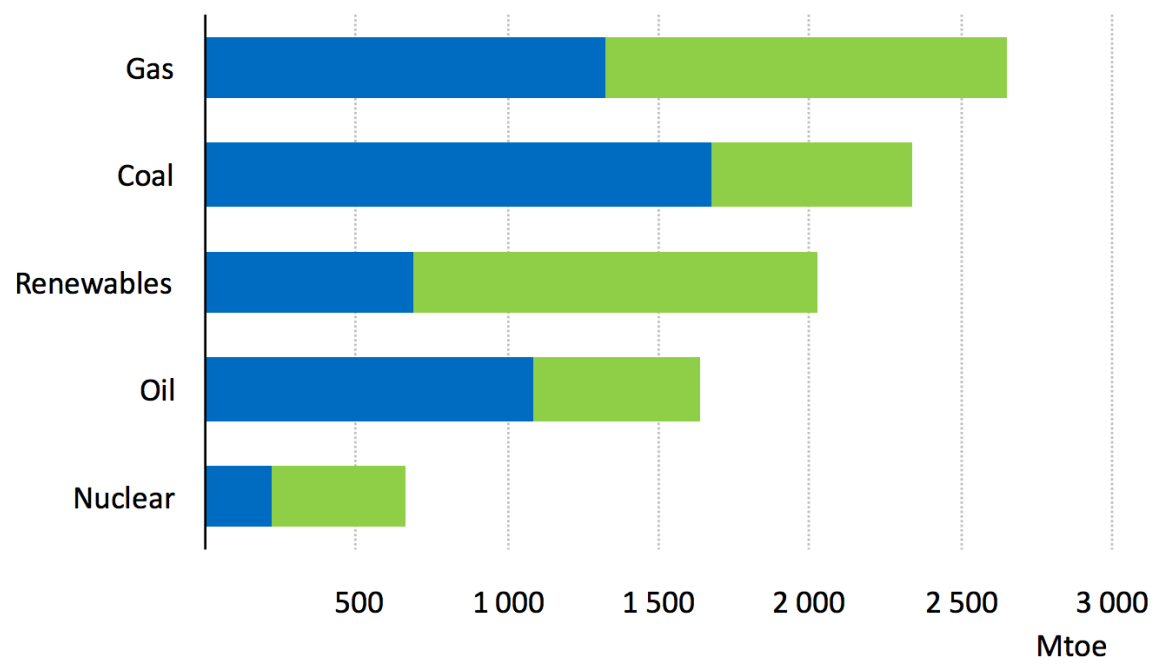

- 1987-2011

- 2011-2035

Figure 1.1. Total primary energy demand from 1987 to 2011 and predicted demand 2011-2035 as sorted by source 
Renewable sources of energy are derived from natural processes that do not involve the consumption of exhaustible resources, such as fossil fuels and uranium. Currently, the main renewable energy sources include hydropower, wind, solar, geothermal energy, and combustible waste. Despite high growth rates in clean energy, solar power generation still represents only a small fraction of global energy consumption (1.7\%). ${ }^{4}$ Of the renewable energy possibilities, solar energy is the most promising. The sun is the one source that on its own could supply the world projected energy demand in a sustainable fashion. ${ }^{6}$ To put it in perspective, the amount of solar energy reaching the earth in one day could power the planet for an entire year (Figure 1.2). ${ }^{7}$ Moreover, unlike other sources of energy, photovoltaic has a negligible environmental footprint, can be deployed almost anywhere and could utilize existing technologies and manufacturing processes, making it cheap and efficient to implement. ${ }^{7}$

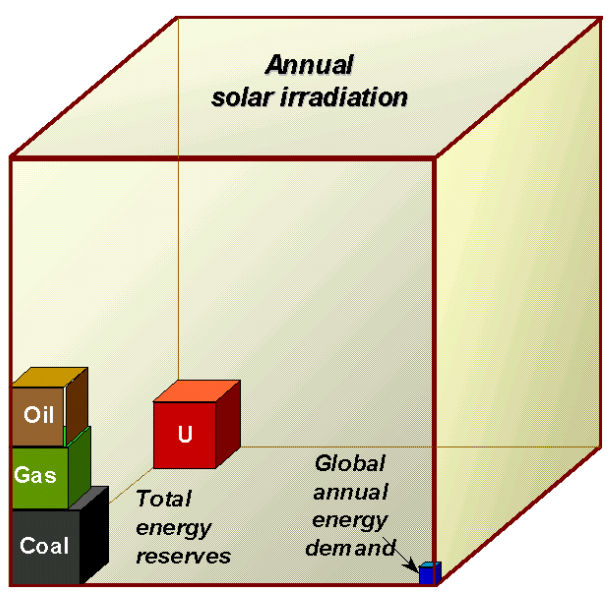

Figure 1.2. Comparison of the annual energy gifted from the sun with total energy reserves and demand 


\subsection{Dye sensitized solar cells (DSSC):}

Solar or photovoltaic (PV) cells directly convert light into electricity. A highly promising, next-generation photovoltaic device is the dye-sensitized solar cell. The device is comprised of two electrodes; a photoanode and a counter electrode, with an electrolyte filling the void space between electrodes (Figure 1.3). Both electrodes are made from a thin transparent conductive layer of fluorine-doped tin dioxide (FTO) or indium-doped tin oxide (ITO). The cathode is a conductive glass covered with a thin layer of metallic platinum, which has a catalytic effect in the reduction process of the electronic mediator. ${ }^{8}$ As such, the DSSC is a promising candidate for a low-cost alternative to conventional semiconductor photovoltaic devices. ${ }^{9}$

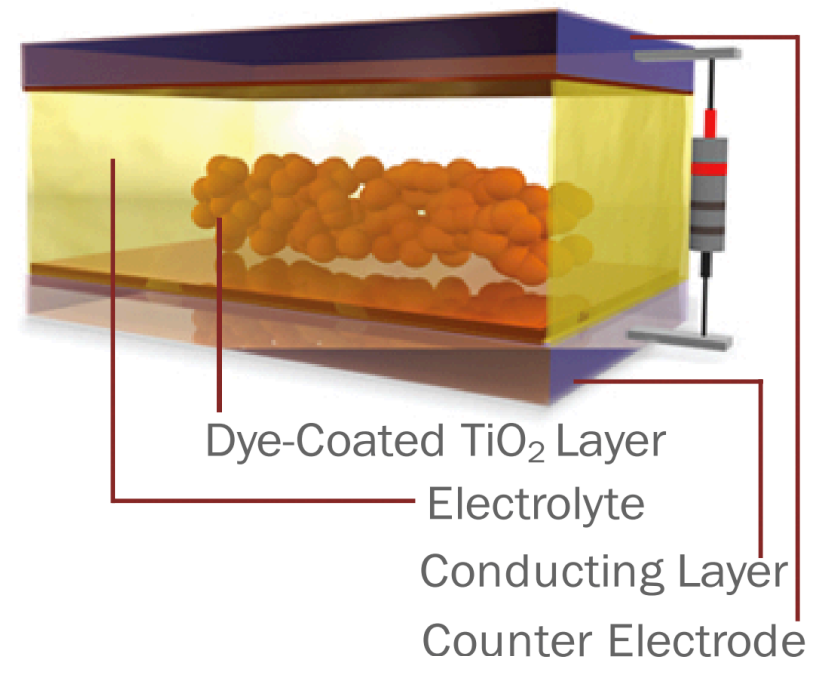

Figure 1.3. Device anatomy of the DSSC 
The thermodynamic working principle of the DSSC is shown in Figure 1.4. Upon photoexcitation (1) an electron is promoted from the ground state (S) to excited state $\left(S^{*}\right)$ of the dye. If sufficient charge separation occurs in the dye electron density will be redistributed towards the anchor (2), and an electron will inject into the conduction band of $\mathrm{TiO}_{2}$. The electron travels through the $\mathrm{TiO}_{2}$ and the external load (3), before going to the cathode where it reduces the electrolyte species $\left(\mathrm{I}^{-} / \mathrm{I}_{3}^{-}\right)$. Finally, the electrolyte shuttles the electron back to the dye (4), and the dye is regenerated and the cycle can happen again. ${ }^{10}$ Therefore, the thermodynamic driving force in this device is the excited state of the dye, and the excited state must be higher than the conduction band edge of the $\mathrm{TiO}_{2}$ for efficient sensitization. In fact, all forward electron transfers must be energetically favorable to have efficient electron transfer and charge-transport. ${ }^{10,11}$

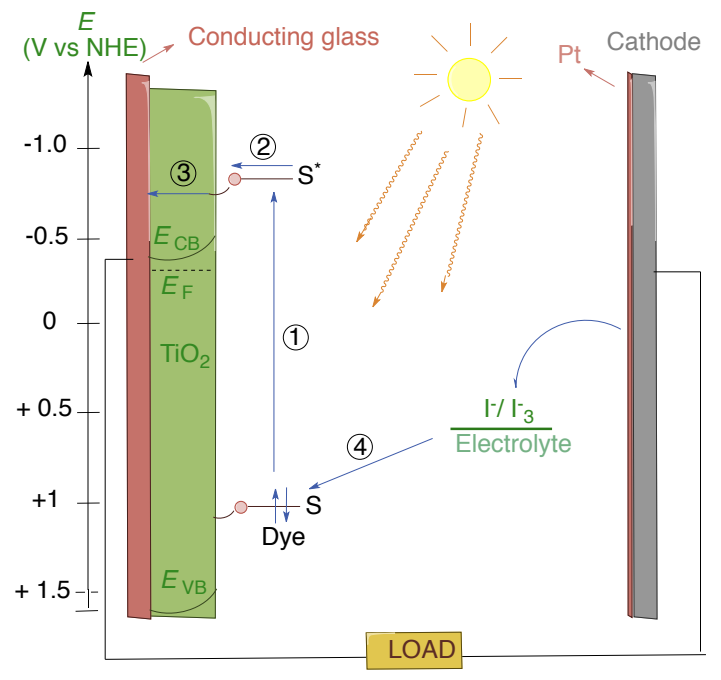

Figure 1.4. Working principle of the DSSC 
The DSSC also has several competing kinetic rates that must be considered in order for the device to function appropriately. All desirable electron transfers are in competition with a series of unwanted electron transfers that can short circuit the cycle. As in natural photosynthesis, kinetic competitions between the various forward and loss pathways are important to determine the quantum efficiencies of charge separation and collection of charge. Therefore, rates of electron transfer are used as key factors in determining energy conversion efficiency. Figure 1.5, highlights the favorable (shown in green) and disfavorable kinetic processes (shown in red). Ultimately the favorable processes must be faster than the disfavorable processes in order to generate a positive photocurrent. Each favorable charge-transfer step increases the separation of electrons and reduces the free energy stored in this state. ${ }^{11}$

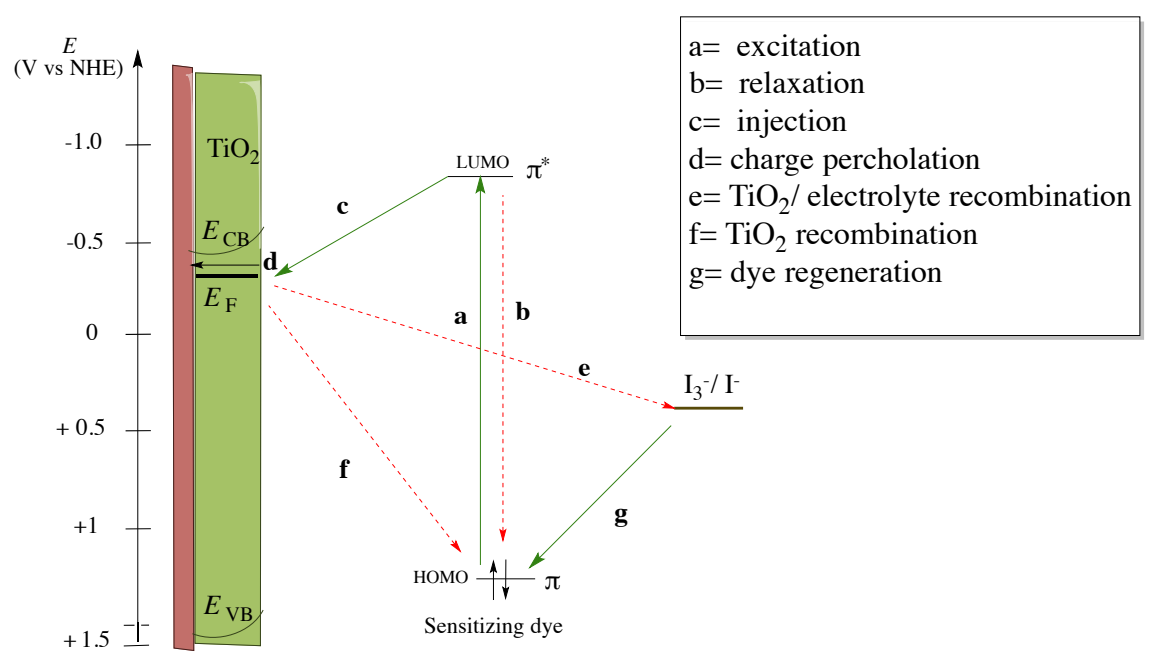

Figure 1.5. Kinetics in a DSSC. ${ }^{12,13}$

As shown in Figure 1.5, upon absorption the favorable rates include; injection, percolation and regeneration. The disfavorable processes include; relaxation and recombination (for which there are two kinds). ${ }^{14,15}$ Electron injection competes with relaxation of the excited dye; $\mathrm{TiO}_{2} /$ dye recombination competes with dye regeneration; and $\mathrm{TiO}_{2}$ /electrolyte recombination competes with percolation away from the semiconductor surface. Typically, the major waste process in a DSSC is back electron transfer at the semiconductor-electrolyte interface between electrons in the conduction band and electrolyte. ${ }^{16,18}$ However, $\mathrm{TiO}_{2} /$ electrolyte recombination can be overcome 
with surface passivation. Electron injection is several orders of magnitude faster than relaxation and is seldomly observed to be the kinetic bottleneck, unless there is a trapped excited state within the dye molecule. ${ }^{16,17}$

\subsection{How molecules absorb light:}

By definition, a photon of light is absorbed when an electron is promoted from low energy or non-bonding orbitals into an empty higher energy orbital. ${ }^{18}$ However, this does not rationalize the extent to which absorption occurs; a much more important consideration for photovoltaic applications. The dye is the powerhouse of the DSSC device, and these dyes or chromophores are molecules that have been designed to absorb strongly (high molar extinction coefficient). Like pigments found in nature (i.e., chlorophyll) it is desirable if these dyestuffs absorb strongly in the visible and near IR regions of the electromagnetic spectrum.

Designing an efficient chromophore the following features should be included (Figure 1.6). While all factors are important, extending conjugation within molecules leads to a decrease in the HOMO-LUMO gap $\left(\pi-\pi^{*}\right)$, and a bathochromic shift of the absorption.

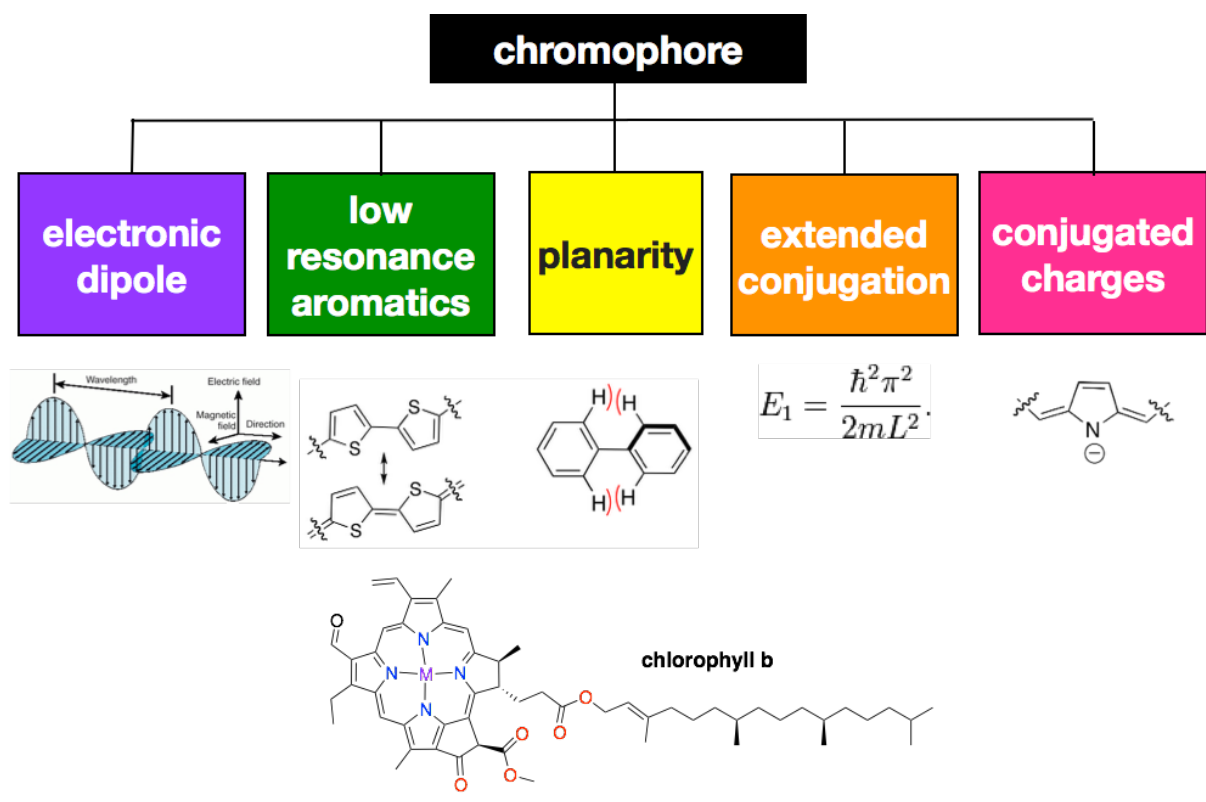

Figure 1.6. Things to consider when building a better chromophore 
The efficacy of light absorption, and the fundamental reason why molecules absorb radiation, is quantified by the molar extinction coefficient $(\varepsilon)$ :

$$
\varepsilon \propto \sigma \mathrm{P}
$$

Where $\sigma$ is the optical cross section and $\mathrm{P}$ is the probability of absorption. The optical cross section is proportional to the size and conjugation in a molecule, and the probability, $\mathrm{P}$, of absorption is proportional to wave function overlap;

$$
\mathrm{P} \propto\left\langle\Psi|\mu| \Psi^{*}\right\rangle
$$

Where $\Psi$ is the wave function describing the ground state electron density and $\Psi^{*}$ describes the electron density in the excited state; $\mu$ is the polarizability. The polarizability represents a molecules propensity to undergo charge redistribution upon photon absorption, and the wave function overlap between the ground and excited states can be calculated using time-dependent density functional theory (vide infra).

\subsection{Anatomy of a DSSC dye:}

The sensitizing dye is a critical component of the DSSC, because it is responsible for light harvesting, and electron injection into the semiconductor. Its absorption spectrum should cover the visible and near-infrared (NIR) portion of the spectrum, to maximize efficiency. ${ }^{19}$ As previously discussed, all DSSC dyes have a common structural motif. All dyes must have a redox active (and redox stable) electron donating group (D), a $\pi$ conjugated spacer and an electron-withdrawing anchor (A), capable of binding to titania $\left(\mathrm{TiO}_{2}\right)$. This common D- $\pi$-A feature has been extensively studied (Figure 1.7). Often referred to as 'push-pull' systems, there is a wealth of literature examples that are well outside the scope of this thesis. Therefore the remainder of this section will focus on the 'champion' (greater than $10 \%$ efficiency) or historically significant DSSC dye molecules. ${ }^{20,21}$ 


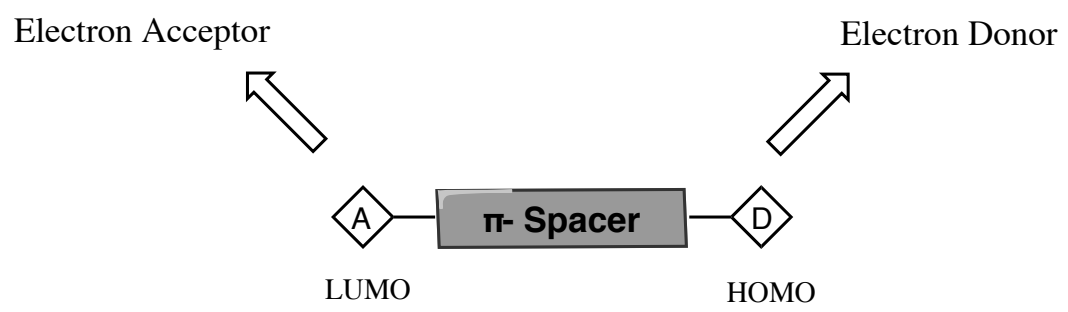

Figure 1.7. Donor-acceptor motifs with $\pi$-spacer

\subsubsection{The anchor}

The anchor used in DSSC dyes has seen the least amount of variation. Owing for the need to bind to titania, the most studied acceptor groups have been anchoring groups like: - $\mathrm{COOH},-\mathrm{H}_{2} \mathrm{PO}_{3}$ and $-\mathrm{SO}_{3} \mathrm{H}$, etc. ${ }^{19}$ More recently, cyanoacetic acid anchors have been incorporated because of their increased electron withdrawing behavior when compared to carboxylic acids.

\subsubsection{The donor and $\pi$-spacer}

Both the donor and $\pi$-spacers have seen considerable variation in the DSSC dye anatomy. Depending on the nature of the sensitizing transition, the DSSC dye anatomy can be further broken down into metal-containing and non-metal dyes. As such, the remainder of the discussion will be broken down into two significant categories, shown below:

1. Metal complexes using metal-to-ligand charge transfer (MLCT) as the mode of sensitization and, ${ }^{22-24}$

2. Metal-free organic dyes that use $\pi-\pi^{*}$ as the mode of sensitization. ${ }^{25}$

\subsubsection{Metal containing dyes}

While metal-based dyes are not the focus of this thesis, for the sake of context and completeness, a brief discussion is contained herein. Unlike organic dyes, metal-based DSSC dyes sensitize titania using a metal-to-ligand charge transfer (MLCT). This by its very nature, requires a redox active metal and a ligand $\pi^{*}$-system to accept the excited electron. Historically, the first dye to achieve 'champion' status was the ruthenium 
complex, 1.1 (a power conversion efficiency of 11.2\%); (Figure 1.8). This rutheniumbased dye was first reported by Grätzel in $1991 .{ }^{26}$ In this dye, the HOMO is delocalized over the thiocyanate-ruthenium portion of the molecule, and the LUMO is delocalized over the $\pi$-system of the ligand and the carboxylate anchors.

Therefore in this context, the $\mathrm{Ru}^{2+}$ metal centre is the redox active donor, and the pyridyl ligand is the $\pi$-spacer and carboxylate groups, the acceptor (D- $\pi$-A). After this discovery, a wealth of champion ruthenium-dyes were prepared. ${ }^{28}$ The major drawbacks of ruthenium-based complexes are the high cost and limited supply of ruthenium. ${ }^{27,28}$

Based on nature's effective chlorophyll model a number of different photosensitizing complexes have been studied that contain porphyrins and phthalocyanines. More recently, a new class of mixed metal-organic compounds has emerged as champion dyes. The zinc porphyrin-based dye 1.2, does not incorporate a redox active metal, but instead uses the zinc metal within the porphyrin core to increase stability and planarity within the system (Figure 1.8). Instead, the bis-arylamine is the redox active donor group, the porphyrin is the $\pi$-spacer and the carboxylic acid group is the acceptor/anchor. The dominant optical transition in the zinc-porphyrin dye is not MLCT transition, but rather a $\pi-\pi^{*}$ transition that is responsible for sensitization of the semiconductor. Therefore, $\mathbf{1 . 2}$ (with an efficiency of $15 \%$ ) $^{29}$ technically, behaves more like an organic dye owing to its mode of sensitization, but this example does highlight the diversity and hybrid nature of dyes, and serves as a segue to discuss the donors and $\pi$-spacers used in strictly organic motifs. ${ }^{24}$ 


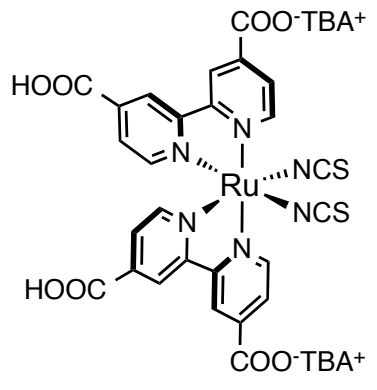

1.1

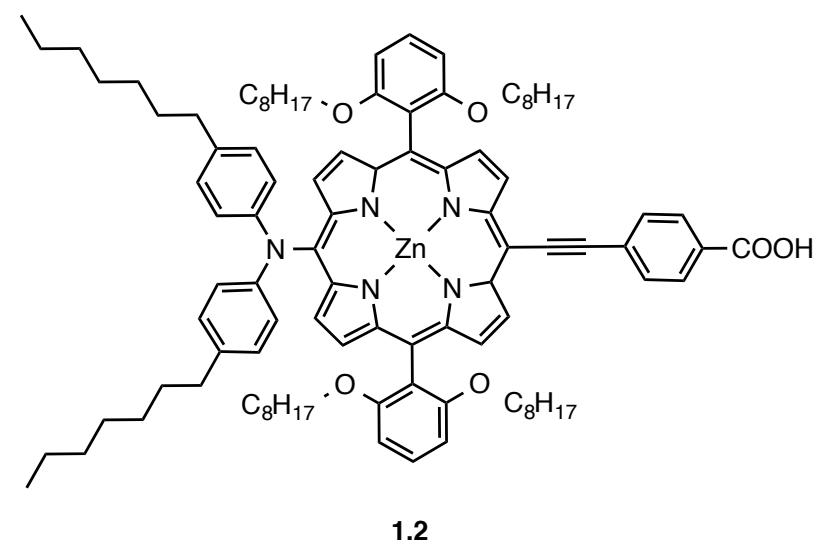

Figure 1.8. Champion metal dyes. ${ }^{27,28}$

\subsubsection{Metal free dyes}

While the majority of the champion dyes have been ruthenium-based, there has been a significant push to create efficient carbonaceous analogs. Metal-free dyes are simple and cheap to prepare and it is possible to tune their optical and electrochemical properties through a myriad of synthetic techniques. Consequently, carrier transport properties can be improved by optimizing the interaction with both the semiconductor and electrolyte, while charge generation can be improved by modifying the dye structure; all of which can be tailored using organic chemistry. ${ }^{30}$ As a result, a large number of organic DSSC dyes have been reported and summarized in various reviews. ${ }^{31,32}$

Owing to the redox stability, arylamines are most commonly employed as donors in organic DSSC dyes. Of these, triphenylamines (TPA) have been the most studied electron donor group due to their redox stability, strong electron donating ability and aggregation resistance thanks to a non-planar geometry. A strong electron donating effect, is further improved with the introduction of various alkoxy substituents. ${ }^{33}$ Yanagida and co-workers were the first researchers to introduce the triphenylamine unit as an electron donor in organic dyes. ${ }^{34}$ Sun and co-workers optimized triphenylaminebased dyes and published a series of efficient organic dyes, based on a similar structural motif. $^{35}$ Despite only having a power conversion efficiency of 5.2\% (1.3), this seminal work serves as a historical benchmark in dye design (Figure 1.9). ${ }^{36}$ 


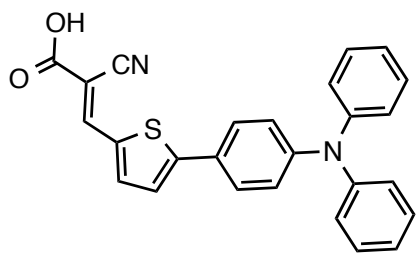

1.3

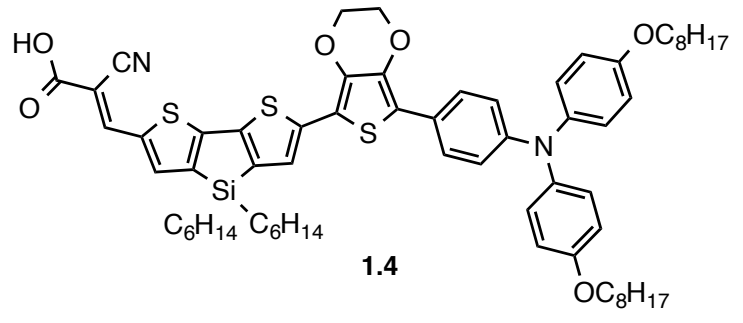

Figure 1.9. Comparing the affect of some different $\pi$-spacers

Substitution of methoxy-TPA dye has also been modified with methoxy groups to effectively raise the HOMO energy and red-shift the absorption spectrum. ${ }^{37}$ In this dye family, the TPA unit is the donor, the thiophene is the $\pi$-spacer, and the cyanoacetic acid represents the acceptor/anchor group. In fact, building on Sun's initial structural motif, Wang and coworkers ${ }^{17}$, optimized the $\pi$-spacer design (extended conjugation, added surface pacifying groups), and reported the first metal free dye to achieve 'champion' status (1.4).

Table 1.1. Comparison of two of triphenylamine-based dyes

\begin{tabular}{|c|c|c|c|c|c|}
\hline Compound & $\begin{array}{c}\boldsymbol{J}_{\text {sc }} \\
\left(\mathrm{mA} / \mathrm{cm}^{2}\right)\end{array}$ & $\mathbf{V}_{\text {oc }}$ & $\mathbf{F F}$ & $\boldsymbol{\eta}(\%)$ & $\begin{array}{c}\boldsymbol{\varepsilon} / \boldsymbol{\lambda}_{\max } \\
\left(10^{4} \mathrm{M}^{-1} \mathrm{~cm}^{-1}\right) /(\mathrm{nm})\end{array}$ \\
\hline $\mathbf{1 . 3}^{36}$ & 12.8 & 0.62 & 0.66 & 5.2 & $2.5 / 494$ \\
\hline $\mathbf{1 . 4}^{35}$ & 17.94 & 0.77 & 0.730 & 10.1 & $3.4 / 530$ \\
\hline
\end{tabular}

The $\pi$-spacer plays a fundamental role, as it is responsible for the electronic communication between the donor and acceptor moiety. Extending the conjugation leads to a broader red-shifted absorption. The $\pi$-spacer linkage with the donor also facilitates conjugation between the donor and the spacer effectively increasing electronic communication between these two groups and this is a necessary requirement for charge separation in the excited state. ${ }^{20,21}$ (Figure 1.10 and Table 1.2), highlight a number of 
dyes, that have exploited the Sun motif, and their structure property relationships are highlight below. Not surprisingly, molecule 1.9 has the lowest performance within this set owing to it possessing a blue shifted absorption because it lacks a $\pi$-spacer.
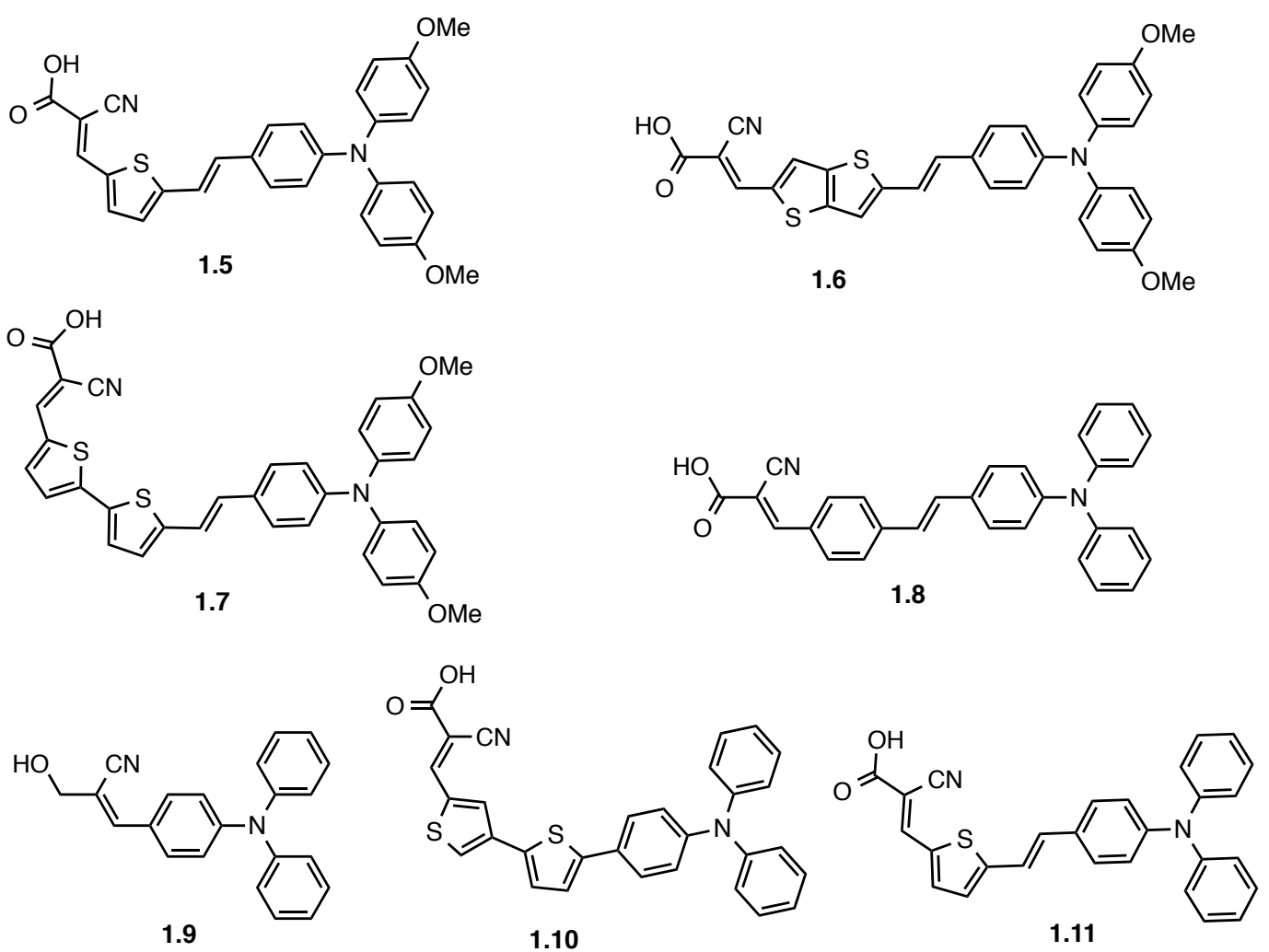

Figure 1.10. Sun-like dye motifs comparing the affect of varied $\pi$-spacers 
Table 1.2. Comparison of a number of dyes with similar electron donors and acceptors to the current research program: ${ }^{31,37-41}$

\begin{tabular}{|c|c|c|c|c|c|}
\hline Compound & $\begin{array}{c}\boldsymbol{J}_{\boldsymbol{s c}} \\
\left(\mathrm{mA} / \mathrm{cm}^{2}\right)\end{array}$ & $\mathbf{V}_{\text {oc }}$ & $\mathbf{F F}$ & $\boldsymbol{\eta}(\mathbf{\%})$ & $\boldsymbol{\varepsilon} / \boldsymbol{\lambda}_{\max }$ \\
\hline $\mathbf{1 . 5}^{42}$ & 14 & 0.69 & 0.71 & 6.9 & $\left(10^{4} \mathrm{M}^{-1} \mathrm{~cm}^{-1}\right) /(\mathrm{nm})$ \\
\hline $\mathbf{1 . 6}^{41}$ & 15.5 & 0.61 & 0.70 & 6.6 & $3.3 / 462$ \\
\hline $\mathbf{1 . 7}^{41}$ & 15.3 & 0.63 & 0.73 & 7.0 & $4.8 / 443$ \\
\hline $\mathbf{1 . 8}^{38}$ & 18.1 & 0.74 & 0.68 & 9.1 & $4.7 / 621$ \\
\hline $\mathbf{1 . 9}^{36,43}$ & 6.1 & 0.60 & 0.68 & 2.5 & $1.5 / 400$ \\
\hline $\mathbf{1 . 1 0}^{44}$ & 16 & 0.63 & 0.61 & 6.2 & $4.2 / 457$ \\
\hline $\mathbf{1 . 1 1}^{37,40}$ & 12 & 0.69 & 0.72 & 5.9 & $3.3 / 537$ \\
\hline
\end{tabular}

Building on the success of Wang's dye, and more closely related to the focus of this thesis, dyes containing fused thiophene $\pi$-spacers have attracted significant attention. ${ }^{45,46}$ In an attempt to increase the electron density within the $\pi$-spacer, benzodithiophene (BDT) derivatives have been targeted in DSSC dyes. The collated data in Table 1.3 illustrates the comparison of several dye molecules containing BDT $\pi$-spacers. (Figure $1.11)$

Comparing 1.12 with 1.14 we see an improved performance in $\mathbf{1 . 1 2}$ when using the higher symmetry BDT cores, despite having a lower extinction coefficient. This is likely a result of better conjugation between the donor and acceptor through the core, but differences in surface orientation and dye loading on $\mathrm{TiO}_{2}$, may also be an issue. When examining 1.12 and 1.13, the use of an alkyne (in 1.13) appears to decrease the performance. Near parity between absorption coefficients, and a blue shifted absorption, suggests that the electron withdrawing nature of the alkyne (relative to the alkene) has mitigated the donors effect on the $\pi$-spacer, resulting in poorer charge separation. The biggest surprise in this series is seen when comparing 1.12 with 1.15. Despite having a 
more idealized absorption, and device fill factor, the performance is lower for $\mathbf{1 . 1 5}$. The Voc is remarkably different between the two samples and this suggests a discrepancy with the $\mathrm{TiO}_{2}$ or electrolyte composition. These types of discrepancies are a common occurrence in this field, and it is difficult to draw conclusions regarding structureproperty relationships between intergroup studies owing to the quality and composition of both the electrolyte and titania. As such, this in an impetus for us to reexamine this class of structure in more detail.
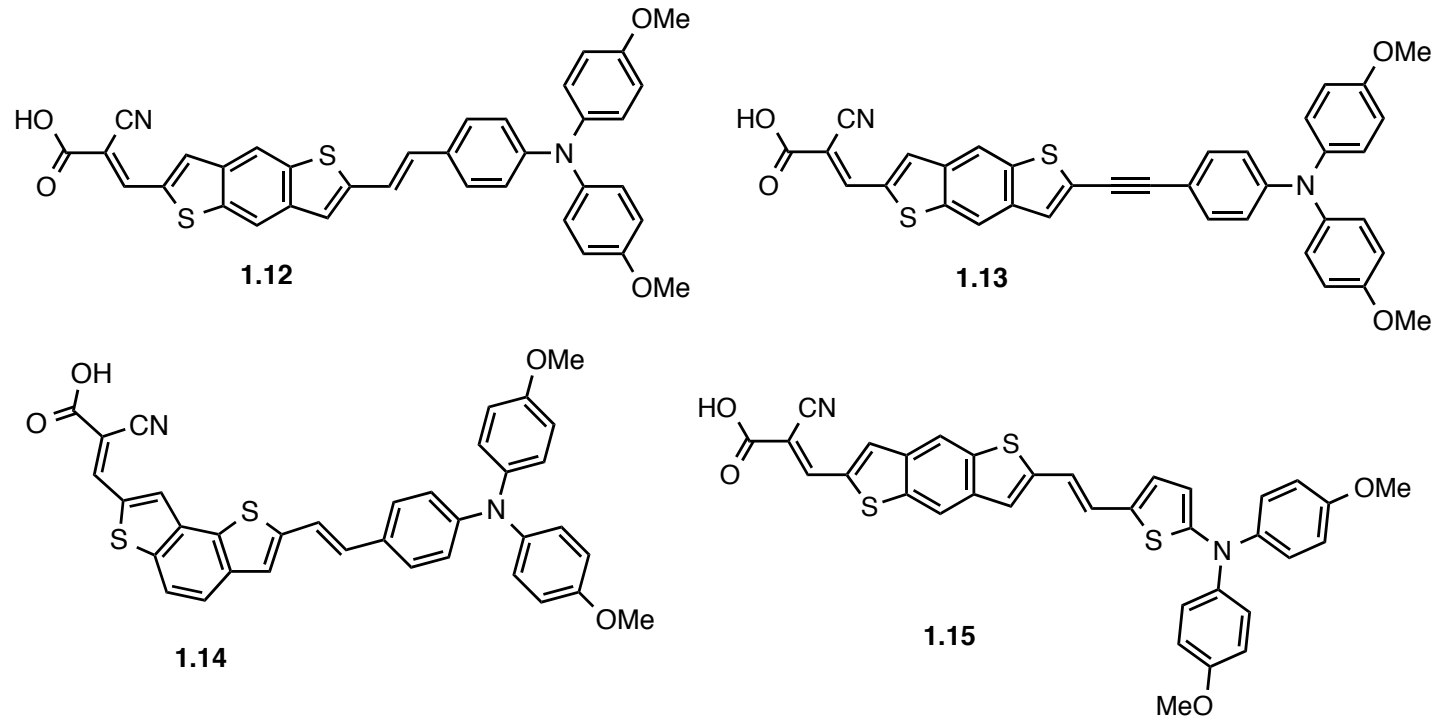

Figure 1.11. Dyes containing a benzocondensed thiophene $\pi$-spacer. ${ }^{20,46,47}$

Table 1.3. Comparison of a number of BDT-based dyes.

\begin{tabular}{|l|c|c|c|c|c|c|}
\hline & $\boldsymbol{E}_{\boldsymbol{g}}$ & $\begin{array}{c}\boldsymbol{J}_{\boldsymbol{s c}} \\
(\mathbf{e V})\end{array}$ & $\begin{array}{c}\mathbf{V}_{\text {oc }} \\
\left(\mathrm{mA} / \mathrm{cm}^{2}\right)\end{array}$ & $\mathbf{F F}$ & $\boldsymbol{\eta}(\mathbf{\%})$ & $\begin{array}{c}\boldsymbol{\varepsilon} / \boldsymbol{\lambda}_{\text {max }} \\
\left(10^{4} \mathrm{M}^{-1} \mathrm{~cm}^{-1}\right) /(\mathrm{nm})\end{array}$ \\
\hline $\mathbf{1 . 1 2}^{47}$ & 3.19 & 10.65 & 0.710 & 0.675 & 5.11 & $2.0 / 484$ \\
\hline $\mathbf{1 . 1 3}^{43}$ & 3.12 & 4.88 & 0.72 & 0.705 & 2.64 & $1.8 / 460$ \\
\hline $\mathbf{1 . 1 4}^{47}$ & 2.41 & 7.97 & 0.651 & 0.639 & 3.74 & $5.8 / 476$ \\
\hline $\mathbf{1 . 1 5}$ & 2.45 & 9.7 & 0.57 & 0.70 & 3.9 & $2.7 / 508$ \\
\hline
\end{tabular}


Similar discrepancies have also been observed in another BDT family. The only difference between $\mathbf{1 . 1 6}$ and $\mathbf{1 . 1 7}$ is the inclusion of a bromine atom in 1.17. This was a very odd addition, because halogen atoms are known to facilitate relaxation pathways from the excited state. Therefore, to this end, $\mathbf{1 . 1 6}$ should have a better performance with a higher efficiency (Figure 1.12, Table 1.4). However, this was not observed which brings into question the device performance in $\mathbf{1 . 1 6}$.

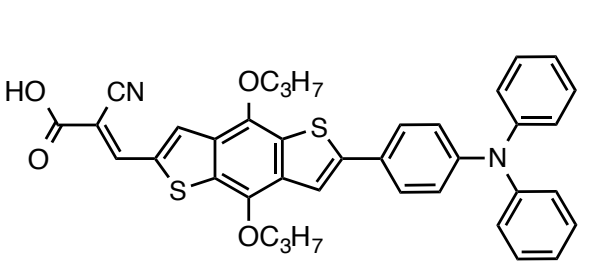

1.16

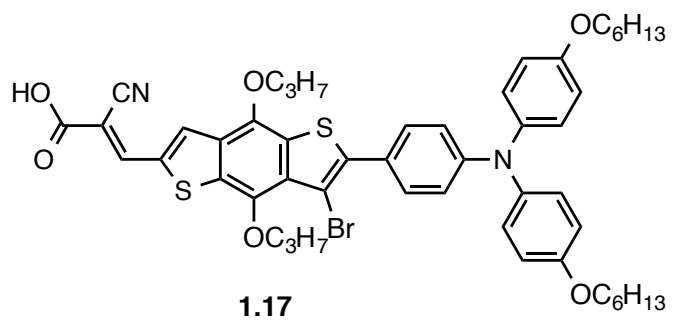

Figure 1.12. Electron rich dyes containing BDT as a $\pi$-spacer. ${ }^{48,49}$

Table 1.4. Halogenation's effect on BDT dye performance.

\begin{tabular}{|c|c|c|c|c|c|}
\hline Compound & $\begin{array}{c}\boldsymbol{J}_{\text {sc }} \\
\left(\mathrm{mA} / \mathrm{cm}^{2}\right)\end{array}$ & $\mathbf{V}_{\text {oc }}$ & $\mathbf{F F}$ & $\boldsymbol{\eta}(\mathbf{\%})$ & $\begin{array}{c}\boldsymbol{\varepsilon} / \boldsymbol{\lambda}_{\max } \\
\left(10^{4} \mathrm{M}^{-1} \mathrm{~cm}^{-1}\right) /(\mathrm{nm})\end{array}$ \\
\hline $\mathbf{1 . 1 6}{ }^{49}$ & 8.34 & 0.57 & 0.71 & 1.78 & $3.2 / 447$ \\
\hline $\mathbf{1 . 1 7} 7^{48}$ & 11.9 & 0.713 & 0.67 & 2.87 & $5.6 / 355$ \\
\hline
\end{tabular}

\subsection{Physicochemical characterization:}

In order to appropriately assess the structure-property relationships and the suitability of dyes for DSSC applications, several physicochemical measurements are required. Of the molecular properties of interest the following are the most significant;

- predicted charge separation in the excited state - calculated by TD-DFT

- extinction coefficients for dominant absorptions - determined with UV-Vis

- absorption profile - determined with UV-Vis

- HOMO energy level - determined using electrochemistry 
- LUMO energy level - estimated from the HOMO energy level and UV-Vis

While the LUMO energy in theory could also be estimated from electrochemistry, the instability of TPA donors (the most common organic donor) to undergo reduction prohibits this experimental observation. As one can see from Figure 1.13, having access to these dye metrics allows the researcher to determine a dyes thermodynamic suitability for DSSC applications.

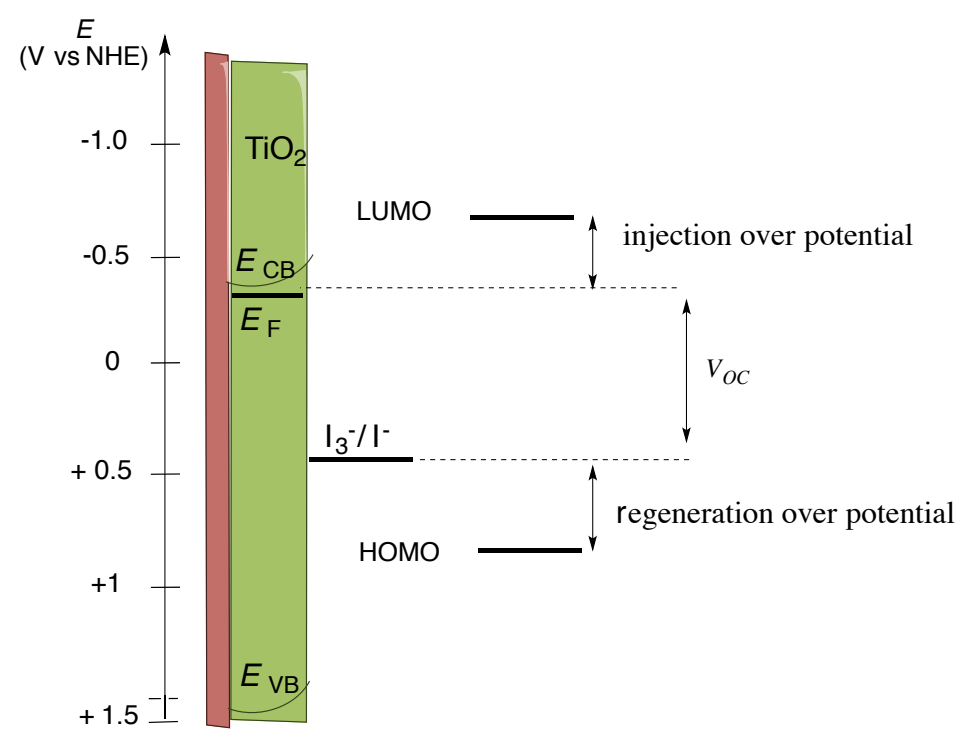

Figure 1.13. Different energy levels in DSSC applications

\subsubsection{Electronic spectroscopy: Ultraviolet visible (UV-Vis)}

Typically, dye molecules, which have electron density with low excitation energies, absorb strongly in the UV-Vis region of the electromagnetic spectrum (otherwise they would be unsuitable for photovoltaic applications). UV-vis spectroscopy probes the electronic transitions within dye molecules; as a result it is used to determine the absorbance spectrum of a compound (typically in solution). Upon absorption of electromagnetic radiation, electrons are promoted from the ground state (HOMO-x) to an excited singlet excited state (LUMO+y) of the compound or material. The dominant transition is not necessarily the HOMO-LUMO energy gap, but it can be predicted using TD-DFT calculations, and as such UV-Vis and DFT are complementary data sets. 
Ideally, a dye would have an absorption profile that superimposes with the solar spectrum (Figure 1.14); however, this does not necessarily imply that a dye would be able to sensitize a semiconductor. ${ }^{50,51,52}$ Again, DFT calculations can help to clarify the 'effective' transitions.

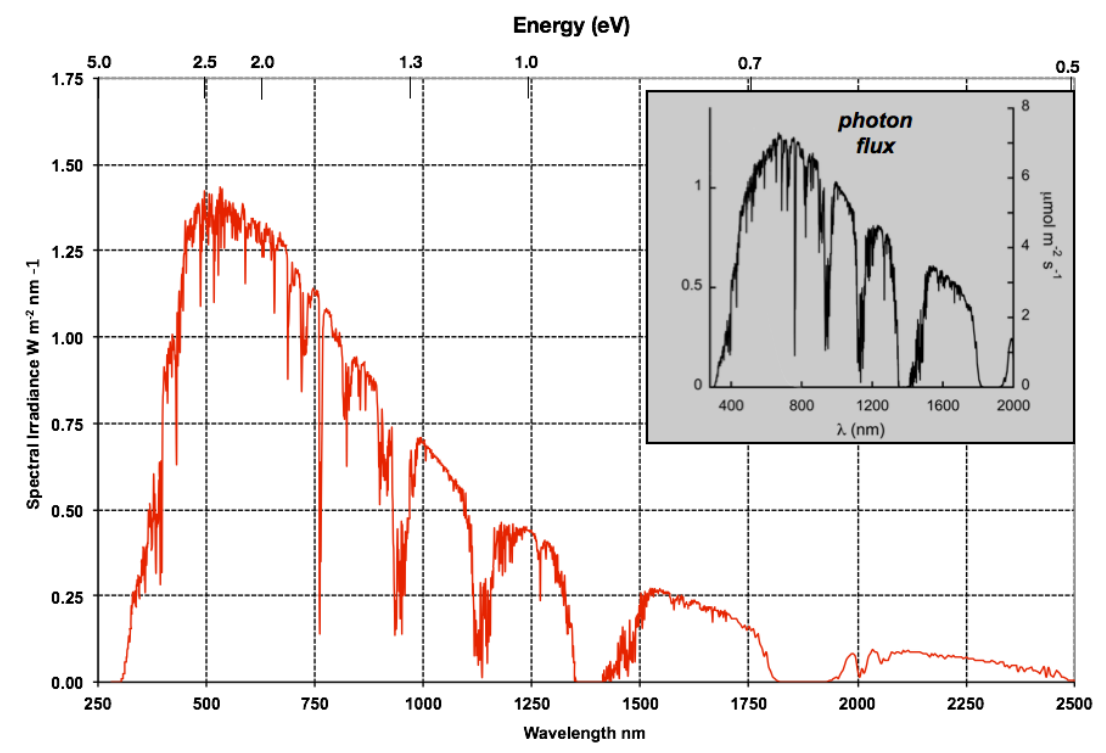

Figure 1.14. Solar irradiance at terrestrial level. inset photon flux as a function of wavelength. ${ }^{53}$

Using the Beer-Lambert relationship $(\mathrm{A}=\varepsilon \mathrm{lc})$, the extinction coefficient can also be extracted from UV-Vis data. The extinction coefficient is a key parameter because it quantifies the intensity or propensity of a dye to absorb light at a given wavelength. While this can be predicted using TD-DFT yet another important consideration is dye design.

\subsubsection{Computational methods: Density functional theory (DFT)}

Density functional theory is used to calculate (and predict) the quantum mechanical ground states and excited states of matter. ${ }^{54}$ As a result, DFT is now widely used to calculate molecular and material properties. While the method does have limitations owing to the gas phase nature of the calculations, it is a reasonably good method to compare with experimental values. ${ }^{55,56,57}$ In particular, time-dependent density 
functional theory (TD-DFT) has become a popular method for analyzing optical properties of molecules. TD-DFT calculates the properties of electronically coupled excited states; as a result, TD-DFT can predict dominant optical transitions (and the orbitals that are involved). In addition, one can also determine partial atomic charges and dipole moments both of which are essential to mimic charge transfer (CT) states. ${ }^{58,59}$ As previously mentioned, the method compliments UV-Vis spectroscopy, where the relative intensities of the optical transitions can also be determined.

\subsubsection{Electrochemistry: Cyclic voltammetry (CV)}

Cyclic voltammetry is an electrochemical technique, which is used to study the electrochemical properties of dye molecules in solution. The cyclic nature of this technique refers to the fact that the potential of a working electrode is cycled through a given voltage window over time and the resulting current is measured. Voltammetric measurements are carried out in solution using an electrochemical cell which has three electrodes: 1) A working electrode, usually made of platinum. 2) Reference electrode, which provides calibration; often this is a pseudo-reference, because an internal standard (like ferrocene) is added. 3) The counter electrode, which is often platinum. ${ }^{60,61}$

This electrochemical technique can extract oxidation and reduction potentials of ions and molecules, and assess their redox stability/activity. Typically, for a one electron process, the first oxidation potential in $\mathrm{CV}$ approximates the energy of the HOMO (for a reversible transition), and the first reduction potential correlates to the energy of the LUMO orbital of a molecule. Cyclic voltammetry is a sensitive technique and when examining structure property-relationships small changes in the dye structure often manifest in observable differences in the HOMO and/or LUMO energies.

\subsubsection{Device efficiency}

While molecular properties paint an informative picture of dye behaviour, there is no insight that can be substituted for device efficiency. Upon constructing a device, there are a number of experiments that can be conducted (many of which are outside the scope of this thesis) that can be used to quantify cell performance. However, the I-V (current- 
voltage) plot is the most significant. From the IV curve, one can determine; open circuit voltage $\left(V_{O C}\right)$, the short-circuit current $\left(J_{\mathrm{SC}}\right)$, and fill factor $(F F)$. When the product of these three terms is divided by the intensity of the incident light $\left(\mathrm{P}_{\text {in }}\right)$, the power conversion efficiency of a solar cell $(\eta)$ can be calculated according to the formula.

$$
\eta=\left(J_{S C} x V_{O C} x F F\right) / P_{\text {in }}
$$

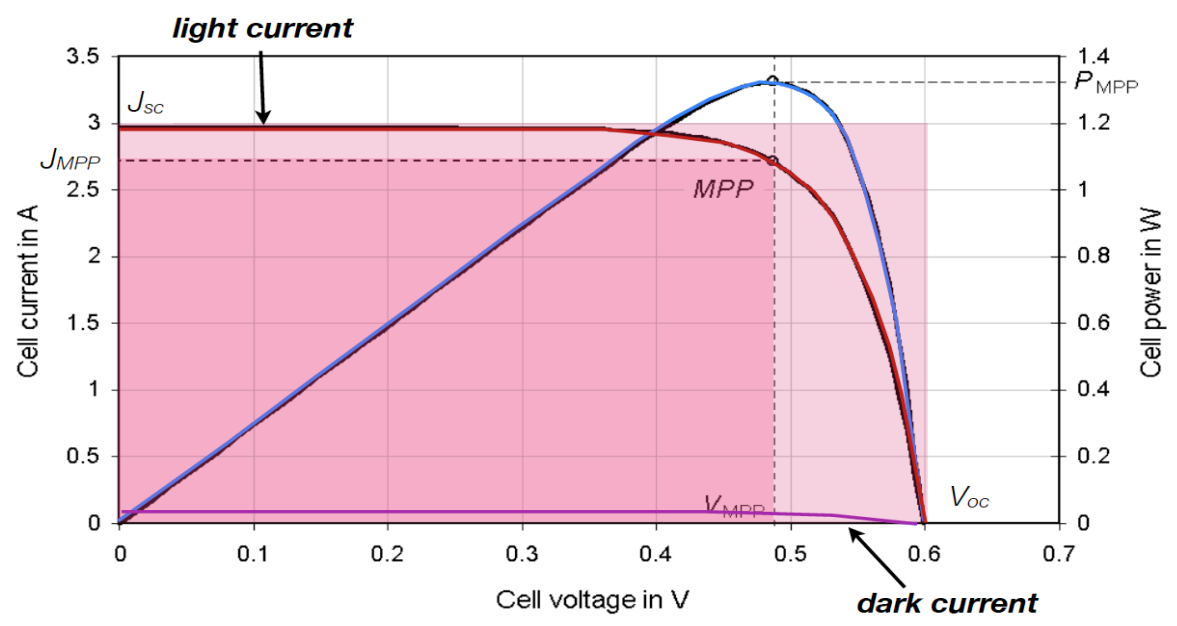

Figure 1.15. DSSC performance

The fill factor can assume values between 0 and less than 1 . It is defined at the point where the ratio of the maximum power $\left(\mathrm{P}_{\max }\right)$ is reached of the solar cell per unit area divided by the $\mathrm{V}_{\mathrm{OC}}$ and $J_{\mathrm{SC}}$ following the formula:

$$
F F=J_{M p p} V_{M P P} / J_{S C} V_{O C}
$$

The $V_{O C}$ is the maximum voltage available from a solar cell at zero current. To a first approximation, $V_{O C}$ is the difference between the Fermi level of the semiconductor and the redox potential of the electrolyte (Figure 1.13). The Fermi energy level is defined as the highest occupied molecular orbital in the valence band at $0 \mathrm{~K}$, in semiconductors its position is in the band gap, close to the valence band. ${ }^{62}$ The $J_{S C}$ (the photocurrent per unit area under short-circuit conditions), is directly related to the optical properties of the dye and dynamic processes involving the dye within the cell. As such, the short circuit current is frequently discussed in DSSC literature, as a dye structure-property 
relationship.

In addition to the above parameters, a device needs to be prepared to appreciate efficiency, dye loading on the $\mathrm{TiO}_{2}$ surface, interfacial capacitance, etc. As such there is no substitute for device data; however, analyzing the structure-property data above can provide enormous insights even in the absence of device data when a number of different dyes are typically prepared, to compare and contrast structural and electronic variability.

\subsection{Thesis objectives:}

Synthesizing new and more efficient dyes for light harvesting (in particular photovoltaics) is a competitive field of research. Unfortunately, as mentioned previously, this rapidly growing area of research sometimes lacks the proper control experiments and structure-property evaluations needed to fully appreciate dye design. At the moment organic-based DSSC dyes are costly because of elaborate synthetic schemes, and organic-based photovoltaics will only become mainstream if they can improve the cost and long term stability of the device.

Within this context, the present MSc research project has focused on the syntheses of several families of metal-free organic dyes characterized by a donor-spacer-acceptor (D$\pi$-A) motif. Our examination focuses primarily on the development of novel $\pi$-spacers meant to lower the overall synthetic cost, improve device efficiency and dye redox stability. While we are not the first to introduce the benzocondensed thiophene units as $\pi$-spacers, we seek to further elaborate on the existing ${ }^{63}$ literature precedent with a more thorough characterization of structure-property relationships. In addition, we have been inspired by nature and have included the more electron deficient fused thiophene quinone $\pi$-spacer. With this in mind the aim of this thesis is to synthesize three new families of dye molecules (Figure 1.16, 1.18-1.24 below) and evaluate the following structure-property relationships; 
- The effect of changing the electron density of the $\pi$-spacer by comparing

\subsection{9, 1.21 and 1.22}

- The effect of changing the donor within the quinone family by comparing

\section{$1.22,1.23$ and 1.24}

- The effect of extending the conjugation on charge separation, by including an additional thiophene $\pi$-spacer in the comparison of $\mathbf{1 . 1 8}$ to

\subsection{9 and 1.20 to 1.21}

When examining structure property relationships, even the hydrodynamic volume of the dye can have significant difference in dye loading in the DSSC. However, the $\pi$-spacers used in this study all have similar sizes, and as a result we can approximate that any significant difference will be a result of the electronics of the $\pi$-spacer. Unfortunately, owing to the lack of fabrication facilities (delays outside the control of this thesis). This thesis will focus predominantly on synthesis \& characterization, DFT calculations and solution measurements (UV-Vis, CV).

Based on the structural-property relationships highlighted above, the following hypotheses are;

- Typically a more electron-rich dye will have better charge separation in the excited state because of its polarizable nature. Therefore, it is predicted that more electron-rich $\pi$-spacer will out perform the other families. The quinone being a redox acceptor may trap the excited state, minimizing charge separation

- Increasing the donor strength, will red-shift the absorption window, typically leading to better spectral overlap with the Sun. Therefore it is expected that the OMe and OHex donors will outperform the underivatized TPA dye in 1.22-1.24.

- Extending conjugation red-shifts the absorption window, typically leading to better spectral overlap with the Sun. Therefore it is expected that including an additional thiophene may increase performance. However, this added spacer, may also hinder charge separation in the excited state, and counter this effect. 

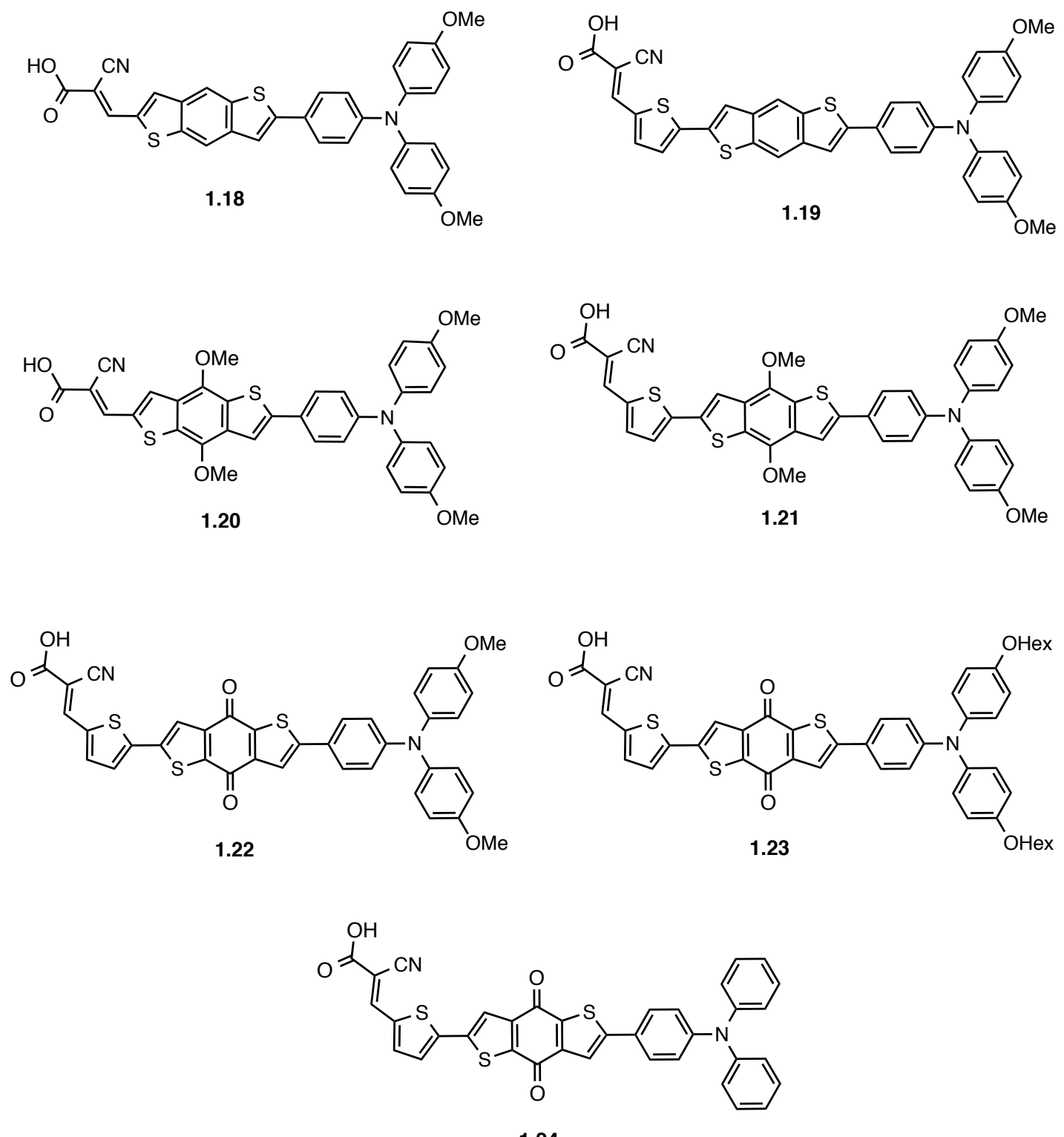

Figure 1.16. A variety of dyes with fused-thiophene $\pi$-spacers 


\section{Chapter 2: Synthesis of dyes containing fused thiophene $\pi$ - spacers}

This research project focuses on the synthesis of metal-free organic dyes with a donor- $\pi$ spacer-acceptor (D- $\pi-A)$ motif in which a benzo or quinone condensed thiophene unit serves as a $\pi$-bridge. Using fused thiophene $\pi$-spacers has caught our attention because of their rigid, $\pi$-conjugated and condensed-polycyclic structure as well as their unique electronic properties and the design and synthesis of several novel fused thiophene dyes are reported herein. The $\pi$-conjugated linker connecting the electron-donor and the acceptor of a dye plays an important role in tuning and modifying the optical properties of DSSC devices by controlling the intra-molecular electron-transfer. ${ }^{64,65}$ While the structure-property relationships of these dyes can be found in Chapter 3, the focus on this chapter will be on synthesis and structural characterization. Owing to the large structures of these dyes, the following abbreviated naming strategy has been employed (Table 2.1).

Table 2.1. Full names and abbreviated dye names:

\begin{tabular}{|c|l|c|}
\hline Compound & \multicolumn{1}{|c|}{ Original Name } & Short Name \\
\hline $\mathbf{2 . 1 4}$ & $\begin{array}{l}\text { 4-(benzo[1,2- } b: 4,5-b \text { ' } \text { dithiophen-2-yl)- } N, N \text {-bis(4- } \\
\text { methoxyphenyl)aniline }\end{array}$ & BDT-TPA-OMe \\
\hline $\mathbf{2 . 5}$ & $\begin{array}{l}\left(4-\left(4,4^{\prime}, 5,5^{\prime} \text {-tetramethyl1,3,2-dioxaborolan-2- }\right.\right. \\
\text { yl)phenyl)-di-(4methoxyphenyl)amine }\end{array}$ & TPA-ester \\
\hline $\mathbf{2 . 1 5}$ & $\begin{array}{l}\text { 6-(4-(bis(4-methoxyphenyl)amino)phenyl)benzo[1,2- } \\
b: 4,5-b \text { ' } \text { dithiophene-2-carbaldehyde }\end{array}$ & $\begin{array}{l}\text { Formyl BDT-TPA- } \\
\text { OMe }\end{array}$ \\
\hline $\mathbf{1 . 1 8}$ & $\begin{array}{l}3-(6-(4-(\text { bis(4-methoxyphenyl)amino)phenyl)benzo[1,2- } \\
b: 4,5-b \text { ' }] \text { dithiophen-2-yl)-2-cyanoacrylic acid }\end{array}$ & BDT-TPA-OMe dye \\
\hline
\end{tabular}




\begin{tabular}{|c|c|c|}
\hline Compound & Original Name & Short Name \\
\hline 2.17 & $\begin{array}{l}\text { 4-(6-bromobenzo[1,2-b:4,5-b']dithiophen-2-yl)- } N, N- \\
\text { bis(4-methoxyphenyl)aniline }\end{array}$ & $\begin{array}{l}\text { Bromo BDT-TPA- } \\
\text { OMe }\end{array}$ \\
\hline 2.18 & $\begin{array}{l}\text { 4-(6-(5-(1,3-dioxolan-2-yl)thiophen-2-yl)benzo[1,2- } \\
b: 4,5-b \text { ' dithiophen-2-yl)- } N, N \text {-bis(4- } \\
\text { methoxyphenyl)aniline }\end{array}$ & $\begin{array}{c}\text { Thiophene BDT- } \\
\text { OMe TPA }\end{array}$ \\
\hline 2.19 & $\begin{array}{l}\text { 5-(6-(4-(bis(4-methoxyphenyl)amino)phenyl)benzo[1,2- } \\
\left.b: 4,5-b^{\prime}\right] \text { dithiophen-2-yl)thiophene-2-carbaldehyde }\end{array}$ & $\begin{array}{l}\text { Formyl thiophene- } \\
\text { BDT-TPA- OMe }\end{array}$ \\
\hline 1.19 & $\begin{array}{l}(E)-3-(5-(6-(4-(\operatorname{bis}(4- \\
\text { methoxyphenyl)amino)phenyl)benzo[1,2-b:4,5- } \\
b \text { ]dithiophen-2-yl)thiophen-2-yl)-2-cyanoacrylic acid }\end{array}$ & $\begin{array}{l}\text { Thiophene-BDT- } \\
\text { TPA-OMe dye }\end{array}$ \\
\hline 2.25 & $\begin{array}{l}\text { 4-(4,8-dimethoxybenzo[1,2- } b: 4,5-b \text { ' dithiophen-2-yl)- } \\
N, N \text {-bis(4-methoxyphenyl)aniline }\end{array}$ & $\begin{array}{l}\text { Dimethoxy-BDT- } \\
\text { TPA-OMe }\end{array}$ \\
\hline 2.26 & $\begin{array}{l}\text { 6-(4-(bis(4-methoxyphenyl)amino)phenyl)-4,8- } \\
\text { dimethoxybenzo[1,2-b:4,5- } b \text { ] dithiophene-2- } \\
\text { carbaldehyde }\end{array}$ & $\begin{array}{l}\text { Formyl } 4,8- \\
\text { dimethoxy-BDT- } \\
\text { TPA-OMe }\end{array}$ \\
\hline 1.20 & $\begin{array}{l}\text { (E)-3-(6-(4-(bis(4-methoxyphenyl)amino)phenyl)-4,8- } \\
\text { dimethoxybenzo[1,2-b:4,5-b }] \text { dithiophen-2-yl)-2- } \\
\text { cyanoacrylic acid }\end{array}$ & BDT-OMe-TPA dye \\
\hline $2.28 \mathrm{a}$ & $\begin{array}{l}\text { 4-(6-bromo-4,8-dimethoxybenzo[1,2-b:4,5- } \\
b \text { ']dithiophen-2-yl)- } N, N \text {-bis(4-methoxyphenyl)aniline }\end{array}$ & $\begin{array}{l}\text { Monobromo } \\
\text { dimethoxy-BDT- } \\
\text { TPA- OMe }\end{array}$ \\
\hline 2.29 & $\begin{array}{l}\text { 4-(6-(5-(1,3-dioxolan-2-yl)thiophen-2-yl)-4,8- } \\
\text { dimethoxybenzo[1,2-b:4,5-b ]dithiophen-2-yl)- } N, N \text { - } \\
\text { bis(4-methoxyphenyl)aniline }\end{array}$ & $\begin{array}{l}\text { Thiophene } \\
\text { dimethoxy-BDT- } \\
\text { TPA- OMe }\end{array}$ \\
\hline 2.30 & $\begin{array}{l}\text { 5-(6-(4-(bis(4-methoxyphenyl)amino)phenyl)-4,8- } \\
\text { dimethoxybenzo[1,2-b:4,5- } b \text { ']dithiophen-2- } \\
\text { yl)thiophene-2-carbaldehyde }\end{array}$ & $\begin{array}{l}\text { Formyl thiophene- } \\
\text { BDT-TPA-OMe }\end{array}$ \\
\hline
\end{tabular}




\begin{tabular}{|c|c|c|}
\hline Compound & Original Name & Short Name \\
\hline 1.21 & $\begin{array}{l}\text { 3-(5-(6-(4-(bis(4-methoxyphenyl)amino)phenyl)-4,8- } \\
\text { dimethoxybenzo[1,2-b:4,5-b'dithiophen-2-yl)thiophen- } \\
\text { 2-yl)-2-cyanoacrylic acid }\end{array}$ & $\begin{array}{c}\text { BDT-OMe-TPA } \\
\text { thiophene dye }\end{array}$ \\
\hline 2.37 & $\begin{array}{l}\text { 2-(5-(1,3-dioxolan-2-yl)thiophen-2-yl)-6-(4- } \\
\text { (bis(4methoxyphenyl)aminophenyl) benzo[1,2-b:4,5- } \\
\text { b']dithiophene-4,8-dione }\end{array}$ & $\begin{array}{c}\text { Thiophene quinone- } \\
\text { TPA- OMe }\end{array}$ \\
\hline 2.38 & $\begin{array}{l}\text { 5-(6-(4-(bis(4-methoxyphenyl)amino)phenyl)-4,8- } \\
\text { dioxo-4,8 dihydrobenzo[1,2-b:4,5-b']dithiophen-2- } \\
\text { yl)thiophene-2-carbaldehyde }\end{array}$ & $\begin{array}{l}\text { Formyl thiophene- } \\
\text { quinone-TPA-OMe }\end{array}$ \\
\hline 1.22 & $\begin{array}{l}\text { 3-(5-(6-(4-(bis(4-methoxyphenyl)amino)phenyl)-4,8- } \\
\text { dioxo-4,8-dihydrobenzo[1,2-b:4,5-b } \text { ]dithiophen-2- } \\
\text { yl)thiophen-2-yl)-2-cyanoacrylic acid }\end{array}$ & $\begin{array}{c}\text { Quinone- thiophene- } \\
\text { TPA-OMe dye }\end{array}$ \\
\hline 2.43 & $\begin{array}{l}\text { ((4-(6-(5-(1,3-dioxolan-2-yl)thiophen-2-yl)-4,8-dioxo- } \\
\text { 4,8-dihydrobenzo[1,2-b:4,5-b ]dithiophen-2- } \\
\text { yl)phenyl)azanediyl)bis(4,1-phenylene) }\end{array}$ & $\begin{array}{c}\text { Thiophene quinone- } \\
\text { TPA-OHex }\end{array}$ \\
\hline 2.44 & $\begin{array}{l}\text { ((4-(6-(5-formylthiophen-2-yl)-4,8-dioxo-4,8- } \\
\text { dihydrobenzo[1,2-b:4,5-b]dithiophen-2- } \\
\text { yl)phenyl)azanediyl)bis(4,1-phenylene) dihexanoate }\end{array}$ & $\begin{array}{l}\text { Formyl thiophene- } \\
\text { quinone-TPA-OHex }\end{array}$ \\
\hline 1.23 & $\begin{array}{l}\text { E)-3-(5-(6-(4-(bis(4 } \\
\text { (hexanoyloxy)phenyl)amino)phenyl)-4,8-dioxo-4,8- } \\
\text { dihydrobenzo[1,2-b:4,5- } b \text { ' dithiophen-2-yl)thiophen-2- } \\
\text { yl)-2-cyanoacrylic acid dye }\end{array}$ & $\begin{array}{l}\text { Quinone-thiophene- } \\
\text { TPA-OHex dye }\end{array}$ \\
\hline 2.48 & $\begin{array}{l}\text { 2-(5-(1,3-dioxolan-2-yl)thiophen-2-yl)-6-(4- } \\
\text { (diphenylamino)phenyl)benzo[1,2-b:4,5-b } b \text { dithiophene- } \\
\text { 4,8-dione }\end{array}$ & $\begin{array}{c}\text { Thiophene quinone- } \\
\text { TPA }\end{array}$ \\
\hline 2.49 & $\begin{array}{l}\text { 5-(6-(4-(diphenylamino)phenyl)-4,8-dioxo-4,8- } \\
\text { dihydrobenzo[1,2-b:4,5-b']dithiophen-2-yl)thiophene-2- } \\
\text { carbaldehyde }\end{array}$ & $\begin{array}{l}\text { Formyl thiophene- } \\
\text { quinone-TPA-OHex }\end{array}$ \\
\hline 1.24 & $\begin{array}{l}\text { 2-cyano-3-(5-(6-(4-(diphenylamino)phenyl)-4,8-dioxo- } \\
\left.4 \lambda^{5}, 8 \lambda^{5} \text {-benzo[2,3- } b: 5,6-b\right] \text { dithiophen-2-yl)thiophen-2- } \\
\text { yl)acrylic acid }\end{array}$ & $\begin{array}{c}\text { Quinone-thiophene } \\
\text { TPA dye }\end{array}$ \\
\hline
\end{tabular}




\subsection{Synthesis of electron donor (2.5):}

As stated in Chapter 1, the objective of this thesis is to design a small library of homologous compounds that differ in their $\pi$-bridge and donor group. To this end, triphenylamine (TPA) derivatives have been chosen as donor units. In addition, the presence of the methoxy or hexyloxy groups increases the electron density on the donor group, extending the absorption profile in the visible spectrum, avoiding charge recombination and increasing the electron lifetime.

The TPA-boronic esters (2.5) were prepared in reasonable yields starting with an Ullmann condensation strategy (Scheme 2.1). Aryl iodides and aniline were combined to prepare (2.3), using a previously reported procedure. ${ }^{66}$ The key to the procedure is the addition of $\mathrm{CuCl}$ and $\mathrm{KOH}$ at $100{ }^{\circ} \mathrm{C}$ after dissolving the ligand and reactants. The TPA derivatives (2.3) were then brominated in reasonable yields to achieve family 2.4. The desired product was then obtained from a metal-halogen exchange reaction (2.5) followed by quenching with 2 -isopropoxy-4,4',5,5'-tetramethyl-[1,3,2]-dioxaborolane. With the exception of dyes $\mathbf{1 . 2 3}$ and $\mathbf{1 . 2 4}$ bis-methoxy TPA (2.5b) was selected as the donor for most dyes so that the results obtained could be readily contrasted with previous findings. ${ }^{67}$

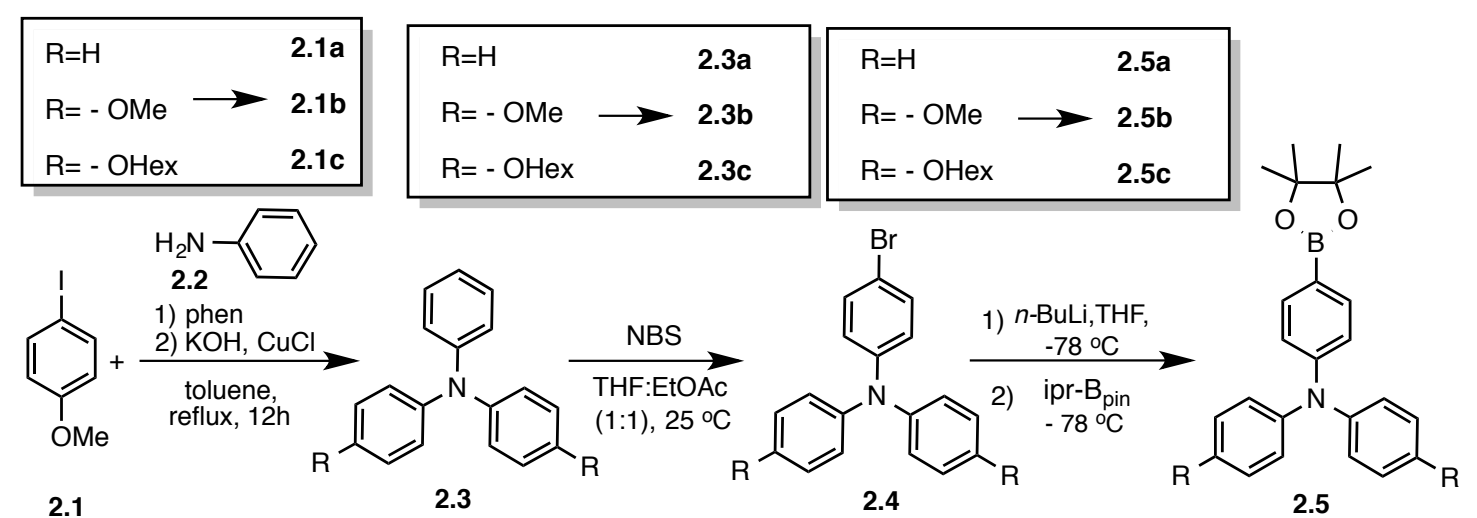

Scheme 2.1. Synthesis of donor building blocks (2.5) 


\subsection{Synthesis of thiophene $\pi$-spacer building block $(2.8)$ :}

Yet another variable feature within our dye motifs is the inclusion of an additional a $\pi$ spacer thiophene group, which was employed in target molecules 1.19, 1.21, 1.23 and 1.25. This added unit is known to red-shift and broaden the absorption profile, as a consequence of the increased conjugation within the system. Furthermore, increasing the number of thiophene units can affect photovoltaic properties due to different levels of aggregation on $\mathrm{TiO}_{2}{ }^{42,68}$ To explore the structure-property effect of adding an additional $\pi$-spacer, a thiophene building block capable of hybridizing with our Suzuki crosscoupling strategies was prepared. Starting from 5-bromo-thiophenecarbaldehyde (2.6), the protected aldehyde (2.7) was prepared as an acetal (Scheme 2.2). This protected aldehyde was then converted in a respectable yield to the boronic ester $\mathbf{2 . 8}$ using a metal halogen exchange ${ }^{67}$ followed by quenching with 2-isopropoxy-4,4,5,5-tetramethyl-1,3,2dioxaborolane.

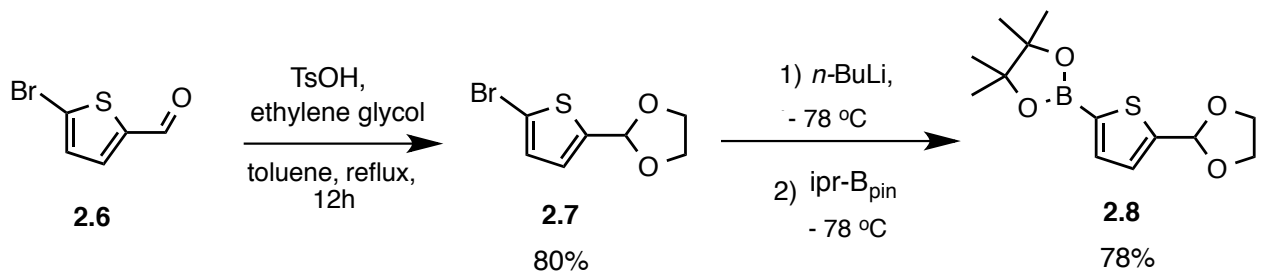

Scheme 2.2. Synthesis of thiophene spacer building block (2.8)

\subsection{Synthesis of the BDT-TPA-OMe dye (1.18):}

As previously discussed in chapter 1, one of the structure-property relationships studied in this thesis is the affect of various fused thiophene cores with the $\pi$-spacers. To construct the dye targets, similar synthetic strategies were employed. Suzuki couplings, electrophilic brominations, Vilsmeier-Haack formylations and Knoevenagel condensations are repeating themes in many of our dye synthetic sequences. The BDTTPA-OMe dye (1.18) possesses a benzodithiophene core and is the first in a series of dyes meant to examine the effect of varied $\pi$-spacer electron density on the dye properties. This core serves as a midpoint in our study, because it is more electron rich 
than the quinone derivative (1.22), and less electron rich than the methoxy substitutedBDT (1.20). Unfortunately, synthetic limitations precluded the possibility of preparing the direct quinone homolog, but nonetheless, the structures of $\mathbf{1 . 1 8}$ and $\mathbf{1 . 2 0}$ are similar, and comparisons can be made.

The synthesis of $\mathbf{1 . 1 8}$ (Scheme 2.3) begins with the preparation of the BDT core. 1,4dibromo-2,5-diiodobenzene $\mathbf{( 2 . 1 0 )}$ was prepared through a electrophilic aromatic substitution, followed by a Sonogashira coupling reaction to produce 2.11. The Sonogashira reaction was studied using two different bases/solvents: 1) DIPEA or 2) THF:NEt 3 . The second base/solvent system resulted in an increase in yield from $45 \%$ to $86 \%$. Therefore, it was employed for all Sonogashira couplings. The condensation of the alkyne with an anionic sulfur source resulted in the preparation of benzo[1,2-b:4,5$\mathrm{b}^{\prime}$ ]dithiophene (BDT) (2.12) This condensation was tested multiple times in small scale and has led to variable yields (38\%-78\%). Purification of this compound was also challenging due to the difficulty of removing residual NMP with multiple washes. However, enough $\mathbf{2 . 1 2}$ was prepared and upon bromination using a stoichiometric amount of NBS, 2.13 was isolated. The bromination reaction was observed to be sluggish and increasing the temperature from $30{ }^{\circ} \mathrm{C}$ to $70{ }^{\circ} \mathrm{C}$ optimized the yield. A Suzuki coupling reaction between $\mathbf{2 . 1 3}$ and $\mathbf{2 . 5}$ b resulted in the BDT-TPA-OMe derivative (2.14) in good yields. Owing to the catalyst stability, the oxidatively stable precatalyst $\mathrm{Pd}\left(\mathrm{PPh}_{3}\right)_{2} \mathrm{Cl}_{2}$ was employed to make the carbon-carbon bond, but we have also had similar success with $\mathrm{Pd}\left(\mathrm{PPh}_{3}\right)_{4}$. 2.14 was converted to the aldehyde (2.15), using a Vilsmeier-Haack reaction in moderate yields. Finally, a Knoevenagel condensation led to the target molecule being obtained (1.18) in good yield. 

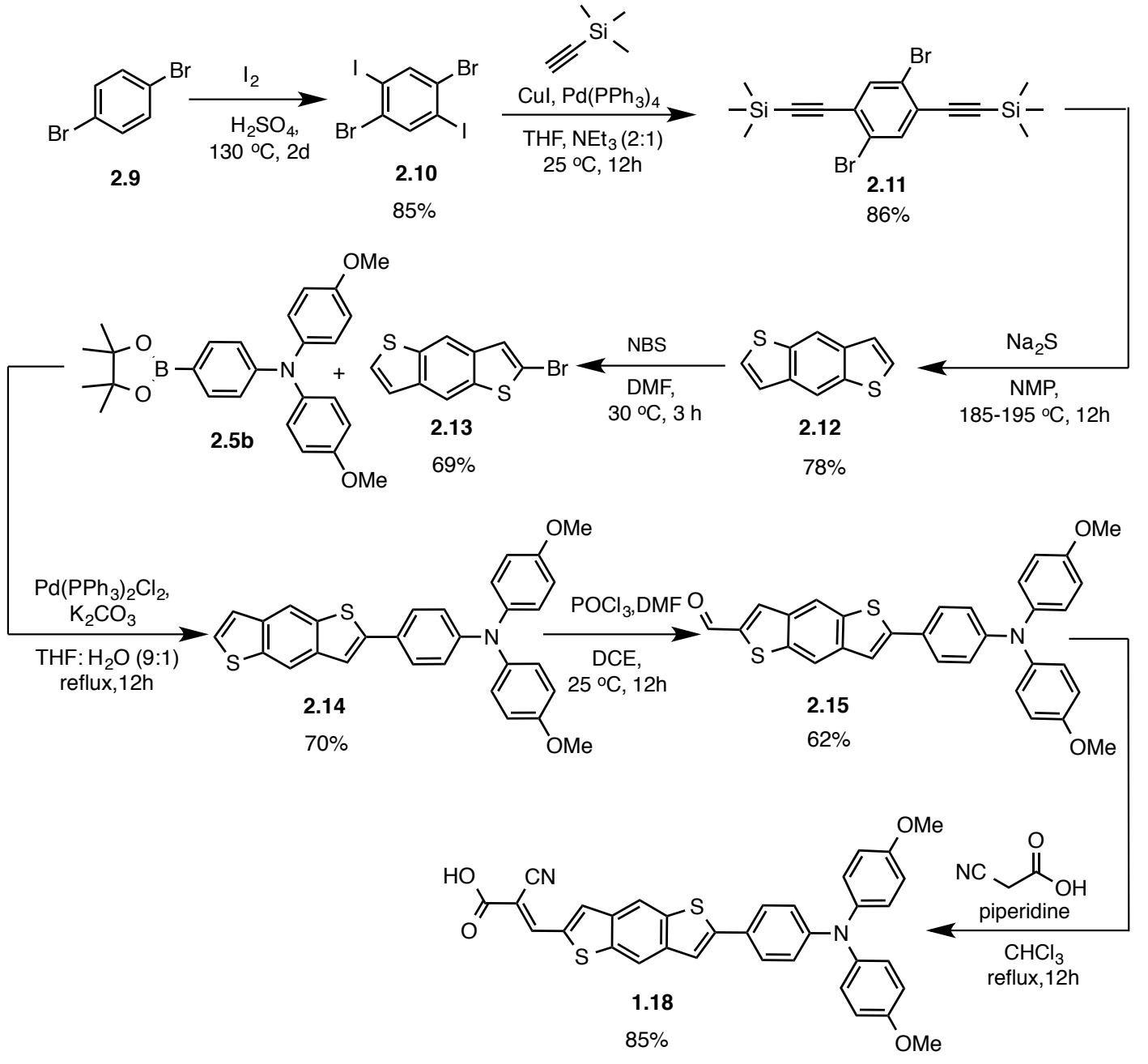

Scheme 2.3. Synthesis of BDT dye (1.18)

\subsection{Synthesis of the thiophene-BDT-TPA-OMe dye (1.19):}

The synthesis of target molecule $\mathbf{1 . 1 9}$ began with the bromination of $\mathbf{2 . 1 2}$ to yield $\mathbf{2 . 1 6}$. The bromination has been done in DCM as well but using DMF at a higher temperature resulted in a better yield being achieved. This reaction was followed by a Suzuki coupling reaction to prepare 2.17a. Not surprisingly, the disproportionation product was also observed $\mathbf{2 . 1 7 b}$, and has been characterized as a benchmark TPA compound (Scheme 2.4). After, another Suzuki coupling reaction on 2.17, 2.18 was achieved. The 
deprotection reaction was employed to achieve 2.19, and the aldehyde was converted to the target molecule 1.19 through a Knoevenagel condensation reaction.<smiles></smiles>

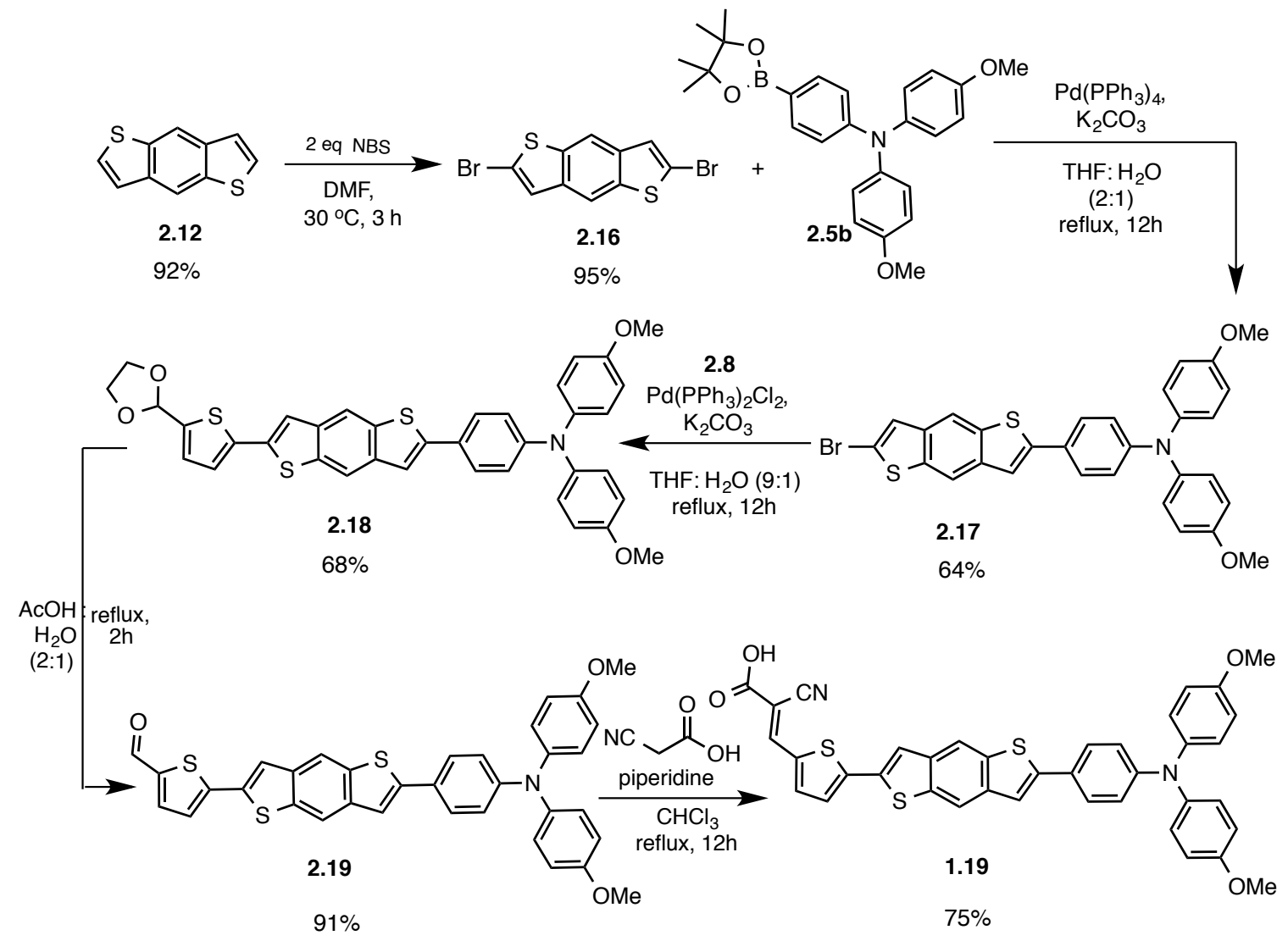

Scheme 2.4. Synthesis of BDT dye 1.19, 217a and 217b 


\subsection{Synthesis of the BDT-OMe-TPA dye (1.20):}

The synthesis of the target molecule $\mathbf{1 . 2 0}$ begins with a nucleophilic substitution reaction on thiophene-3-carbonyl chloride (2.20) to achieve 2.21. Next, 2.22 was deprotonated with $n$-BuLi, resulting in a dimeric nucleophilic acyl substitution. Reducing $\mathbf{2 . 2 2}$, resulted in the formation of 2.23. This reduction offered a modest synthetic challenge. While there is literature precedent, the reduction with $\mathrm{Zn}$ under basic conditions had limited success (Table 2.2, trial 1 and 2). However, using $\mathrm{NaBH}_{4}$, gave the product $\mathbf{2 . 2 3}$ in pleasing yields. Next, a bromination with a stoichiometric amount of NBS gave 2.24, which was followed by a Suzuki coupling reaction to get 2.25. The Vilsmeier-Haack reaction was used to synthesize 2.26. Finally, the target molecule 1.20 was achieved from 2.26 using a Knoevenagel condensation reaction (Scheme 2.5).

Table 2.2. Comparison of reactions used for the synthesis of 4,8-dimethoxy-benzo [1,2$b: 4,5-b]$ dithiophene.

\begin{tabular}{|c|c|c|}
\hline Trial & Conditions & Yield \\
\hline Trial 1 & 1) $85^{\circ} \mathrm{C}, 2 \mathrm{~h}, \mathrm{H}_{2} \mathrm{O} / \mathrm{THF}, \mathrm{Zn}, \mathrm{NaOH}$ & - \\
\hline Trial 2 & 2) $50^{\circ} \mathrm{C}, 12 \mathrm{~h}, \mathrm{H}_{2} \mathrm{O} / \mathrm{THF}, \mathrm{MeOTs}$ & \\
\hline Trial 3 & 2) $85^{\circ} \mathrm{C}, 12 \mathrm{~h}, \mathrm{H}_{2} \mathrm{O} /$ ethanol, $\mathrm{Zn}, \mathrm{NaOH}$ & \\
& 2) $20^{\circ} \mathrm{C}, 12 \mathrm{~h}, \mathrm{H}_{2} \mathrm{O} /$ ethanol, $\mathrm{MeOTs}, 72 \mathrm{~h}, \mathrm{H}_{2} \mathrm{O} /$ ethanol, $\mathrm{NaBH}_{4}$ & \\
\hline
\end{tabular}




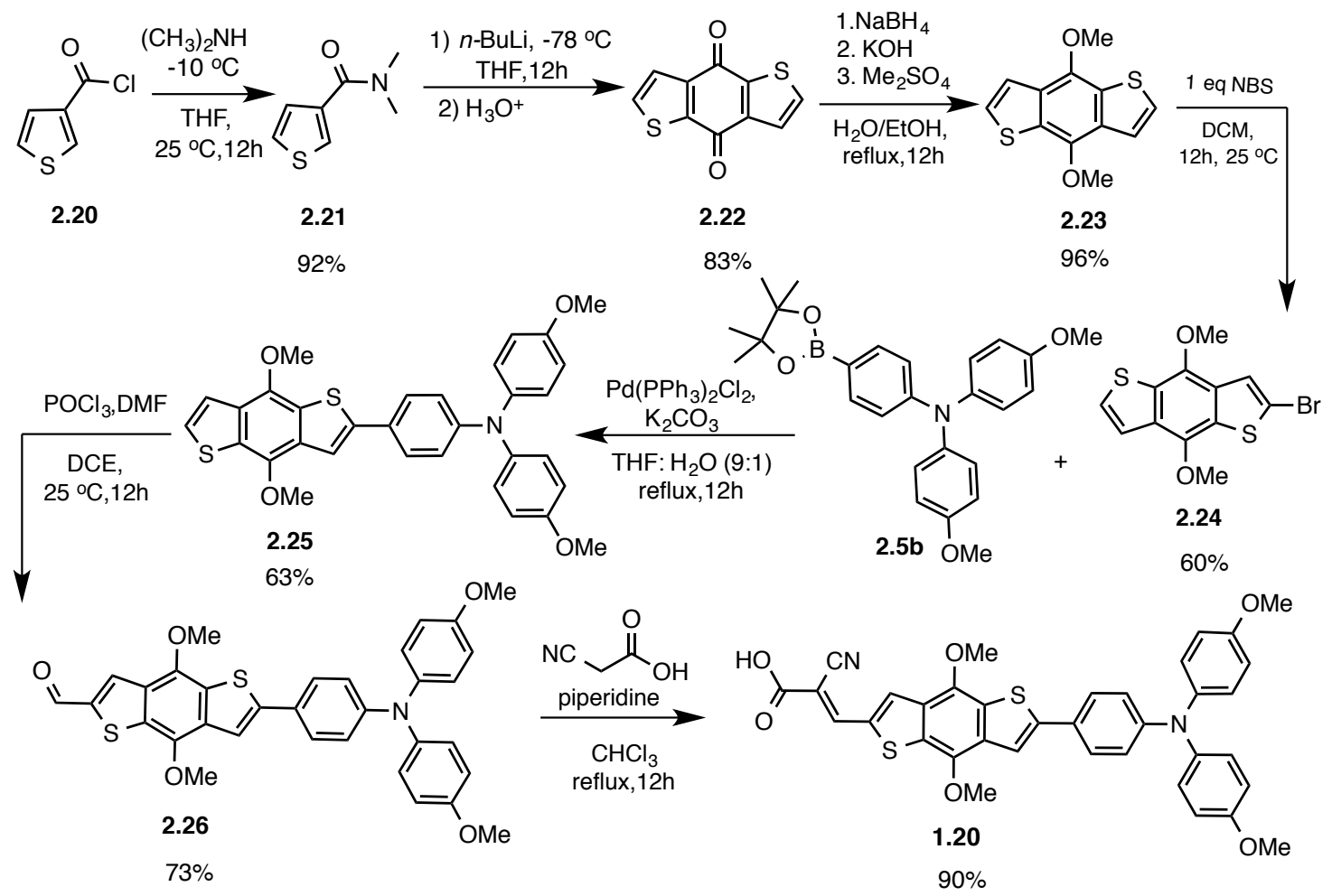

Scheme 2.5. Synthesis of MeO-BDT dye (1.20)

\subsection{Synthesis of the BDT-OMe-TPA thiophene dye (1.21):}

The synthesis of dye 1.21, began with the dibromination of bis-methoxy BDT (2.23), resulting in 2.27 (Scheme 2.6). The bromination reaction was most efficient using NBS in DCM. The same reaction has been done in DMF but the product was obtained in a low yield. This could be due to the high solubility of the product in DMF and the inability to remove it. Then adding 2.27 to $\mathbf{2 . 5}, \mathbf{2 . 2 8} \mathrm{a}$ was achieved as a main product. $\mathbf{2 . 2 8 \mathrm { b }}$ was also observed as a by-product of the Suzuki coupling reaction (Scheme 2.7). A second Suzuki coupling with the thiophene building block resulted in the formation of 2.29, which was not isolated. During column chromatography the acetal partially deprotected, and the mixture of $\mathbf{2 . 2 9}$ and $\mathbf{2 . 3 0}$ was carried through to the deprotection to yield the aldehyde 2.30. Finally, the Knoevenagel condensation reaction yielded the product (1.21) (Scheme 2.6). 


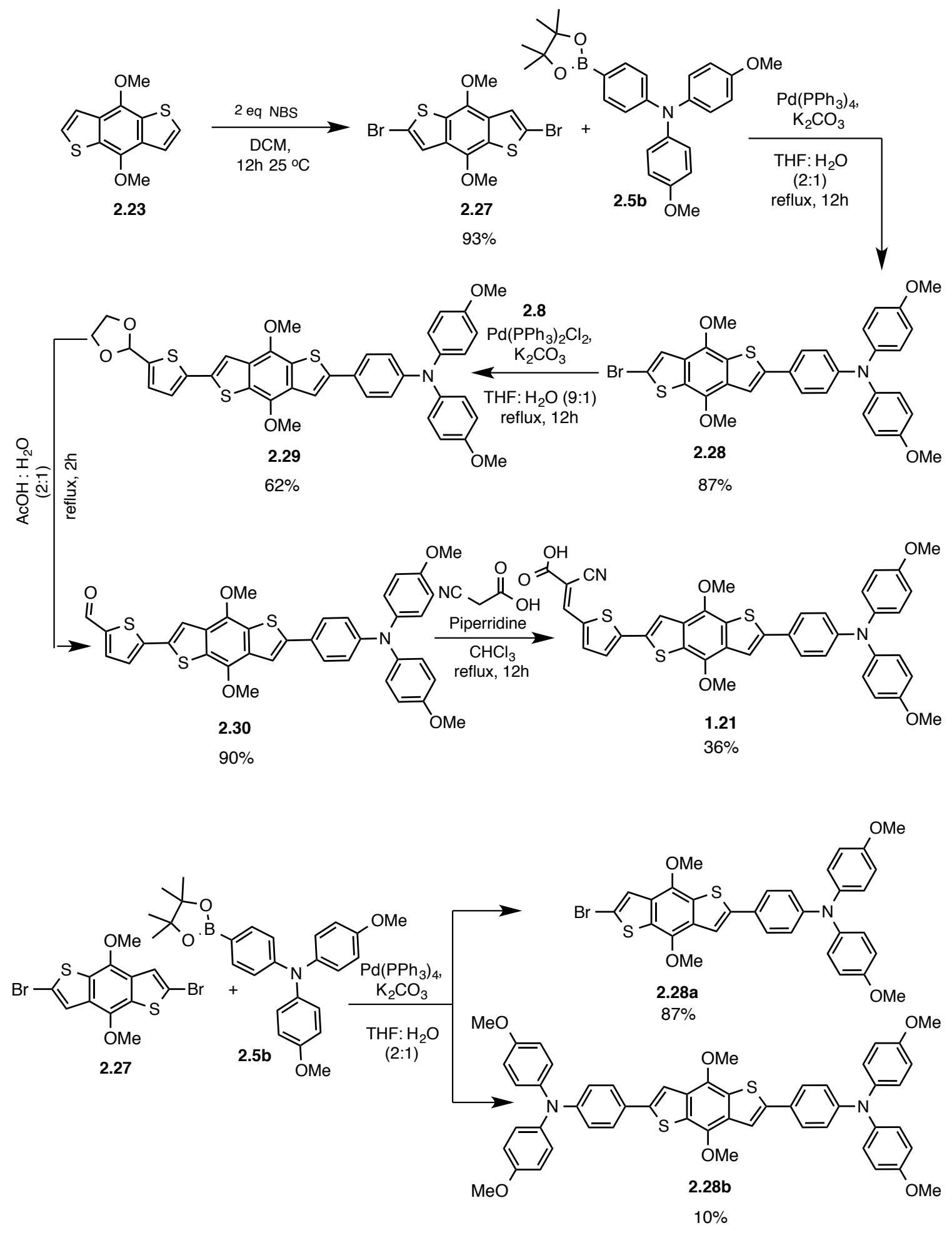

Scheme 2.6. Synthesis of MeOBDT-Thiophene dye (1.21) and by-product (2.28a and 2.28b) 


\subsection{Synthesis of quinone-thiophene-TPA-OMe dye (1.22):}

The quinone dye synthesis starts with the bromination of thiophene-3-carboxylic acid (2.31) to make 2.32. The reaction of $\mathbf{2 . 3 2}$ with thionyl chloride resulted in the acid chloride 2.33. The acid chloride was then converted to the amide $\mathbf{2 . 3 4}$, where through a dimeric nucleophilic acyl substitution reaction after lithiation, yielded the $\pi$-spacer (2.35). This sequence was required in order to add the bromine substituents, because direct bromination of $\mathbf{2 . 2 2}$ was not possible owing to the quinones electron withdrawing character. For pragmatic reasons, the Suzuki coupling sequence presented in Scheme 2.6 was reversed and the thiophene spacer was added first to create $\mathbf{2 . 3 6}$, followed by a second cross-coupling to yield 2.37. Deprotection of $\mathbf{2 . 3 7}$ yielded the aldehyde $\mathbf{2 . 3 8}$, which was subjected to a Knoevenagel condensation to give the dye product 1.22. 


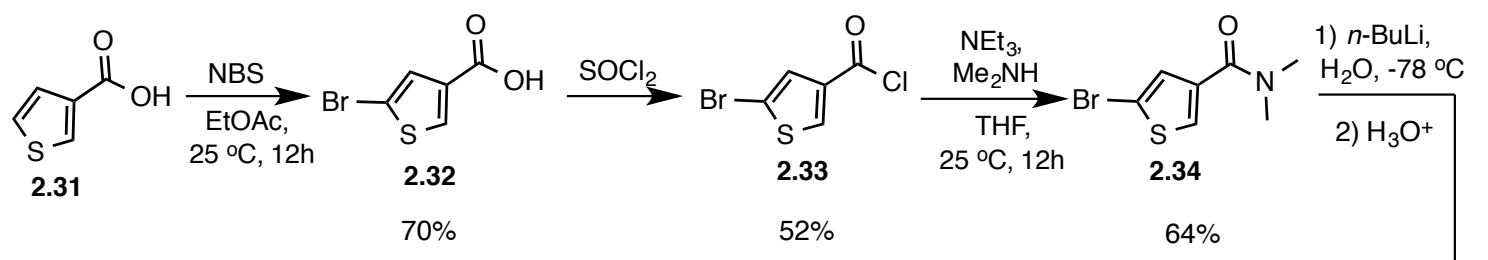

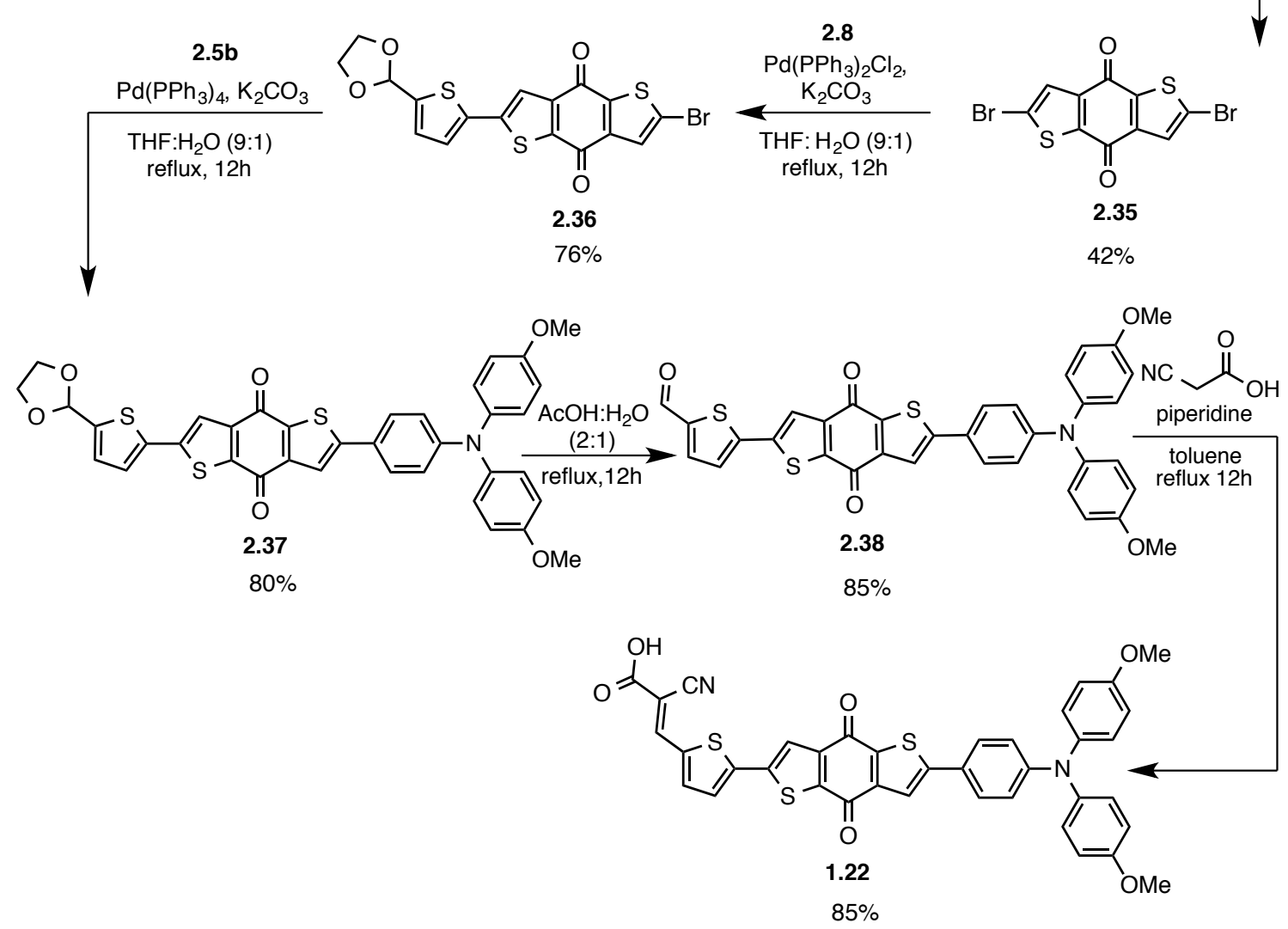

Scheme 2.7. Synthesis of quinone-thiophene dye (1.22)

\subsection{Synthesis of the quinone-thiophene-TPA-OHex dye (1.23) and quinone-thiophene TPA dye (1.24):}

The quinone-thiophene-TPA-OHex dye (1.23) and quinone-thiophene TPA dye (1.24) derivatives were prepared in a similar fashion to the dyes 1.18-1.22, with the only difference being the nature of the TPA coupling units (2.39 and $\mathbf{2 . 4 2}$, respectively). The synthetic sequences are shown in scheme 2.8 and scheme 2.9 , respectively. 


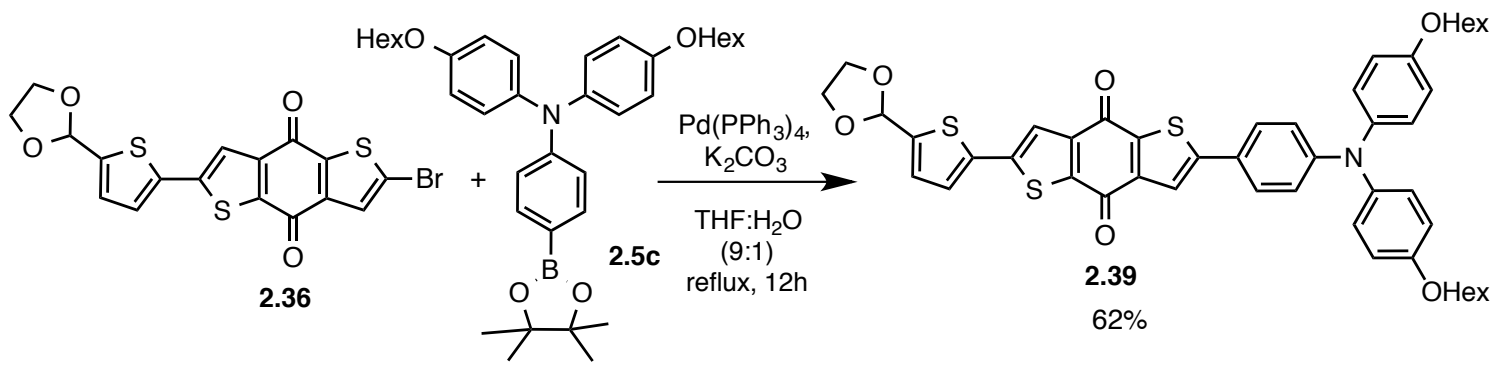

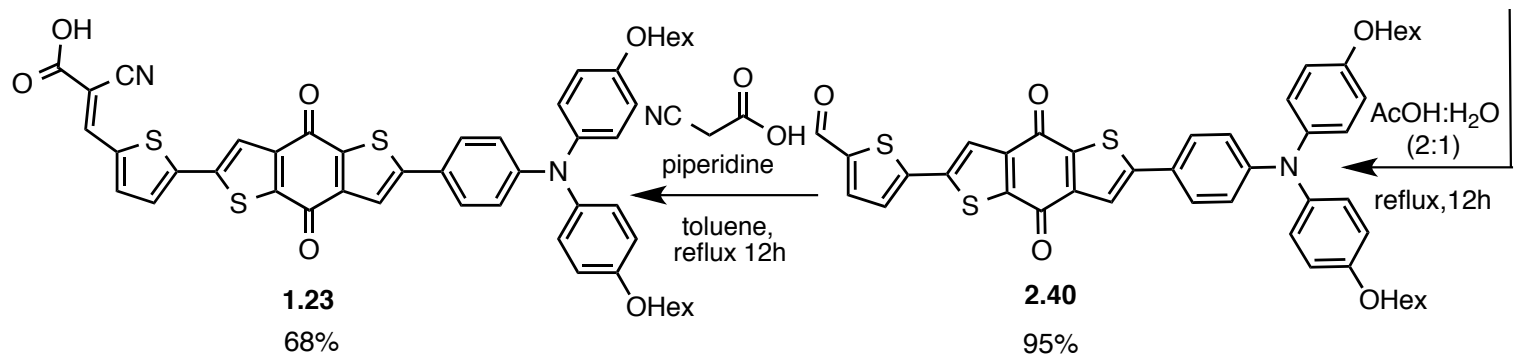

Scheme 2.8. Synthesis of quinone-thiophene dye (1.23)
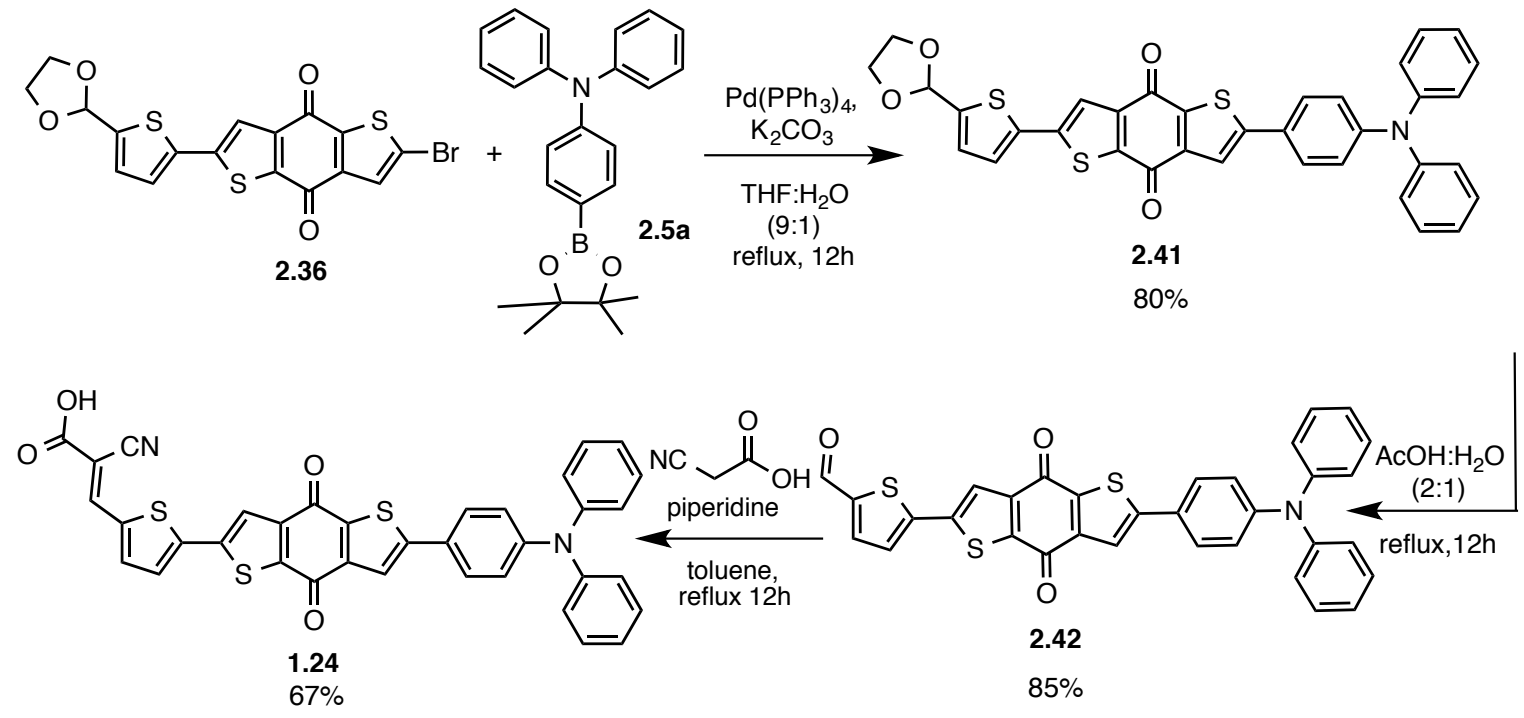

Scheme 2.9. Synthesis of quinone-thiophene dye (1.26) 


\section{Chapter 3: Results and discussion}

The following chapter highlights the physicochemical properties of the target dye molecules and relevant precursors synthesized and presented in Chapter 2. Owing to the redox-active nature of these $\pi$-spacers (BDT and quinone derivatives) physicochemical properties have been collated for all isolated molecules that have a $\pi$-spacer linked to the redox-active triphenylamine donor.

\subsection{Theoretical predictions using Density Functional Theory}

Theoretical calculations were performed using the Gaussian software suite.$^{69}$ utilizing the hybrid functional B3LYP with the basis set $6-311+\mathrm{G}(\mathrm{d}, \mathrm{p})$. Optimized structures were used to examine the orbital symmetry in the frontier orbitals to determine if the electron density was sufficiently delocalized in the excited state and localized primarily on the anchor group (when present). In addition, calculated UV-Vis spectra were determined using TD-DFT using the optimized B3LYP ground states. No solvent model was employed and TD-DFT was performed in the gas phase. These methods have been previously shown to adequately describe the electronic and optical properties of similar push-pull dyes. ${ }^{70}$ Dominant transitions from the TD-DFT have been presented as assignments in Tables 3.1, 3.2 and 3.3. Generally, as reported previously ${ }^{71}$, the HOMOs are localized on the TPA group while the LUMOs are delocalized along the BDT spacer (and thiophene group in the target molecules 1.19, 1.21, 1.22, 1.23 and 1.24) and the cyanoacetic acid acceptor group. However, charge distribution upon excitation in the molecules $1.22,1.23$ and 1.24 primarily leaves charge density along the quinone ( $\pi$ spacer). The following descriptions elaborate on these observations for each dye family and are presented below.

\subsubsection{BDT-containing dyes $1.18 \& 1.19$ and precursors}

As shown in Figure 3.1, the DFT calculations predict that there will be sufficient charge redistribution, and localized on anchor when transitioning from the HOMO to LUMO. The DFT of 1.18 illustrates that the most charge density is transferred to the accepter in the excited state. This is consistent with molecules 2.14, 2.15 and 1.18. In the LUMO, as 
electron-withdrawing groups are introduced on the spacer, there is increasing amounts of charge density localized opposite the TPA donor.<smiles>COc1ccc(N(c2ccc(OC)cc2)c2ccc(-c3cc4cc5sc(/C=C(\C#N)C(=O)O)cc5cc4s3)cc2)cc1</smiles>
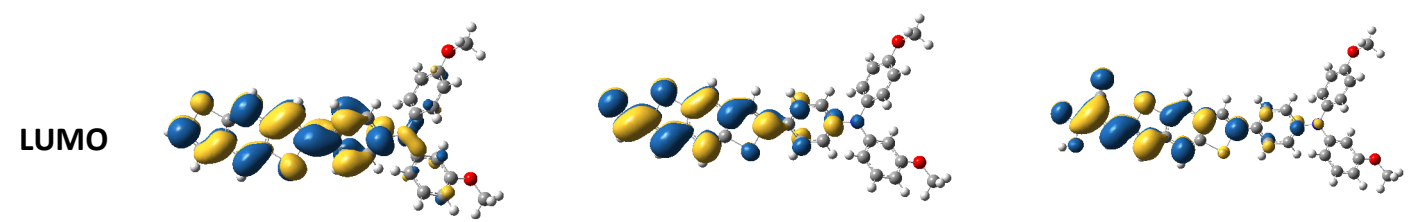

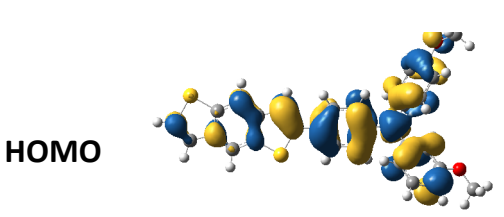

2.14

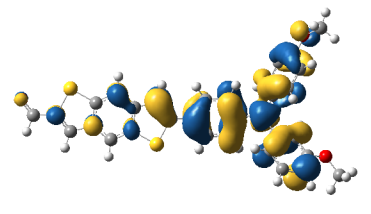

2.15

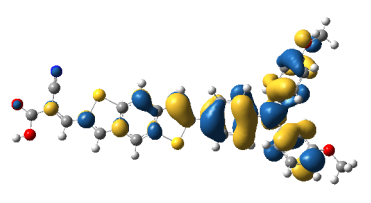

1.18

Figure 3.1. DFT calculation of target molecule $\mathbf{1 . 1 8}$

When comparing $\mathbf{1 . 1 9}$ and $\mathbf{1 . 1 8}$ there are not significant differences in charge distribution in either HOMO or LUMO as seen in Figure 3.2. Generally, while it may bathochromically shift the absorption spectrum, the inclusion of thiophene does not significant effect the localization of charge density in either the HOMO or LUMO. In the thiophene containing series, charge density localizes at the OMe-TPA site as the electronwithdrawing character of the molecules increases. Localization upon charge transfer occurs on the opposite end of the molecule for the LUMO's as observed in Figure 3.2. 

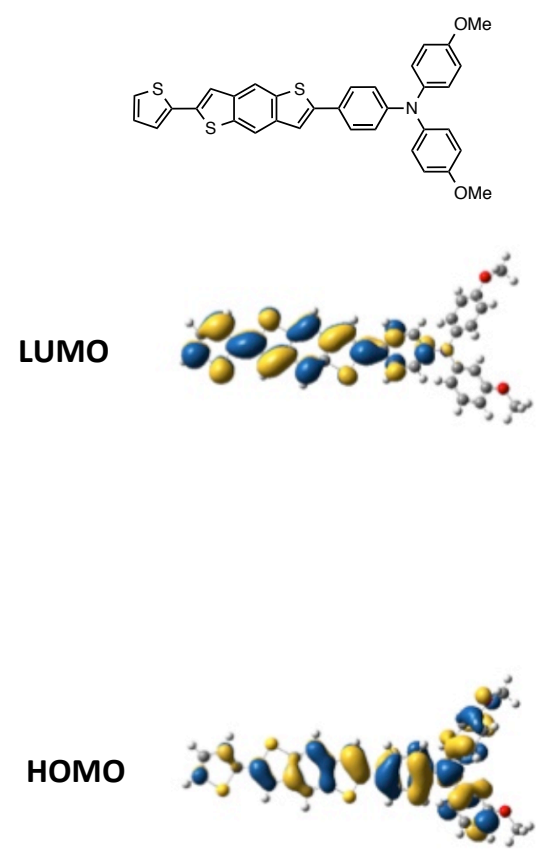

2.18
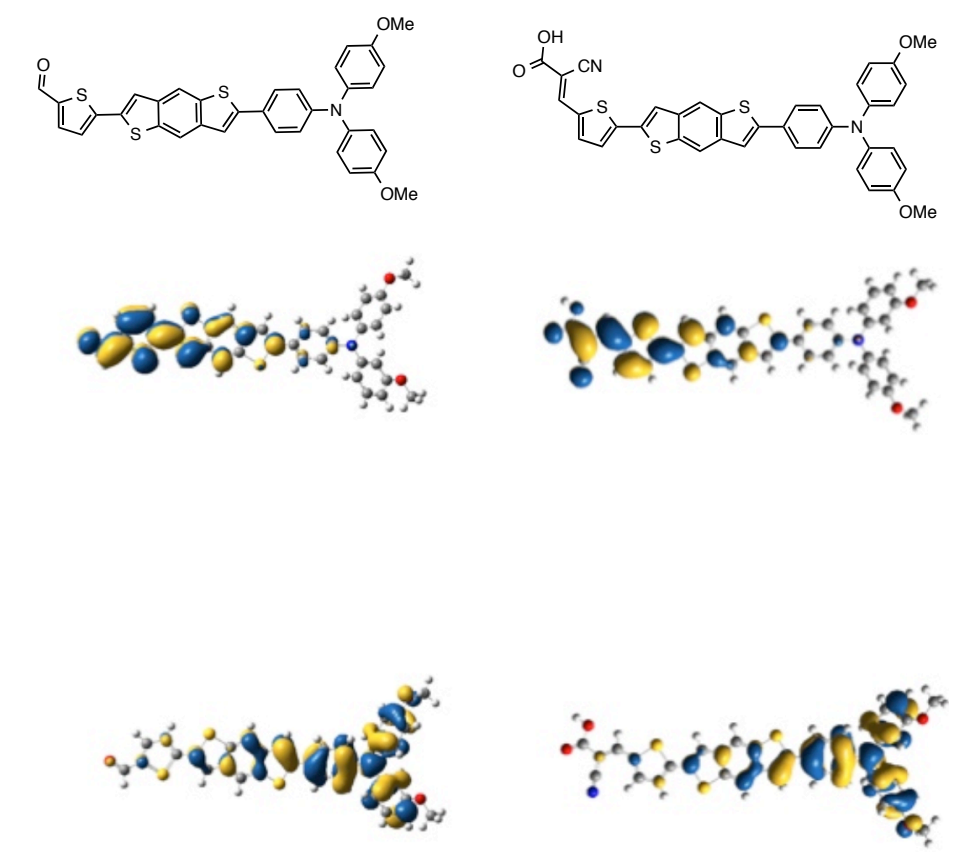

2.19

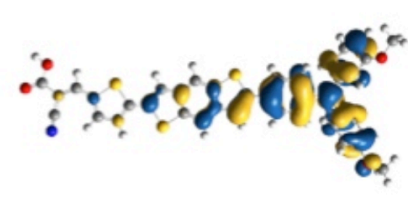

1.19

Figure 3.2. DFT calculation of target molecule $\mathbf{1 . 1 9}$

\subsubsection{OMe-BDT containing dyes $1.20 \& 1.21$ and precursors}

OMe groups where installed on the $\pi$-spacer to increase the polarizability in the dye scaffold and as a result hopefully increase the extinction coefficient and charge redistribution in the excited state. This was consistently observed in the DFT predictions. Figure 3.3 displays the increase in charge density localized on the $\pi$-spacer in comparison to the target molecules $\mathbf{1 . 1 8}$ and 1.19, which do not have electron donor groups attached to the $\pi$-spacer. Furthermore, increased coefficients are observed on the acceptor side of the family in the LUMO. As previously observed charge density localization in the HOMO and LUMO states are consistent with the BDT family. 


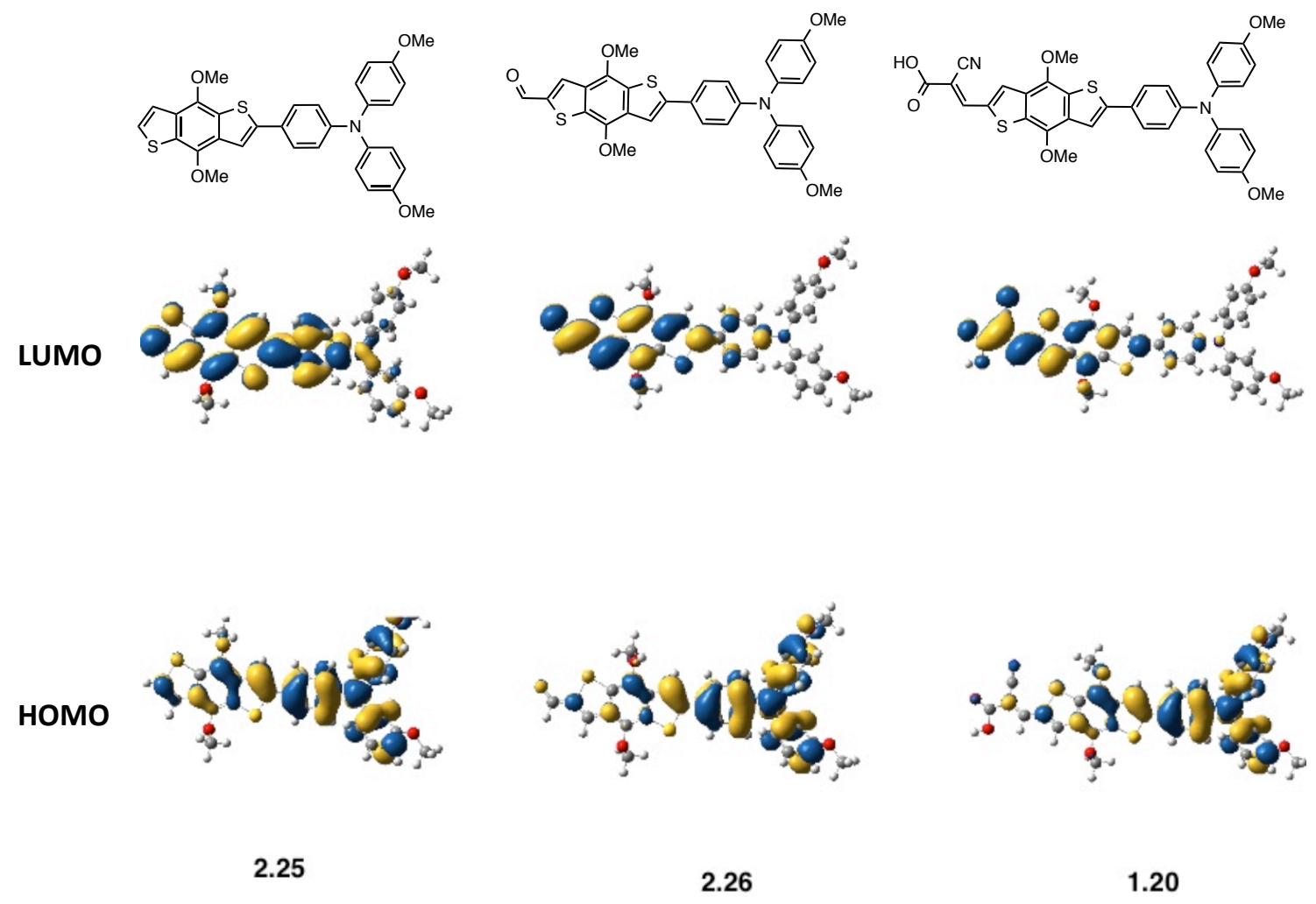

Figure 3.3. DFT calculation of target molecule $\mathbf{1 . 2 0}$

As mentioned previously in Figure 3.2, adding thiophene should red-shift and broadened the absorption envelope, but the inclusion of an additional $\pi$-spacer does not significantly effect charge transfer characteristics when comparing the HOMO \& LUMO states of the dye series presented. This was similarly observed in the precursors and dye $\mathbf{1 . 2 1}$ as shown below in Figure 3.4. 

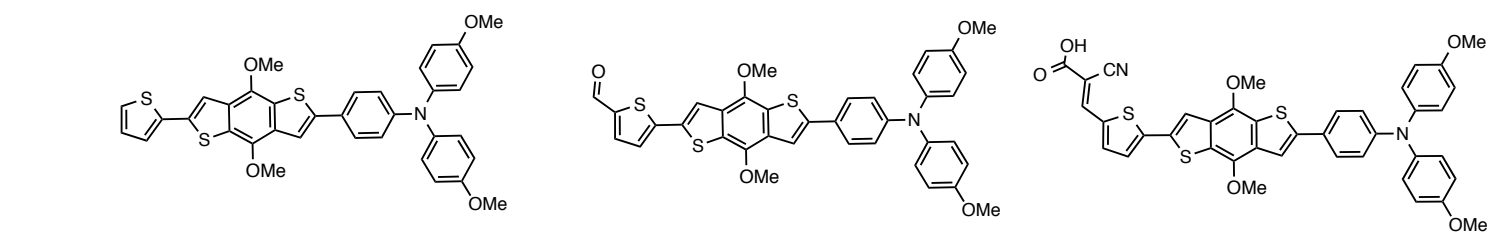

LUMO
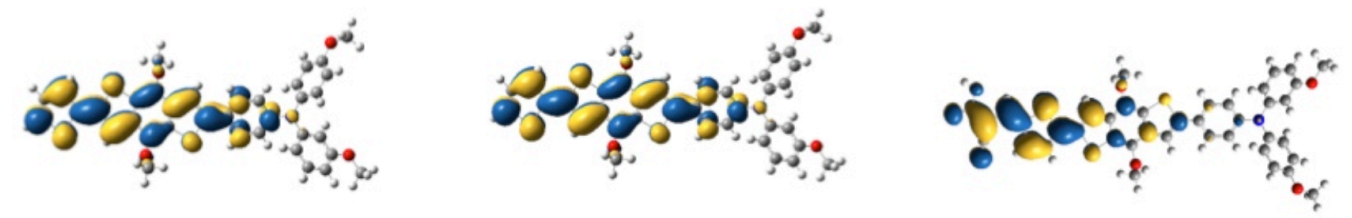

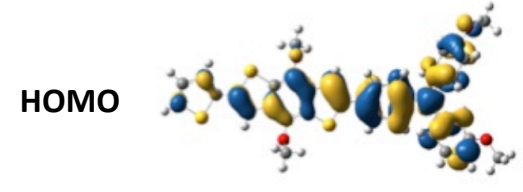

2.29

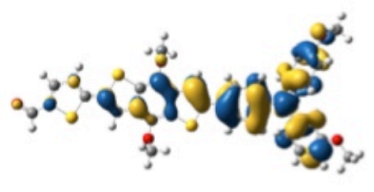

2.30

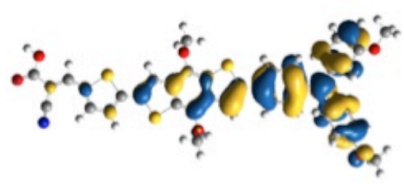

1.21

Figure 3.4. DFT calculation of target molecule $\mathbf{1 . 2 1}$

\subsubsection{Quinone containing dyes $1.22,1.23 \& 1.24$ and precursors}

Unlike the previously discussed $\pi$-spacers, the inclusion of a quinoidal architecture does lead to significant polarization of charge densities in both the HOMO and LUMO states compared to previously reported DFT's in this chapter (Figure 3.5). While HOMO electron densities are isolated predominantly on the TPA fragment, LUMO charge density is predominantly localized along the $\pi$-spacer but redistributes more along the thiophene and towards the cyanoacetic acid anchor moiety as electron-withdrawing strength increases. 

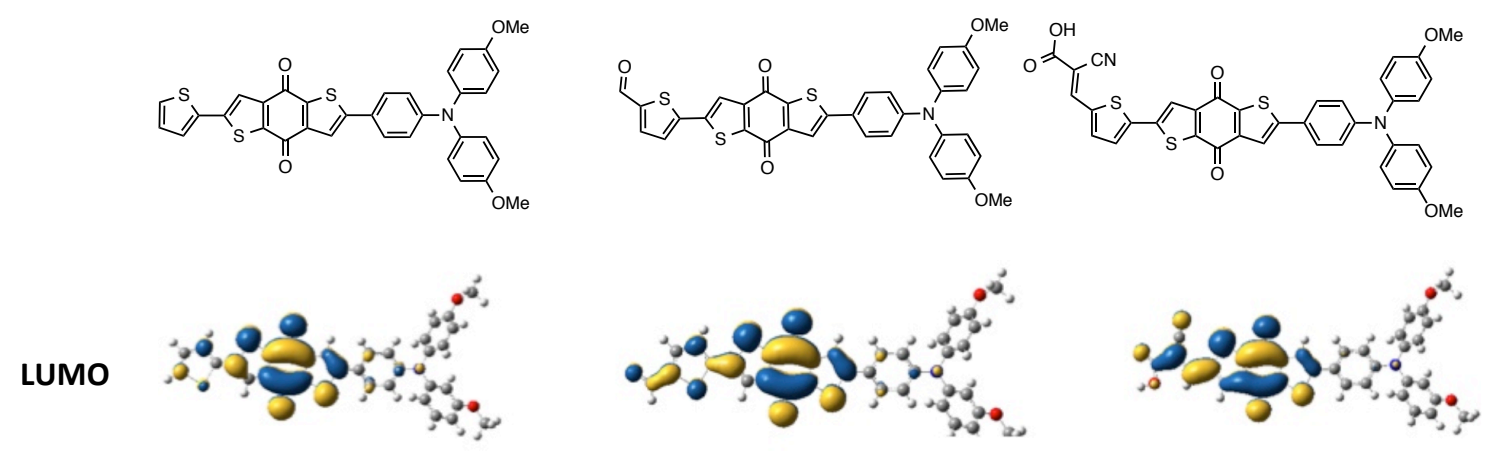

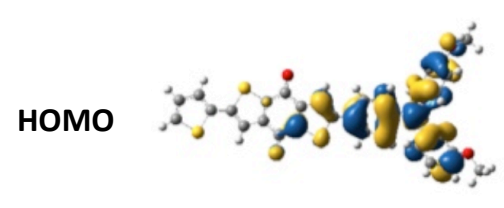

2.43

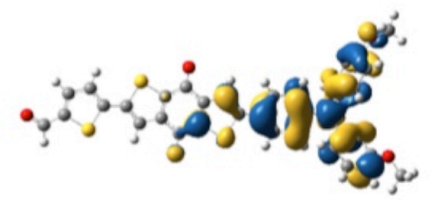

2.44

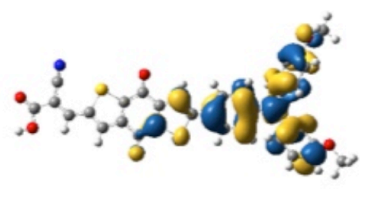

1.22

Figure 3.5. DFT calculation of target molecule $\mathbf{1 . 2 2}$

The DFT calculation with the replacement of the methoxy substituent on TPA with a hexyloxy group is displayed in Figure 3.6. There is no distinction that can be made in charge redistribution from the HOMO to LUMO states when compared against previous molecules. The electronics of hexyloxy is similar to methoxy because electron density is donated via resonance from the oxygen and the alkyl chains do not play a significant role. 

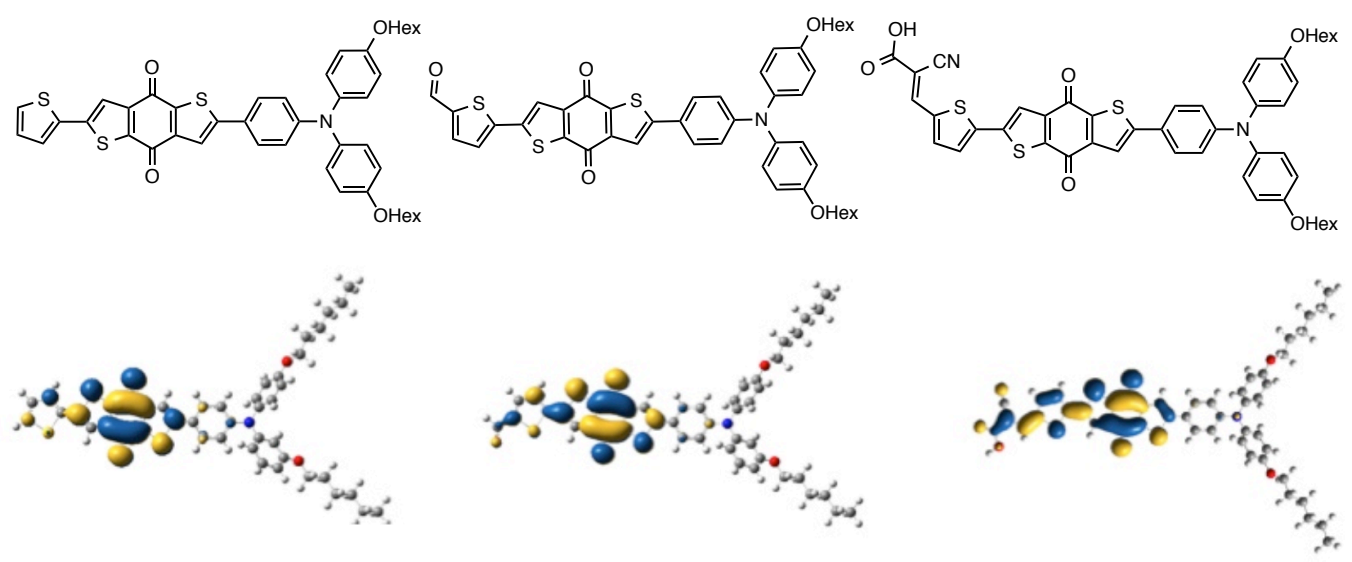

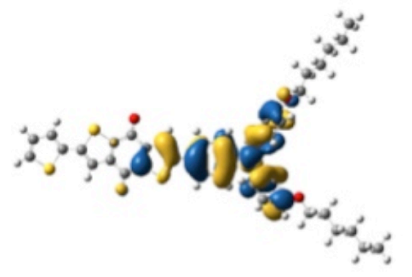

2.43

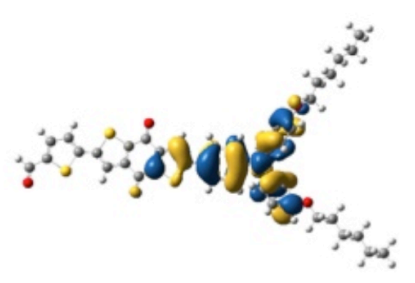

2.44

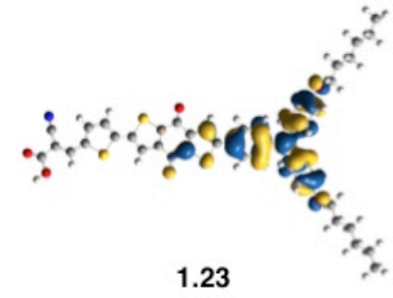

Figure 3.6. DFT calculation of target molecule $\mathbf{1 . 2 3}$

The molecules in Figure 3.7 lack the electron donating methoxy and hexyloxy substituents on the TPA donor unit. As a result, there is a shift of electron density towards the $\pi$-spacer in the HOMO levels for this sub-family. Furthermore, owing to the electron accepting nature of the quinone $\pi$-spacer electron density is predominantly isolated on this portion of the molecule in the LUMO, especially when comparing the HOMO and LUMO states predicted by DFT in Figure 3.4 and Figure 3.7.

Consistent with these DFT predictions, using this quinone $\pi$-spacer it may be possible to observe a thermally accessible lower energy charge transfer band in the UV-vis spectra. 


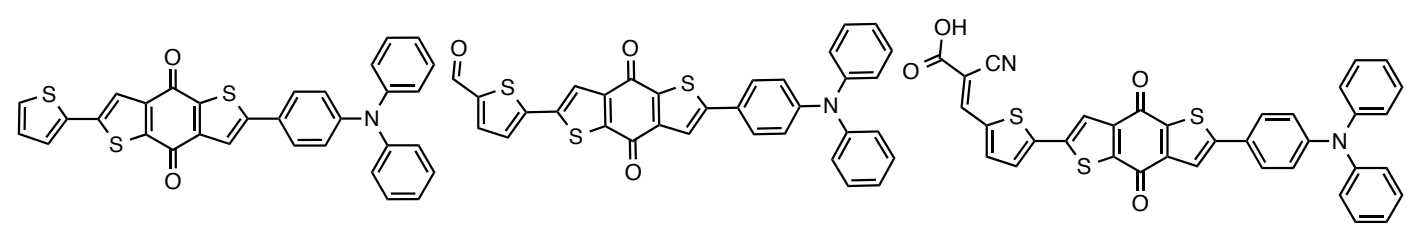

LUMO
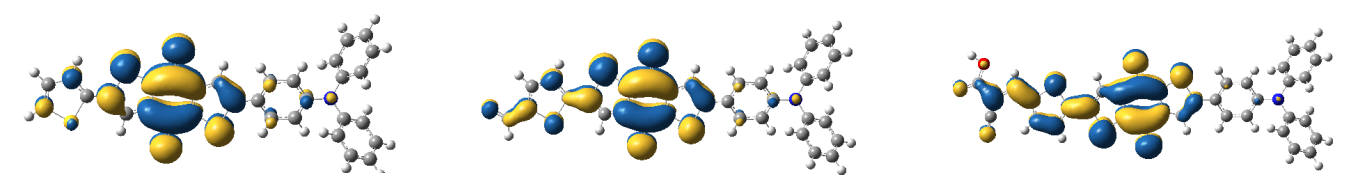

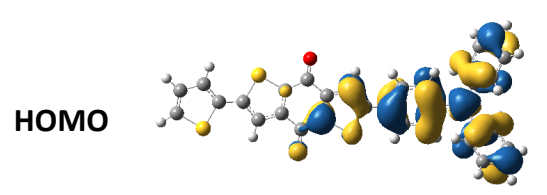

2.48

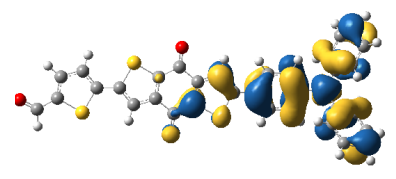

2.49

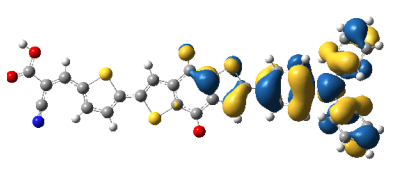

1.24

Figure 3.7. DFT calculation of the target molecule $\mathbf{1 . 2 4}$

\subsection{Experimental Properties in Solution}

To compliment and appreciate the DFT predictions both UV-Vis and electrochemical measurements where performed in DCM solutions. To determine the relative suitability of the HOMO and LUMO energies, electrochemical measurements include cyclic voltammetry (CV; solutions at $\left.100 \mathrm{mVs}^{-1}\right)$ and differential pulse voltammetry (DPV). These measurements were conducted in $0.1 \mathrm{M} \mathrm{NBu}_{4} \mathrm{PF}_{6}$ as a supporting electrolyte and referenced to NHE using a Fc/ $\mathrm{Fc}^{+}$internal standard $\left(\mathrm{Fc} / \mathrm{Fc}^{+}=0.765 \mathrm{~V}\right)$. The data has been collated in Table 3.1, 3.2 and 3.3 and is discussed below for each dye family, respectively. 


\subsubsection{Summary of results of the BDT dye family and precursors}

The UV-Vis spectra for a representative subgroup of the BDT family is shown in Figure 3.8 and all physicochemical data for this family is collated in Table 3.1. A quick look at Figure 3.8 shows that the predicted trends do hold for the series of molecules $(\mathbf{2 . 1 5}, \mathbf{2 . 1 9}$, \& 1.19). As expected, adding a thiophene spacer (i.e. 2.19) red shifts the absorption envelope compared to $\mathbf{2 . 1 5}$, consistent with extending conjugation between the donor and acceptor. Furthermore introducing a strong electron-withdrawing group (in the form of a cyanoacetic acid moiety, 1.19), further bathochromically shifts the absorption into the visible portion of the spectrum. Although not shown in Figure 3.8, the target molecule 1.18 and precursors did not obey the same trends. In fact, likely owing to the strong electron richness of the dye, $\mathbf{1 . 1 8}$ decomposes in solution, and the dye spectrum was not isolated. Consistent with NMR, the dye decomposes over time to the quinone species.

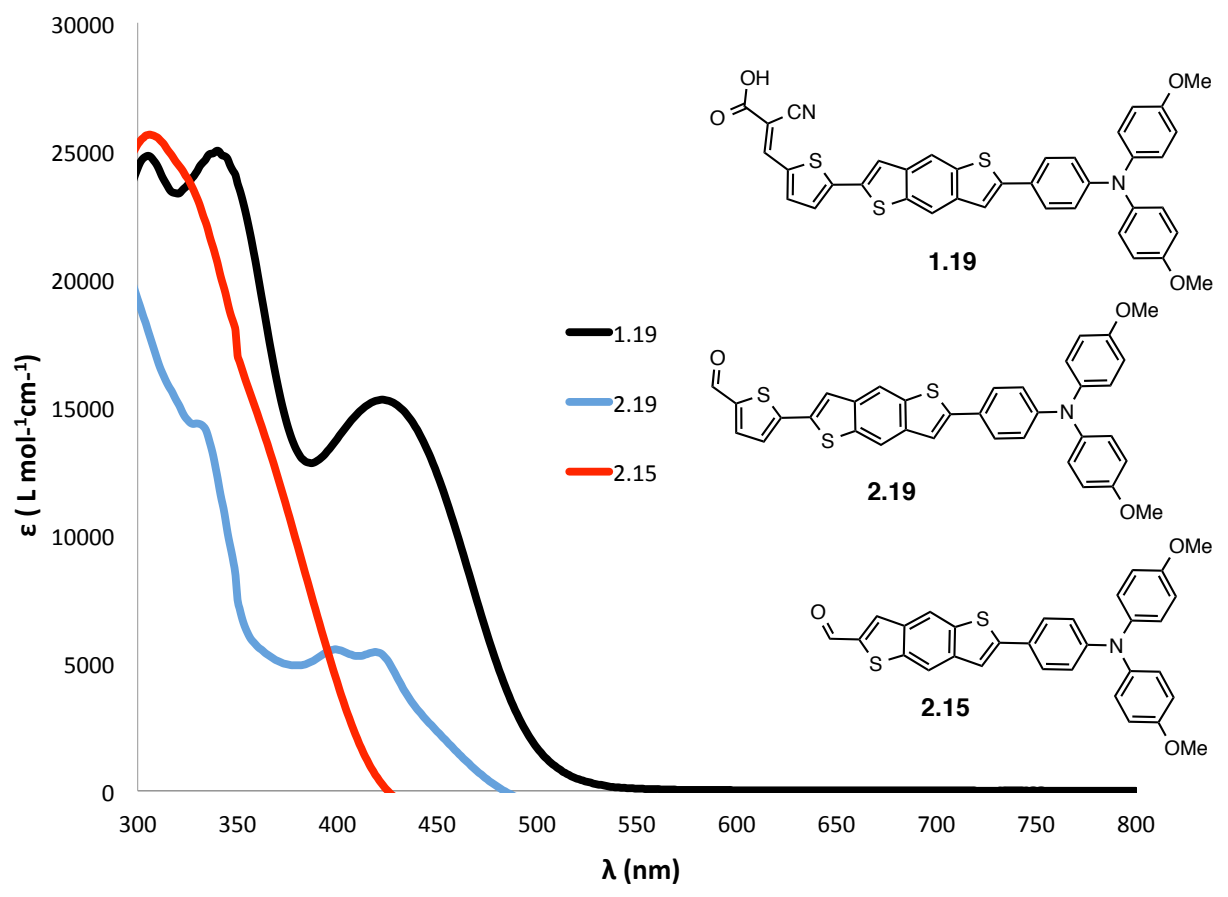

Figure 3.8. UV-Vis of BDT family in DCM 
Representative BDT voltammograms for $\mathbf{2 . 1 5}$ and 2.19 are shown in Figure 3.9. Despite the BDT spacer being redox active on its own (1.49 V vs NHE, Table 3.1), this family of dye precursors only shows one reversible oxidation wave that we have attributed to oxidation of the HOMO (primarily isolated on the TPA moiety). The second redox process is believed to take place at higher oxidation potentials outside the solvent stability window for DCM.

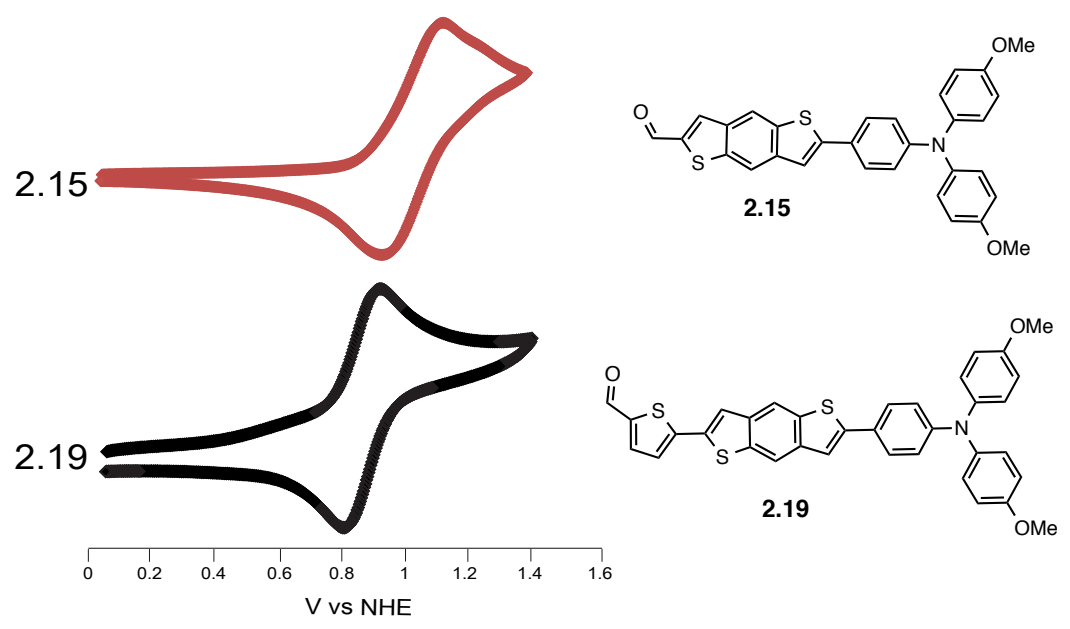

Figure 3.9. Comparison of cyclic voltammograms for dye precursors 2.15 and 2.19 
Table 3.1. Physicochemical charatcerization of the BDT dye family

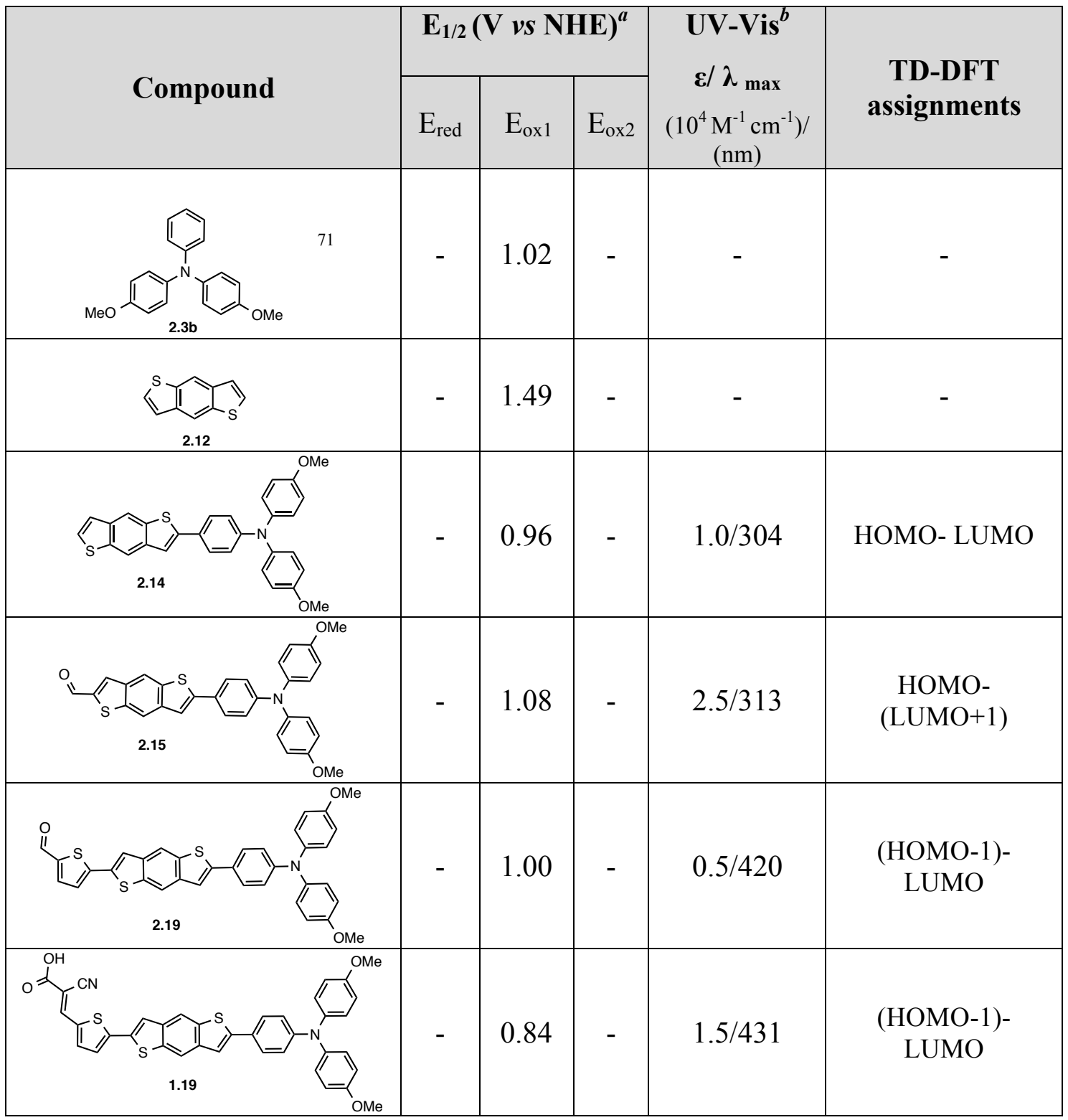

a) Data collected using $0.1 \mathrm{M} \mathrm{NBu}_{4} \mathrm{PF}_{6} \mathrm{DCM}$ solutions at $100 \mathrm{mVs}^{-1}$ and referenced to a $[\mathrm{Fc}] /[\mathrm{Fc}]+$ internal standard followed by conversion to NHE; $[\mathrm{Fc}] /[\mathrm{Fc}+]=+765 \mathrm{mV}$ vs. NHE in $\mathrm{DCM} ; b)$ Low energy or visible transitions from UV-Vis of BDT-OMe family in DCM.

Table 3.1 summarizes the remaining physicochemical characterization for this family. Consistent with the previously discussed UV-Vis and electrochemical insights above, all molecules show red-shifting of the absorption spectrum upon extending conjugation, with 
the exception of the dye molecule itself (which is believed to undergo an oxidative decomposition in aerated solutions; therefore its value can not be accurately determined). In addition, all molecules have a one electron reversible oxidation at $\sim 1 \mathrm{~V}$ attributed to the HOMO energy level located predominantly on the TPA moiety. Not all dominant transitions are HOMO to LUMO, but the frontier orbitals are involved in the dominant transitions.

\subsubsection{Summary of results of the OMe-BDT dye family}

The UV-Vis spectra for a representative subgroup of the OMe-BDT family is shown in Figure 3.10 and all physicochemical data for this family is collated in Table 3.2. A quick look at Figure 3.10 shows that the predicted trends do hold for the series of molecules (2.25, $2.26 \& 1.20)$. Within the series, increasing the acceptor strength attached to the $\pi$ spacer does redshift the absorption spectrum into the visible portion of the spectrum. This is consistent with increasing the acceptor strength and lowering the LUMO level.

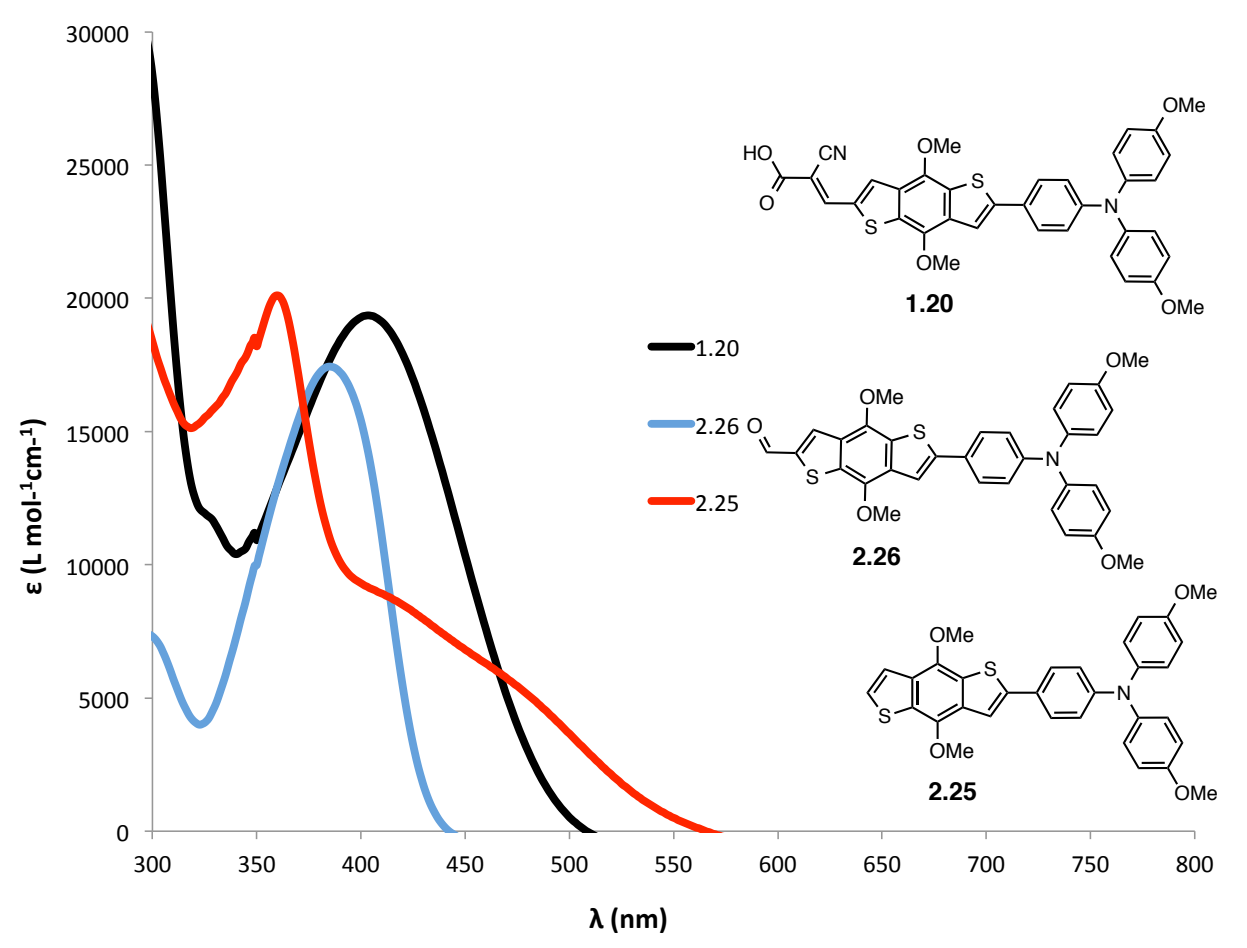

Figure 3.10. UV-Vis spectra in DCM for a select subset of the BDT-OMe dye family 
Contrary to the simple one-electron reversible processes observed in the BDT family of dyes all the compounds that contain TPA and the OMe-BDT $\pi$-spacer fragment, possess rich electrochemistry with 2 one-electron oxidations as observed by CV (see Figure 3.11). The coupling of TPA moieties to OMe-BDT significantly alters the potential of both redox-active units. These trends can be clearly observed in the OMe-BDT family of precursors and dyes (Figure 3.11 and Table 3.2). Owing to the hybrid delocalized nature of the HOMO orbital (based on DFT), it is difficult to assign the first oxidation to any particular subunit or electrophore, as both waves seem to be effected with the installation of stronger electron donating groups.
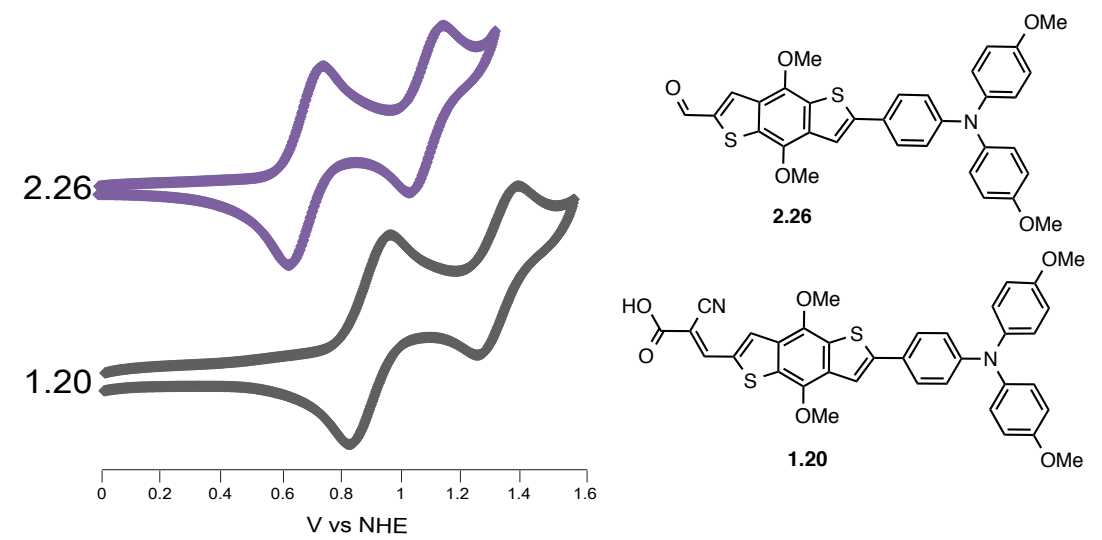

Figure 3.11. Comparison of cyclic voltammograms for dye $\mathbf{1 . 2 0}$ and molecule $\mathbf{2 . 2 6}$

Table 3.2 summarizes the remaining physicochemical characterization for this family. Consistent with the previously discussed UV-Vis and electrochemical insights above, all molecules show red-shifting of the absorption spectrum upon extending conjugation. In addition, all molecules have 2 one-electron oxidation processes. As presented in Table 3.1 , the coupling of a TPA moiety to BDT had a negligible effect on the oxidation of BDT. Conversely, the oxidation of OMe-BDT was destabilized when coupled to OMeTPA, and vice versa, owing to the strong electron donating ability of each subunit. Installation of thiophene at the terminal end of the molecule (comparing 2.26 and 2.30), destabilizes the HOMO. The destabilization is a proximity effect whereby the thiophene spatially separates the electron-withdrawing aldehyde from the rest of the molecule. All 
significant optical transitions originate from the HOMO in this family.

Table 3.2. Physicochemical characterization of the OMe-BDT dye family

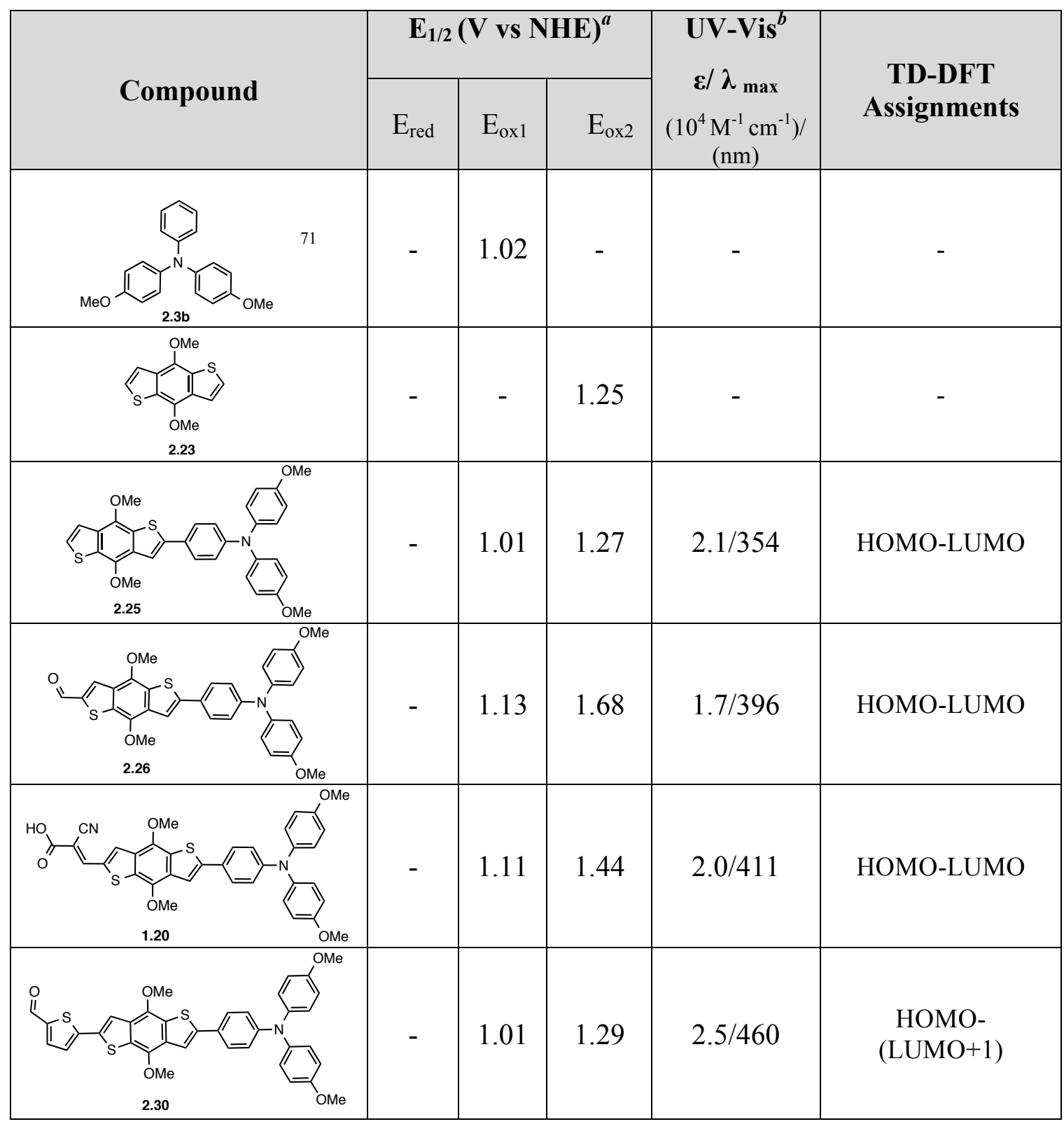

a) Data collected using $0.1 \mathrm{M} \mathrm{NBu}_{4} \mathrm{PF}_{6} \mathrm{DCM}$ solutions at $100 \mathrm{mVs}^{-1}$ and referenced to a $[\mathrm{Fc}] /[\mathrm{Fc}]+$ internal standard followed by conversion to $\mathrm{NHE} ;[\mathrm{Fc}] /[\mathrm{Fc}+]=+765 \mathrm{mV}$ vs. NHE in $\mathrm{DCM} ; b$ ) UV-Vis of BDT-OMe family in DCM. 


\subsubsection{Summary of results of quinone dyes and precursors}

The UV-vis spectra for two representative subgroups of the quinone-dye family is shown in Figure 3.12 and 3.13 and all physicochemical data for this family is collated in Table 3.3 and 3.4, respectively. A glance at both Figure 3.12 and 3.13 shows that the predicted trends hold for the quinone based dyes; as the conjugation is extended red shifting occurs within the series. In addition upon significantly desymmetrizing the quinone core, the extinction coefficients increase dramatically. Furthermore, as the donating strength of the TPA is increased (adding -OR substituents), a bathochromic shift is observed. There is no significant difference between the using -OHex or -OMe in the physical properties of the dyes. Furthermore, a charge transfer band (consistent with DFT predictions) emerges at $\sim 610 \mathrm{~nm}$ for all derivatives possessing the quinone and TPA unit. This is observed regardless of the TPA donor used (see Figure 3.13). As a result, three absorption bands (2 maxima and one shoulder) are observed for all TPA-quinone containing compounds. The longest wavelength absorption around 500-600 $\mathrm{nm}$ corresponds to converting the quinone to radical, while the blue-shifted spectrum $(350-400 \mathrm{~nm}) \pi-\pi^{*}$ correspond to transition of the conjugated core originates from the electronic transition. 


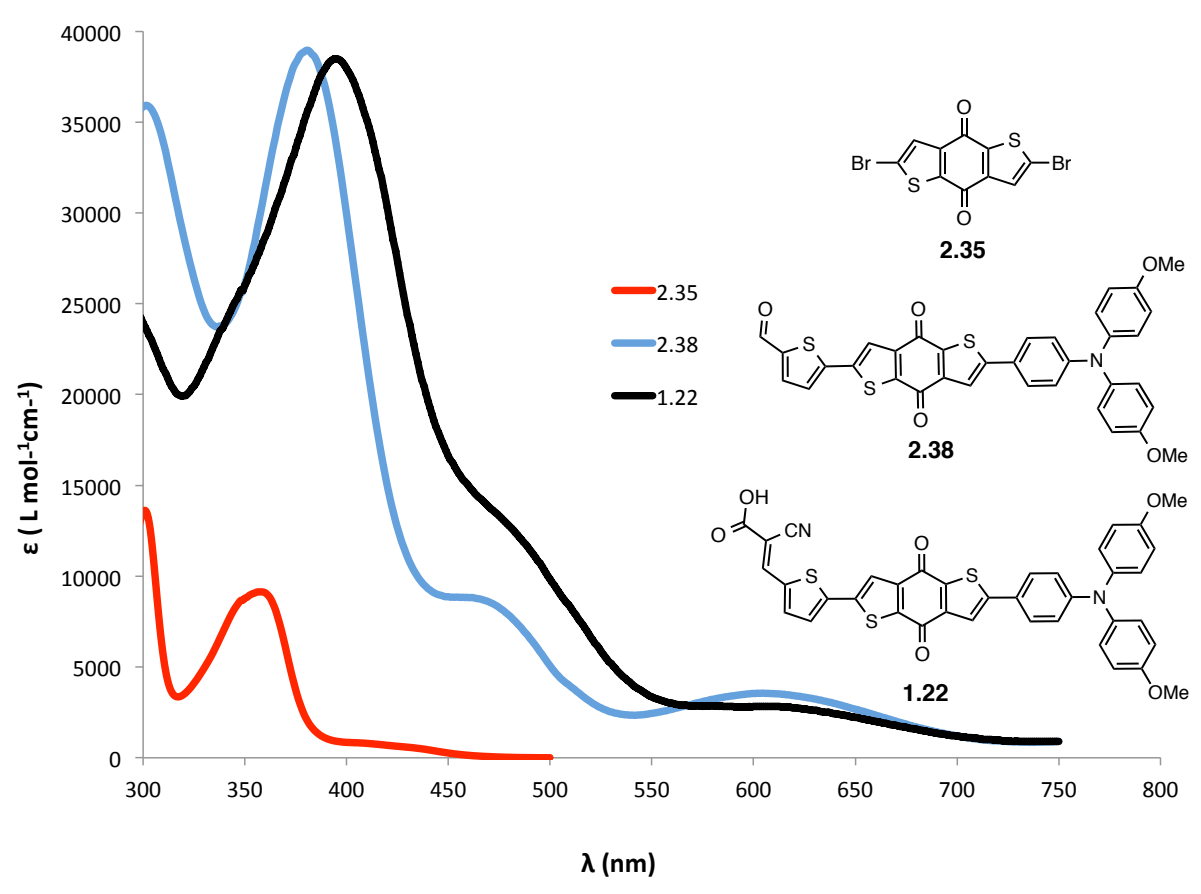

Figure 3.12. UV-Vis spectra in DCM for quinone-thiophene dye family

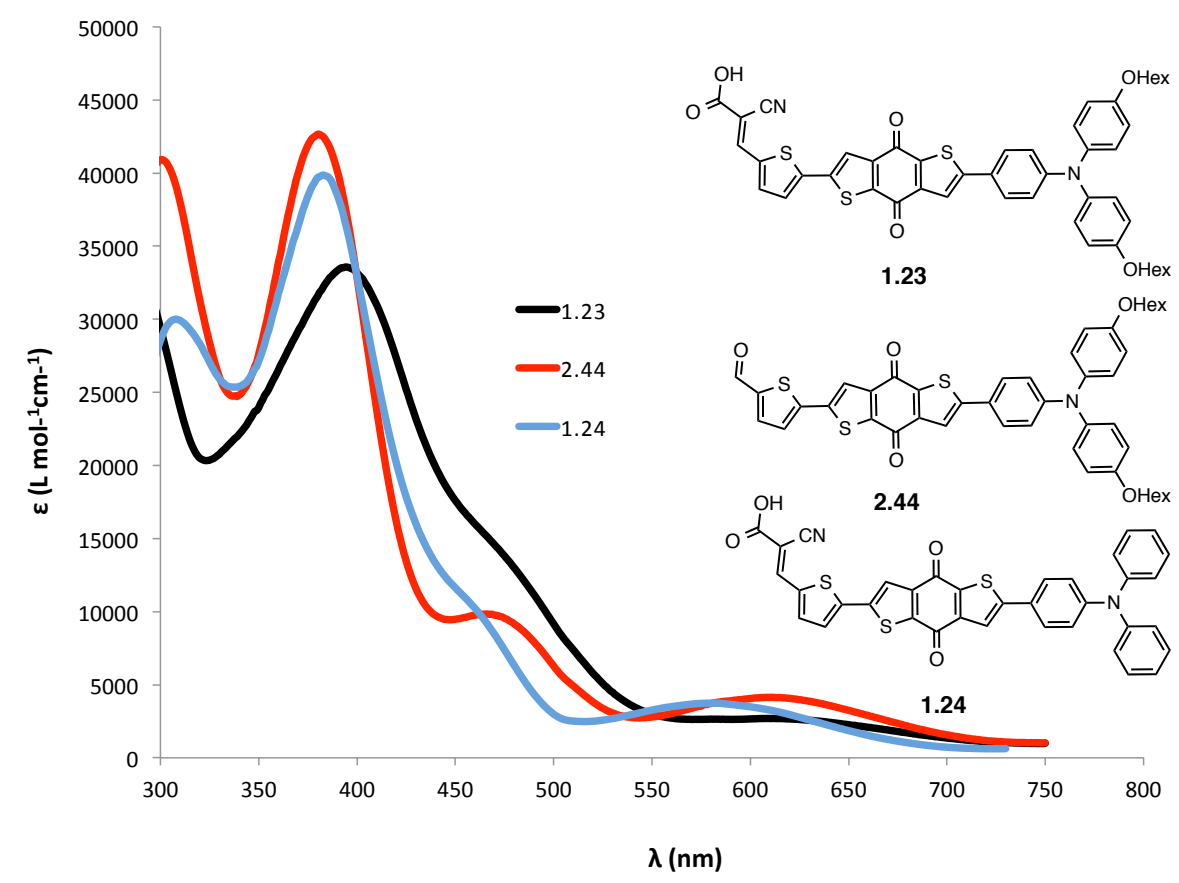

Figure 3.13. UV-Vis spectra in DCM for quinone- thiophene-TPA-OHex and thiophene TPA dye 
Table 3.3 and Table 3.4 summarize the remaining physicochemical characterization for this quinone-based family. Consistent with the previously discussed UV-vis, all molecules show red-shifting of the absorption spectrum upon extending conjugation. Unfortunately, time precluded the possibility of analyzing all of the quinone samples electrochemically, but as expected for all TPA containing derivatives, one reversible oxidation peak would be observed. In those instances where measurements were taken, the electron withdrawing nature of the quinone can be observed as the TPA oxidation wave is stabilized relative to the non-quinone derivatives. 
Table 3.3. Physicochemical charaterization of the quinone dye family : Part A

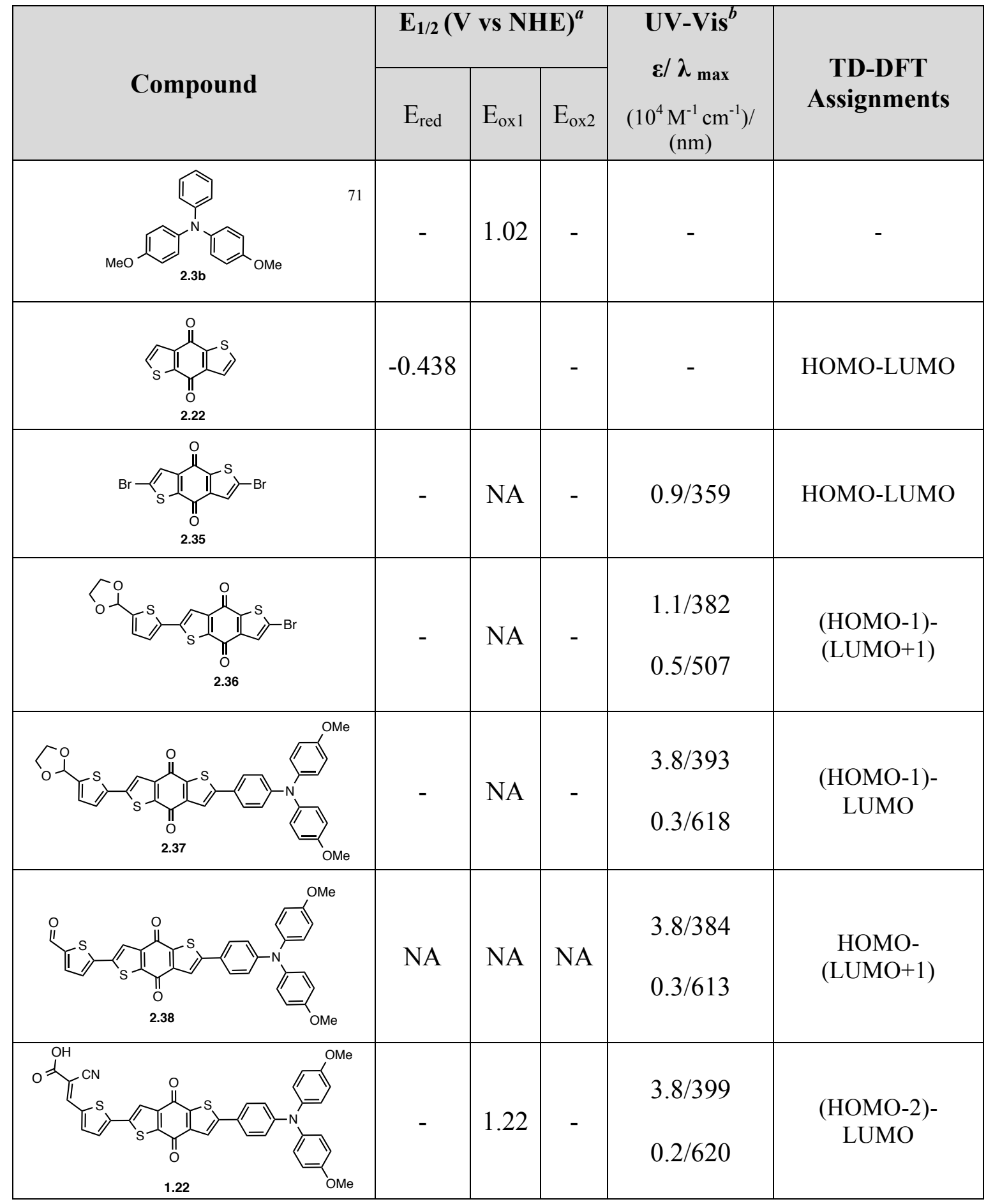

a) Data collected using $0.1 \mathrm{M} \mathrm{NBu}_{4} \mathrm{PF}_{6} \mathrm{DCM}$ solutions at $100 \mathrm{mVs}^{-1}$ and referenced to a $[\mathrm{Fc}] /[\mathrm{Fc}]+$ internal standard followed by conversion to NHE; $[\mathrm{Fc}] /[\mathrm{Fc}+]=+765 \mathrm{mV}$ vs. NHE in $\mathrm{DCM} ; b) \mathrm{UV}-\mathrm{V}$ is of quinone-OMe family in DCM. NA = not available and they were not tested. 
Table 3.4. Physicochemical charatcerization of the quinone dye family: Part $B$

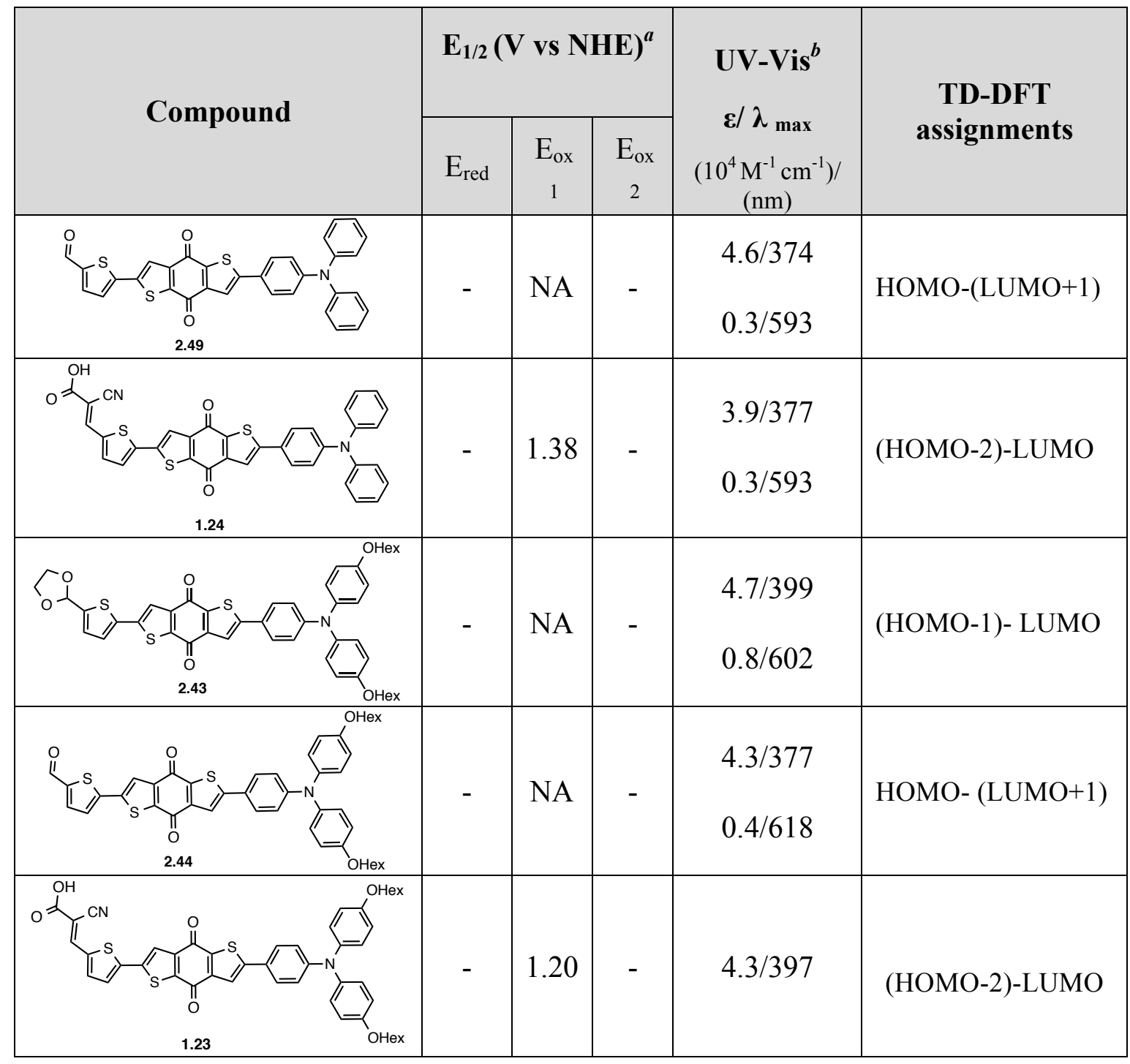

a) Data collected using $0.1 \mathrm{M} \mathrm{NBu}_{4} \mathrm{PF}_{6} \mathrm{DCM}$ solutions at $100 \mathrm{mVs}^{-1}$ and referenced to a $[\mathrm{Fc}] /[\mathrm{Fc}]+$ internal standard followed by conversion to $\mathrm{NHE} ;[\mathrm{Fc}] /[\mathrm{Fc}+]=+765 \mathrm{mV}$ vs. NHE in DCM; $b$ ) UV-Vis of quinone family in DCM. NA = not available and they were not tested. 


\section{Chapter 4: Conclusions and future work}

\subsection{Conclusions}

The objectives of this thesis were to prepare three new families of dyes suitable for DSSC applications. As such, this thesis has outlined the synthesis and characterization of seven new thiophene-fused organic dyes (1.18-1.24). Each of these dyes has been synthesized using similar methodology, and has been characterized electrochemically and optically (UV-Vis and DFT) in order to clarify the relationship between the chemical structure potential applicability for photovoltaic applications.

The effect of changing the electron density of the $\pi$-spacer by comparing 1.19, 1.21 and 1.22, has demonstrated that while OMe-BDT have strong electron donating ability, quinones, conversely have strong electron withdrawing character when coupled with the TPA donor, in fact this coupling is so significant that charge transfer occurs at low energy, based on optical measurements. This seems to be more significant when stronger donors are used (OHex or $\mathrm{OMe})$. Thiophene as an additional spacer does effectively extend the conjugation, and red shift the absorption, but it is yet to be determined if that charge separation, will be suitable for DSSC charge injection.

From our investigation and characterization it would appear that the OMe-BDT family of $\pi$-spacers would be most desirable for DSSC applications. At first glance, this could be rationalized by the undesirable characteristics in the other two families. Based on empirical findings, the BDT derivatives exhibit inherent instability at the BDT core, and the strong coupling of the quinones, may create a trapped excited state unable to effectively sensitize titania. These disqualifications cannot be overlooked, but the OMeBDT derivatives do have a number of desirable features in their own right. The electron rich core, and the rich redox stability at the appropriate energy levels is a very promising feature. But further studies and measurements still need to be made to fully appreciate this structure-property relationship. Furthermore, when comparing the result of this study with literature (Table 4.1) there seems to be a significant and unpredicted difference in 
long wavelength absorption maximum, and the observation of a reversible reduction, something we have not observed in any of our TPA containing molecules.

Table 4.1 Physicochemical comparison to known literature dyes with similar stucture.

\begin{tabular}{|c|c|c|c|c|c|}
\hline \multirow{2}{*}{ Compound } & \multicolumn{3}{|c|}{$E_{1 / 2}(\mathrm{~V} \text { vs NHE })^{a}$} & \multirow{2}{*}{$\begin{array}{c}\mathbf{U V}-\mathbf{V i s}{ }^{b} \\
\boldsymbol{\varepsilon} / \lambda_{\text {max }} \\
\left(10^{4} \mathrm{M}^{-1} \mathrm{~cm}^{-1}\right) / \\
(\mathrm{nm})\end{array}$} & \multirow{2}{*}{$\begin{array}{c}\text { TD-DFT } \\
\text { Assignments }\end{array}$} \\
\hline & $\mathrm{E}_{\text {red }}$ & $\mathrm{E}_{\mathrm{ox} 1}$ & $E_{\text {ox2 }}$ & & \\
\hline 1.20 & - & 1.11 & 1.44 & $2.0 / 411$ & HOMO-LUMO \\
\hline 1.16 & -1.51 & 1.12 & - & $3.2 / 447$ & NA \\
\hline
\end{tabular}




\subsection{Future work}

The following is a list of future work that needs to be explored further to fully appreciate the structure-property relationships contained herein:

- limited time constraints prohibited the complete electrochemical characterization of quinone based precursors and this needs to be completed,

- a carefully analysis of $\mathbf{1 . 2 0}$ and $\mathbf{1 . 1 6}$ needs to be conducted to be certain that there are no significant discrepancies in this thesis,

- owing to the lack of fabrication facilities (delays outside the control of this thesis), device fabrication and testing is required to fully characterize the structure-property relationships.

- The decomposition of $\mathbf{1 . 1 8}$, needs to be examined in more detail and the information garnered may be helpful in synthesizing a notable exception in to the dye families studied in this family :

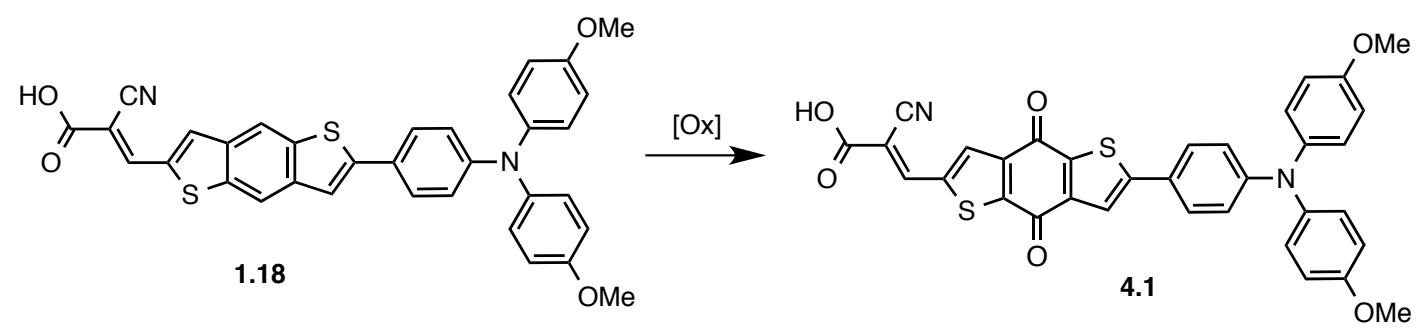

- Direct-aryl coupling or $\mathrm{CH}$ activation may be a method that could also be studied to improve or limit the number of synthetic steps.

In summary, the synthetic routes employed and the systematic study developed during this MSc thesis, will be useful for future improvement of similar structures and their utility in photovoltaic applications. 


\section{Chapter 5: Experimental}

\subsection{General Synthetic Considerations:}

All reagents were purchased from Aldrich except $\mathrm{Pd}\left(\mathrm{PPh}_{3}\right)_{4}$ and $\mathrm{Pd}\left(\mathrm{PPh}_{3}\right)_{2} \mathrm{Cl}_{2}$ (Pressure Chemical Co., Pittsburg, PA). Purification by column chromatography was carried out using silica (Silicycle: ultrapure flash silica). Analytical thin-layer chromatography was performed on aluminum-backed sheets precoated with silica 60 F254 adsorbent $(0.25 \mathrm{~mm}$ thick; Silicycle) and visualized under UV light. Melting points were determined using a Perkin Elmer Diamond Differential Scanning Calorimeter. Routine ${ }^{1} \mathrm{H}$, and ${ }^{13} \mathrm{C}\{1 \mathrm{H}\}$, were recorded at $400 \mathrm{MHz}$, respectively, on a Bruker AV 400 instrument at ambient temperature. Chemical shifts $(\delta)$ are reported in parts per million (ppm) from low to high field and referenced to a residual nondeuterated solvent $\left(\mathrm{CHCl}_{3}\right)$ for ${ }^{1} \mathrm{H}$ and ${ }^{13} \mathrm{C}$ nuclei. Standard abbreviations indicating multiplicity are used as follows: $\mathrm{s}=$ singlet; $\mathrm{d}=$ doublet; $m$ = multiplet.

\subsection{Synthesis:}

4-methoxy-N-(4-methoxyphenyl)-N-phenylaniline (2.3b). Under an atmosphere of $\mathrm{N}_{2}$,

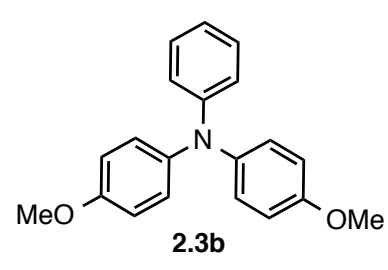

2.1 (p-iodoanisole) (6.35 g, $27 \mathrm{mmol}), \mathbf{2 . 2}$ (aniline) (1.0 mL, 11 mmol) and 1,10-phenanthroline (0.39 g, $2.2 \mathrm{mmol})$ were solubilized in toluene $(20 \mathrm{~mL})$. The solution was heated to 100 (4.9 g, $87 \mathrm{mmol}$ ). The mixture was refluxed overnight and after being cooled to room temperature, $\mathrm{AcOH}(3 \mathrm{~mL})$ and toluene $(15 \mathrm{~mL})$ was added. The mixture was washed with $\mathrm{H}_{2} \mathrm{O}(1 \times 30 \mathrm{~mL})$ once and extracted with toluene. The combined organic layers were dried over $\mathrm{MgSO}_{4}$, filtered and volatiles were removed in vacuo. The crude product was purified via column chromatography over silica using hexanes:EtOAc $(9: 1)$ as the eluent affording the desired product as a cream solid. (6.9 g, $78 \%$ ). The spectroscopic data agreed with previously reported literature. ${ }^{66}$ 
4-bromo- $N, N$-bis (4-methoxyphenyl)aniline (2.4b). Under an atmosphere of $\mathrm{N}_{2}, 2.3 \mathrm{~b}$

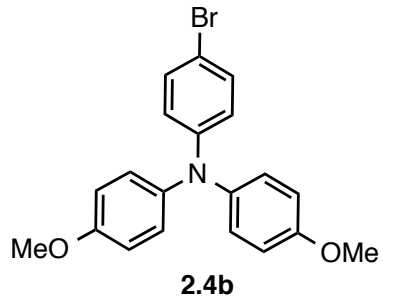
(4-methoxy- $N$-(4-methoxyphenyl)- $N$-phenylaniline) (6.3 g, 21 mmol) was dissolved in $150 \mathrm{~mL}$ of THF:EtOAc (1:1) and $N$ bromosuccinimide $(4.1 \mathrm{~g}, 23 \mathrm{mmol})$ was added in one portion. The mixture was then stirred overnight. Volatiles were removed in vacuo and the crude was purified via column chromatography using hexanes:EtOAc $(9: 1)$ as the eluent, affording the desired product as a cream solid. ( $6.34 \mathrm{~g}, 80 \%)$. The spectroscopic data agreed with previously reported literature. $^{67}$

\section{4-methoxy-N-(4-methoxyphenyl)-N-(4-(4,4,5,5-tetramethyl-1,3,2-dioxaborolan-2-}

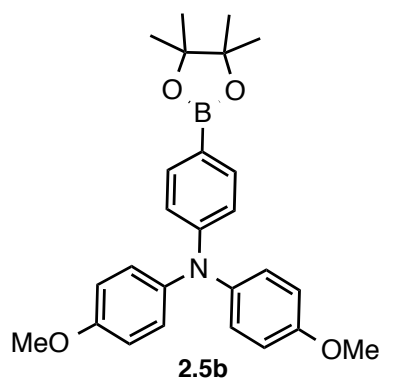

yl)phenyl)aniline. (2.5b). Under an atmosphere of $\mathrm{N}_{2}, \mathbf{2 . 4 b}$ (4bromo-N,N-bis(4-methoxyphenyl)aniline) (7.9 g, $20.5 \mathrm{mmol})$ was dissolved in dry THF $(75 \mathrm{~mL})$ and the solution was cooled to -78 ${ }^{\circ} \mathrm{C} . n$-BuLi (1.6 M, $\left.15.4 \mathrm{~mL}, 24.5 \mathrm{mmol}\right)$ was added dropwise and the mixture was stirred for $30 \mathrm{~min}$ at this temperature. 2isopropoxy-4,4',5,5'-tetramethyl-[1,3,2]-dioxaborolane $(6.1 \mathrm{~mL}$,

$31 \mathrm{mmol}$ ) was added in one portion and the mixture was stirred for $30 \mathrm{~min}$ at $-78{ }^{\circ} \mathrm{C}$. Then the mixture was allowed to warm to room temperature overnight. $\mathrm{MeOH}(5 \mathrm{~mL})$ was added and volatiles were removed in vacuo. The crude product was purified via column chromatography using hexanes:EtOAc (9:1) as the eluent, affording the desired product as an off-white solid. (6.91 g, $78 \%$ ). The spectroscopic data agreed with previously reported literature. ${ }^{67}$

2-(5-bromothiophen-2-yl)-1,3-dioxolane (2.7). A solution of 2.6 (5-bromothiophene-2carbaldehyde) (5.0 g, $26 \mathrm{mmol})$ and ethylene glycol $(10 \mathrm{~mL}, 183 \mathrm{mmol})$

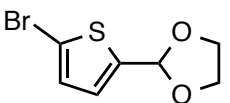

2.7

in toluene $(175 \mathrm{~mL})$ was prepared and to this, $p$-toluenesulfonic acid $(0.135 \mathrm{~g}, 0.8 \mathrm{mmol})$ was added. The flask was equipped with a DeanStark apparatus and the mixture was refluxed overnight. After being cooled to room temperature, the mixture was neutralized with aqueous $\mathrm{Na}_{2} \mathrm{CO}_{3}$ and the organic layer was separated and dried over $\mathrm{MgSO}_{4}$. After removal of volatiles in vacuo, the crude material was purified via column chromatography using $\mathrm{CH}_{2} \mathrm{Cl}_{2}$ : hexanes (1:1) as the eluent, 
affording the desired product as a yellow oil. Further purification through vacuum distillation can also be performed. (4.92 g, $80 \%$ ). The spectroscopic data agreed with previously reported literature. ${ }^{67}$

\section{5-[1,3]dioxolan-2-yl-thien-2-yl)-4,4',5,5'-tetramethyl-[1,3,2]-dioxaborolane}

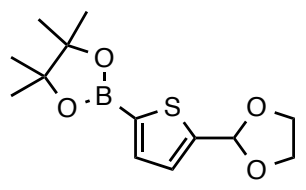

2.8

Under an atmosphere of $\mathrm{N}_{2}, 2.7$ (2-(5-bromothiophen-2-yl)-1,3dioxolane) $(5.7 \mathrm{~g}, 30 \mathrm{mmol})$ was solubilized in dry THF $(60 \mathrm{~mL})$ and the solution was cooled to $-78^{\circ} \mathrm{C} . n$-BuLi $(1.6 \mathrm{M}, 22.4 \mathrm{~mL}, 36$ mmol) was added dropwise and the mixture was stirred at this temperature for $45 \mathrm{~min}$. 2-isopropoxy-4,4',5,5'-tetramethyl-[1,3,2]-dioxaborolane (8.3 $\mathrm{mL}, 45 \mathrm{mmol}$ ) was added in one portion and the mixture stirred at $-78{ }^{\circ} \mathrm{C}$ for $30 \mathrm{~min}$, then allowed to warm to room temperature overnight. The reaction was quenched with $\mathrm{MeOH}$ $(5 \mathrm{~mL})$ and the volatiles were removed in vacuo. The crude product was purified via column chromatography using $\mathrm{CH}_{2} \mathrm{Cl}_{2}$ :EtOAc (9:1) as the eluent affording a yellow solid. (5.36 g $78 \%$ ). The spectroscopic data agreed with previously reported literature. ${ }^{67}$

1,4-dibromo-2,5-diiodobenzene (2.10). A solution of 2.9 (1,4-dibromobenzene) (23.6 g,

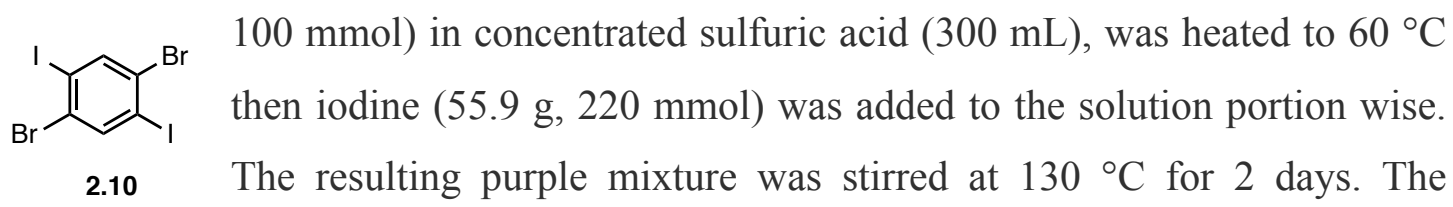
sublimed iodine was intermittently washed back into the reaction mixture by shaking the flask every 4 hours. The resulting mixture was cooled to room temperature, poured into ice water $(300 \mathrm{~mL})$ and then extracted with DCM $(3 \times 30 \mathrm{~mL})$. The organic layer was then washed with a dilute solution of sodium hydroxide $(300 \mathrm{~mL})$ in order to remove any excess iodine. The organic layer was separated and the aqueous sodium hydroxide layer was extracted once with DCM $(3 \times 30 \mathrm{~mL})$. The combined organic layers were then dried over anhydrous $\mathrm{MgSO}_{4}$, filtered and the solvent removed to give a white solid, which was recrystallized from hexane. (41.42 g, 85\%). ${ }^{1} \mathrm{H}$ NMR (400 MHz, $\left.\mathrm{CDCl}_{3}\right): \delta$ (ppm) 8.04 $(\mathrm{s}, 2 \mathrm{H})$. The spectroscopic data agreed with previously reported literature. ${ }^{73,74}$ 
1,4-dibromo-2,5-bis[2-(trimethylsilyl)ethynyl]benzene (2.11). A solution of 2.10 (1,4-

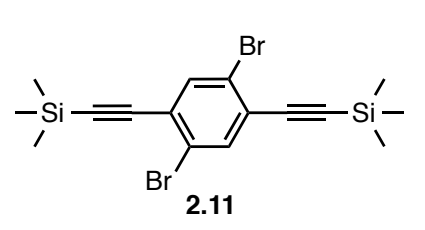

dibromo-2,5-diiodobenzene) (15 g, $30.75 \mathrm{mmol}), \mathrm{CuI}(0.879$

$\mathrm{g}, 4.613 \mathrm{mmol})$ and the $\mathrm{Pd}\left(\mathrm{PPh}_{3}\right) \mathrm{Cl}_{2}(2.6 \mathrm{~g}, 2.3 \mathrm{mmol})$ was

sparged under nitrogen for 10 minutes in THF:NEt 3 (80mL:40mL), then ethynyltrimethylsilane $(15.10 \mathrm{~g}, 153.78$

mmol) was injected through the septum and the mixture stirred at room temperature under nitrogen overnight. The solvents were removed in vacuo and DCM $(150 \mathrm{~mL})$ was added to the mixture. The DCM layer was washed $(3 \times 100 \mathrm{~mL})$ with a saturated $\mathrm{NH}_{4} \mathrm{Cl}$ solution. The organic layer was collected and dried with $\mathrm{MgSO}_{4}$ and the solvent removed in vacuo. The crude product was purified using a column chromatography of hexane/ethyl acetate (9:1) to give the product as a yellow solid. (11.32 g, 86\%). The spectroscopic data agreed with previously reported literature. ${ }^{75,76}$

Benzo[1,2-b:4,5-b']dithiophene (BDT) (2.12). To a suspension of sodium sulfide nonahydrate (5.6 g, $23.35 \mathrm{mmol})$ in NMP $(40 \mathrm{~mL}), 2.11$ (1,4-dibromo-

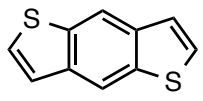

2.12 2,5-bis(trimethylsilylethynyl)benzene) ( $2.5 \mathrm{~g}, 6.3 \mathrm{mmol})$ was added and then heated to $185-195{ }^{\circ} \mathrm{C}$ for $12 \mathrm{~h}$. The mixture was poured into saturated aqueous ammonium chloride solution $(200 \mathrm{~mL})$. The resulting solid was collected by filtration and dissolved in DCM $(50 \mathrm{~mL})$. The aqueous layer was extracted with DCM $(2 \times 30 \mathrm{~mL})$ and the combined organic layers were washed with brine $(4 \times 100$ $\mathrm{mL})$ and then with water $(4 \times 100 \mathrm{~mL})$ to remove the NMP. The solution was dried over $\mathrm{MgSO}_{4}$ and evaporated in vacuo. The product was purified by column chromatography giving a colorless microcrystals as a product. (0.86 g, 78\%). ${ }^{1} \mathrm{H}$ NMR $(400 \mathrm{MHz}$, $\left.\mathrm{CDCl}_{3}\right): \delta(\mathrm{ppm}) 7.35(\mathrm{~d}, J=5.5 \mathrm{~Hz}, 2 \mathrm{H}), 7.46(\mathrm{~d}, J=5.5 \mathrm{~Hz}, 2 \mathrm{H}), 8.31(\mathrm{~s}, 2 \mathrm{H})$. The spectroscopic data agreed with previously reported literature. ${ }^{73}$

2-bromobenzo[1,2-b:4,5-b']dithiophene (2.13). To a solution of 2.12 (benzo[1,2-b:4,5-

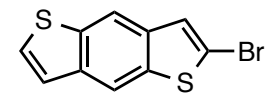

2.13

b']dithiophene) (0.10 g, $0.53 \mathrm{~mol})$, NBS (0.094g, $0.53 \mathrm{~mol})$ was added in DMF $(20 \mathrm{~mL})$. The reaction mixture was warmed to $50{ }^{\circ} \mathrm{C}$, stirred for $3 \mathrm{~h}$, and then left overnight at room temperature. The mixture was then poured into a solution of sodium hydroxide ( $5 \%$ in aq., $100 \mathrm{~mL}$ ). The crude product was then subjected to column chromatography, using hexane/DCM (9:1) as an eluent. 
The pure product was obtained as a white crystal. $(0.098 \mathrm{~g}, 69 \%) .{ }^{1} \mathrm{H}$ NMR $(400 \mathrm{MHz}$, $\left.\mathrm{CDCl}_{3}\right): \delta(\mathrm{ppm}) 8.39(\mathrm{~s}, 1 \mathrm{H}), 8.35(\mathrm{~s}, 1 \mathrm{H}), 7.51(\mathrm{~s}, 1 \mathrm{H}), 7.47(\mathrm{~d}, 2 \mathrm{H}), 7.41(\mathrm{~d}, 2 \mathrm{H})$. The spectroscopic data agreed with previously reported literature. ${ }^{77}$

\section{4-(benzo[1,2-b:4,5- $\left.b^{\prime}\right]$ dithiophen-2-yl)- $N, N$-bis(4-methoxyphenyl)aniline (2.14). A}

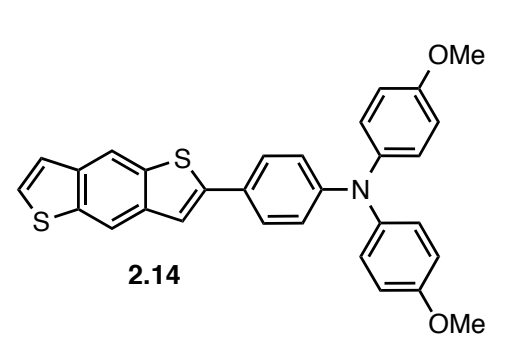
solution of 2.13 (2-bromobenzo[1,2-b:4,5-b']dithiophene) $(0.07 \mathrm{~g}, 0.26 \mathrm{mmol})$ and $\mathbf{2 . 5 b}\left(4-\left(4,4^{\prime}, 5,5\right.\right.$ 'tetramethyl1,3,2-dioxaborolan-2-yl)phenyl)-di$(4$, methoxyphenyl)amine $(0.168 \mathrm{~g}, \quad 0.39 \mathrm{mmol})$ in THF: $\mathrm{H}_{2} \mathrm{O}(1: 1)(20 \mathrm{~mL})$ was sparged for 10 min with $\mathrm{N}_{2}$ followed by the addition of $\mathrm{K}_{2} \mathrm{CO}_{3}(0.180 \mathrm{~g}, 1.30 \mathrm{mmol})$ and the $\mathrm{Pd}\left(\mathrm{PPh}_{3}\right)_{2} \mathrm{Cl}_{2}(0.018 \mathrm{~g}$, $0.03 \mathrm{mmol})$. The reaction was refluxed overnight. The mixture was cooled to room temperature and $\mathrm{H}_{2} \mathrm{O}$ was added. The aqueous phase was extracted with DCM and volatiles were removed in vacuo. Using column chromatography with hexane/DCM (1:1) as the eluent, pure product was obtained as a bright yellow solid. $(0.09 \mathrm{~g}, 70 \%) .{ }^{1} \mathrm{H}$ NMR (400 MHz, $\left.\mathrm{CDCl}_{3}\right): \delta(\mathrm{ppm}) 8.42(\mathrm{~s}, 1 \mathrm{H}), 8.32(\mathrm{~s}, 1 \mathrm{H}), 7.47$ (d, 1H), $7.43(2,2 \mathrm{H}), 7.37$ (d, 1H), $7.34(\mathrm{~s}, 1 \mathrm{H}), 7.14(\mathrm{~d}, 4 \mathrm{H}), 7.05(\mathrm{~d}, 2 \mathrm{H}), 6.88(\mathrm{~d}, 4 \mathrm{H}), 3.81(\mathrm{~s}, 6 \mathrm{H}) .{ }^{13} \mathrm{C}$ NMR $(400$ $\left.\mathrm{MHz}, \mathrm{CDCl}_{3}\right): \delta(\mathrm{ppm}) 156.1,148.5,140.7,138.8,137.4,137.3,135.7,135.2,129.2$, $126.8,124.3,124.0,120.3,117.0,116.7,114.8,106.5,55.5,29.7 . \mathrm{MS}: \mathrm{m} / \mathrm{z} 493.1166$ $\left(\mathrm{C}_{30} \mathrm{H}_{23} \mathrm{NO}_{2} \mathrm{~S}_{2}\right)^{+}$.

\section{6-(4-(bis(4-methoxyphenyl)amino)phenyl)benzo[1,2-b:4,5-b']dithiophene-2-}

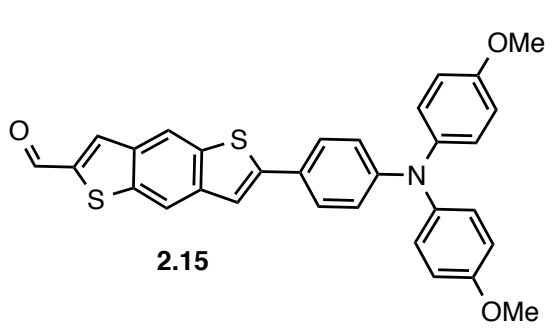
carbaldehyde(2.15). A solution of DMF and $\mathrm{POCl}_{3}$ $(0.013 \mathrm{~g}, 0.8 \mathrm{mmol})$ was stirred in DCE for 5 minutes at $0{ }^{\circ} \mathrm{C}$. After being warmed to room temperature, the mixture was stirred for another 30 min. To a solution of $2.14(0.110 \mathrm{~g}, 0.22 \mathrm{mmol})$,

DCE $(10 \mathrm{~mL})$ was added and the mixture was added and stirred $2 \mathrm{~h}$ at $50{ }^{\circ} \mathrm{C}$. After being cooled to room temperature, the solution was slowly poured into an ice-cold solution of saturated $\mathrm{Na}_{2} \mathrm{CO}_{3}(100 \mathrm{~mL})$. After being warmed to room temperature, the mixture was stirred $30 \mathrm{~min}$. The DCE product layer was washed with DCM/water and the organic fraction dried with $\mathrm{MgSO}_{4}$, filtered and the solvent removed in vacuo. Using column 
chromatography with hexane/EtOAc (8:2) as the eluent, pure product was obtained as an orange solid. (0.072 g, 62\%). ${ }^{1} \mathrm{H} \mathrm{NMR}\left(400 \mathrm{MHz}, \mathrm{CDCl}_{3}\right)$ : $\delta$ (ppm) $9.96(\mathrm{~s}, 1 \mathrm{H}), 8.33$ (s, $1 \mathrm{H}), 8.25(\mathrm{~s}, 1 \mathrm{H}), 7.53(\mathrm{~s}, 1 \mathrm{H}), 7.52(\mathrm{~s}, 1 \mathrm{H}), 7.30(\mathrm{~d}, 2 \mathrm{H}), 7.13(\mathrm{~d}, 4 \mathrm{H}), 7.01(\mathrm{~d}, 2 \mathrm{H}), 6.85$ (d, 4H), 3.76 (s, 6H). ${ }^{13} \mathrm{C}$ NMR (400 MHz, $\left.\mathrm{CDCl}_{3}\right): 206.8,156.2,149.2,144.6,143.8$, 140.3, 140.1, 132.6, 130.2, 127.1, 125.5, 123.1, 119.8, 114.8, 114.3, 113.3, 60.9, 55.5, , 30.9, 29.7. MS: $\mathrm{m} / \mathrm{z} 521.1110\left(\mathrm{C}_{31} \mathrm{H}_{23} \mathrm{NO}_{3} \mathrm{~S}_{2}\right)^{+}$.

\section{3-(6-(4-(bis(4-methoxyphenyl)amino)phenyl)benzo[1,2-b:4,5-b']dithiophen-2-yl)-2-}

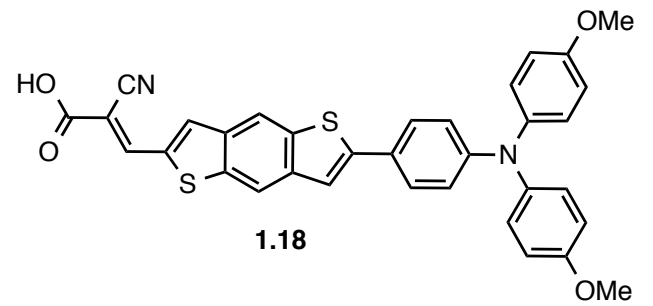
cyanoacrylic acid BDT-TPA-OMe dye (1.18).

To a solution of $2.15(0.050 \mathrm{~g}, 0.10 \mathrm{mmol})$ in a minimal amount of $\mathrm{CHCl}_{3}: \mathrm{MeCN}(10 \mathrm{~mL}, 1: 1)$, cyanoacetic acid $(0.016 \mathrm{~g}, 0.19 \mathrm{mmol})$ and piperidine $(1 \mathrm{~mL})$ were added. The mixture was refluxed overnight and after being cooled to room temperature, the organic layer was washed with $\mathrm{HCl}(1 \mathrm{~N} / 50 \mathrm{~mL})$. Volatiles were removed in vacuo, the crude material recrystallized with $\mathrm{CDCl}_{3} /$ hexane, and the product obtained as an orange crystals. (0.048 g, 85\%). ${ }^{1} \mathrm{H}$ NMR (400 $\left.\mathrm{MHz}, \mathrm{CDCl}_{3}\right): \delta$ (ppm) $8.46(\mathrm{~s}, 1 \mathrm{H}), 8.29$ (s, 2H), 7.61 (s, 1H), 7.51 (s, 1H), 7.40 (d, 2H), 7.20 (d, 4H), 7.04 (d, 2H), 6.9 (d, 4H), 3.79 (s, 6H). ${ }^{13} \mathrm{C}$ NMR (400 MHz, $\mathrm{CDCl}_{3}$ ): 156.4, 149.2, 142.0, 140.30, 130.9, 128.6, 127.4, 127.2, 122.9, 119.4, 119.1, 118.0, 116.7, 114.9, 55.5, 47.9, 44.7, 44.4, 31.9, 30.4, 28.1, 24.7, 22.6,. MS: m/z 587.11282 $\left(\mathrm{C}_{34} \mathrm{H}_{24} \mathrm{~N}_{2} \mathrm{O}_{4} \mathrm{~S}_{2}\right)^{+}$.

2,6-dibromo-benzo[1,2-b:4,5-b']dithiophene (2.16). To a solution of $\mathbf{2 . 1 2}$ (BDT) (0.120 g, $0.63 \mathrm{mmol})$, NBS (0.337 g, $1.86 \mathrm{mmol})$ was added in DMF (30 , The reaction mixture was warmed to $50{ }^{\circ} \mathrm{C}$, stirred for $3 \mathrm{~h}$, 2.16 and then poured into a solution of sodium hydroxide $5 \%(100 \mathrm{~mL})$. The pure product was obtained as a white crystal. (0.201 g, 92\%). ${ }^{1} \mathrm{H}$ NMR (400 MHz, $\left.\mathrm{CDCl}_{3}\right): \delta(\mathrm{ppm}) 8.34(\mathrm{~s}, 1 \mathrm{H}), 7.56(\mathrm{~s}, 1 \mathrm{H})$. The spectroscopic data agreed with previously reported literature. ${ }^{77}$ 


\section{4-(6-bromobenzo[1,2-b:4,5- $\left.b^{\prime}\right]$ dithiophen-2-yl)- $N, N$-bis(4-methoxyphenyl)aniline}

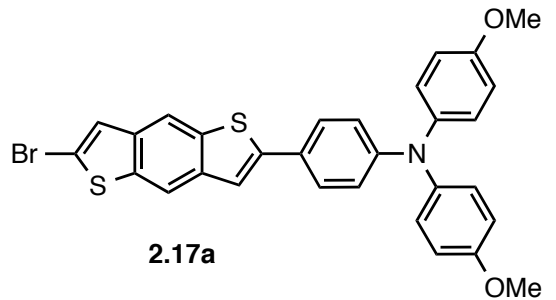

(2.17). A solution of $2.16(0.140 \mathrm{~g}, 0.40 \mathrm{mmol})$ and $2.5(0.139 \mathrm{~g}, 0.32 \mathrm{mmol})$ in THF: $\mathrm{H}_{2} \mathrm{O}(1: 1)(30 \mathrm{~mL})$ was sparged for 10 min under $\mathrm{N}_{2}$ followed by the addition of $\mathrm{K}_{2} \mathrm{CO}_{3}(0.278 \mathrm{~g}, 2.02 \mathrm{mmol})$ and $\mathrm{Pd}\left(\mathrm{PPh}_{3}\right)_{2} \mathrm{Cl}_{2}(0.047 \mathrm{~g}, 0.04 \mathrm{mmol})$. The reaction was refluxed overnight. The mixture was cooled to room temperature and $\mathrm{H}_{2} \mathrm{O}$ was added. The aqueous phase was extracted with DCM and volatiles were removed in vacuo. Using column chromatography with hexane/EtOAc (9:2), pure product was obtained as a bright yellow solid. (0.096 g, 64\%). ${ }^{1} \mathrm{H}$ NMR (400 MHz, $\left.\mathrm{CDCl}_{3}\right): \delta$ (ppm) $8.38(\mathrm{~s}, 1 \mathrm{H})$, $8.35(\mathrm{~s}, 1 \mathrm{H}), 7.46(\mathrm{~s}, 1 \mathrm{H}), 7.42(\mathrm{~s}, 1 \mathrm{H}), 7.40(\mathrm{~d}, 2 \mathrm{H}), 7.09(\mathrm{~d}, 4 \mathrm{H}), 6.87(\mathrm{~d}, 2 \mathrm{H}), 6.83(\mathrm{~d}$, 4H), $3.81(\mathrm{~s}, 6 \mathrm{H}) .{ }^{13} \mathrm{C}$ NMR (400 $\left.\mathrm{MHz}, \mathrm{CDCl}_{3}\right): \delta(\mathrm{ppm}) 156.1,148.5,140.7,138.8$, $136.9,136.6,135.7,135.2,129.2$, 126.8, 124.3, 124.0, 120.3, 117.0, 116.7, 114.8, 106.5, 55.5, 29.7. MS: $\mathrm{m} / \mathrm{z} 571.0266\left(\mathrm{C}_{30} \mathrm{H}_{22} \mathrm{BrNO}_{2} \mathrm{~S}_{2}\right)^{+}$.

\section{4-(6-(5-(1,3-dioxolan-2-yl)thiophen-2-yl)benzo[1,2-b:4,5-b']dithiophen-2-yl)- $N, N$ -}

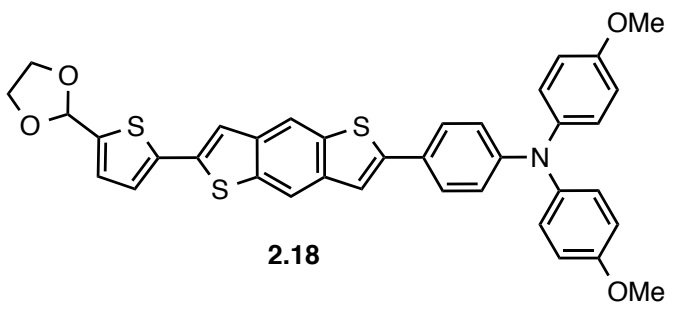

bis(4-methoxyphenyl)aniline (2.18). A suspension of $2.17(0.075 \mathrm{~g}, 0.13 \mathrm{mmol})$ and $2.8(0.035 \mathrm{~g}, 0.13 \mathrm{mmol})$ in $\mathrm{THF}: \mathrm{H}_{2} \mathrm{O}(9: 1)$ $(30 \mathrm{~mL})$ was sparged 10 min with $\mathrm{N}_{2}$. To this solution, $\mathrm{K}_{2} \mathrm{CO}_{3}(0.091 \mathrm{~g}, 0.66 \mathrm{mmol})$ and $\mathrm{Pd}\left(\mathrm{PPh}_{3}\right)_{2} \mathrm{Cl}_{2}(0.015 \mathrm{~g}, 0.01 \mathrm{mmol})$ were added and then refluxed $12 \mathrm{~h}$ under an atmosphere of $\mathrm{N}_{2}$. After being cooled to room temperature, $\mathrm{H}_{2} \mathrm{O}(30 \mathrm{~mL})$ was added and the organic layer was separated. The aqueous layer was extracted with DCM $(3 \times 20 \mathrm{~mL})$ and the combined organic layers were dried over $\mathrm{MgSO}_{4}$, filtered and volatiles were removed in vacuo. The crude material was purified through column chromatography using $\mathrm{CH}_{2} \mathrm{Cl}_{2}$ as the eluent. (0.025 g, 30\%). ${ }^{1} \mathrm{H}$ NMR (400 MHz, $\left.\mathrm{CDCl}_{3}\right): \delta(\mathrm{ppm}) 8.32$ (s, 1H), 8.29, (s, 1H), $7.62(\mathrm{~d}, 2 \mathrm{H}), 7.47(\mathrm{~s}, 1 \mathrm{H}), 7.46(\mathrm{~s}, 1 \mathrm{H}), 7.45(\mathrm{~d}, 2 \mathrm{H}), 7.10(\mathrm{~d}, 4 \mathrm{H})$, $6.88(\mathrm{~d}, 4 \mathrm{H}), 6.10(\mathrm{~s}, 1 \mathrm{H}), 4.15(\mathrm{~d}, 2 \mathrm{H}), 4.04(\mathrm{~d}, 2 \mathrm{H}), 3.81(\mathrm{~s}, 6 \mathrm{H})$. 


\section{5-(6-(4-(bis(4-methoxyphenyl)amino)phenyl)benzo[1,2-b:4,5-b']dithiophen-2}

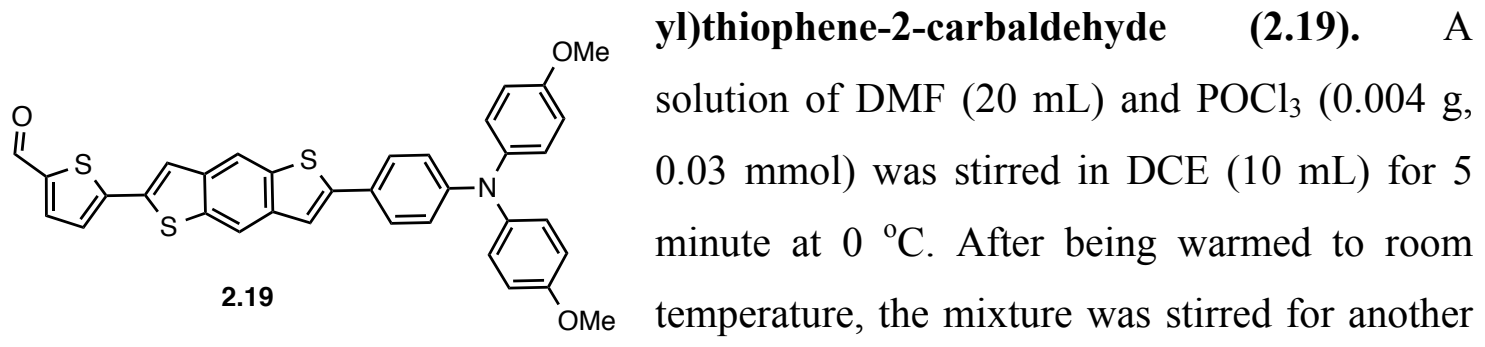

$30 \mathrm{~min}$. To the mixture of $2.18(0.050 \mathrm{~g}, 0.08 \mathrm{mmol})$, DCE $(10 \mathrm{~mL})$ and the mixture were added and stirred $2 \mathrm{~h}$ at $50{ }^{\circ} \mathrm{C}$. After being cooled to room temperature, the solution was slowly poured into saturated $\mathrm{Na}_{2} \mathrm{CO}_{3}(100 \mathrm{~mL})$ and then cooled to $0{ }^{\circ} \mathrm{C}$. After being warmed to room temperature, the mixture was stirred $30 \mathrm{~min}$. The DCE and product layer were washed with $\mathrm{DCM}$ /water and the organic fraction dried with $\mathrm{MgSO}_{4}$, filtered then removed in vacuo. Using column chromatography with DCM/hexane (7:3) as the eluent, pure product obtained as an orange solid. (0.042 g, 91\%). ${ }^{1} \mathrm{H}$ NMR $\left(400 \mathrm{MHz}, \mathrm{CDCl}_{3}\right): \delta$ (ppm) $9.96(\mathrm{~s}, 1 \mathrm{H}), 8.65$ (s, 1H), $8.44(\mathrm{~s}, 1 \mathrm{H}), 7.84(\mathrm{~d}, 1 \mathrm{H}), 7.72(\mathrm{~s}, 1 \mathrm{H}), 7.51(\mathrm{~d}, 1 \mathrm{H})$, $7.43(\mathrm{~d}, 2 \mathrm{H}), 7.40(\mathrm{~s}, 1 \mathrm{H}), 7.13(\mathrm{~d}, 4 \mathrm{H}), 7.04(\mathrm{~d}, 2 \mathrm{H}), 6.88(\mathrm{~d}, 4 \mathrm{H}), 3.80(\mathrm{~s}, 6 \mathrm{H}) .{ }^{13} \mathrm{C} \mathrm{NMR}$ (400 MHz, $\left.\mathrm{CDCl}_{3}\right): 206.8,182.7,156.1,148.5,147.1,142.4,140.7,139.0,137.8,136.9$, $136.8,136.7,134.1,129.1,128.5,127.5,126.8,123.9,120.3,117.0,116.5,114.1,30.9$.

(E)-3-(5-(6-(4-(bis(4-methoxyphenyl)amino)phenyl)benzo[1,2-b:4,5- $\left.b^{\prime}\right]$ dithiophen-2-

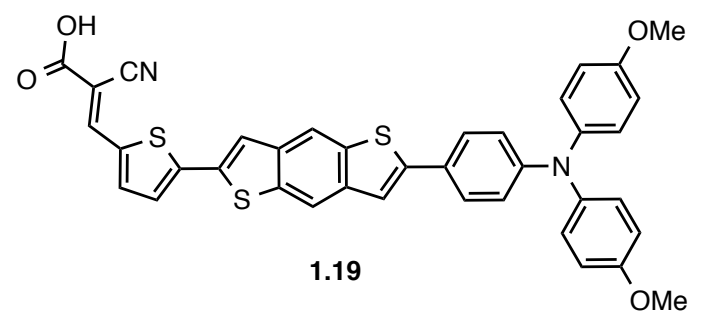
yl)thiophen-2-yl)-2-cyanoacrylic acid dye (1.19). To a solution of $2.19(0.050 \mathrm{mg}, 0.080$ mmol) in a minimal amount $(20 \mathrm{~mL})$ of $\mathrm{CHCl}_{3}: \mathrm{MeCN}(1: 1)$, cyanoacetic acid $(0.014$ $\mathrm{g}, 0.17 \mathrm{mmol})$ and piperidine $(0.014 \mathrm{~g}, 0.17$ mmol) were added. The mixture was refluxed overnight and after being cooled to room temperature, the organic layer was washed with $\mathrm{HCl}(1 \mathrm{~N})(50 \mathrm{~mL})$. Volatiles were removed in vacuo. The crude material was recrystallized with $\mathrm{CDCl}_{3} /$ hexane and the product obtained as an orange crystals. (0.06 g, 75\%). ${ }^{1} \mathrm{H}$ NMR (400 $\left.\mathrm{MHz}, \mathrm{CDCl}_{3}\right)$ : $\delta(\mathrm{ppm}) 8.48(\mathrm{~s}, 1 \mathrm{H}), 8.31(\mathrm{~s}, 1 \mathrm{H}), 8.22(\mathrm{~s}, 1 \mathrm{H}), 7.74(\mathrm{~s}, 1 \mathrm{H}), 7.67(\mathrm{~d}, 1 \mathrm{H}), 7.42(\mathrm{~d}, 1 \mathrm{H})$, $7.38(\mathrm{~d}, 2 \mathrm{H}), 6.90(\mathrm{~d}, 4 \mathrm{H}), 6.73(\mathrm{~d}, 4 \mathrm{H}), 3.81(\mathrm{~s}, 6 \mathrm{H})$. Compound was too insoluble to be subjected to ${ }^{13} \mathrm{C}$ NMR analysis. 
$N, N$-dimethyl-3-thiophene carboxamide (2.21). A solution of 2.20 (thiophene-3-

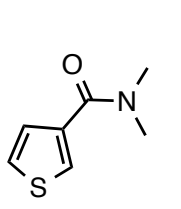
carbonyl chloride) (2.5 g, $17.05 \mathrm{mmol})$ was cooled in dry THF (30 mL),

2.21 stirred overnight at room temperature. The mixture was washed with $\mathrm{H}_{2} \mathrm{O}$ and the organic layer was dried with $\mathrm{MgSO}_{4}$. The solvent was removed in vacuo and pure product was obtained as an orange oil. $(2.39 \mathrm{~g}, 92 \%) .{ }^{1} \mathrm{H} \mathrm{NMR}\left(400 \mathrm{MHz}, \mathrm{CDCl}_{3}\right): \delta$ (ppm) $7.28(\mathrm{dd}, 1 \mathrm{H}), 7.06(\mathrm{dd}, 1 \mathrm{H}), 6.96(\mathrm{dd}, 1 \mathrm{H}), 3.46(\mathrm{~s}, 6 \mathrm{H})$. The spectroscopic data agreed with previously reported literature. ${ }^{78}$

Benzo [1,2-b:4,5-b']dithiophene (2.22). To a solution of 2.21 ( $N, N$-dimethylthiophene-<smiles>O=C1c2ccsc2C(=O)c2ccsc21</smiles3-carboxamide) (1.00 g, $6.44 \mathrm{mmol})$ in dry THF $(20 \mathrm{~mL}), n$-BuLi (4.63, $1.6 \mathrm{M})$ was added dropwise under a $\mathrm{N}_{2}$ atmosphere at $-40{ }^{\circ} \mathrm{C}$. The mixture was stirred for $30 \mathrm{~min}$ at this temperature then slowly warmed to room temperature and stirred overnight. Ice water $(100 \mathrm{~mL})$ was added to the mixture and the resulting precipitate formed was filtered. The product was recrystallized from hexane to afford a yellow solid. (1.17 g, 83\%). ${ }^{1} \mathrm{H}$ NMR (400 $\left.\mathrm{MHz}, \mathrm{CDCl}_{3}\right): \delta(\mathrm{ppm}) 7.68(\mathrm{~d}, 2 \mathrm{H}), 7.65(\mathrm{~d}, 2 \mathrm{H})$. The spectroscopic data agreed with previously reported literature. ${ }^{25}$

Benzo 4,8-dimethoxy [1,2-b:4,5- $\left.b^{\prime}\right]$ dithiophene (2.23). To a solution of 2.22 (benzo [1,2-b:4,5-b]dithiophene) $(1.04 \mathrm{~g}, 4.73 \mathrm{mmol})$ in ethanol $(10 \mathrm{~mL})$ and

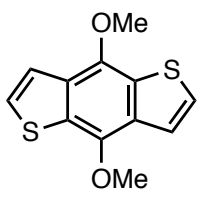

2.23 water $(10 \mathrm{~mL}), \mathrm{NaBH}_{4}(0.996 \mathrm{~g}, 26.2 \mathrm{mmol})$ was added in portions over $30 \mathrm{~min}$. The resulting mixture was stirred for another $30 \mathrm{~min}$, and then a solution of $\mathrm{KOH}(10 \mathrm{M}, 2 \mathrm{~mL})$ was added; the mixture was stirred for 30 minutes, heated to reflux and then dimethyl sulfate $(5.70 \mathrm{~g}, 45 \mathrm{mmol})$ was added over $1 \mathrm{~h}$. The resulting mixture was refluxed for $5 \mathrm{~h}$ and then cooled to room temperature, extracted with EtOAc $(2 \times 30 \mathrm{~mL})$, and purified by chromatography to give a white solid. (1.14 g, 96.6\%). ${ }^{1} \mathrm{H}$ NMR $\left(400 \mathrm{MHz}, \mathrm{CDCl}_{3}\right) \delta(\mathrm{ppm}) 7.51(\mathrm{~d}, 2 \mathrm{H}), 7.40(\mathrm{~d}$, $2 \mathrm{H}), 4.14(\mathrm{~S}, 6 \mathrm{H})$. The spectroscopic data agreed with previously reported literature. ${ }^{79}$ 
2-bromo-4,8-dimethoxybenzo[1,2-b:4,5- $\left.b^{\prime}\right]$ dithiophene (2.24). To a solution of 2.23

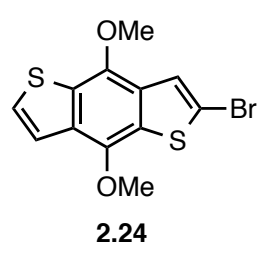
(benzo 4,8-dimethoxy [1,2- $b: 4,5-b$ ] dithiophene) (1.0 g, $3.99 \mathrm{mmol})$ in DCM (30 mL), NBS $(0.711 \mathrm{~g}, 3.99 \mathrm{mmol})$ was added. The reaction mixture was stirred overnight. Washing with water $(1 \times 30 \mathrm{~mL})$ and removing the solvent in vacuo, the crude material was purified through column chromatography with hexane/EtOAc (9:1); pure product was obtained as a white solid. (0.86 g, 60\%). ${ }^{1} \mathrm{H}$ NMR (400 MHz, $\left.\mathrm{CDCl}_{3}\right): \delta(\mathrm{ppm}) 7.49$ (s, 1H), 7.48 (d, $1 \mathrm{H}), 7.41(\mathrm{~d}, 1 \mathrm{H}), 4.05(\mathrm{~s}, 6 \mathrm{H}) .{ }^{13} \mathrm{C} \mathrm{NMR}\left(400 \mathrm{MHz}, \mathrm{CDCl}_{3}\right)$ : 173.3, 145.6, 144.0, 136.7, $132.1,131.6,128.8,126.6,120.2,117.9,61.1$.

\section{4-(4,8-dimethoxybenzo[1,2-b:4,5-b']dithiophen-2-yl)- $N, N$-bis(4-}

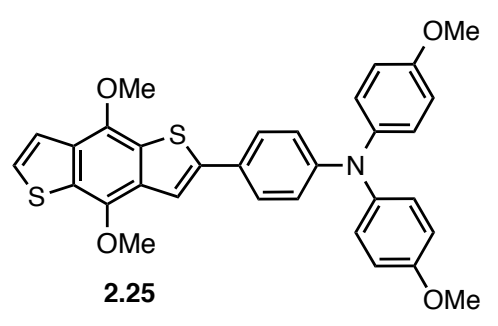

methoxyphenyl)aniline (2.25). A solution of $2.24(0.650$

g, $1.97 \mathrm{mmol})$ and 2.5 ((4-(4,4',5,5)tetramethyl-1,3,2dioxaborolan-2-yl)phenyl)-di-(4,methoxyphenyl)amine) (0.852 g, $1.97 \mathrm{mmol})$ in THF: $\mathrm{H}_{2} \mathrm{O}(9: 1)(30 \mathrm{~mL})$ was sparged for 10 minutes with $\mathrm{N}_{2}$. Then $\mathrm{K}_{2} \mathrm{CO}_{3}(1.367 \mathrm{~g}$,

$9.89 \mathrm{mmol})$ and the $\mathrm{Pd}\left(\mathrm{PPh}_{3}\right)_{2} \mathrm{Cl}_{2}(0.140 \mathrm{~g}, 0.20 \mathrm{mmol})$ were added and the reaction was refluxed overnight. The mixture was cooled to room temperature and $\mathrm{H}_{2} \mathrm{O}(30 \mathrm{~mL})$ was added. The product was extracted with $\mathrm{CH}_{2} \mathrm{Cl}_{2}$ and the organic layer was dried over $\mathrm{MgSO}_{4}$. Volatiles were removed in vacuo. The crude material was purified through column chromatography using DCM/hexane (7:3) and a pure yellow solid was obtained. (0.69 g, 63\%). ${ }^{1} \mathrm{H}$ NMR (400 MHz, $\left.\mathrm{CDCl}_{3}\right): \delta(\mathrm{ppm}) 7.56(\mathrm{~s}, 1 \mathrm{H}), 7.55(\mathrm{~d}, 1 \mathrm{H}), 7.66(\mathrm{~d}$, $1 \mathrm{H}), 7.36(\mathrm{~d}, 1 \mathrm{H}), 7.09(\mathrm{~d}, 4 \mathrm{H}), 6.90(\mathrm{~d}, 2 \mathrm{H}), 6.86(\mathrm{~d}, 4 \mathrm{H}), 4.14(\mathrm{~s}, 6 \mathrm{H}), 3.81(\mathrm{~s}, 6 \mathrm{H}) .{ }^{13} \mathrm{C}$ NMR (400 MHz, $\mathrm{CDCl}_{3}$ ): $\delta$ (ppm) 206.8, 156.2, 149.0, 145.0, 144.9, 144.2, 140.4, 132.6, $131.0,130.0,128.7,127.1,126.9,125.6,125.7,120.2,120.0,114.8,113.4,60.9,30.9$. MS: m/z $553.1371\left(\mathrm{C}_{32} \mathrm{H}_{27} \mathrm{NO}_{4} \mathrm{~S}_{2}\right)^{+}$. 


\section{6-(4-(bis(4-methoxyphenyl)amino)phenyl)-4,8-dimethoxybenzo[1,2-b:4,5-}

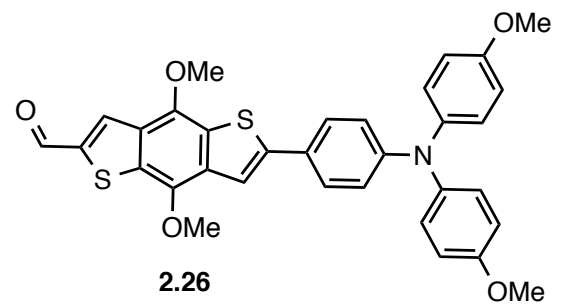

$b^{\prime}$ 'dithiophene-2-carbaldehyde (2.26). A solution of DMF $(30 \mathrm{~mL})$ and $\mathrm{POCl}_{3}(0.11 \mathrm{~g}, 0.07 \mathrm{mmol})$ was stirred in DCE $(10 \mathrm{~mL})$ for 5 minutes at $0{ }^{\circ} \mathrm{C}$. After being warmed to room temperature, the mixture was stirred for another $30 \mathrm{~min}$. To a mixture of $2.25(0.110$ g, $0.20 \mathrm{mmol})$, DCE $(10 \mathrm{~mL})$ was added and the mixture stirred for $2 \mathrm{~h}$ at $50{ }^{\circ} \mathrm{C}$. After being cooled to room temperature, the solution was slowly poured into saturated $\mathrm{Na}_{2} \mathrm{CO}_{3}$ $(100 \mathrm{~mL})$ and then cooled to $0{ }^{\circ} \mathrm{C}$. After being warmed to room temperature, the mixture was stirred $30 \mathrm{~min}$. The DCE and product layer were washed with water $(30 \mathrm{~mL})$ and then with DCM (3 $\times 30 \mathrm{~mL})$ and the organic fraction dried with $\mathrm{MgSO}_{4}$, filtered then removed in vacuo. Using column chromatography with hexane/EtOAc (8:2) as the eluent, pure product obtained as an orange solid. (0.084 g, 73\%). ${ }^{1} \mathrm{H}$ NMR $\left(400 \mathrm{MHz}, \mathrm{CDCl}_{3}\right): \delta$ (ppm) $10.46(\mathrm{~s}, 1 \mathrm{H}), 7.46(\mathrm{~s}, 1 \mathrm{H}), 7.43(\mathrm{~s}, 1 \mathrm{H}), 7.41(\mathrm{~d}, 2 \mathrm{H}), 7.15(\mathrm{~d}, 4 \mathrm{H}), 6.84(\mathrm{~d}, 2 \mathrm{H})$, 6.862(d, 4H), $4.12(\mathrm{~s}, 6 \mathrm{H}), 3.81(\mathrm{~s}, 6 \mathrm{H}) .13 \mathrm{C} \mathrm{NMR}(400 \mathrm{MHz}, \mathrm{CDCl} 3): \delta(\mathrm{ppm})$ 187.1, $171.0,156.6,156.1,150.2,145.9,144.8,139.8,132.8,131.1,129.2,128.6,127.4,123.2$, 119.9, 117.0, 114.8, 61.2, 60.6, 60.3, 55.4. MS: m/z 581.6532 $\left(\mathrm{C}_{33} \mathrm{H}_{27} \mathrm{NO}_{5} \mathrm{~S}\right)^{+}$.

(E)-3-(6-(4-(bis(4-methoxyphenyl)amino)phenyl)-4,8-dimethoxybenzo[1,2-b:4,5-

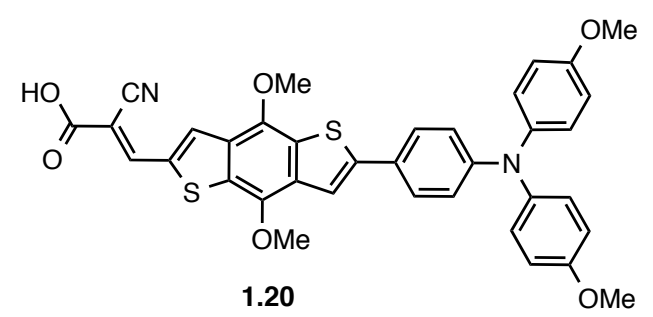
$b^{\prime}$ ]dithiophen-2-yl)-2-cyanoacrylic acid dye (1.20). To a solution of 2.26 (0.100 g, 0.17 mmol) in a minimal amount of $\mathrm{CHCl}_{3}$ : $\mathrm{MeCN}$ $(1: 1)(30 \mathrm{~mL})$, cyanoacetic acid $(0.029 \mathrm{~g}, 0.34$ mmol) and piperidine $(0.029 \mathrm{~g}, 0.34 \mathrm{mmol})$ were added. The mixture was refluxed overnight and after being cooled to room temperature, the organic layer was washed with $\mathrm{HCl}(1 \mathrm{~N}, 50 \mathrm{~mL})$. Volatiles were removed in vacuo. The crude material was recrystallized with $\mathrm{CDCl}_{3} /$ hexane and the product obtained as an orange crystals. Yield (0.100 g, 90\%). ${ }^{1} \mathrm{H}$ NMR (400MHz, $\left.\mathrm{CDCl}_{3}\right): \delta(\mathrm{ppm}) 8.94(\mathrm{~s}, 1 \mathrm{H}), 7.48(\mathrm{~d}, 2 \mathrm{H}), 7.42(\mathrm{~d}, 2 \mathrm{H}), 7.01(\mathrm{~d}, 4 \mathrm{H}), 6.90(\mathrm{~d}, 2 \mathrm{H}), 6.86$ $(\mathrm{d}, 4 \mathrm{H}), 4.12(\mathrm{~s}, 6 \mathrm{H}), 3.79(\mathrm{~s}, 6 \mathrm{H}) .{ }^{13} \mathrm{C} \mathrm{NMR}\left(400 \mathrm{MHz}, \mathrm{CDCl}_{3}\right): \delta(\mathrm{ppm})$ 207.0, 156.5, 
152.7, 150.3, 149.4, 145.5, 144.5, 144.9, 140.0, 131.7, 131.5, 130.0, 129.8, 128.4, 127.2, $126.8,124.2,121.4,119.4,118.0,114.7,61.3,60.7,55.4,28.1$.

2,6-dibromo-4,8-dimethoxybenzo[1,2-b:4,5- $\left.\boldsymbol{b}^{\prime}\right]$ dithiophene (2.27). To a solution of

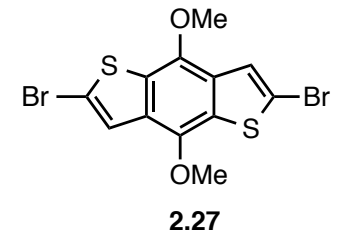
2.23 (benzo 4,8-dimethoxy [1,2-b:4,5-b'] dithiophene) (1.0 g, 3.99 mmol) in DCM (30 mL), NBS (0.711 g, $3.99 \mathrm{mmol})$ was added. The reaction mixture was stirred overnight. After washing with water $(3 \times 30 \mathrm{~mL})$ and removing the solvent in vacuo, the crude material was purified through column chromatography over silica with hexane/EtOAc (9:1) as the eluent. Pure product was obtained as a white solid. (1.5 g, 93\%). ${ }^{1} \mathrm{H}$ NMR $\left(400 \mathrm{MHz}, \mathrm{CDCl}_{3}\right): \delta(\mathrm{ppm}) 7.43$ (s, 2H), 4.07 (s, 6H). ${ }^{13} \mathrm{C}$ NMR $\left(400 \mathrm{MHz}, \mathrm{CDCl}_{3}\right)$ : 206.8, 143.3, 130.7, 122.9, 115.2, 61.0, 30.9.

\section{4-(6-bromo-4,8-dimethoxybenzo[1,2-b:4,5- $\left.b^{\prime}\right]$ dithiophen-2-yl)- $N, N$-bis(4-}

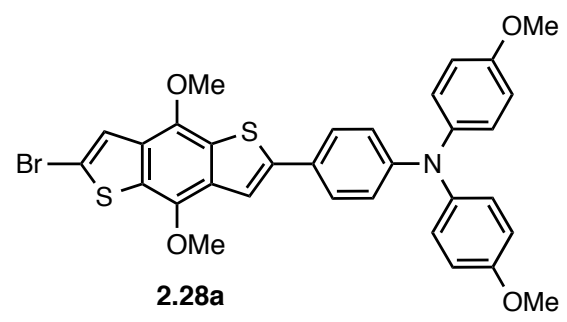

methoxyphenyl)aniline (2.28a). A solution of 2.27(3,7dibromo-4,8-dimethoxy-benzo[1,2-b:4,5-b'] dithiophene) $(0.300 \mathrm{~g}, 0.74 \mathrm{mmol})$ and 2.5 ((4(4,4',5,5'tetramethyl1,3,2-dioxaborolan-2-yl)phenyl)di-(4methoxyphenyl)amine) $(0.285 \mathrm{~g}, 0.66 \mathrm{mmol})$ in THF: $\mathrm{H}_{2} \mathrm{O}(9: 1)$ was sparged for 10 minutes with $\mathrm{N}_{2}$.

Next, $\mathrm{K}_{2} \mathrm{CO}_{3}(0.509 \mathrm{~g}, 3.68 \mathrm{mmol})$ and $\mathrm{Pd}(\mathrm{PPh})_{3} \mathrm{Cl}_{2}(0.052 \mathrm{~g}, 0.07 \mathrm{mmol})$ were added and the reaction was refluxed overnight. The mixture was cooled to room temperature and $\mathrm{H}_{2} \mathrm{O}(30 \mathrm{~mL})$ was added. The product was extracted with $\mathrm{CH}_{2} \mathrm{Cl}_{2}(3 \times 30 \mathrm{~mL})$ and the organic layer was dried over $\mathrm{MgSO}_{4}$. Volatiles were removed in vacuo. The crude material was purified through column chromatography over silica using $\mathrm{CH}_{2} \mathrm{Cl}_{2}$ /hexane (1:1) yielding a pure yellow solid. (0.40 g, 87\%). ${ }^{1} \mathrm{H} \mathrm{NMR}\left(\mathrm{CDCl}_{3}, 400 \mathrm{MHz}\right): \delta(\mathrm{ppm})$ 7.67 (s, 1H), $7.64(\mathrm{~s}, 1 \mathrm{H}), 7.53(\mathrm{~d}, 2 \mathrm{H}), 7.48(\mathrm{~s}, 1 \mathrm{H}), 7.09$ (d, 4H), 6.90 (d, 2H), $6.85(\mathrm{~d}$, 4H), 4.1(m, 6H), $3.81(\mathrm{~s}, 6 \mathrm{H}) .{ }^{13} \mathrm{C} \mathrm{NMR}\left(400 \mathrm{MHz}, \mathrm{CDCl}_{3}\right): \delta(\mathrm{ppm}) 206.8,182.7,156.1$, $148.5,140.1,140.7,137.8,136.9,136.8,136.7,134.1,129.2,126.8,126.0,123.9,120.32$, 117.0, 116.5, 114.8, 55.5, 30.9. MS: m/z 631.0472 $\left(\mathrm{C}_{32} \mathrm{H}_{26} \mathrm{BrNO}_{4} \mathrm{~S}_{2}\right)^{+}$. 


\section{4-(6-(5-(1,3-dioxolan-2-yl)thiophen-2-yl)-4,8-dimethoxybenzo[1,2-b:4,b']dithiophen-}

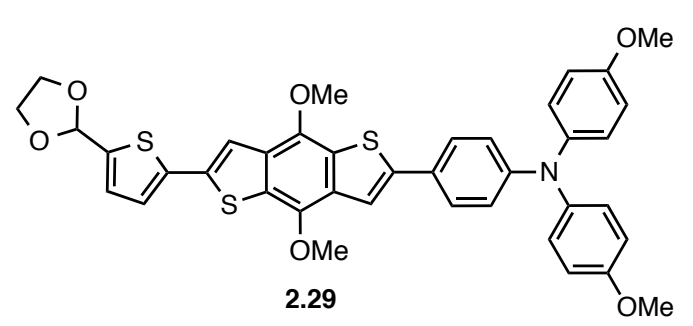

2-yl)-N,N-bis(4-methoxyphenyl)aniline

was added $\mathrm{K}_{2} \mathrm{CO}_{3}(0.157 \mathrm{~g}, 1.14 \mathrm{mmol})$ and $\mathrm{Pd}\left(\mathrm{PPh}_{3}\right)_{4}(0.027 \mathrm{~g}, 0.02)$ and the mixture were refluxed for $12 \mathrm{~h}$ under an atmosphere of $\mathrm{N}_{2}$. After being cooled to room temperature. Next, $\mathrm{H}_{2} \mathrm{O}(30 \mathrm{~mL})$ was added and the organic layer was collected. The aqueous layer was extracted with $\mathrm{CH}_{2} \mathrm{Cl}_{2}(3 \times 20 \mathrm{~mL})$ and the combined organic layers were dried over $\mathrm{MgSO}_{4}$, filtered and volatiles were removed in vacuo. The crude material was purified through column chromatography using $\mathrm{CH}_{2} \mathrm{Cl}_{2}$ as eluent to afford a brown solid as a product. (0.041 g, 62\% yield). ${ }^{1} \mathrm{H} \mathrm{NMR}\left(\mathrm{CDCl}_{3}, 400 \mathrm{MHz}\right) \delta(\mathrm{ppm}) 7.43(\mathrm{~d}$, 2H), $7.31(\mathrm{~d}, 2 \mathrm{H}), 7.18(\mathrm{~d}, 4 \mathrm{H}), 6.72(\mathrm{~d}, 4 \mathrm{H}), 6.17(\mathrm{~s}, 1 \mathrm{H}), 4.21(\mathrm{~s}, 1 \mathrm{H}), 4.10(\mathrm{~s}, 1 \mathrm{H}), 3.83$ $(\mathrm{s}, 6 \mathrm{H})$.

\section{5-(6-(4-(bis(4-methoxyphenyl)amino)phenyl)-4,8-dimethoxybenzo[1,2-b:4,5-}

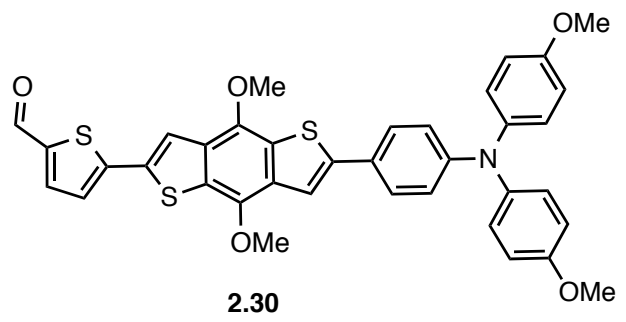

g, $0.07 \mathrm{mmol})$, DCE $(10 \mathrm{~mL})$ was added and the mixture was stirred for $2 \mathrm{~h}$ at $50{ }^{\circ} \mathrm{C}$. After being cooled to room temperature, the solution was slowly poured into saturated $\mathrm{Na}_{2} \mathrm{CO}_{3}(100 \mathrm{~mL})$ and then cooled to $0{ }^{\circ} \mathrm{C}$. After being warmed to room temperature, the mixture were stirred $30 \mathrm{~min}$. The DCE and product layer were washed with DCM/water and the organic fraction dried with $\mathrm{MgSO}_{4}$, filtered then removed in vacuo. Using column chromatography with hexane/EtOAc (8:2) as the eluent, pure product was obtained as an orange solid. (0.042 g, $90 \%) .{ }^{1} \mathrm{H}$ NMR $\left(\mathrm{CDCl}_{3}, 400 \mathrm{MHz}\right): \delta$ (ppm) 9.89 (s, 1H), $7.73(\mathrm{~s}, 1 \mathrm{H}), 7.72(\mathrm{~d}, 1 \mathrm{H}), 7.54(\mathrm{~d}, 2 \mathrm{H}), 7.53(\mathrm{~s}, 1 \mathrm{H}), 7.38(\mathrm{~d}, 1 \mathrm{H}), 7.10(\mathrm{~d}, 4 \mathrm{H})$, 
$6.94(\mathrm{~d}, 2 \mathrm{H}), 6.68(\mathrm{~d}, 4 \mathrm{H}), 3.81(\mathrm{~s}, 6 \mathrm{H}) .{ }^{13} \mathrm{C}$ NMR $\left(\mathrm{CDCl}_{3}, 400 \mathrm{MHz}\right): \delta(\mathrm{ppm})$ 182.4, 156.3, 146.9, 145.6, 144.3, 142.6, 140.2, 137.1, 134.6, 131.0, 127.2, 127.0, 125.5, 119.8, $114.8,113.4,66.8,61.1,60.0,58.7,55.5,23.8,19.6,14.1,13.5,10.9$.

\section{(E)-3-(5-(6-(4-(bis(4-methoxyphenyl)amino)phenyl)-4,8-dimethoxybenzo[1,2-}

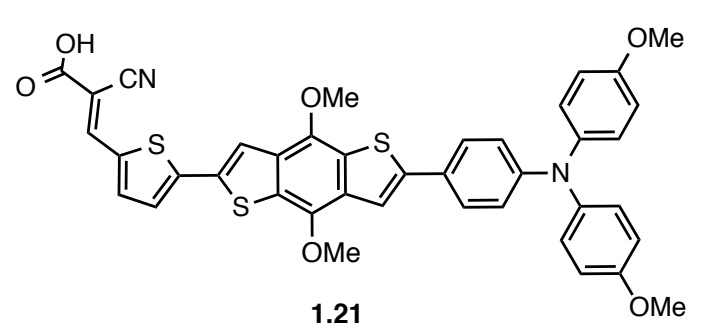

b:4,5b']dithiophen-2-yl)thiophen-2-yl)-2cyanoacrylic acid dye (1.21). To a solution of $2.30(0.05 \mathrm{~g}, 0.08 \mathrm{mmol})$ in a minimal amount of $\mathrm{CHCl}_{3}: \mathrm{MeCN}(1: 1)$, cyanoacetic acid $(0.13$ $\mathrm{g}, 0.15 \mathrm{mmol})$ and piperidine $(0.13 \mathrm{~g}, 0.15$

mmol) were added. The mixture was refluxed overnight and after being cooled to room temperature, the organic layer was washed with $\mathrm{HCl}(1 \mathrm{~N}, 50 \mathrm{~mL})$. Volatiles were removed in vacuo. The crude material was recrystallized with $\mathrm{CDCl}_{3} /$ hexane and the product obtained as an orange crystals. $(0.020 \mathrm{~g}, 36 \%) .{ }^{1} \mathrm{H}$ NMR $\left(400 \mathrm{MHz}, \mathrm{CDCl}_{3}\right): \delta$ (ppm) 8.00 (s, 1H), 7.73 (s, 1H), 7.71 (s, H), 7.54 (d, 1H), 7.52 (d, 2H), 7.51 (d, 1H), 4.16 (s, 3H), 4.09 (s, 3H), 3.81 (s, $6 \mathrm{H}) .{ }^{13} \mathrm{C}$ NMR (400 MHz, $\mathrm{CDCl}_{3}$ ): 160.9, 158.4, 156.3, 140.2,127.2, 127.0, 119.7, 114.8, 113.1, 55.5, 47.9, 47.6, 46.9, 44.5, 43.6, 40.7, 31.9, $29.6,26.5,26.2,26.1,25.7,25.1,24.9,24.1,22.6,22.5,22.1,14.1$.

5-bromothiophene-3-carboxylic acid (2.32). To a solution of 2.31 (7.15 g, $55.79 \mathrm{mmol})$<smiles>O=C(O)c1c[se]c(Br)c1</smiles>
in EtOAc (200 mL), NBS (10.92 g, $61.37 \mathrm{mmol})$ was added and stirred overnight. Volatiles were removed in vacuo and the solid was washed with water. (9.29 g, 70\%). ${ }^{1} \mathrm{H}$ NMR (400 MHz, $\left.\mathrm{CDCl}_{3}\right): \delta 8.12(\mathrm{~d}, 1 \mathrm{H})$, $7.51(\mathrm{~d}, 1 \mathrm{H})$. The spectroscopic data agreed with the literature. ${ }^{80}$

5-bromothiophene-3-carbonyl chloride (2.33). A solution of $2.32(3.63 \mathrm{~g}, 17.57 \mathrm{mmol})$

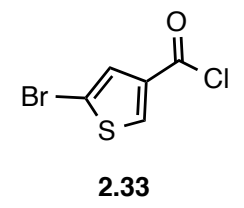
and $\mathrm{SOCl}_{2}(30 \mathrm{~mL})$ was refluxed overnight under an atmosphere of $\mathrm{N}_{2}$. Volatiles were removed in vacuo to afford a brown oil as the pure product. Yield (2.06 g, 52\%). ${ }^{1} \mathrm{H}$ NMR (400 MHz, $\mathrm{CDCl}_{3}$ ): $\delta 8.12$ $(\mathrm{d}, 1 \mathrm{H}), 7.80(\mathrm{~d}, 1 \mathrm{H})$. The spectroscopic data agreed with the literature (WO2010036497). 
5-bromo-N,N-dimethylthiophene-3-carboxamide (2.34). To a solution of 2.33 (10.12

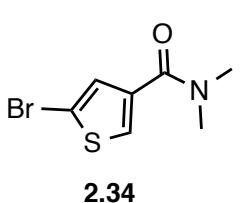
$\mathrm{g}, 44.88 \mathrm{mmol})$ in dry THF $(40 \mathrm{~mL}), \mathrm{NEt}_{3}(20 \mathrm{~mL})$ was added dropwise at $0{ }^{\circ} \mathrm{C}$ under an atmosphere of $\mathrm{N}_{2}$ followed by the addition of $\mathrm{Me}_{2} \mathrm{NH}(2.0 \mathrm{~g}, 120 \mathrm{mmol})$. The solution was warmed to room temperature and stirred at room temperature for $12 \mathrm{~h}$, then $\mathrm{H}_{2} \mathrm{O}(100$ $\mathrm{mL}$ ) was added and the organic layer was separated. The aqueous layer was extracted with $\mathrm{Et}_{2} \mathrm{O}(3 \times 30 \mathrm{~mL})$ and the combined organic layers were dried over $\mathrm{MgSO}_{4}$, filtered and volatiles removed in vacuo. The crude material was purified through column chromatography with $\mathrm{CH}_{2} \mathrm{Cl}_{2}$ : EtOAc (4:1) as the eluent to afford a yellow solid as the product. (6.71g, 64\%). ${ }^{1} \mathrm{H}$ NMR (400 MHz, $\left.\mathrm{CDCl}_{3}\right): 7.41$ (d, 1H), 7.17 (d, 1H), 3.07 (m, $6 \mathrm{H}) ;{ }^{13} \mathrm{C}$ NMR (100MHz, $\left.\mathrm{CDCl}_{3}\right): 165.5,137.3,129.8,127.8,112.7,39.2$ (broad), 35.5 (broad).

2,6-dibromo-benzo [1,2-b:4,5-b']dithiophene (2.35). A solution of LDA (0.5g, 4.91

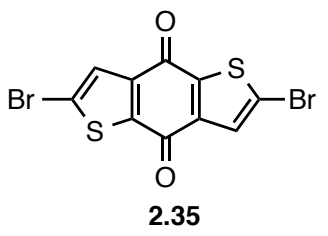
mmol) was added dropwise to a solution of 2.34 (1.00 g, 4.27 mmol) in dry THF $(20 \mathrm{~mL})$ at $0{ }^{\circ} \mathrm{C}$ under an atmosphere of $\mathrm{N}_{2}$. The mixture was stirred $1.5 \mathrm{~h}$ after the last addition and then ice water $(100 \mathrm{~mL})$ were added. The organic layer was separated and the aqueous layer was extracted with $\mathrm{CH}_{2} \mathrm{Cl}_{2}(3 \times 30 \mathrm{~mL})$. The combined organic layers were dried over $\mathrm{MgSO}_{4}$, filtered and volatiles were removed in vacuo. The crude material was purified through column chromatography over silica using hexane: $\mathrm{CH}_{2} \mathrm{Cl}_{2}(1: 1)$ as the eluent to afford a bright yellow solid. (0.33 g, 42\%). ${ }^{1} \mathrm{H}$ NMR (400 $\mathrm{MHz}, \mathrm{CDCl}_{3}$ ): $7.59(\mathrm{~s}, 2 \mathrm{H})$. The spectroscopic data agreed with the literature (WO2008011957A1).

\section{5-(1,3-dioxolan-2-yl)thiophen-2-yl)-6-bromobenzo[1,2-b:4,5-b']dithiophene-4,8-}

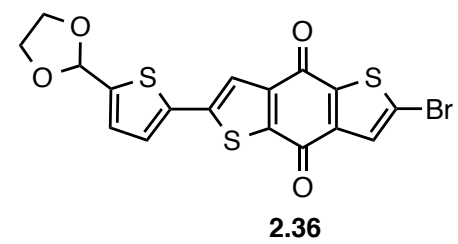

dione (2.36). A suspension of $\mathbf{2 . 3 5}(0.36 \mathrm{~g}, 0.97 \mathrm{mmol})$ and $2.9(0.32 \mathrm{~g}, 1.16 \mathrm{mmol})$ in THF: $\mathrm{H}_{2} \mathrm{O}(9: 1) \quad(75 \mathrm{~mL})$ was sparged for 10 minutes with $\mathrm{N}_{2}$. To this suspension was added $\mathrm{K}_{2} \mathrm{CO}_{3}(0.670 \mathrm{~g}, 4.85 \mathrm{mmol})$ and $\mathrm{Pd}\left(\mathrm{PPh}_{3}\right)_{4}(0.112 \mathrm{~g}$, $0.097 \mathrm{~mL}$ ) and the mixture was refluxed for $12 \mathrm{~h}$ under an atmosphere of $\mathrm{N}_{2}$. After being cooled to room temperature $\mathrm{H}_{2} \mathrm{O}(200 \mathrm{~mL})$ was added and the organic layer was separated. The aqueous layer was extracted with $\mathrm{CH}_{2} \mathrm{Cl}_{2}(3 \times 50$ 
$\mathrm{mL}$ ) and the combined organic layers were dried over $\mathrm{MgSO}_{4}$, filtered and volatiles were removed in vacuo. The crude material was purified through column chromatography using $\mathrm{CH}_{2} \mathrm{Cl}_{2}$ as the eluent. (0.39 g, 76\%). ${ }^{1} \mathrm{H}$ NMR (400 MHz, $\left.\mathrm{CDCl}_{3}\right)$ : $7.62(\mathrm{~s}, 1 \mathrm{H})$, $7.60(\mathrm{~s}, 1 \mathrm{H}), 7.28(\mathrm{~d}, 1 \mathrm{H}), 7.14(\mathrm{~d}, 1 \mathrm{H}), 6.10(\mathrm{~s}, 1 \mathrm{H}), 4.10(\mathrm{~m}, 2 \mathrm{H}),{ }^{13} \mathrm{CNMR}(100 \mathrm{MHz}$, $\mathrm{CDCl}_{3}$ ): 173.5, 173.1, 146.2, 145.2, 144.7, 143.2, 141.4, 135.9, 129.4, 127.4, 126.4, 125.7, 123.7, 122.2, 100.0, 65.5. FTIR ( $\mathrm{KBr}$ pellet): $1646 \mathrm{~cm}^{-1}(v \mathrm{C}=\mathrm{O}) . \mathrm{MS}: \mathrm{m} / \mathrm{z}$ $451.8835\left(\mathrm{C}_{17} \mathrm{H}_{9} \mathrm{BrO}_{4} \mathrm{~S}_{3}\right)^{+}$.

\section{2-(5-(1,3-dioxolan-2-yl)thiophen-2-yl)-6-(4-(bis(4-}

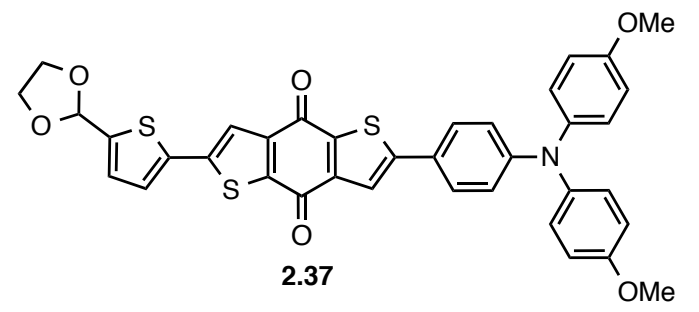

methoxyphenyl)amino)phenyl)benzo[1,2b:4,5-b']dithiophene-4,8-dione (2.37). A suspension of $\mathbf{2 . 3 6}(0.150 \mathrm{~g}, 0.33 \mathrm{mmol})$ and the $2.5(0.1856 \mathrm{~g}, 0.33 \mathrm{mmol})$ in $50 \mathrm{~mL}$ of THF: $\mathrm{H}_{2} \mathrm{O}(9: 1)$ was sparged for 10 min with $\mathrm{N}_{2}$. To this suspension was added $\mathrm{K}_{2} \mathrm{CO}_{3}(0.228 \mathrm{~g}, 1.65 \mathrm{mmol})$ and $\mathrm{Pd}\left(\mathrm{PPh}_{3}\right)_{4}(0.038 \mathrm{~g}$, $0.33 \mathrm{mmol}$ ) and the mixture was refluxed for $12 \mathrm{~h}$ under an atmosphere of $\mathrm{N}_{2}$. After being cooled to room temperature, $\mathrm{H}_{2} \mathrm{O}(100 \mathrm{~mL})$ were added and the organic layer was separated. The aqueous layer was extracted with $\mathrm{CH}_{2} \mathrm{Cl}_{2}(3 \times 30 \mathrm{~mL})$ and the combined organic layers were dried over $\mathrm{MgSO}_{4}$, filtered and volatiles were removed in vacuo. The crude material was purified through column chromatography over silica using $\mathrm{CH}_{2} \mathrm{Cl}_{2}$ as eluent to afford the compound as a brown solid. (0.163 g, 80\% yield). ${ }^{1} \mathrm{H}$ NMR (400 $\left.\mathrm{MHz}, \mathrm{CDCl}_{3}\right)$ : $7.65(\mathrm{~m}, 2 \mathrm{H}), 7.47(\mathrm{~m}, 2 \mathrm{H}), 7.11(\mathrm{~m}, 6 \mathrm{H}), 6.88(\mathrm{~m}, 6 \mathrm{H}), 6.11(\mathrm{~s}, 1 \mathrm{H}), 4.10$ (m, 4H), 3.82 (s, 6H); ${ }^{13} \mathrm{CNMR}\left(400 \mathrm{MHz}, \mathrm{CDCl}_{3}\right)$ : 174.7, 174.2, 156.8, 154.2, 150.5, 145.7, 144.3, 144.2, 144.1, 141.7, 140.3, 139.8, 136.3, 127.5, 127.4, 127.2, 126.1, 123.6, $122.2,120.1,119.2,115.1,100.0,65.5,31.1$. 
5-(6-(4-(bis(4-methoxyphenyl)amino)phenyl)-4,8-dioxo-4,8-dihydrobenzo[1,2-b:4,5-

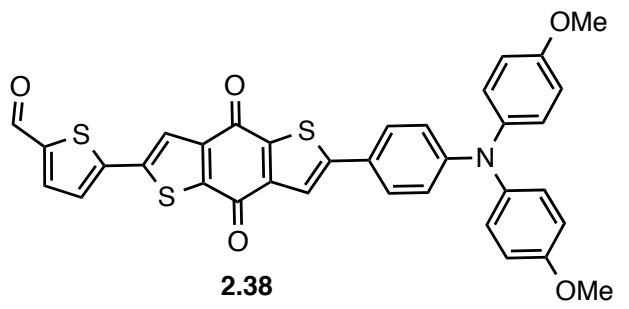
$b^{\prime}$ ]dithiophen-2-yl)thiophene-2-carbaldehyde (2.38). A solution of DMF $(30 \mathrm{~mL})$ and $\mathrm{POCl}_{3}$ (3 $\mathrm{mL})$ was stirred in DCE $(20 \mathrm{~mL})$ for 5 minutes at $0{ }^{\circ} \mathrm{C}$. After being warmed to room temperature, the mixture was stirred for another 30 minutes. To a mixture of $2.37(0.060 \mathrm{~g}, 0.10 \mathrm{mmol})$, DCE $(10 \mathrm{~mL})$ was added and stirred for $2 \mathrm{~h}$ at $50{ }^{\circ} \mathrm{C}$. After being cooled to room temperature, the solution was slowly poured into saturated $\mathrm{Na}_{2} \mathrm{CO}_{3}(100 \mathrm{~mL})$ and then cooled to $0{ }^{\circ} \mathrm{C}$. After being warmed to room temperature, the mixture was stirred for 30 minutes. The DCE and product layer were washed with $\mathrm{DCM} /$ water and the organic fraction dried with $\mathrm{MgSO}_{4}$, filtered then removed in vacuo. Using column chromatography with hexane/EtOAc (8:2) as the eluent, pure product was obtained as an orange solid. (0.49 g, 85\%). ${ }^{1} \mathrm{H}$ NMR (400 $\mathrm{MHz}$, $\left.\mathrm{CDCl}_{3}\right): \delta(\mathrm{ppm}) 9.92(\mathrm{~s}, 1 \mathrm{H}), 7.82(\mathrm{~s}, 1 \mathrm{H}), 7.81(\mathrm{~m}, 1 \mathrm{H}), 7.74(\mathrm{~s}, 1 \mathrm{H}), 7.46(\mathrm{~m}, 3 \mathrm{H}), 7.11$ $(\mathrm{d}, 4 \mathrm{H}), 6.86(\mathrm{~m}, 6 \mathrm{H}), 3.81(\mathrm{~s}, 6 \mathrm{H}) .{ }^{13} \mathrm{CNMR}$ (400 MHz, $\left.\mathrm{CDCl}_{3}\right)$ : Compound was too insoluble to be subjected to ${ }^{13} \mathrm{C}$ NMR analysis.

\section{(E)-3-(5-(6-(4-(bis(4-methoxyphenyl)amino)phenyl)-4,8-dioxo-4,8-dihydrobenzo[1,2-}

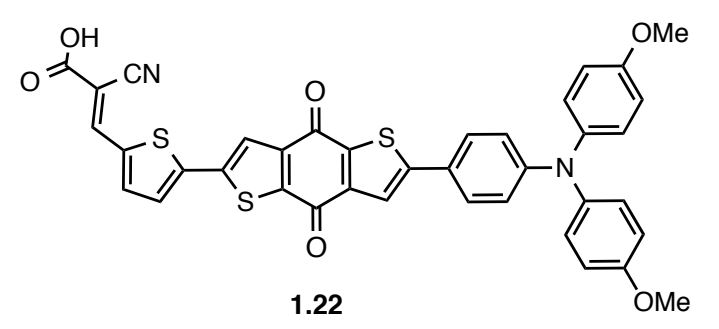

b:4,5-b']dithiophen-2-yl)thiophen-2-yl)-2cyanoacrylic acid dye (1.22). To a solution of $2.38(0.60 \mathrm{~g}, 0.10 \mathrm{mmol})$ in a minimal amount of $\mathrm{CHCl}_{3}$ : $\mathrm{MeCN}(1: 1)$, cyanoacetic acid $(0.18$ $\mathrm{g}, 0.025 \mathrm{mmol})$ and piperidine $(1 \mathrm{~mL})$ were added. The mixture was refluxed overnight and after being cooled to room temperature, the precipitate was filtered to afford the compound as a brown solid. $(0.49 \mathrm{~g}, 85 \%) .{ }^{1} \mathrm{H}$ NMR (400 MHz, $\left.\mathrm{CDCl}_{3}\right): 9.93$ (s, 1H), 7.82 (s, 1H), 7.75 (d, 1H), $7.71(\mathrm{~s}, 1 \mathrm{H}), 7.55$ (s, 1H), $7.52(\mathrm{~m}, 2 \mathrm{H}), 7.45(\mathrm{~d}, 1 \mathrm{H}), 7.32(\mathrm{~m}, 2 \mathrm{H}), 7.15(\mathrm{~m}, 4 \mathrm{H}), 7.10(\mathrm{~m}, 2 \mathrm{H}), 7.08(\mathrm{~m}, 4 \mathrm{H})$. Compound was too insoluble to be subjected to ${ }^{13} \mathrm{C}$ NMR analysis. 
$\mathrm{N}, \mathrm{N}$-bis (4-hexyloxyphenyl)aniline (2.3c). Under an atmosphere of $\mathrm{N}_{2}, 1$-(hexyloxy)-4-

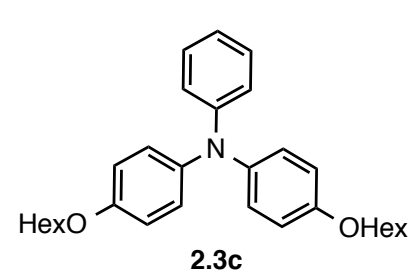

iodobenzene (2.39) (8.25 g, $27.13 \mathrm{mmol})$, aniline (2.2) (1.0 $\mathrm{mL}, 10.85 \mathrm{mmol})$ and 1,10-phenanthroline ( $0.39 \mathrm{~g}, 2.17 \mathrm{mmol})$ was solubilized in $10 \mathrm{~mL}$ of toluene. The solution was heated at $100{ }^{\circ} \mathrm{C}$ and $\mathrm{CuCl}(0.215 \mathrm{~g}, 2.17 \mathrm{mmol})$ were added followed by $\mathrm{KOH}(4.870 \mathrm{~g}, 86.8 \mathrm{mmol})$. The mixture was refluxed overnight and after being cooled to room temperature, $\mathrm{AcOH}(3 \mathrm{~mL})$ and toluene $(15$ $\mathrm{mL})$ was added. The mixture was washed with $\mathrm{H}_{2} \mathrm{O}(1 \times 30 \mathrm{~mL})$ once and extracted with toluene. The combined organic layers were dried over $\mathrm{MgSO}_{4}$, filtered, and volatiles were removed in vacuo. The crude product was purified via column chromatography over silica using hexane:EtOAc $(9: 1)$ as the eluent affording the desired product as a yellow solid. (7.6 g, $70 \%$ ). The spectroscopic data agreed with previously reported literature. ${ }^{81}$

4-bromo- $N, N$-bis (4-hexyloxyphenyl)aniline (2.4c). Under an atmosphere of $\mathrm{N}_{2}, 2.3 \mathrm{c}$<smiles>COc1ccc(N(c2ccc(O)cc2)c2ccc(Br)cc2)cc1</smiles>
( $N, N$-bis (4-hexyloxyphenyl)aniline) (6.35 g, $14.26 \mathrm{mmol})$ was dissolved in THF:EtOAc (1:1) (150 mL) and NBS (2.79 g, $15.68 \mathrm{mmol}$ ) was added in one portion and the mixture was stirred overnight. Volatiles were removed in vacuo and the crude material was purified via column chromatography using hexane:EtOAc (9:1) as the eluent, affording the desired product as a yellow solid. ( $7.8 \mathrm{~g}$, $95 \%$ ). The spectroscopic data agreed with previously reported literature. ${ }^{82}$

\section{4-(4,4',5,5'-tetramethyl1,3,2-dioxaborolan-2-yl)phenyl)-di-(4-hexyloxyphenyl)amine.}

(2.5c). Under an atmosphere of $\mathrm{N}_{2}, \mathbf{2 . 4 c}$ (4-bromo- $N, N$-bis (4-hexyloxyphenyl)aniline)

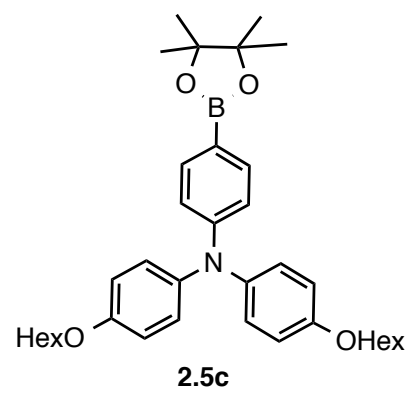

$(7.8 \mathrm{~g}, 14.87 \mathrm{mmol})$ was dissolved in dry THF $(75 \mathrm{~mL})$ and the solution was cooled to $-78^{\circ} \mathrm{C} . n$-BuLi (1.6M, $10.92 \mathrm{~mL}, 17.48$ mmol) was added dropwise and the mixture was stirred for 30 minutes at this temperature. 2-isopropoxy-4,4,5,5-tetramethyl[1,3,2]-dioxaborolane $(4.37 \mathrm{~mL}, 21.85 \mathrm{mmol})$ was added in one portion and the mixture was stirred for 30 minutes at $-78{ }^{\circ} \mathrm{C}$ and was allowed to warm to room temperature overnight. Next, methanol $(5 \mathrm{~mL})$ was 
added and volatiles were removed in vacuo. The crude product was purified via column chromatography using hexanes:EtOAc $(9: 1)$ as the eluent, affording the desired product as an off-white solid. (7.7 $\mathrm{g}, 91 \%)$. The spectroscopic data agreed with previously reported literature. ${ }^{83}$

\section{((4-(6-(5-(1,3-dioxolan-2-yl)thiophen-2-yl)-4,8-dioxo-4,8-dihydrobenzo[1,2-b:4,5-}

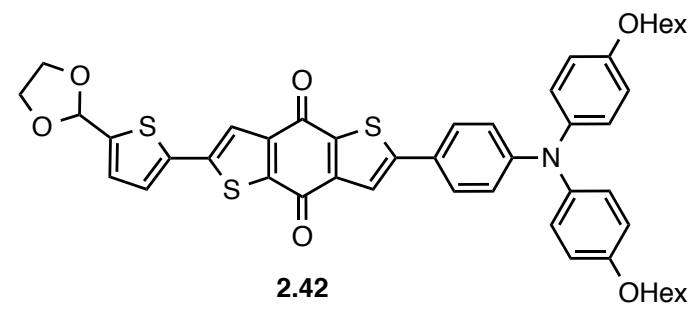
$b^{\prime}$ ]dithiophen-2-yl)phenyl)azanediyl)bis(4,1phenylene) dihexanoate (2.42). A suspension of $2.36(0.081 \mathrm{~g}, 0.18 \mathrm{mmol})$ and the $\mathbf{2 . 5 c}$ $(0.126 \mathrm{~g}, 0.22 \mathrm{mmol})$ in $50 \mathrm{~mL}$ of THF: $\mathrm{H}_{2} \mathrm{O}$ (9:1) was sparged 10 min with $\mathrm{N}_{2}$. To this suspension was added $\mathrm{K}_{2} \mathrm{CO}_{3}(0.124 \mathrm{~g}, 0.90 \mathrm{mmol})$ and $\mathrm{Pd}\left(\mathrm{PPh}_{3}\right)_{4}(0.021 \mathrm{~g}, 0.0180$ mmol) and the mixture was refluxed $12 \mathrm{~h}$ under an atmosphere of $\mathrm{N}_{2}$. After being cooled to room temperature, $\mathrm{H}_{2} \mathrm{O}(100 \mathrm{~mL})$ was added and the organic layer was separated. The aqueous layer was extracted with $\mathrm{CH}_{2} \mathrm{Cl}_{2}(3 \times 30 \mathrm{~mL})$ and the combined organic layers were dried over $\mathrm{MgSO}_{4}$, filtered and volatiles were removed in vacuo. The crude material was purified through column chromatography over silica using $\mathrm{CH}_{2} \mathrm{Cl}_{2}$ as eluent to afford of the compound as a brown solid. (0.091 g, 62\%). ${ }^{1} \mathrm{H}$ NMR (400 MHz, $\mathrm{CDCl}_{3}$ ): 7.65 (s, 1H), $7.63(\mathrm{~s}, 1 \mathrm{H}), 7.46(\mathrm{~d}, 2 \mathrm{H}), 7.27(\mathrm{~d}, 1 \mathrm{H}), 7.13(\mathrm{~d}, 1 \mathrm{H}), 7.09$ (d, 4H ), $6.90(\mathrm{~d}, 2 \mathrm{H})$, $6.86(\mathrm{~d}, 4 \mathrm{H}), 6.11(\mathrm{~s}, 1 \mathrm{H}), 4.10(\mathrm{~m}, 4 \mathrm{H}), 3.94(\mathrm{t}, 4 \mathrm{H}), 1.78(\mathrm{~m}, 4 \mathrm{H}), 1.46(\mathrm{~m}, 4 \mathrm{H}), 1.34$ (m, 8H), 0.91 (t, 6H); (400 MHz, $\left.\mathrm{CDCl}_{3}\right)$ : 174.7, 174.2, 156.4, 154.2, 150.5, 145.7, 144.3, 144.2, 144.1, 141.7, 140.2, 139.6, 136.3, 127.5, 127.4, 127.2, 126.1, 123.4, 122.2, 120.0, 119.1, 115.6, 100.0, 68.4, 65.5, 31.7, 29.4, 25.9, 22.8, 14.2. . FTIR (KBr pellet): $1646 \mathrm{~cm}^{-1}(v \mathrm{C}=\mathrm{O})$.

\section{((4-(6-(5-formylthiophen-2-yl)-4,8-dioxo-4,8-dihydrobenzo[1,2-b:4,5-b']dithiophen-}

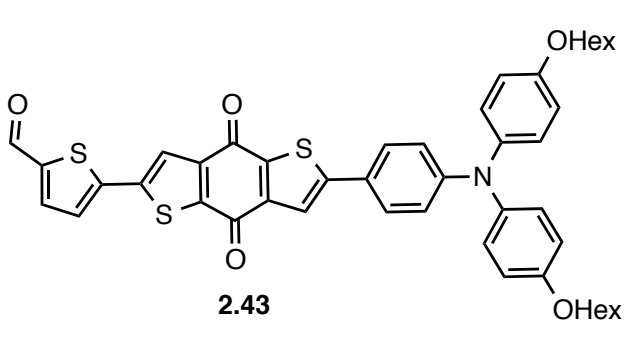
2yl)phenyl)azanediyl)bis(4,1phenylene)dihex

anoate (2.43). A solution of DMF $(30 \mathrm{~mL})$ and $\mathrm{POCl}_{3}(3 \mathrm{~mL})$ was stirred in DCE $(20 \mathrm{~mL})$ for 5 minutes at $0{ }^{\circ} \mathrm{C}$. After being warmed at room temperature, the mixture was stirred for another

$30 \mathrm{~min}$. To the mixture of $\mathbf{2 . 4 2}(0.092 \mathrm{~g}, 0.120 \mathrm{mmol}) \mathrm{DCE}(10 \mathrm{~mL})$ and the mixture was 
added and stirred $2 \mathrm{~h}$ at $50{ }^{\circ} \mathrm{C}$. After being cooled to room temperature, the solution was slowly poured into saturated $\mathrm{Na}_{2} \mathrm{CO}_{3}(100 \mathrm{~mL})$ and then cooled to $0{ }^{\circ} \mathrm{C}$. After being warmed to room temperature, the mixture was stirred 30 minutes. The DCE and product layer were washed with $\mathrm{DCM}$ /water and the organic fraction dried with $\mathrm{MgSO}_{4}$, filtered then removed in vacuo. Using column chromatography with hexane/EtOAc (8:2) as the eluent, pure product was obtained as orange solid. (0.49 g, 86\%). ${ }^{1} \mathrm{H}$ NMR (400 MHz, $\left.\mathrm{CDCl}_{3}\right): \delta(\mathrm{ppm}) 10.32(\mathrm{~s}, 1 \mathrm{H}), 7.74(\mathrm{~s}, 1 \mathrm{H}), 7.68(\mathrm{~s}, 1 \mathrm{H}), 7.53(\mathrm{~d}, 1 \mathrm{H}), 7.31(\mathrm{~d}, 1 \mathrm{H}), 7.09$ (d, 4H), $6.94(\mathrm{~d}, 2 \mathrm{H}), 6.86(\mathrm{~d}, 4 \mathrm{H}), 3.98(\mathrm{t}, 4 \mathrm{H}), 1.83(\mathrm{~m}, 4 \mathrm{H}), 1.52(\mathrm{~m}, 4 \mathrm{H}), 1.39(\mathrm{~m}$, $8 \mathrm{H}), 0.97(\mathrm{t}, 6 \mathrm{H})$. Compound was too insoluble to be subjected to ${ }^{13} \mathrm{C}$ NMR analysis.

\section{(E)-3-(5-(6-(4-(bis(4-(hexanoyloxy)phenyl)amino)phenyl)-4,8-dioxo-4,8-}

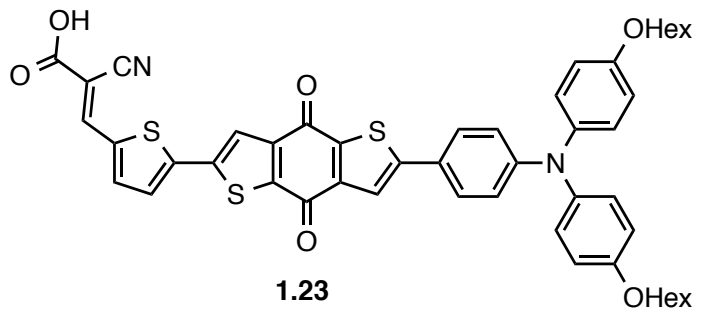
dihydrobenzo[1,2-b:4,5- $\left.b^{\prime}\right]$ dithiophen-2yl)thiophen-2-yl)-2-cyanoacrylic acid dye (1.23). To a solution of $2.43(0.75 \mathrm{~g}, 0.120$ mmol) in a minimal amount of $\mathrm{CHCl}_{3}$ : $\mathrm{MeCN}$ (1:1), cyanoacetic acid (0.18 g, $0.025 \mathrm{mmol})$ and piperidine $(1 \mathrm{~mL})$ were added. The mixture was refluxed overnight and after being cooled to room temperature, the precipitate was filtered to afford the compound as a brown solid. (0.49 g, 85\%). ${ }^{1} \mathrm{H}$ NMR (400 MHz, $\left.\mathrm{CDCl}_{3}\right): 9.17(\mathrm{~s}, 1 \mathrm{H})$, $7.71(\mathrm{~s}, 1 \mathrm{H}), 7.70(\mathrm{~s}, 1 \mathrm{H}), 7.51(\mathrm{~d}, 1 \mathrm{H}), 7.28(\mathrm{~d}, 1 \mathrm{H}), 7.01(\mathrm{~d}, 4 \mathrm{H}), 6.81(\mathrm{~d}, 2 \mathrm{H}), 6.75(\mathrm{~d}$, 4H), $3.88(\mathrm{t}, 4 \mathrm{H}), 1.71(\mathrm{~m}, 4 \mathrm{H}), 1.47(\mathrm{~m}, 4 \mathrm{H}), 1.37(\mathrm{~m}, 8 \mathrm{H}), 0.98(\mathrm{t}, 6 \mathrm{H})$. Compound was too insoluble to be subjected to ${ }^{13} \mathrm{C}$ NMR analysis.

$N, N$-diphenyl- $N$-(4-bromophenyl)amine (2.3a). Under an atmosphere of $\mathrm{N}_{2}$,

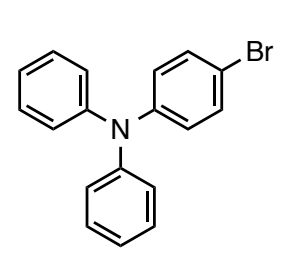

2.3a triphenylamine $(3.0 \mathrm{~g}, 12 \mathrm{mmol})$ was dissolved in $100 \mathrm{~mL}$ of THF:EtOAc (1:1) and NBS (2.3 g, $13 \mathrm{mmol})$ was added in small portions. The flask was covered with Al foil and the mixture was stirred overnight. Volatiles were removed in vacuo and the crude was purified via column chromatography over silica using hexane:DCM (9:1), affording the desired product as a greasy white solid. (3.1 g, 72\%). The spectroscopic data agreed with previously reported literature. ${ }^{84}$ 
4-(4,4',5,5'-tetramethyl-1,3,2-dioxaborolan-2-yl)triphenylamine (2.4a). A solution of

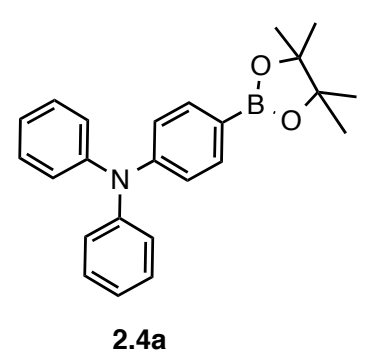

4-bromo-N,N-diphenylaniline (2.3a) (3.00 g, $9.26 \mathrm{mmol})$ in THF $(250 \mathrm{~mL})$ was cooled to $-78^{\circ} \mathrm{C}$. $n$-BuLi (1.6 M in hexanes, 27 $\mathrm{mL}, 71.49 \mathrm{mmol}$ ) was added dropwise over 30 minute. After $1 \mathrm{~h}$, 2-Isopropoxy-4,4,5,5-tetramethyl-1,3,2-dioxaborolane $(5.2 \mathrm{~mL}$, $27.16 \mathrm{mmol}$ ) was added. The mixture was stirred at $-78^{\circ} \mathrm{C}$ for 30

min and then at room temperature for $6 \mathrm{~h}$. The reaction was quenched with $2 \mathrm{M} \mathrm{HCl}$. The layers were separated, and the aqueous layer was extracted 3 times with $\mathrm{CH}_{2} \mathrm{Cl}_{2}$. The organic layers were combined, washed once with saturated aqueous $\mathrm{NaCl}$, dried over $\mathrm{MgSO}_{4}$, and evaporated to yield an off-white solid. The solid was washed with hexane to yield the product as a white powder. $(2.2 \mathrm{~g}, 65 \%)$. The spectroscopic data agreed with previously reported literature. ${ }^{85,86}$

\section{2-(5-(1,3-dioxolan-2-yl)thiophen-2-yl)-6-(4-(diphenylamino)phenyl)benzo[1,2-b:4,5-}

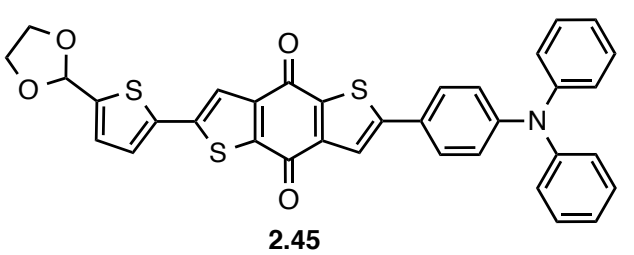

$b^{\prime}$ ]dithiophene-4,8-dione(2.45). A suspension of

$2.36(0.185 \mathrm{~g}, 0.50 \mathrm{mmol})$ and $\mathbf{2 . 4 a}(0.150 \mathrm{~g}, 0.33$ mmol) in THF: $\mathrm{H}_{2} \mathrm{O}(9: 1)(50 \mathrm{~mL})$ was sparged for 10 minutes with $\mathrm{N}_{2}$. To this suspension was added $\mathrm{K}_{2} \mathrm{CO}_{3}(0.228 \mathrm{~g}, 1.68 \mathrm{mmol})$ and $\mathrm{Pd}\left(\mathrm{PPh}_{3}\right)_{4}(0.038 \mathrm{~g}, 0.0330 \mathrm{mmol})$ and the mixture was refluxed for $12 \mathrm{~h}$ under an atmosphere of $\mathrm{N}_{2}$. After being cooled to room temperature, $\mathrm{H}_{2} \mathrm{O}(100 \mathrm{~mL})$ was added and the organic layer was separated. The aqueous layer was extracted with $\mathrm{CH}_{2} \mathrm{Cl}_{2}(3 \times 30 \mathrm{~mL})$ and the combined organic layers were dried over $\mathrm{MgSO}_{4}$, filtered, and volatiles were removed in vacuo. The crude material was purified through column chromatography over silica using $\mathrm{CH}_{2} \mathrm{Cl}_{2}$ as the eluent to afford of the compound as a brown solid. (0.16 g, 80\%). ${ }^{1} \mathrm{H}$ NMR (400 $\left.\mathrm{MHz}, \mathrm{CDCl}_{3}\right): 7.70$ (s, 1H), $7.68(\mathrm{~s}, 1 \mathrm{H}), 7.50(\mathrm{~d}, 2 \mathrm{H}), 7.33(\mathrm{~m}, 2 \mathrm{H}), 7.21(\mathrm{~d}, 2 \mathrm{H}), 7.12(\mathrm{~m}, 4 \mathrm{H}), 7.07(\mathrm{~m}, 2 \mathrm{H})$, $7.02(\mathrm{~m}, 4 \mathrm{H}), 6.73(\mathrm{~s}, 2 \mathrm{H}), 6.07(\mathrm{~s}, 1 \mathrm{H}), 4.08(\mathrm{~m}, 4 \mathrm{H})$. Compound was too insoluble to be subjected to ${ }^{13} \mathrm{C}$ NMR analysis. 
5-(6-(4-(diphenylamino)phenyl)-4,8-dioxo-4,8-dihydrobenzo[1,2-b:4,5-b']dithiophen-

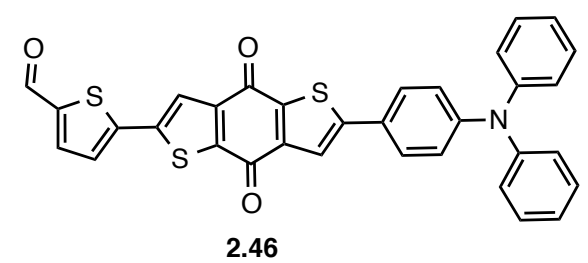

2.46

2-yl)thiophene-2-carbaldehyde (2.46). A solution of $2.45 \mathrm{POCl}_{3}(3 \mathrm{~mL})$ was stirred in DCE $(20 \mathrm{~mL})$ for 5 minutes at $0{ }^{\circ} \mathrm{C}$. After being warmed to room temperature, the mixture was stirred for another 30 minutes. To the mixture of $\mathbf{2 . 4 8}(0.060 \mathrm{~g}, 0.10$ mmol) DCE $(10 \mathrm{~mL})$ and the mixture was added and stirred $2 \mathrm{~h}$ at $50{ }^{\circ} \mathrm{C}$. After being cooled to room temperature, the solution was slowly poured into saturated $\mathrm{Na}_{2} \mathrm{CO}_{3}(100$ $\mathrm{mL}$ ) and then cooled to $0{ }^{\circ} \mathrm{C}$. After being warmed to room temperature, the mixture was stirred for 30 minutes. The DCE and product layer were washed with DCM/water and the organic fraction dried with $\mathrm{MgSO}_{4}$, filtered then removed in vacuo. Using column chromatography with hexane/EtOAc (8:2) as the eluent, pure product obtained as an orange solid (0.49 g, 85\% ). ${ }^{1} \mathrm{H}$ NMR (400 MHz, $\left.\mathrm{CDCl}_{3}\right)$ : 9.93 (s, 1H), $7.82(\mathrm{~s}, 1 \mathrm{H}), 7.75$ (d, 1H), $7.71(\mathrm{~s}, 1 \mathrm{H}), 7.55(\mathrm{~s}, 1 \mathrm{H}), 7.52(\mathrm{~m}, 2 \mathrm{H}), 7.45(\mathrm{~d}, 1 \mathrm{H}), 7.32(\mathrm{~m}, 2 \mathrm{H}), 7.15(\mathrm{~m}$, $4 \mathrm{H}), 7.10(\mathrm{~m}, 2 \mathrm{H}), 7.08(\mathrm{~m}, 4 \mathrm{H})$. Compound was too insoluble to be subjected to ${ }^{13} \mathrm{C}$ NMR analysis

\section{(E)-2-cyano-3-(5-(6-(4-(diphenylamino)phenyl)-4,8-dioxo-4,8-dihydrobenzo[1,2-}

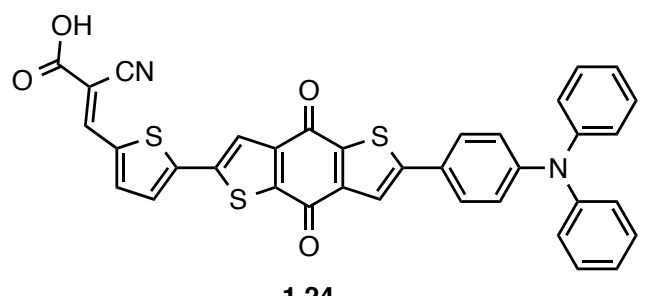

1.24 $\left.b: 4,5-b^{\prime}\right]$ dithiophen-2-yl)thiophen-2-yl)acrylic acid dye (1.24). To a solution of $2.46(0.030 \mathrm{~g}$, $0.052 \mathrm{mmol}$ ) in a minimal amount of $\mathrm{CHCl}_{3}$ :

MeCN (1:1), cyanoacetic acid $(0.009 \mathrm{~g}, 0.105$ $\mathrm{mmol})$ and piperidine $(0.0013 \mathrm{~mL}, 0.013 \mathrm{mmol})$

were added. The mixture was refluxed overnight and after being cooled to room temperature, the precipitate was filtered to afford the compound as a brown solid. ( $0.49 \mathrm{~g}$, 85\%). ${ }^{1} \mathrm{H}$ NMR (400 MHz. $\mathrm{CDCl}_{3}$ ): 9.93 (s, 1H), 7.82 (s, 1H), 7.75 (d, 1H), 7.71 (s, 1H), $7.55(\mathrm{~s}, 1 \mathrm{H}), 7.52(\mathrm{~m}, 2 \mathrm{H}), 7.45(\mathrm{~d}, 1 \mathrm{H}), 7.32(\mathrm{~m}, 2 \mathrm{H}), 7.15(\mathrm{~m}, 4 \mathrm{H}), 7.10(\mathrm{~m}, 2 \mathrm{H}), 7.08$ $(\mathrm{m}, 4 \mathrm{H})$. Compound was too insoluble to be subjected to ${ }^{13} \mathrm{C}$ NMR analysis. $(0.04 \mathrm{~g}$, $67 \%)$. 


\section{Chapter 6: References}

(1) International Energy Agengy. In World Energy Outlook 2013; 2013.

(2) Lund, H. Energy, 2007, 32, 912-919.

(3) Lewis, N. S.; Nocera, D. G. Proc. Natl. Acad. Sci. U. S. A. 2006, 103, 15729-15735.

(4) Group, B. Nucl. Energy, 2009, www.bp.com/statisticalreview.

(5) Chu, S.; Majumdar, A. Nature, 2012, 488, 294-303.

(6) Han, Y. M.; Wang, R. Z.; Dai, Y. J. Renewable and Sustainable Energy Reviews. Renewable and Sustainable Energy Reviews, 2009, 13, 1014-1026.

(7) Wilhelm, I.; Teske, S. Solar generation 6; 2010; p. 100.

(8) Hadipour, A.; de Boer, B.; Blom, P. W. M. Org. Electron. physics, Mater. Appl., 2008, 9, 617-624.

(9) Chung, I.; Lee, B.; He, J.; Chang, R. P. H.; Kanatzidis, M. G. Nature, 2012, 485, 486-489.

(10) Hardin, B. E.; Snaith, H. J.; McGehee, M. D. Nat. Photonics, 2012, 6, 162-169.

(11) Boschloo, G.; Hagfeldt, A. Acc. Chem. Res., 2009, 42, 1819-1826.

(12) Du, J.; Lai, X.; Halpert, J. E.; Yang, Y.; Wang, D. Sci. China Chem., 2011, 54, 930-935.

(13) Hagfeldt, A.; Boschloo, G.; Sun, L.; Kloo, L.; Pettersson, H. Chem. Rev., 2010, 110, 6595-6663.

(14) Tranter, G. In Encyclopedia of Spectroscopy and Spectrometry; 2010; pp. 2877-2880.

(15) Fuglevand, G.; Jackson, J. A.; Jenkins, G. I. Plant Cell, 1996, 8, 2347-2357.

(16) Wang, H.; Liu, M.; Zhang, M.; Wang, P.; Miura, H.; Cheng, Y.; Bell, J. Phys. Chem. Chem. Phys., 2011, 13, 17359-17366.

(17) Daeneke, T.; Mozer, A. J.; Uemura, Y.; Makuta, S.; Fekete, M.; Tachibana, Y.; Koumura, N.; Bach, U.; Spiccia, L. J. Am. Chem. Soc., 2012, 134, 16925-16928.

(18) O’Regan, B. C.; Durrant, J. R. Acc. Chem. Res., 2009, 42, 1799-1808.

(19) Feldt, S. M.; Gibson, E. a; Gabrielsson, E.; Sun, L.; Boschloo, G.; Hagfeldt, A. J. Am. Chem. Soc., 2010, 132, 16714-16724.

(20) Mishra, A.; Fischer, M. K. R.; Bäuerle, P. Angew. Chem. Int. Ed., 2009, 48, 2474-2499.

(21) Balasingam, S. K.; Lee, M.; Kang, M. G.; Jun, Y. Chem. Commun. (Camb)., 2013, 49, $1471-1487$.

(22) Tada-oikawa, S.; Oikawa, S.; Hirayama, J.; Hirakawa, K.; Kawanishi, S. Engineering, 2009, 85, 1391-1399. 
(23) Nazeeruddin, M. K.; Kay, A.; Rodicio, I.; Humphry-Baker, R.; Mueller, E.; Liska, P.;

Vlachopoulos, N.; Graetzel, M. J. Am. Chem. Soc., 1993, 115, 6382-6390.

(24) Yella, A.; Lee, H.-W.; Tsao, H. N.; Yi, C.; Chandiran, A. K.; Nazeeruddin, M. K.; Diau, E. W.-G.; Yeh, C.-Y.; Zakeeruddin, S. M.; Grätzel, M. Science, 2011, 334, 629-634.

(25) Kang, T. E.; Cho, H.-H.; Cho, C.-H.; Kim, K.-H.; Kang, H.; Lee, M.; Lee, S.; Kim, B.; Im, C.; Kim, B. J. ACS Appl. Mater. Interfaces, 2013, 5, 861-868.

(26) O'Regan, B.; Grätzel, M. A low-cost, high-efficiency solar cell based on dye-sensitized colloidal TiO2 films. Nature, 1991, 353, 737-740.

(27) Han, W.-S.; Han, J.-K.; Kim, H.-Y.; Choi, M. J.; Kang, Y.-S.; Pac, C.; Kang, S. O. Inorg. Chem., 2011, 50, 3271-3280.

(28) Probst, B.; Guttentag, M.; Rodenberg, A.; Hamm, P.; Alberto, R. Inorg. Chem., 2011, 50, 34043412 .

(29) Lu, H.-P.; Tsai, C.-Y.; Yen, W.-N.; Hsieh, C.-P.; Lee, C.-W.; Yeh, C.-Y.; Diau, E. W.-G. J. Phys. Chem. C, 2009, 113, 20990-20997.

(30) Koivisto, B. D.; Robson, K. C. D.; Berlinguette, C. P. Inorg. Chem. 2009, 48, 9644-9652.

(31) Liu, W.-H.; Wu, I.-C.; Lai, C.-H.; Lai, C.-H.; Chou, P.-T.; Li, Y.-T.; Chen, C.-L.; Hsu, Y.-Y.; Chi, Y. Chem. Commun. (Camb). 2008, 5152-5154.

(32) Chen, C.; Yang, X.; Cheng, M.; Zhang, F.; Zhao, J.; Sun, L. RSC Adv., 2013, 3, 12688.

(33) Spraul, B. K.; Suresh, S.; Sassa, T.; Ángeles Herranz, M.; Echegoyen, L.; Wada, T.; Perahia, D.; Smith, D. W. Tetrahedron Lett. 2004, 45, 3253-3256.

(34) Kitamura, T.; Ikeda, M.; Shigaki, K.; Inoue, T.; Anderson, N. A.; Ai, X.; Lian, T.; Yanagida, S. Chem. Mater. 2004, 16, 1806-1812.

(35) Zeng, W.; Cao, Y.; Bai, Y.; Wang, Y.; Shi, Y.; Zhang, M.; Wang, F.; Pan, C.; Wang, P. Chem. Mater. 2010, 22, 1915-1925.

(36) Kloo, L. Chem. Commun. (Camb)., 2013, 49, 6580-6583.

(37) Hagberg, D. P.; Edvinsson, T.; Marinado, T.; Boschloo, G.; Hagfeldt, A.; Sun, L. Chem. Commun. (Camb). 2006, 2245-2247.

(38) Hwang, S.; Lee, J. H.; Park, C.; Lee, H.; Kim, C.; Park, C.; Lee, M.-H.; Lee, W.; Park, J.; Kim, K.; Park, N.-G.; Kim, C. Chem. Commun. 2007, 4887.

(39) Hagberg, D. P.; Marinado, T.; Karlsson, K. M.; Nonomura, K.; Qin, P.; Boschloo, G.; Brinck, T.; Hagfeldt, A.; Sun, L. J. Org. Chem. 2007, 72, 9550-9556.

(40) Delcamp, J. H.; Yella, A.; Holcombe, T. W.; Nazeeruddin, M. K.; Grätzel, M. Angew. Chem. Int. Ed. Engl., 2013, 52, 376-380.

Li, G.; Jiang, K.; Li, Y.; Li, S.; Yang, L. J. Phys. Chem. C., 2008, 15, 11591-11599. 
(42) Hagberg, D. P.; Yum, J.-H.; Lee, H.; De Angelis, F.; Marinado, T.; Karlsson, K. M.; HumphryBaker, R.; Sun, L.; Hagfeldt, A.; Grätzel, M.; Nazeeruddin, M. K. J. Am. Chem. Soc., 2008, 130, 6259-6266.

(43) Xu, W.; Peng, B.; Chen, J.; Liang, M.; Cai, F. J. Phys. Chem. C., 2008, 112, 874-880.

(44) Liu, J.; Numata, Y.; Qin, C.; Islam, A.; Yang, X.; Han, L. Chem. Commun. (Camb). 2013, 49, $7587-7589$.

(45) Chen, S.; Zhao, Y.; Bolag, A.; Nishida, J.-I.; Liu, Y.; Yamashita, Y. ACS Appl. Mater. Interfaces., 2012, 4, 3994-4000.

(46) Climent, C.; Casanova, D. Chem. Phys., 2013, 423, 157-166.

(47) Longhi, E.; Bossi, A.; Di Carlo, G.; Maiorana, S.; De Angelis, F.; Salvatori, P.; Petrozza, A.; Binda, M.; Roiati, V.; Mussini, P. R.; Baldoli, C.; Licandro, E. European J. Org. Chem. 2013, 94 , 84-94.

(48) Hao, X.; Liang, M.; Cheng, X.; Pian, X.; Sun, Z.; Xue, S. Org. Lett., 2011, 13, 5424-5427.

(49) Hou, J.; Chen, H.-Y.; Zhang, S.; Yang, Y. J. Phys. Chem. C., 2009, 113, 21202-21207.

(50) Owen, A. Vasa, Org. Lett., 2003, 1, 1-136.

(51) Zheng, W.; Shan, N.; Yu, L.; Wang, X. Dye. Pigment. 2008, 77, 153-157.

(52) Currell, G. In Analytical Instrumentation: Performance Characteristics and Quality; 2000; pp. 6789.

(53) Walzel, M. D.; Lipps, F. W.; Vant-Hull, L. L. A solar flux density calculation for a solar tower concentrator using a two-dimensional hermite function expansion. Solar Energy, 1977, 19, 239253.

(54) Mattsson, A. E.; Schultz, P. a; Desjarlais, M. P.; Mattsson, T. R.; Leung, K. Model. Simul. Mater. Sci. Eng., 2005, 13, R1-R31.

(60) Bontempelli, G.; Toniolo, R. Garche, J. B. T.-E. of E. P. S., Ed.; Elsevier: Amsterdam, 2009; pp. 643-654.

(61) Molina, A.; Torralba, E.; Serna, C.; Ortuño, J. A. Electrochim. Acta., 2013, 106, 244-257. 
(62) Xue, G.; Yu, X.; Yu, T.; Bao, C.; Zhang, J.; Guan, J.; Huang, H.; Tang, Z.; Zou, Z. J. Phys. D. Appl. Phys. 2012, 45, 425104.

(63) Keshtov, M. L.; Sharma, G. D.; Kochurov, V. S.; Khokhlov, a. R. Synth. Met., 2013, 166, 7-13.

(64) Wex B1, Kaafarani BR, Danilov EO, N. D. J Phys Chem A., 2006, 51, 13754-13758.

(65) Hong, J.-A.; Kim, R.; Yun, H.-J.; Park, J.-M.; Shin, S. C.; Kim, Y.-H. Bull. Korean Chem. Soc., 2013, 34, 1170-1174.

(66) Dei, D. K.; Wu, J.; Lund, B.; Smith Jr., D. W. Polym. Prepr. (American Chem. Soc. Div. Polym. Chem., 2011, 52, 740-741.

(67) Steinberger, S.; Mishra, A.; Reinold, E.; Mena-Osteritz, E.; Müller, H.; Uhrich, C.; Pfeiffer, M.; Bäuerle, P. J. Mater. Chem., 2012, 22, 2701.

(68) Yum, J.-H.; Hagberg, D. P.; Moon, S.-J.; Karlsson, K. M.; Marinado, T.; Sun, L.; Hagfeldt, A.; Nazeeruddin, M. K.; Grätzel, M. Angew. Chemie Int. Ed., 2009, 48, 1576-1580.

(69) Frisch, M. J.; Trucks, G. W.; Schlegel, H. B.; Scuseria, G. E.; Robb, M. A.; Cheeseman, J. R.; Scalmani, G.; Barone, V.; Mennucci, B.; Petersson, G. A.; Nakatsuji, H.; Caricato, M.; Li, X.; Hratchian, H. P.; Izmaylov, A. F.; Bloino, J.; Zheng, G.; Sonnenberg, J. L.; Hada, M.; Ehara, M.; Toyota, K.; Fukuda, R.; Hasegawa, J.; Ishida, M.; Nakajima, T.; Honda, Y.; Kitao, O.; Nakai, H.; Vreven, T.; Montgomery Jr., J. A.; Peralta, J. E.; Ogliaro, F.; Bearpark, M.; Heyd, J. J.; Brothers, E.; Kudin, K. N.; Staroverov, V. N.; Kobayashi, R.; Normand, J.; Raghavachari, K.; Rendell, A.; Burant, J. C.; Iyengar, S. S.; Tomasi, J.; Cossi, M.; Rega, N.; Millam, J. M.; Klene, M.; Knox, J. E.; Cross, J. B.; Bakken, V.; Adamo, C.; Jaramillo, J.; Gomperts, R.; Stratmann, R. E.; Yazyev, O.; Austin, A. J.; Cammi, R.; Pomelli, C.; Ochterski, J. W.; Martin, R. L.; Morokuma, K.; Zakrzewski, V. G.; Voth, G. A.; Salvador, P.; Dannenberg, J. J.; Dapprich, S.; Daniels, A. D.; Farkas, Ö.; Foresman, J. B.; Ortiz, J. V; Cioslowski, J.; Fox, D. J. Gaussian 09, Revision A.02. Gaussian Inc Wallingford CT, 2009, 34, Wallingford CT.

(70) Lee, O. P.; Yiu, A. T.; Beaujuge, P. M.; Woo, C. H.; Holcombe, T. W.; Millstone, J. E.; Douglas, J. D.; Chen, M. S.; Fréchet, J. M. J. Adv. Mater., 2011, 23, 5359-5363.

(71) Bonnier, C.; Machin, D. D.; Abdi, O.; Koivisto, B. D. Org. Biomol. Chem. 2013, 11, 3756-3760.

(72) Gao, Y.-R.; Chu, L.-L.; Guo, W.; Ma, T.-L. Chinese Chem. Lett., 2013, 24, 149-152.

(73) Kashiki, T.; Shinamura, S.; Kohara, M.; Miyazaki, E.; Takimiya, K.; Ikeda, M.; Kuwabara, H. Org. Lett., 2009, 11, 2473-2475.

(74) He, F.; Wang, W.; Chen, W.; Xu, T.; Darling, S. B.; Strzalka, J.; Liu, Y.; Yu, L. J. Am. Chem. Soc., 2011, 133, 3284-3287.

(75) Takimiya, K.; Konda, Y.; Ebata, H.; Niihara, N.; Otsubo, T. Org. Lett., 2005, 1, 10569-10571.

(76) Wang, Y.; Parkin, S. R.; Watson, M. D. J.Org. Chem., 2005, 4, 10569-10571.

(77) Dang, T. T. M.; Park, S.-J.; Park, J.-W.; Chung, D.-S.; Park, C. E.; Kim, Y.-H.; Kwon, S.-K. J. Polym. Sci. Part A Polym. Chem., 2007, 45, 5277-5284. 
(78) Hou, J.; Park, M.-H.; Zhang, S.; Yao, Y.; Chen, L.-M.; Li, J.-H.; Yang, Y. Macromolecules., 2008 , 41, 6012-6018.

(79) Mamada, M.; Kumaki, D.; Nishida, J.; Tokito, S.; Yamashita, Y. ACS Appl. Mater. Interfaces., 2010, 2, 1303-1307.

(80) Clayden, J.; Turnbull, R.; Helliwell, M.; Pinto, I. Chem. Commun. (Camb)., 2004, 2, $2430-2431$.

(81) Li, S.; Zhang, C.; Huang, S.; Hu, F.; Yin, J.; Liu, S. H. RSC $A d v ., 2012,2,4215$.

(82) Yu, Q.; Liao, J.; Zhou, S.; Shen, Y.; Liu, J.; Kuang, D.; Su, C. 2011, 22002-22008.

(83) Li, R.; Liu, J.; Cai, N.; Zhang, M.; Wang, P. J. Phys. Chem. B., 2010, 114, 4461-4464.

(84) Zhang, H.; Fan, J.; Iqbal, Z.; Kuang, D. Bin; Wang, L.; Cao, D.; Meier, H. Dye. Pigment., 2013, 99 , 74-81.

(85) Rumi, M.; Barlow, S.; Wang, J.; Perry, J. W.; Marder, S. R. Two-photon absorbing materials and two-photon-induced chemistry. Advances in Polymer Science., 2008, 213, 1-95.

(86) Kim, R.; Lee, S.; Kim, K.-H.; Lee, Y.-J.; Kwon, S.-K.; Kim, J.-J.; Kim, Y.-H. Chem. Commun. (Camb). 2013, 49, 4664-4666. 


\section{Appendix 1: Molecular index for chapter 1}

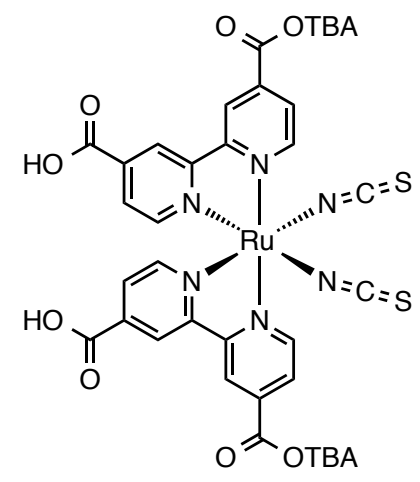

1.1

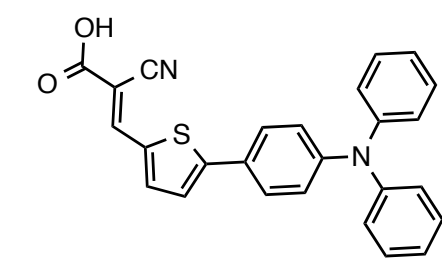

(1.3)
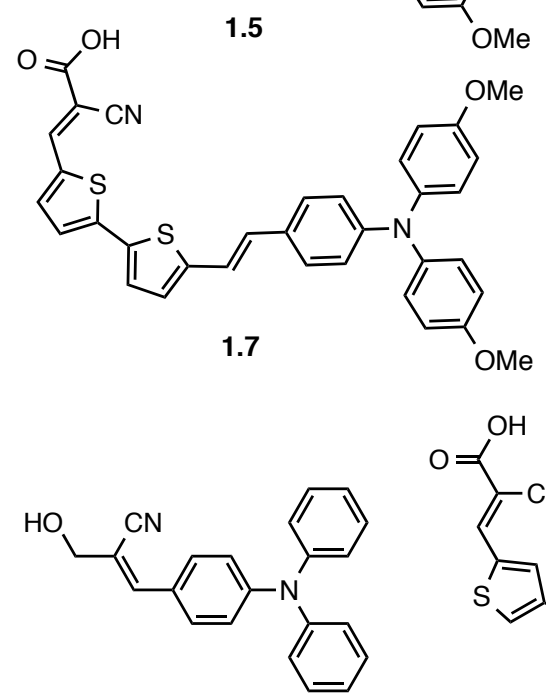

1.9

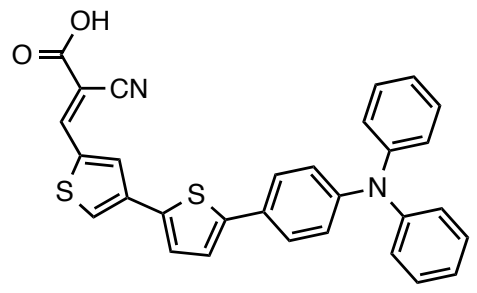

1.10
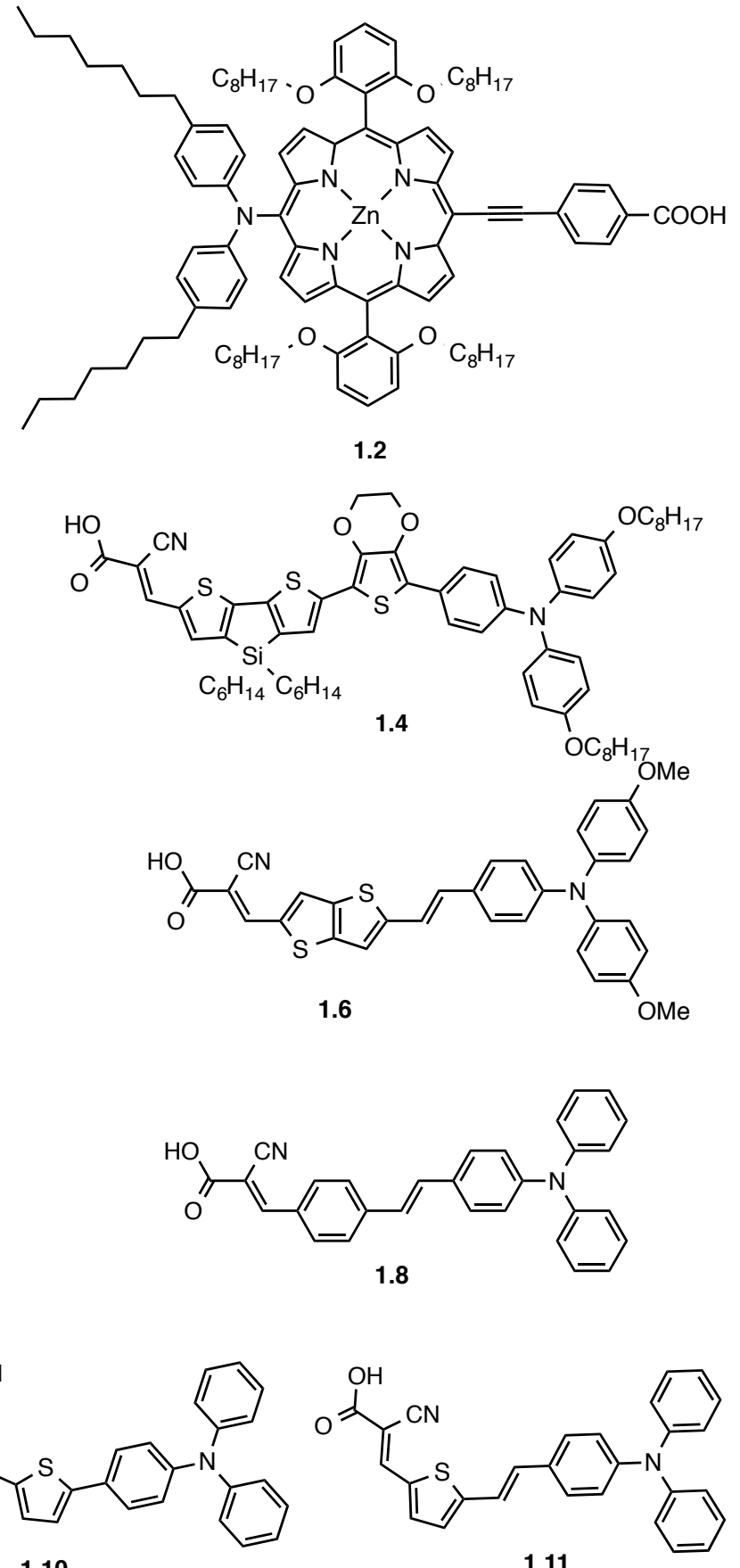

1.11 

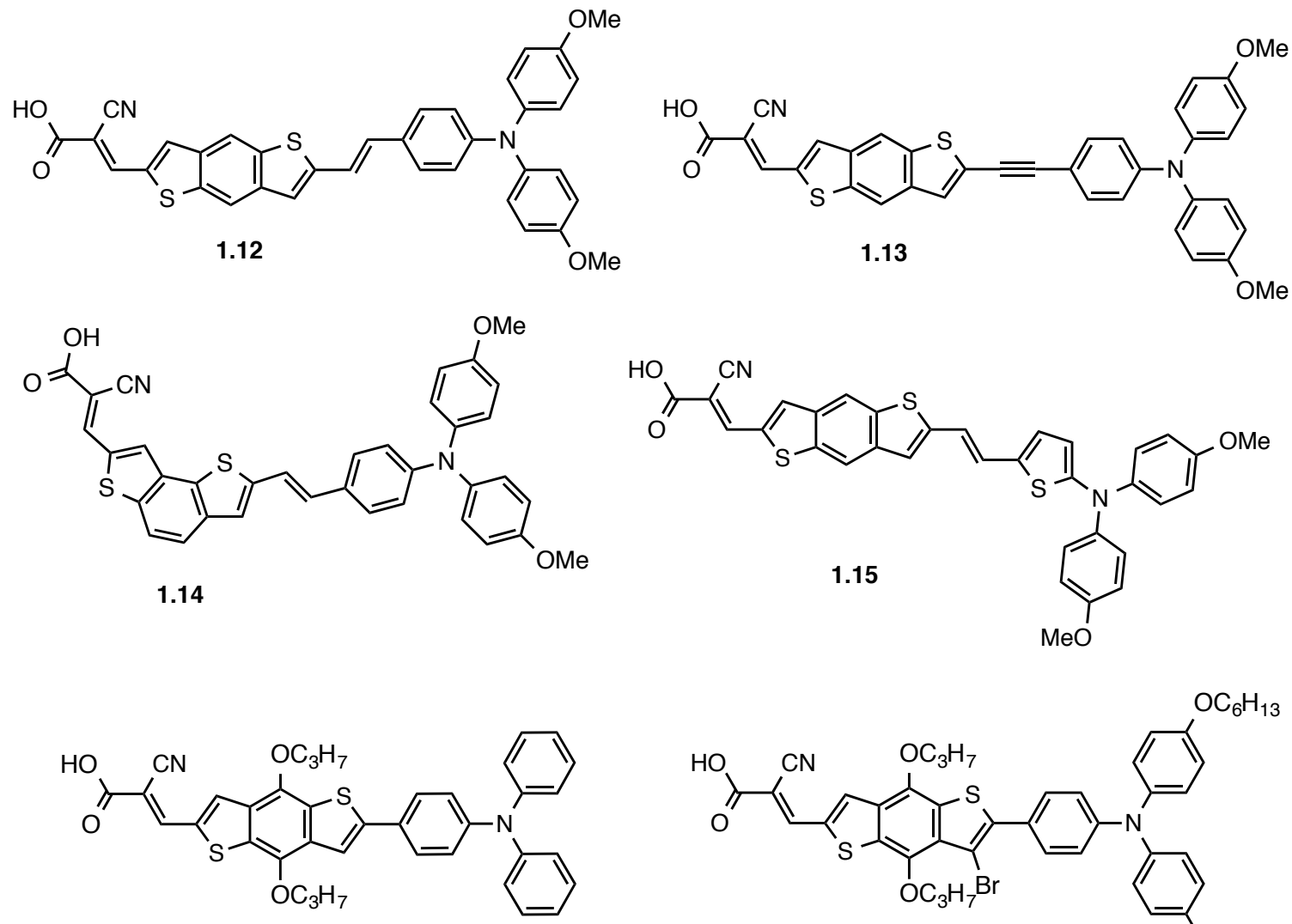

1.16

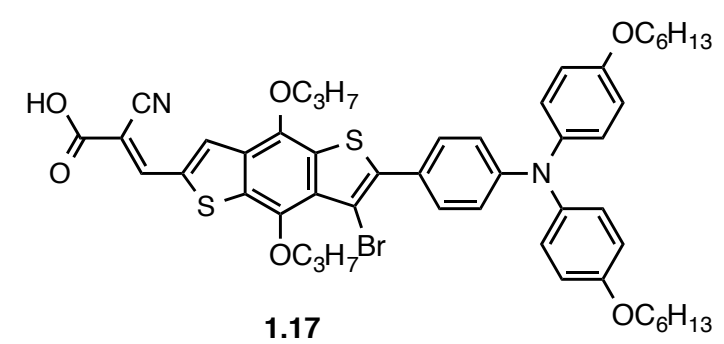



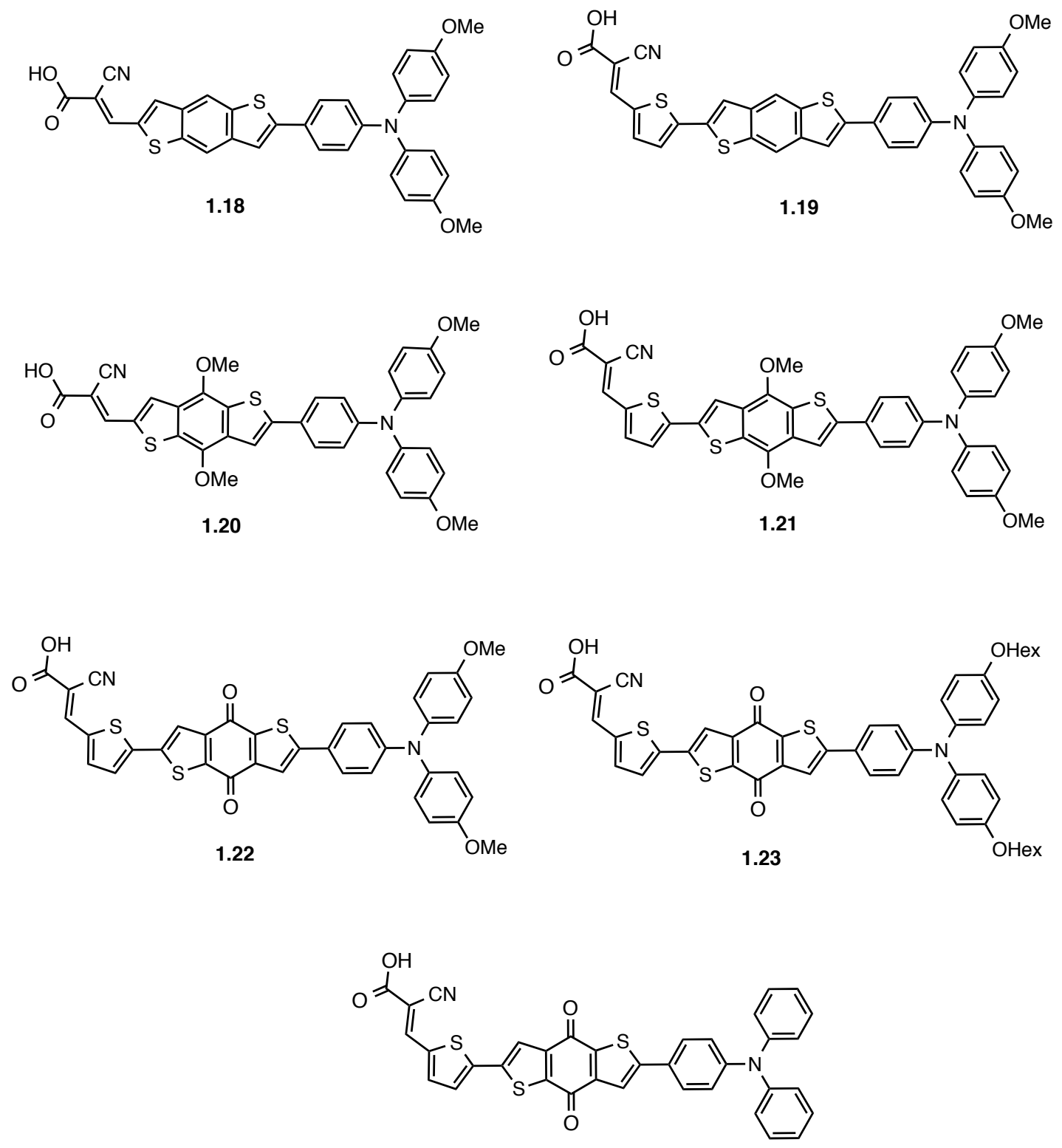

1.24 


\section{Appendix 2: Molecular index for chapter 2}

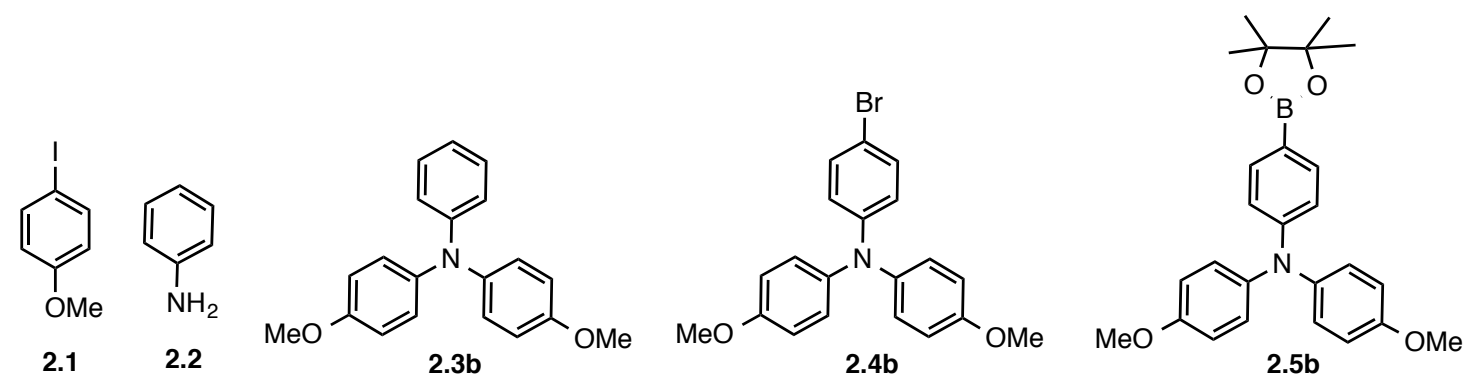

${ }^{\mathrm{Br}}{ }_{1}^{\mathrm{O}}$

2.6

2.7

2.8<smiles>Brc1ccc(Br)cc1</smiles>

2.9<smiles>Brc1cc(I)c(I)cc1Br</smiles>

2.10<smiles>C[Si](C)(C)C#Cc1cc(Br)c(C#C[Si](C)(C)C)cc1Br</smiles>

2.11<smiles>c1cc2cc3sccc3cc2s1</smiles>

2.12<smiles>Brc1cc2cc3sccc3cc2s1</smiles>

2.13<smiles>COc1ccc(N(c2ccc(OC)cc2)c2ccc(-c3cc4cc5sccc5cc4s3)cc2)cc1</smiles><smiles>COc1ccc(N(c2ccc(OC)cc2)c2ccc(-c3cc4cc5sc(Br)cc5cc4s3)cc2)cc1</smiles><smiles></smiles><smiles>COc1ccc(N(c2ccc(OC)cc2)c2ccc(-c3cc4cc5sc(-c6ccc(C=O)s6)cc5cc4s3)cc2)cc1</smiles> 
<smiles>O=C(Cl)c1ccsc1</smiles>

2.20<smiles>CN(C)C(=O)c1ccsc1</smiles>

2.21<smiles>O=CC1=C2C=CC=C2C(=O)C2C=C[SH]=C12</smiles>

2.22<smiles>COc1c2ccsc2c(OC)c2ccsc12</smiles>

2.23<smiles>COc1c2cc(Br)sc2c(OC)c2ccsc12</smiles>

2.24<smiles>COc1ccc(N(c2ccc(OC)cc2)c2ccc(-c3cc4c(OC)c5sc(C=O)cc5c(OC)c4s3)cc2)cc1</smiles><smiles>COc1ccc(N(c2ccc(OC)cc2)c2ccc(-c3cc4c(OC)c5sc(Br)cc5c(OC)c4s3)cc2)cc1</smiles>

$\mathrm{MeO}$<smiles>COc1ccc(N(c2ccc(OC)cc2)c2ccc(-c3cc4c(OC)c5sc(-c6ccc(C7OCCO7)s6)cc5c(OC)c4s3)cc2)cc1</smiles><smiles>COc1ccc(N(c2ccc(OC)cc2)c2ccc(-c3cc4c(OC)c5sc(-c6ccc(C=O)s6)cc5c(OC)c4s3)cc2)cc1</smiles><smiles>O=C(O)c1ccsc1</smiles><smiles>O=C(O)c1csc(Br)c1</smiles><smiles>O=C(Cl)c1csc(Br)c1</smiles><smiles>CN(C)C(=O)c1csc(Br)c1</smiles><smiles>O=C1c2cc(Br)sc2C(=O)c2cc(Br)sc21</smiles><smiles>[111In]</smiles>

2.32

$$
2.33
$$

2.34

OMe 2.35<smiles>O=C1c2cc(-c3ccc(C4OCCO4)s3)sc2C(=O)c2cc(Br)sc21</smiles><smiles>CC=C(C)C1OCCO1</smiles>

2.36<smiles>COc1ccc(N(c2ccc(OC)cc2)c2ccc(-c3cc4c(s3)C(=O)c3sc(-c5ccc(C=O)s5)cc3C4=O)cc2)cc1</smiles> 

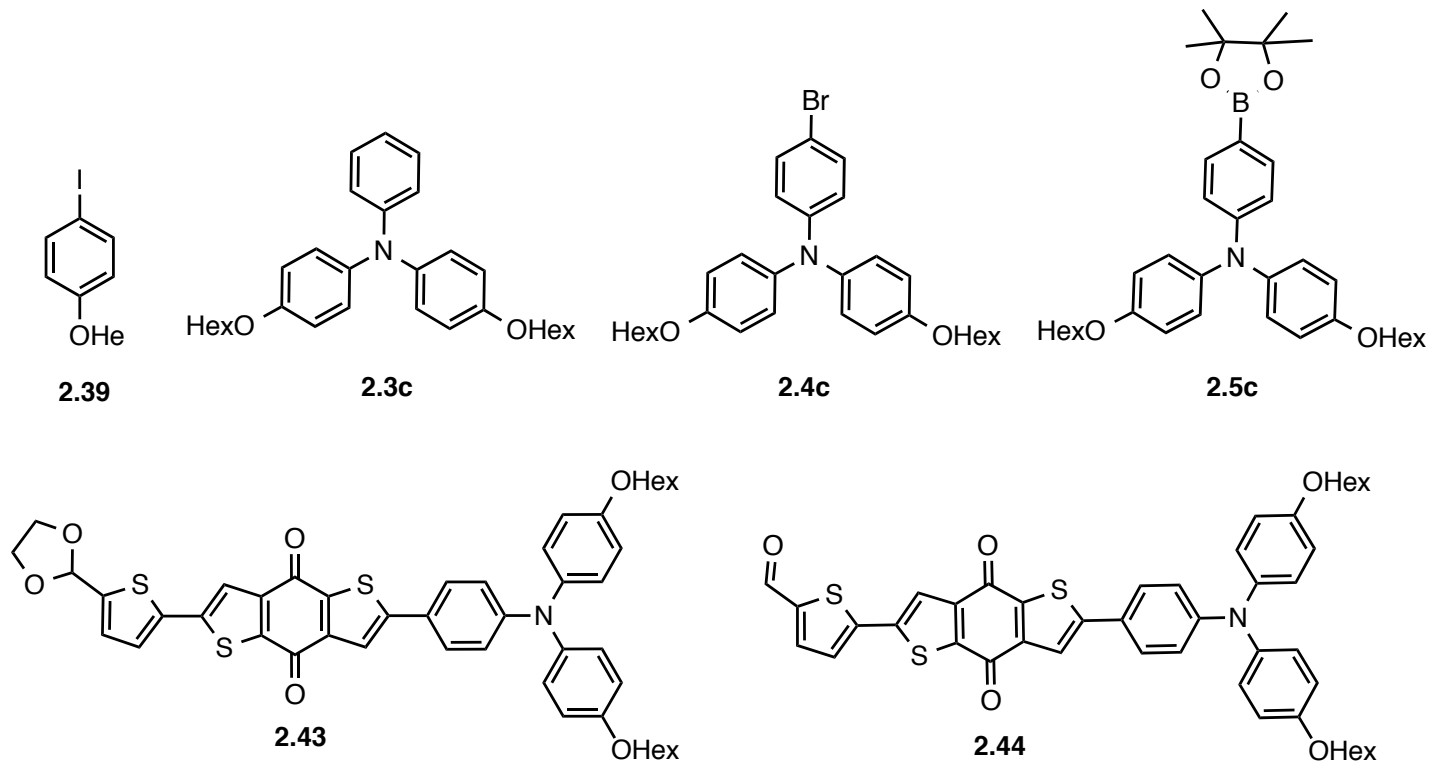

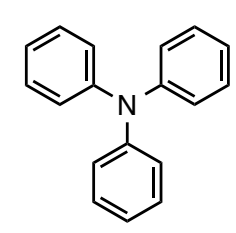

2.3a

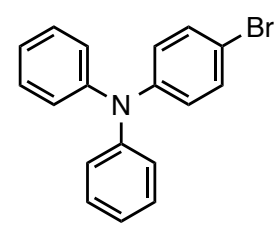

2.4a
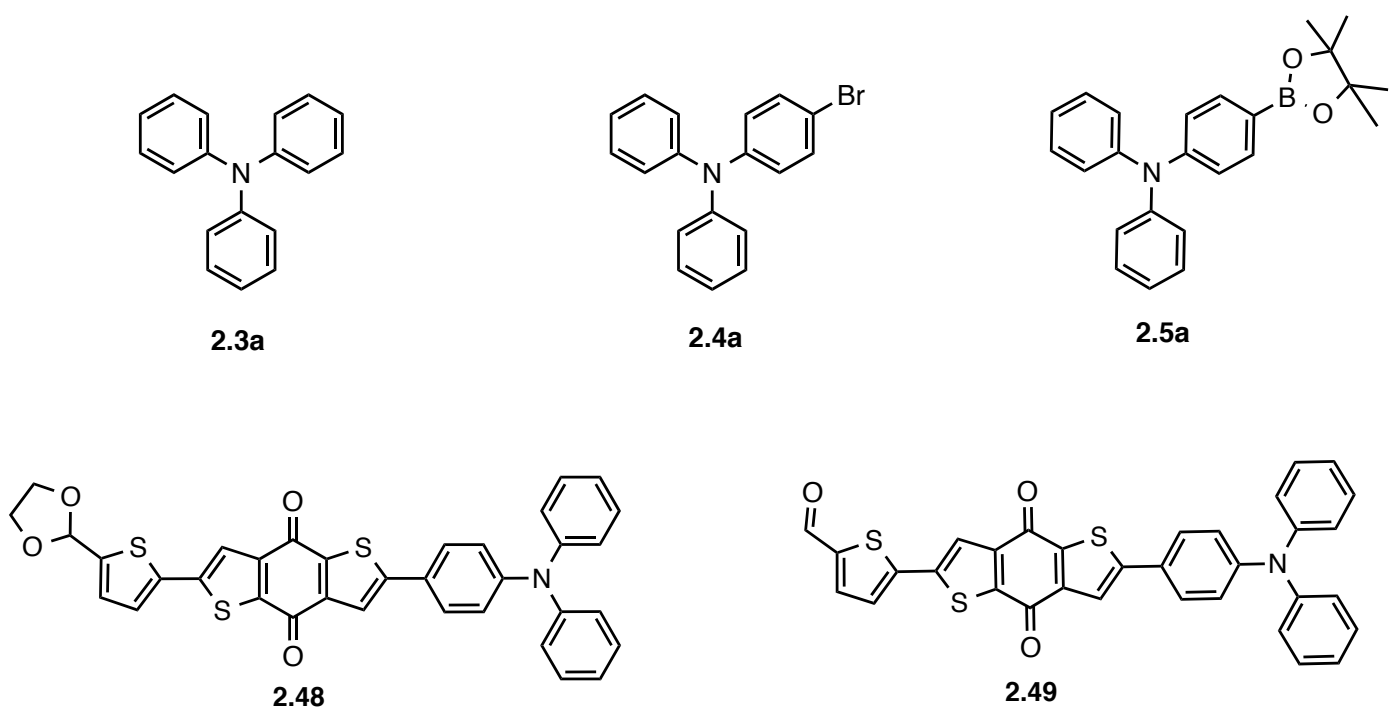
NMR Data
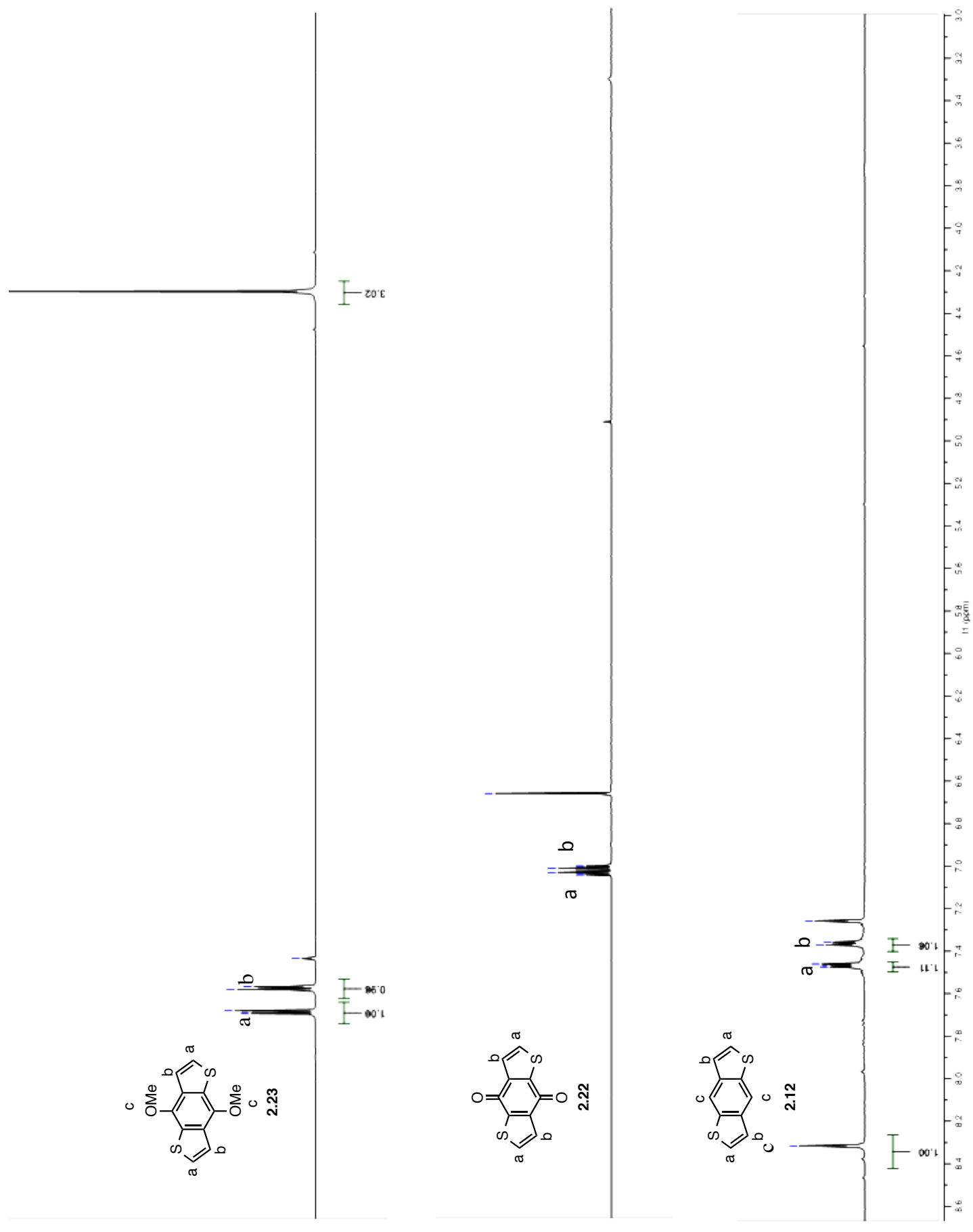


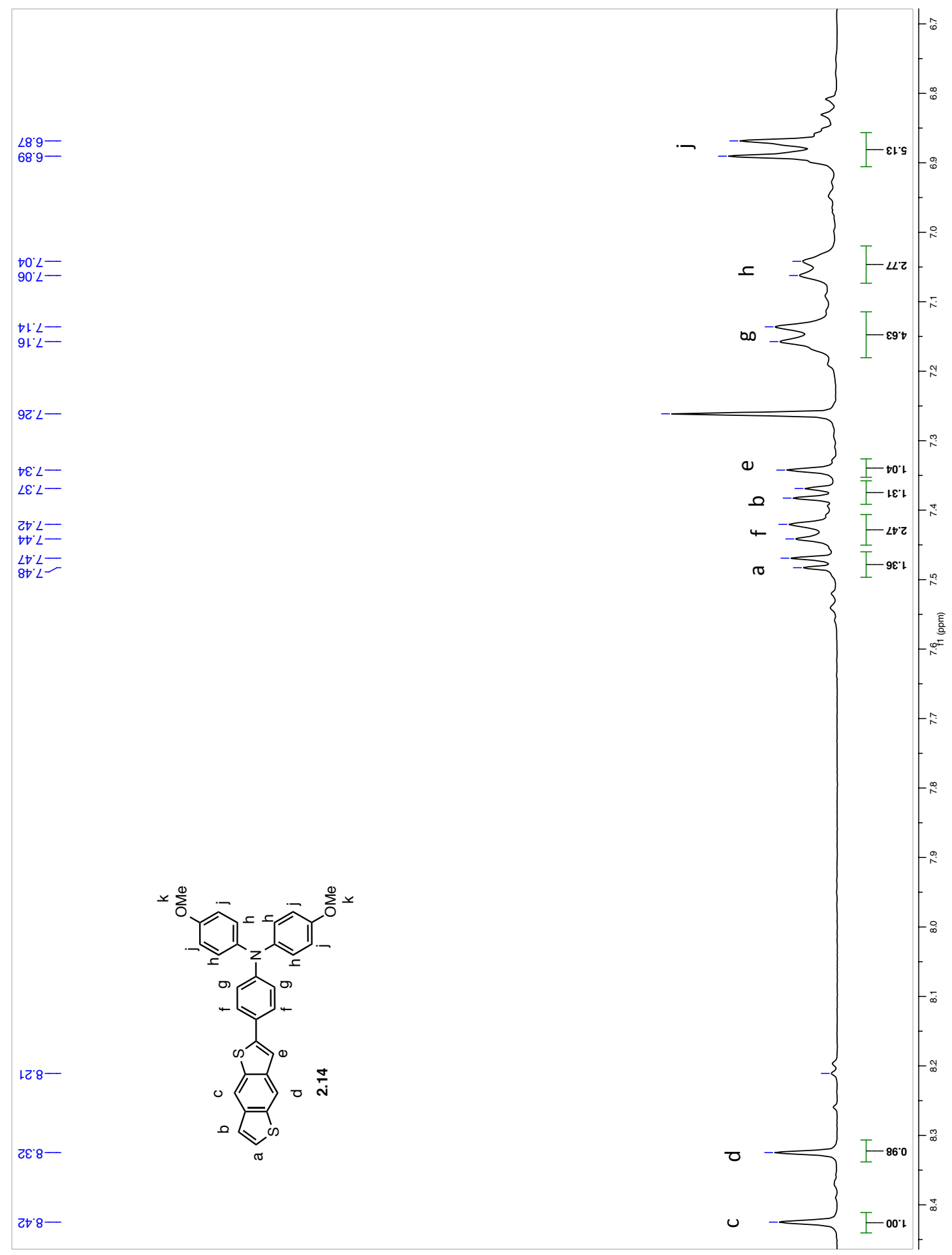




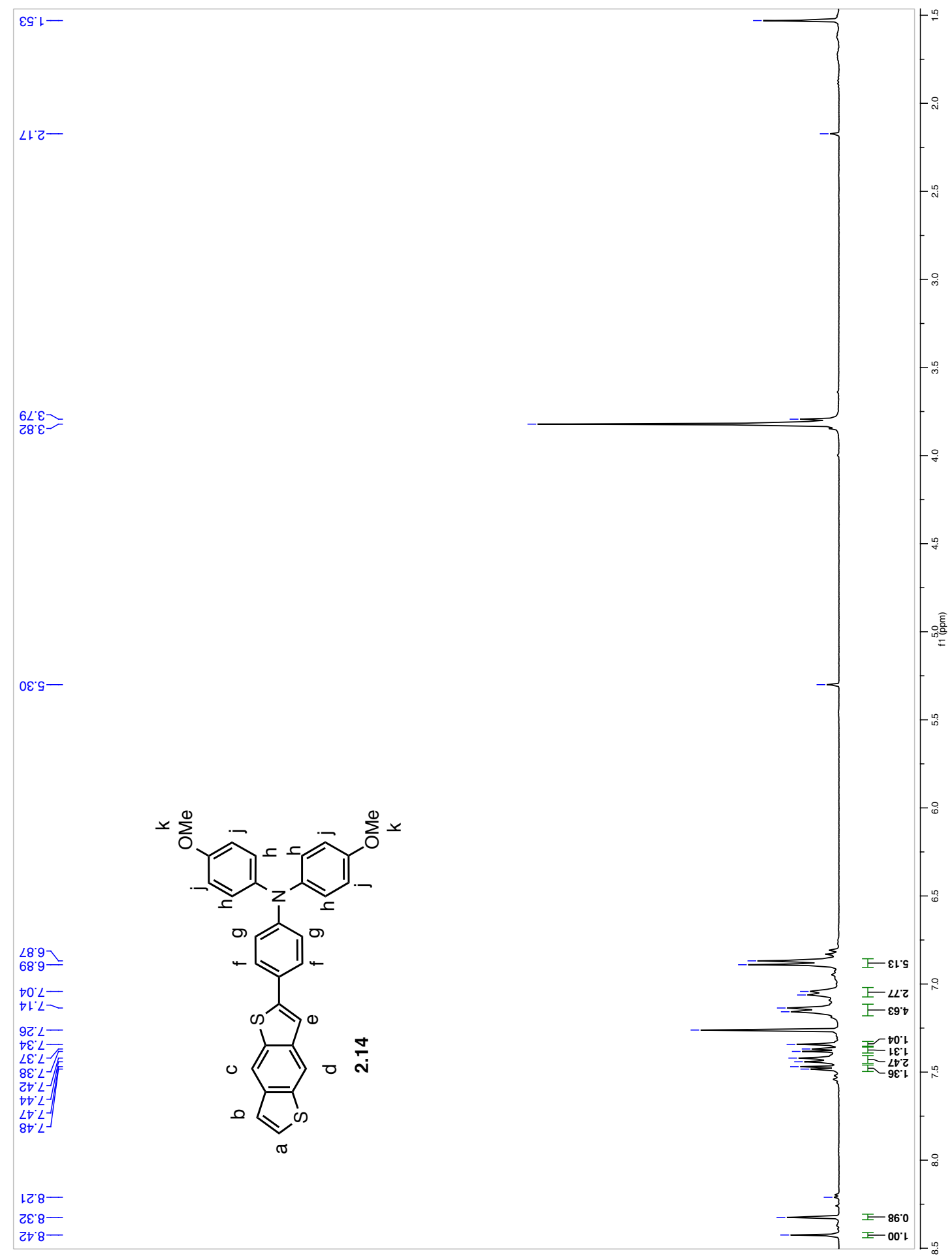




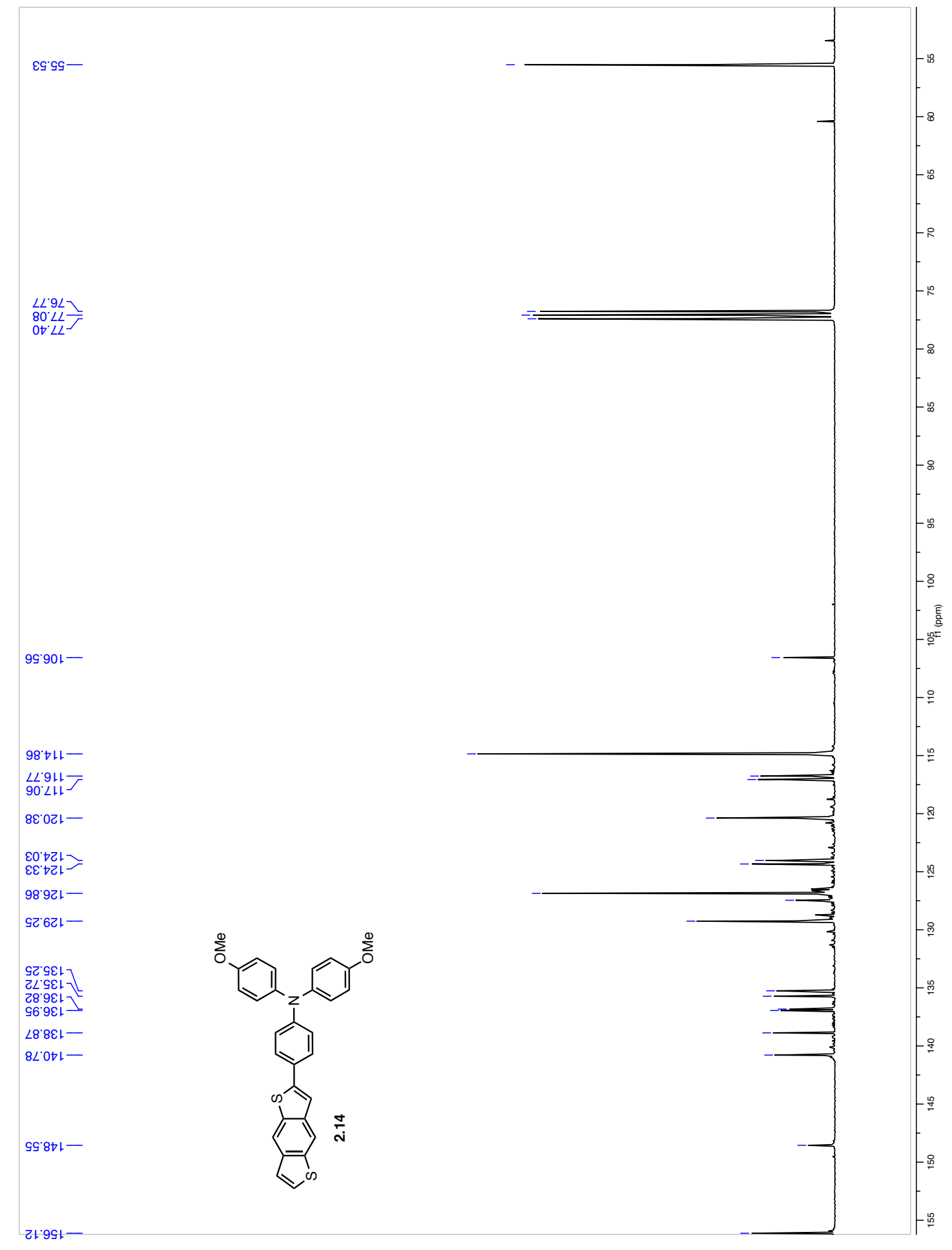



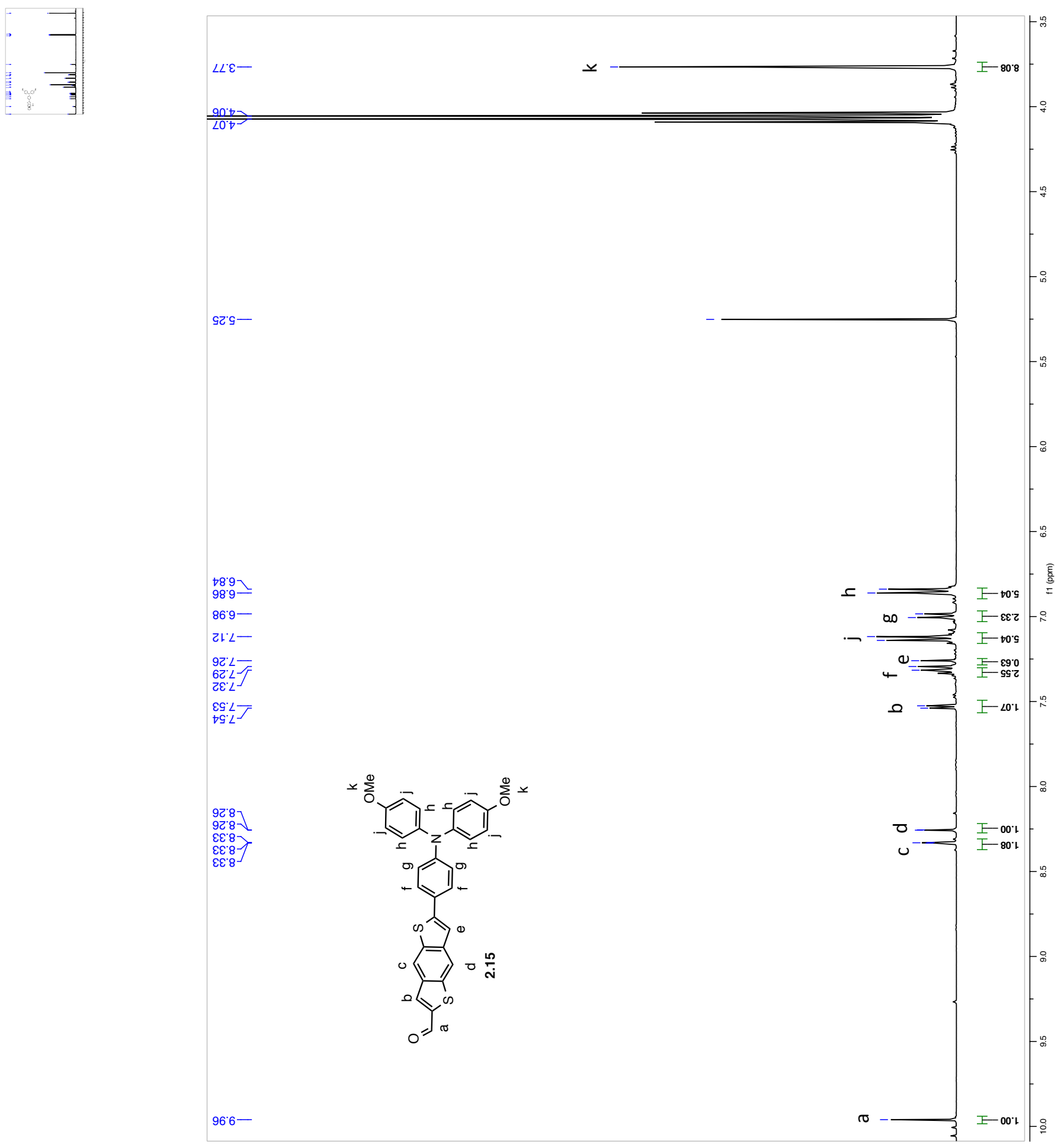


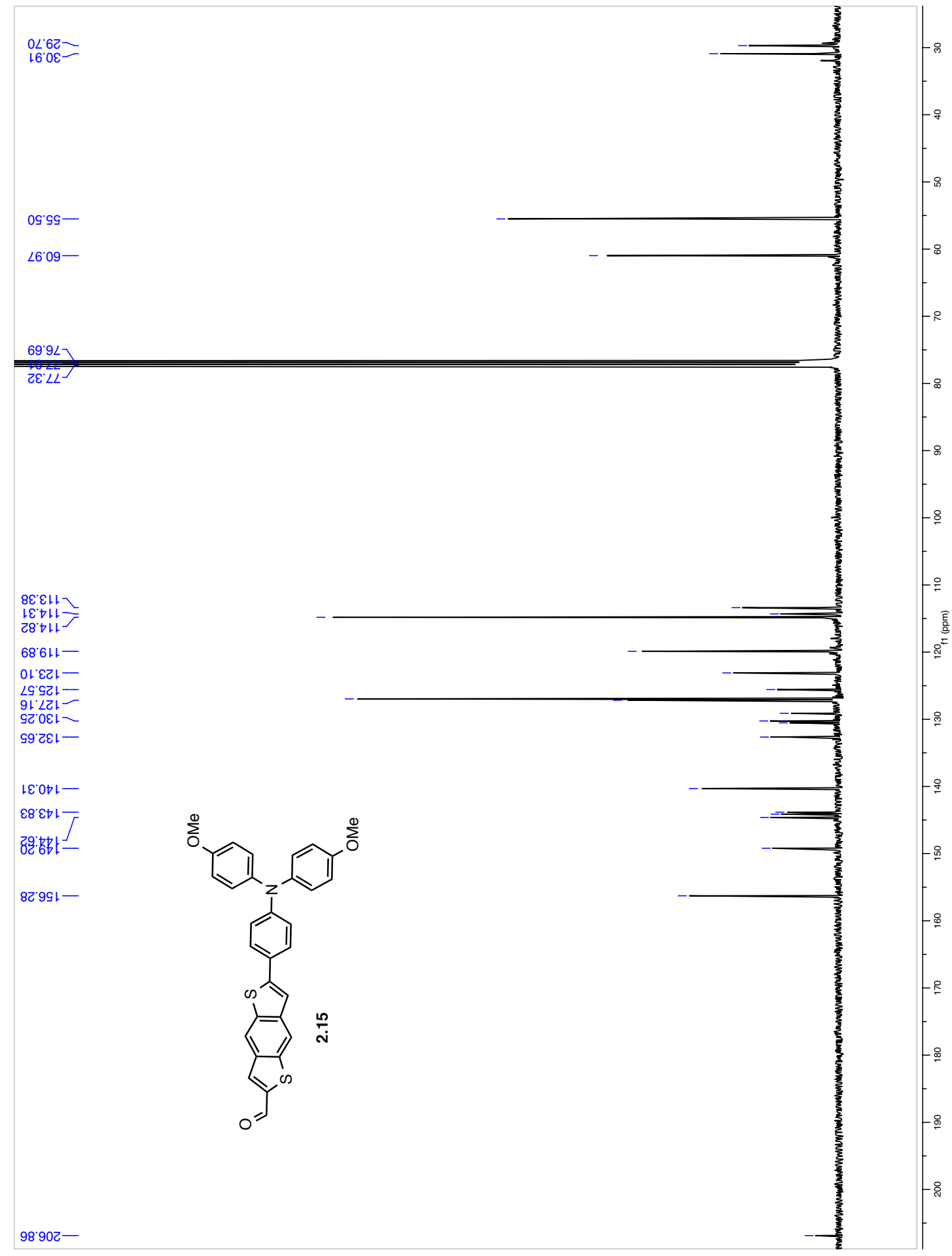




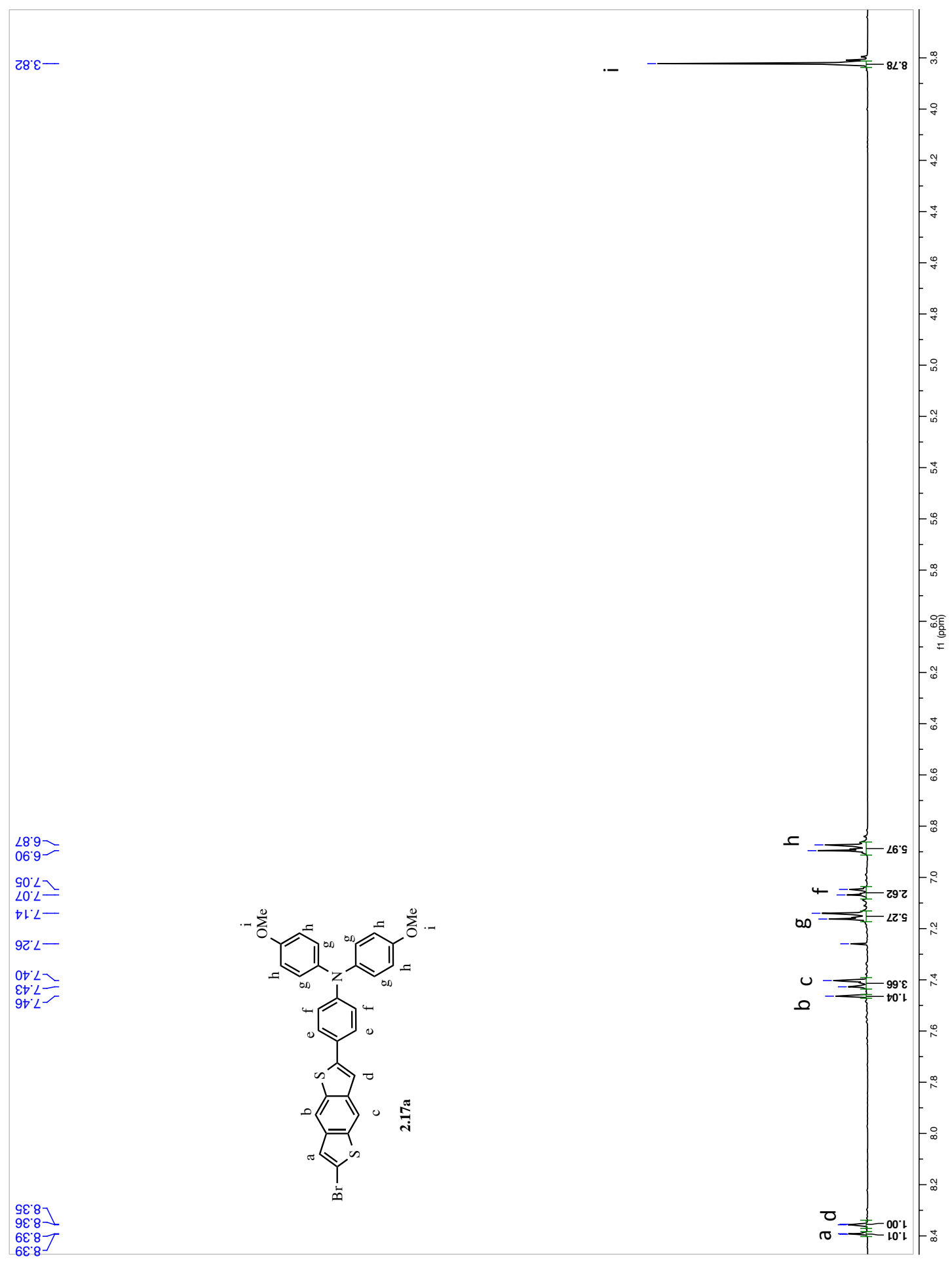




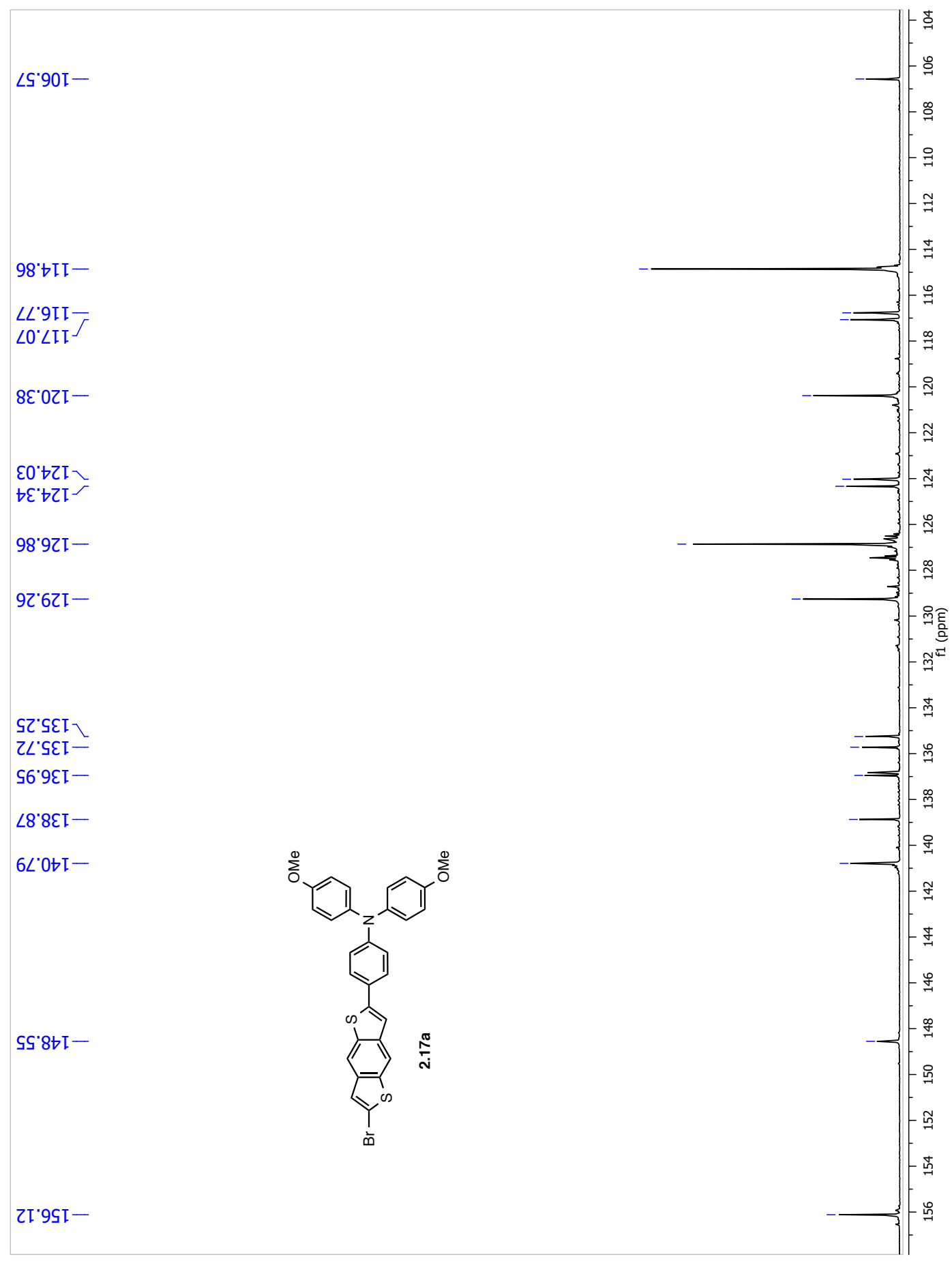




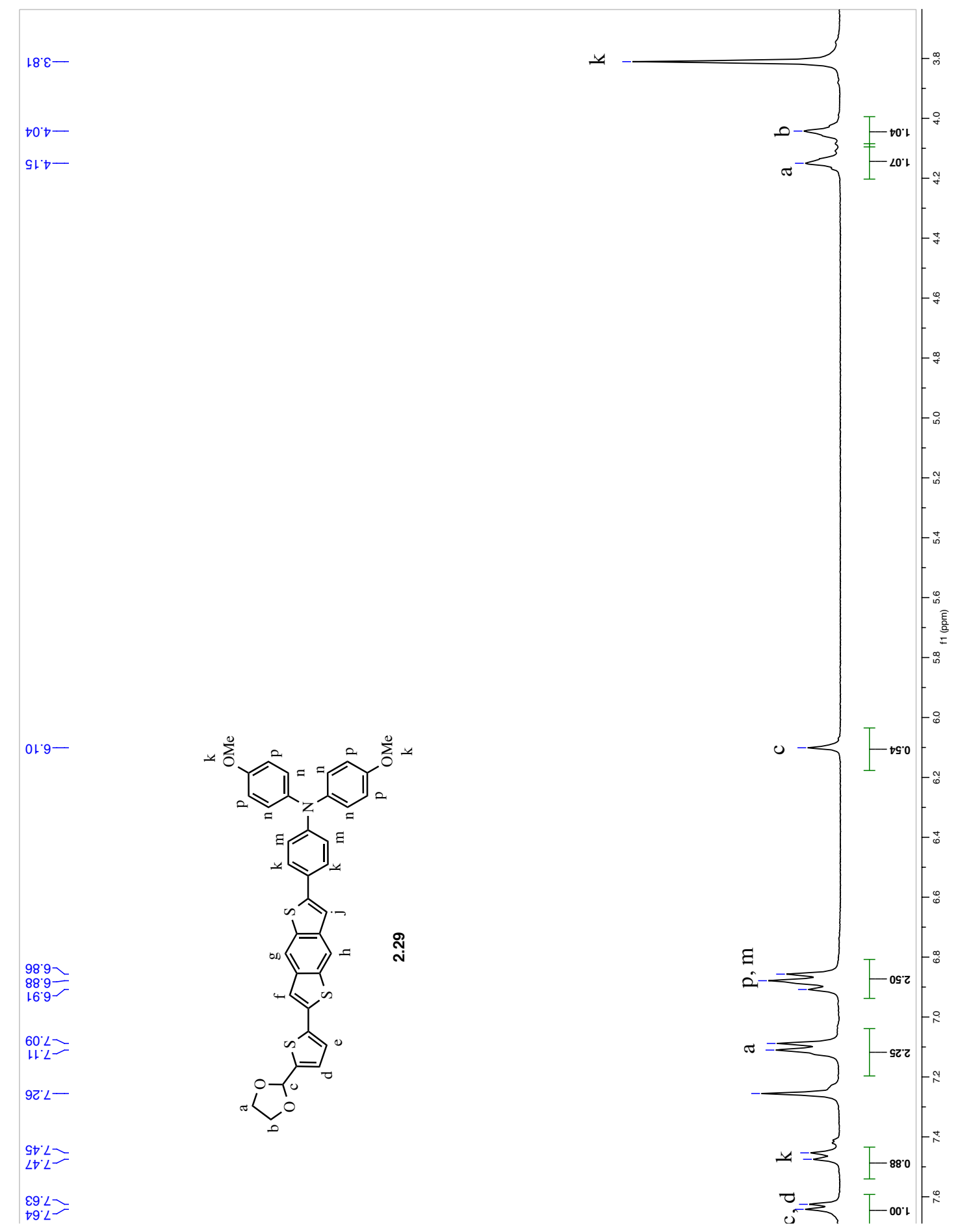




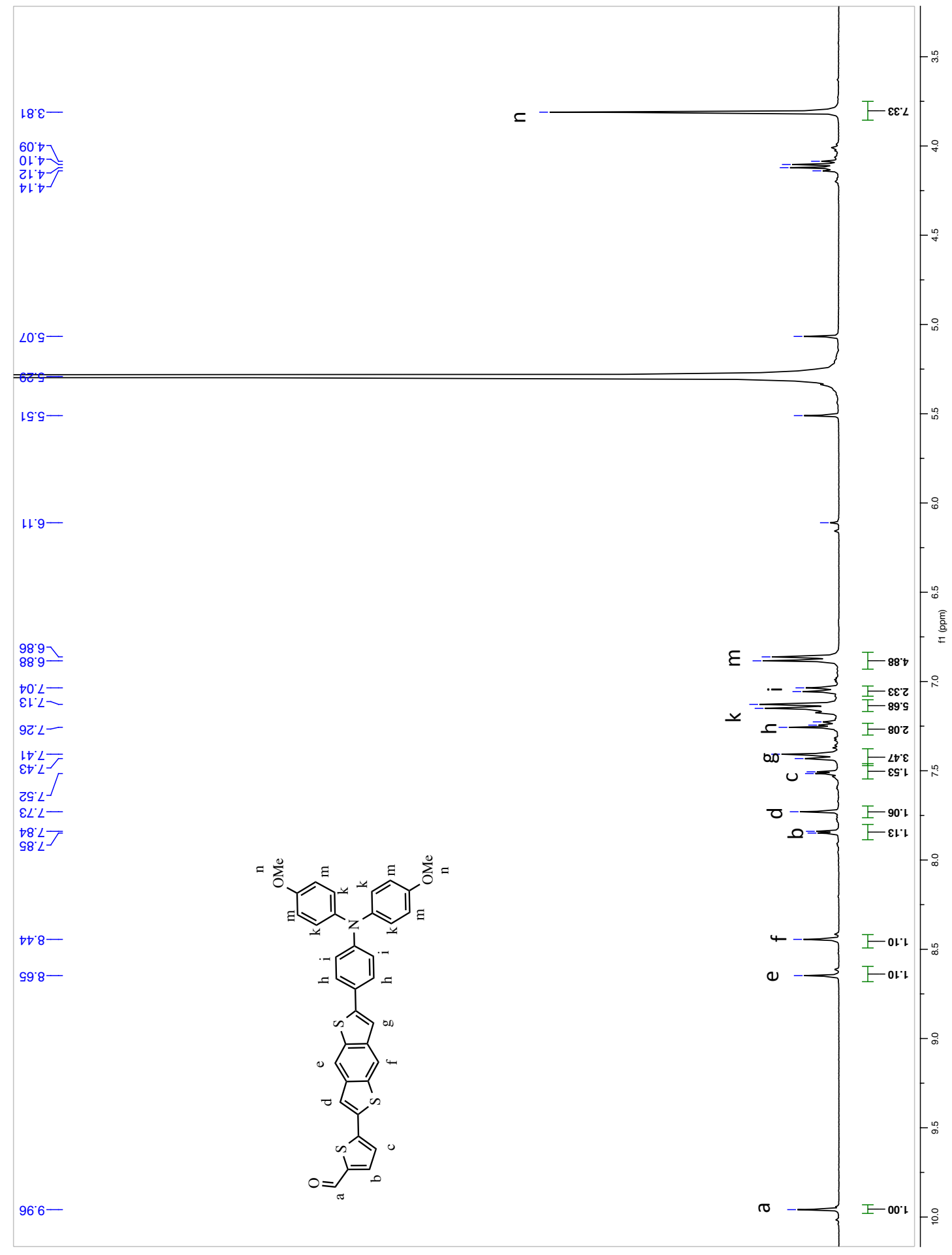




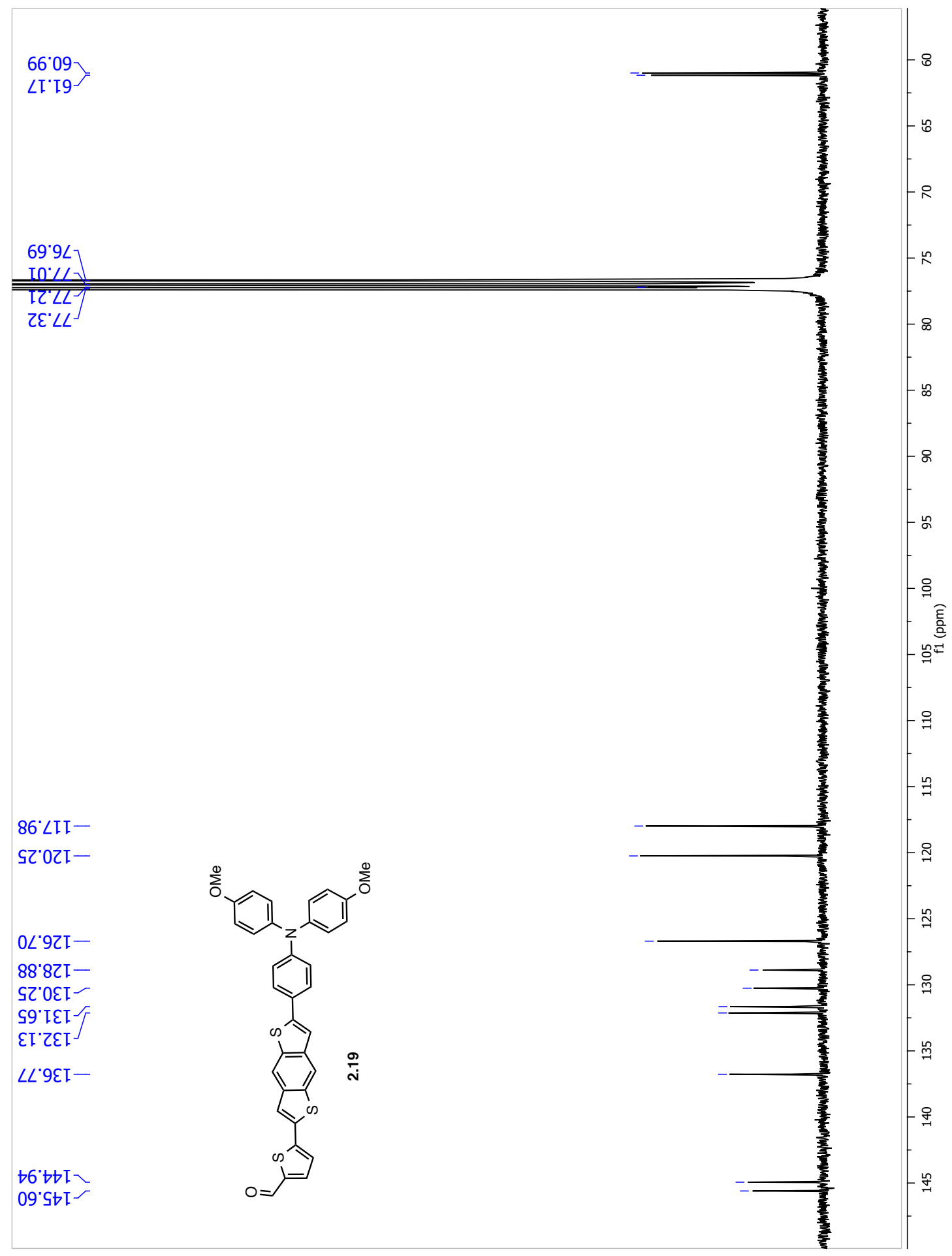




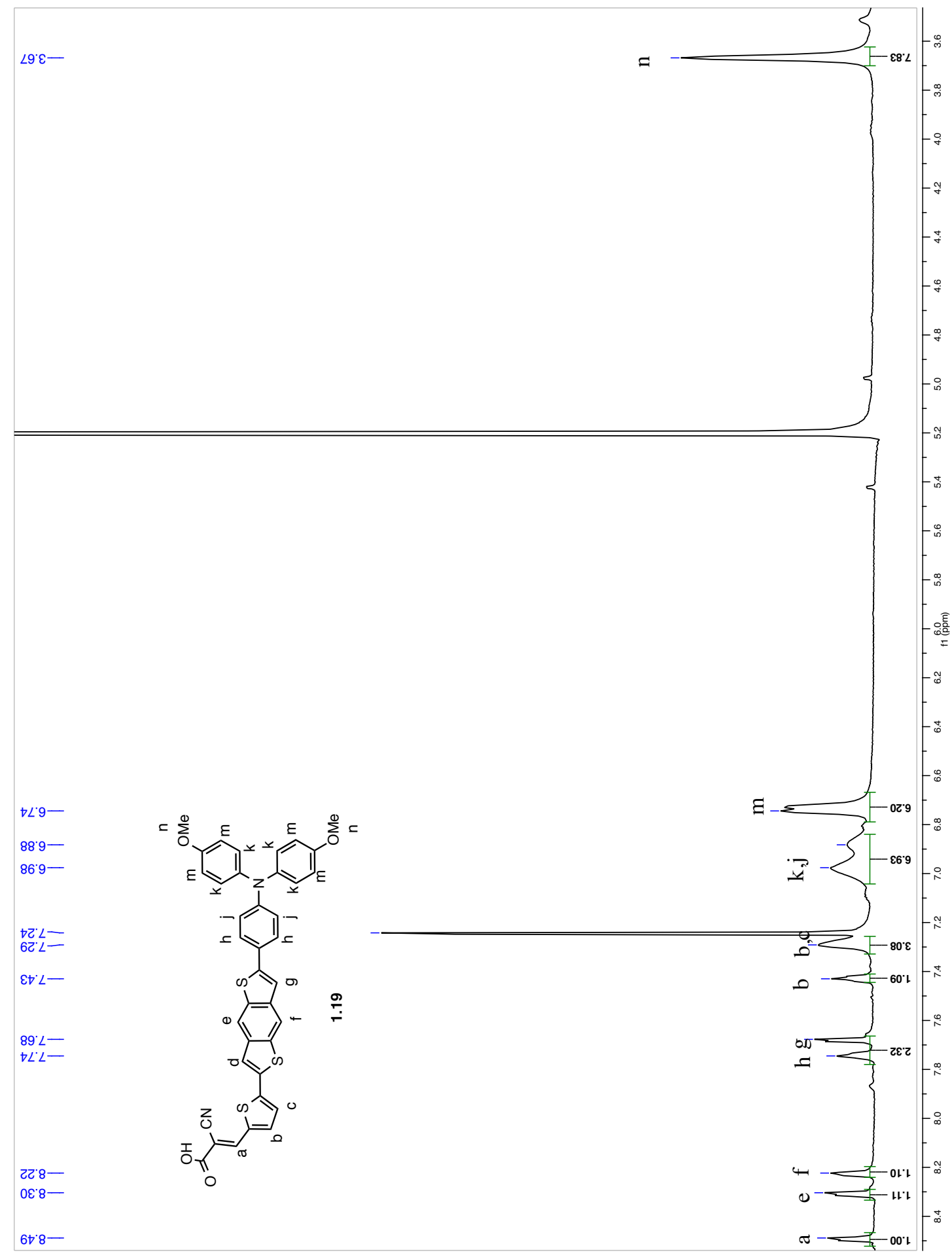




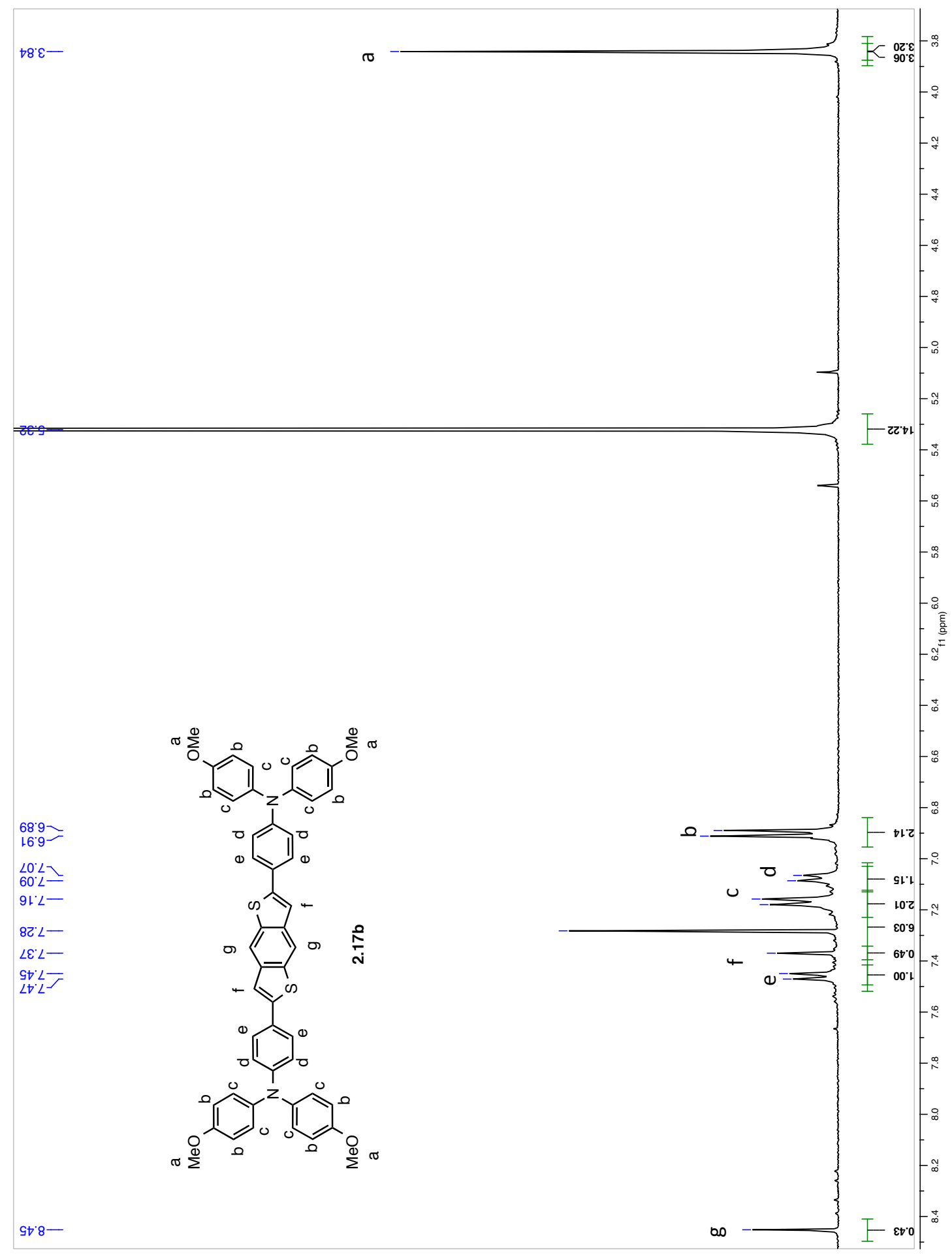




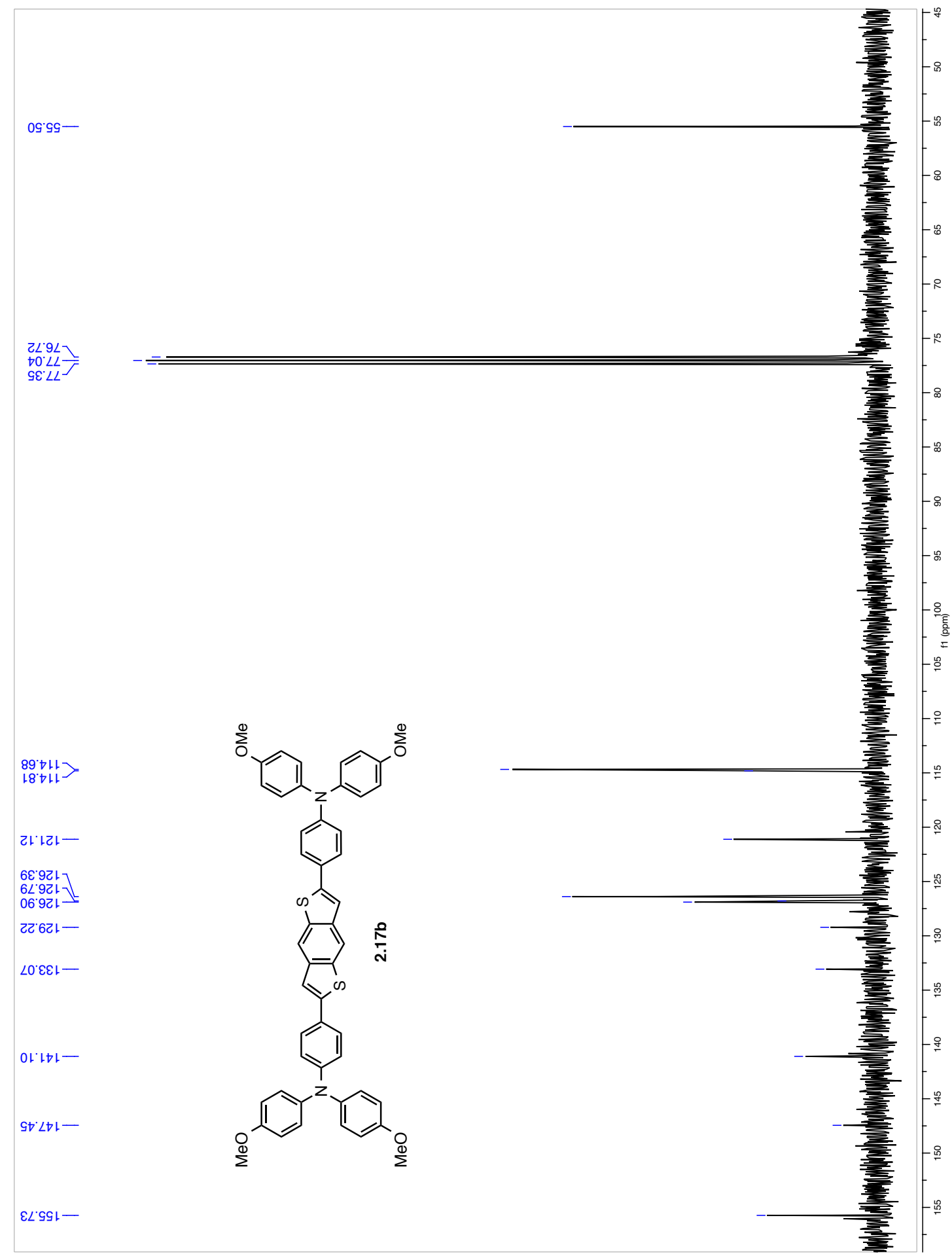




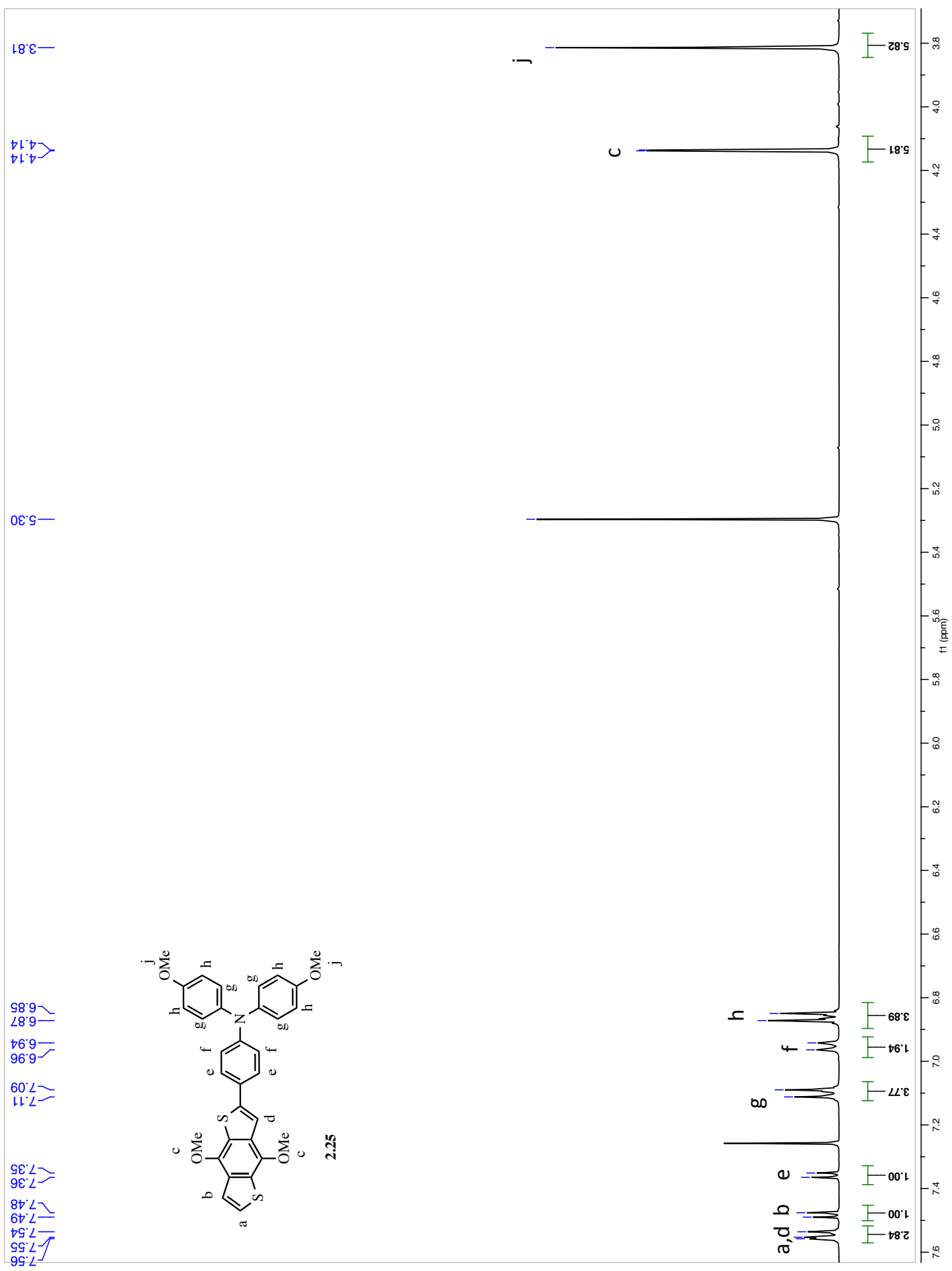




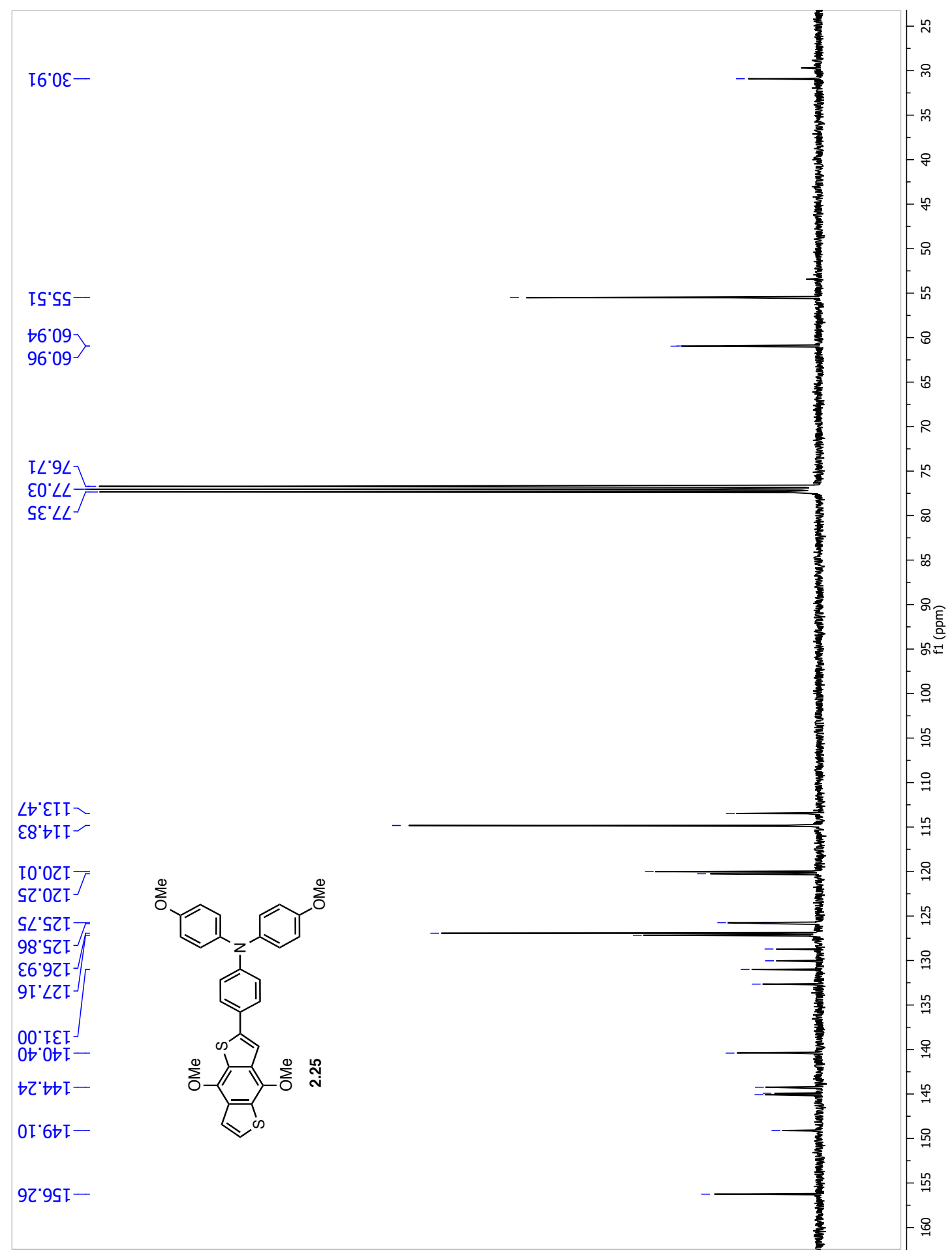




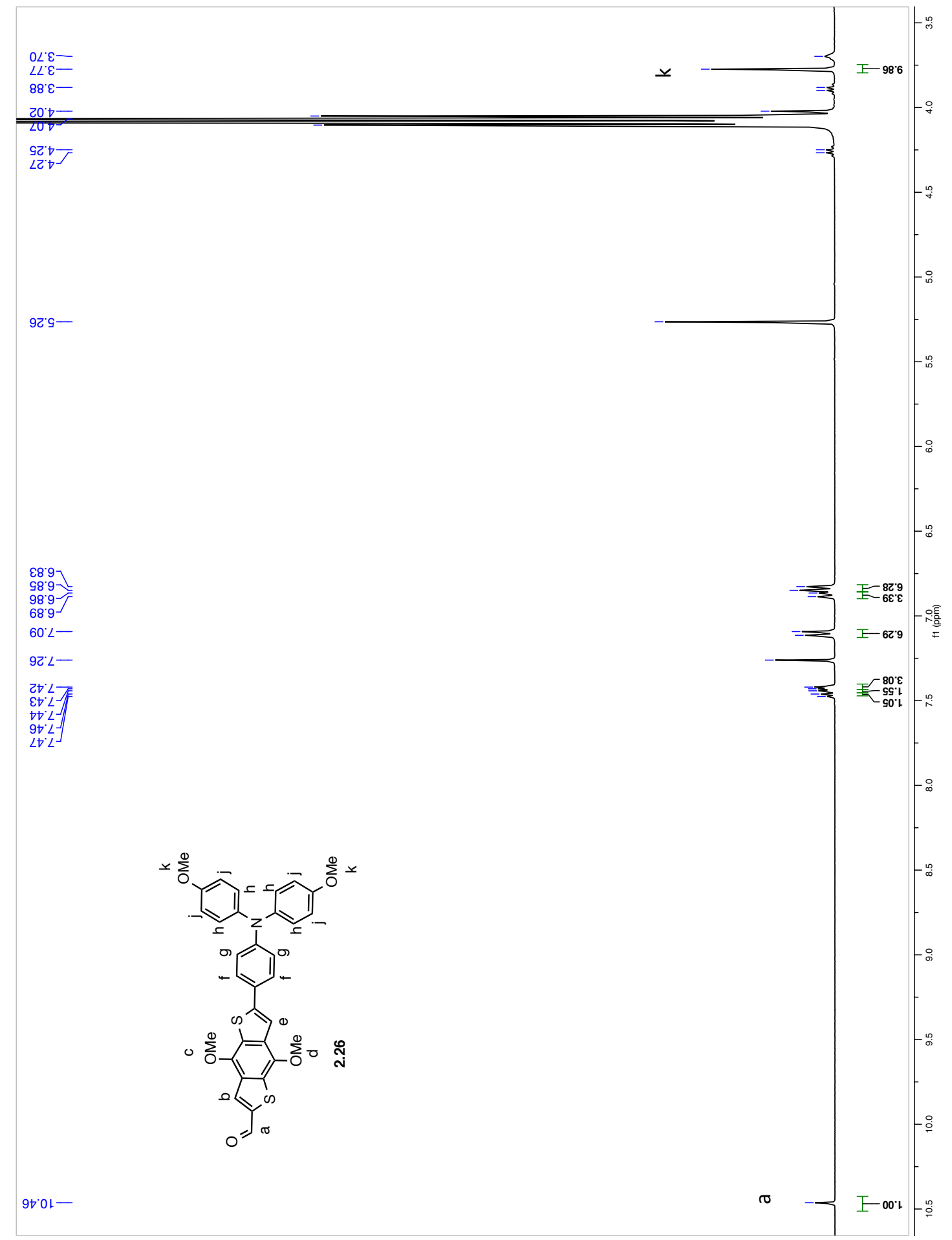




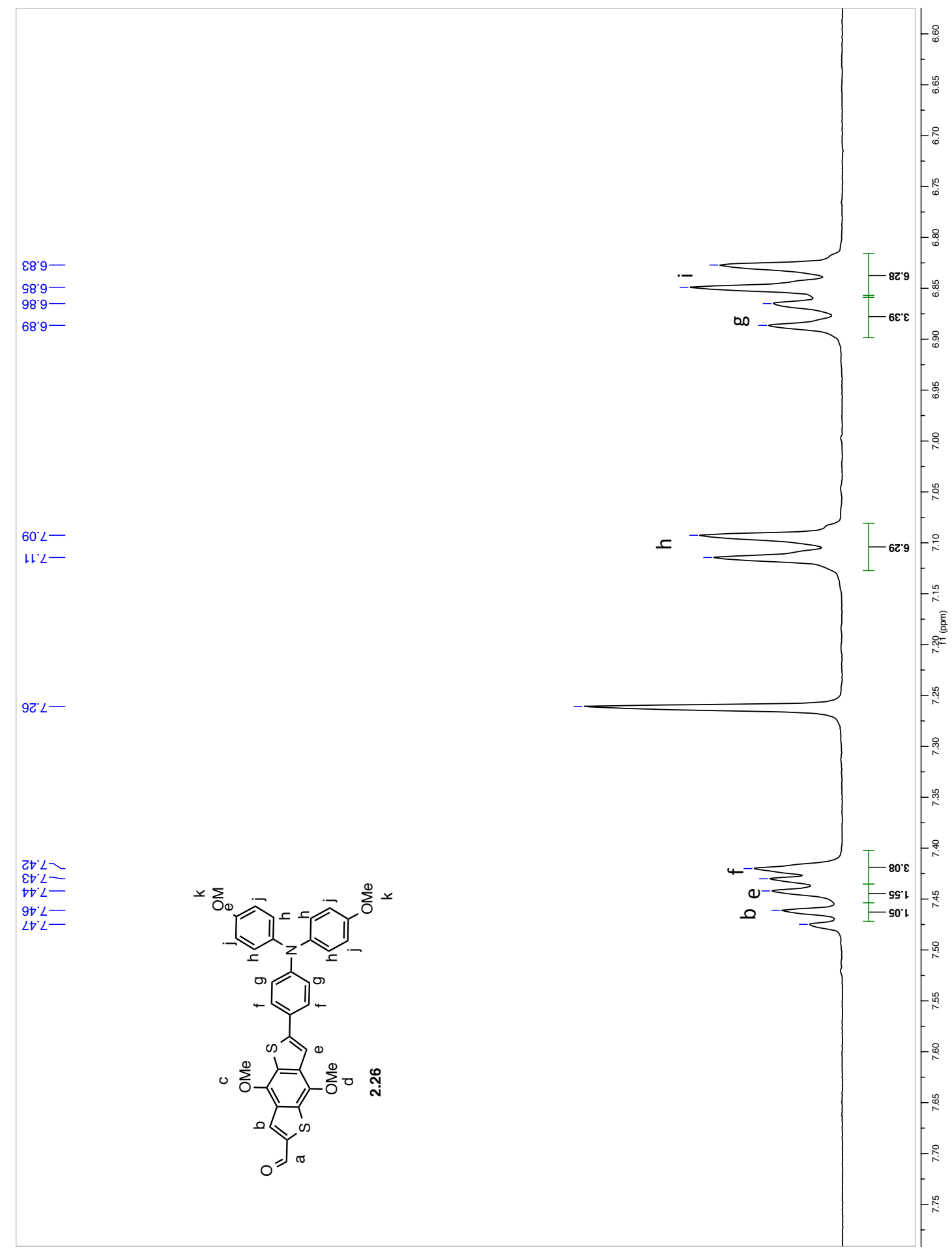




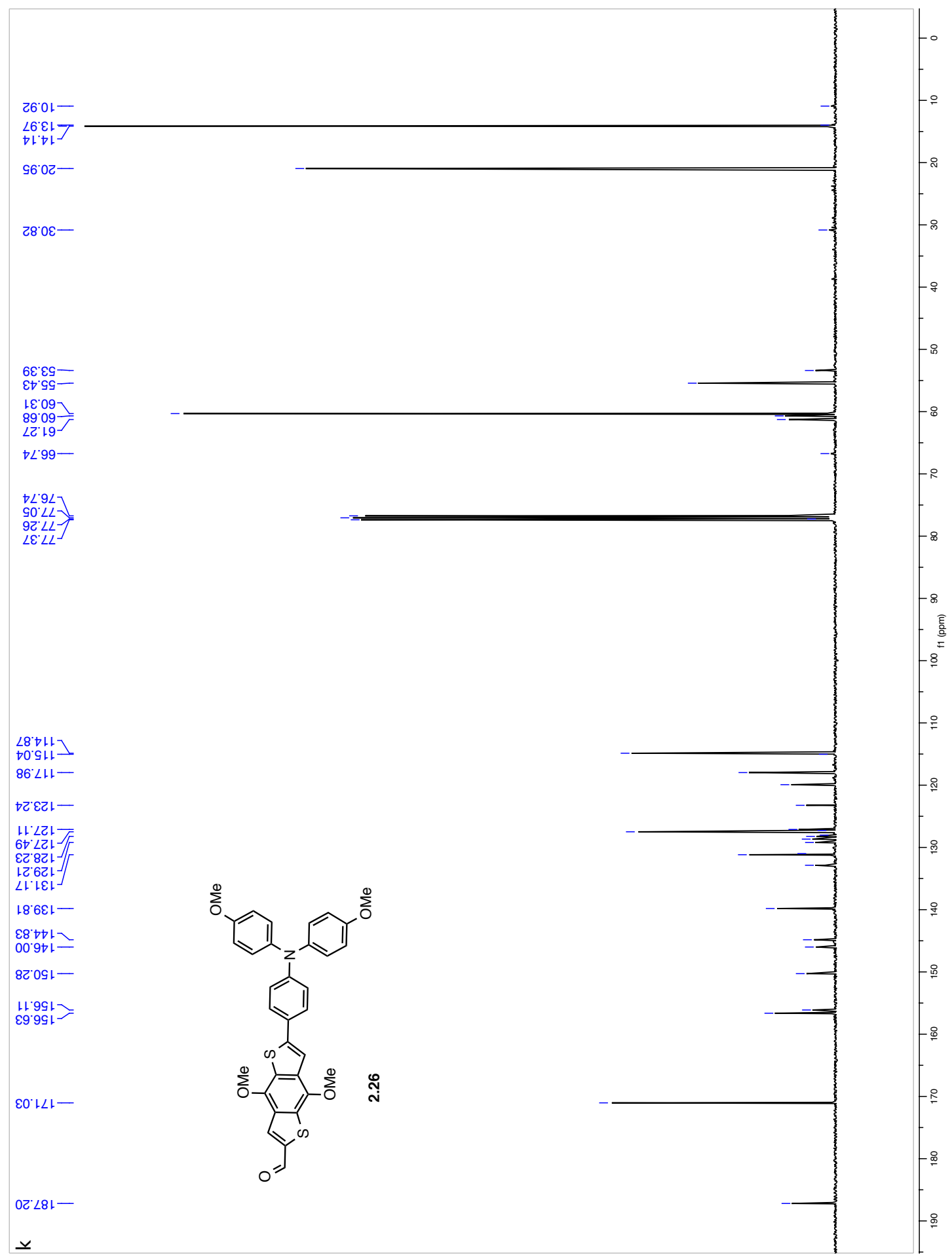




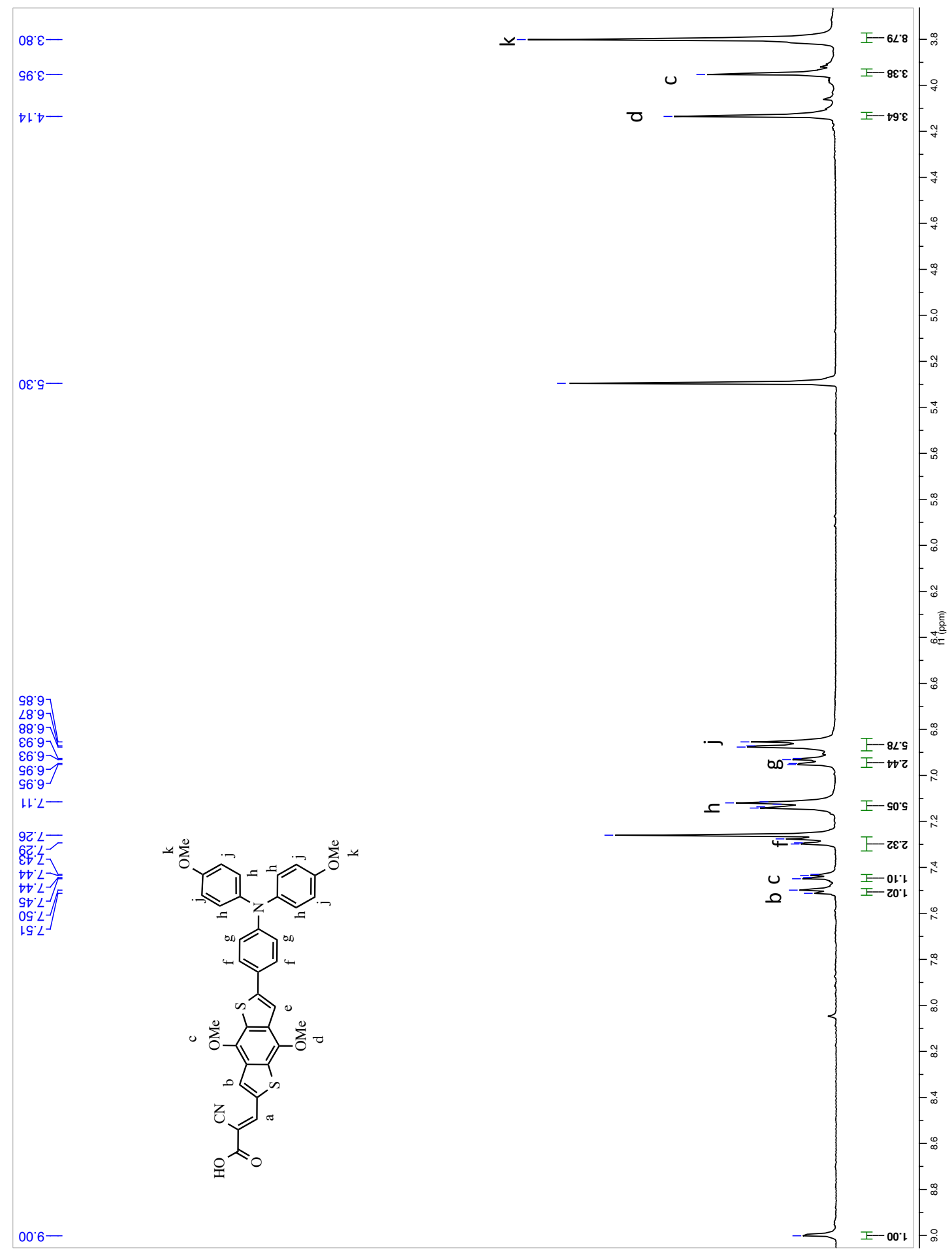




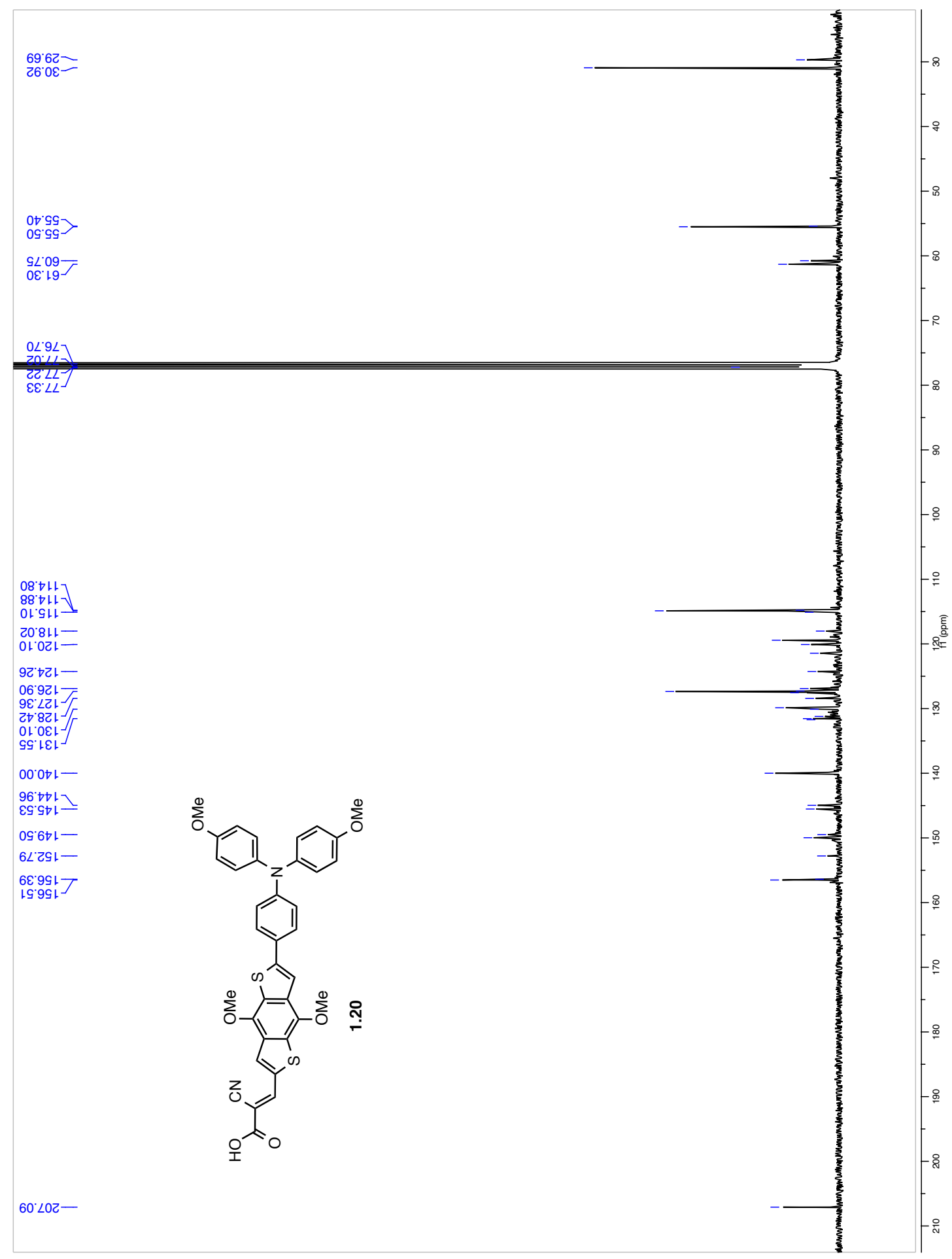




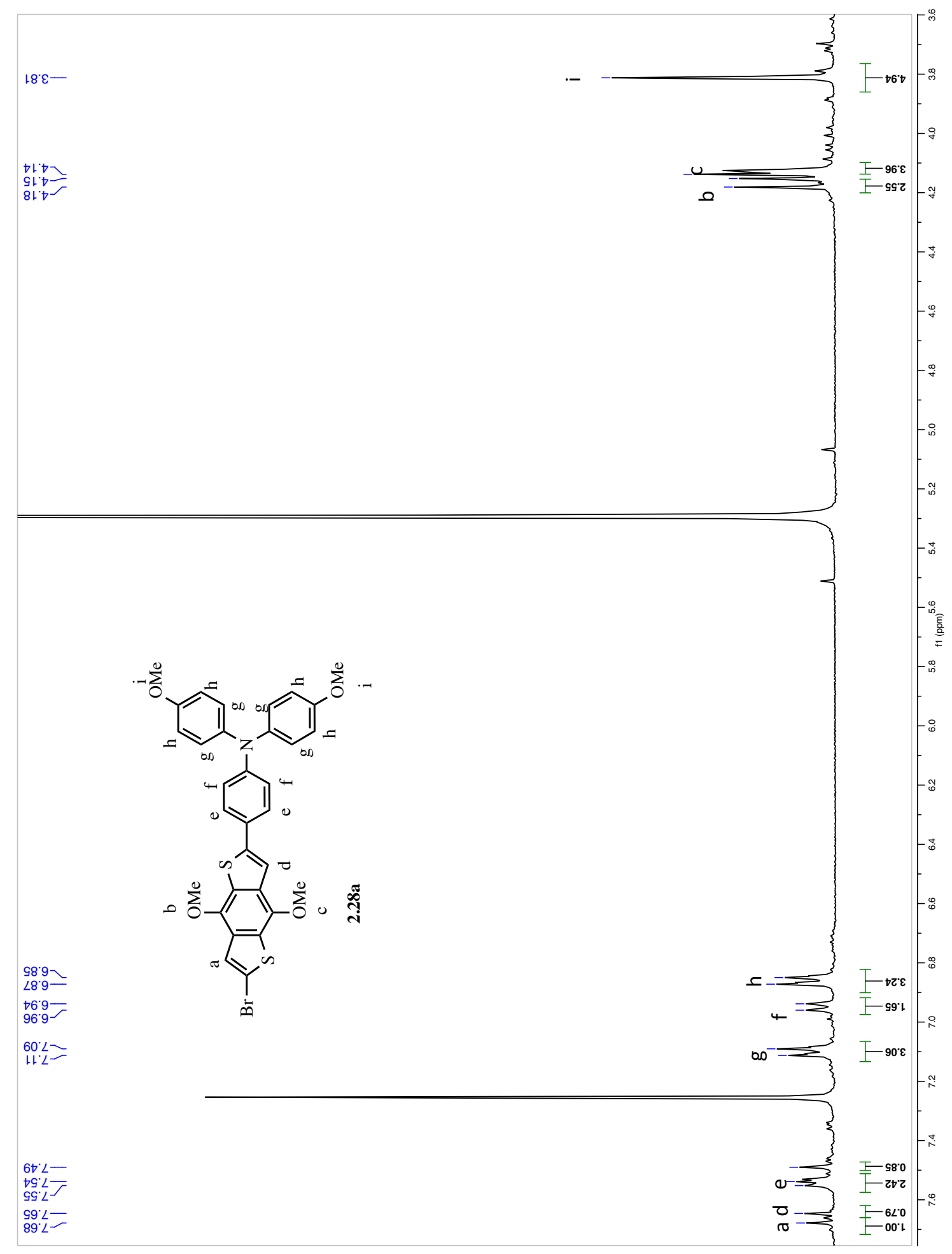




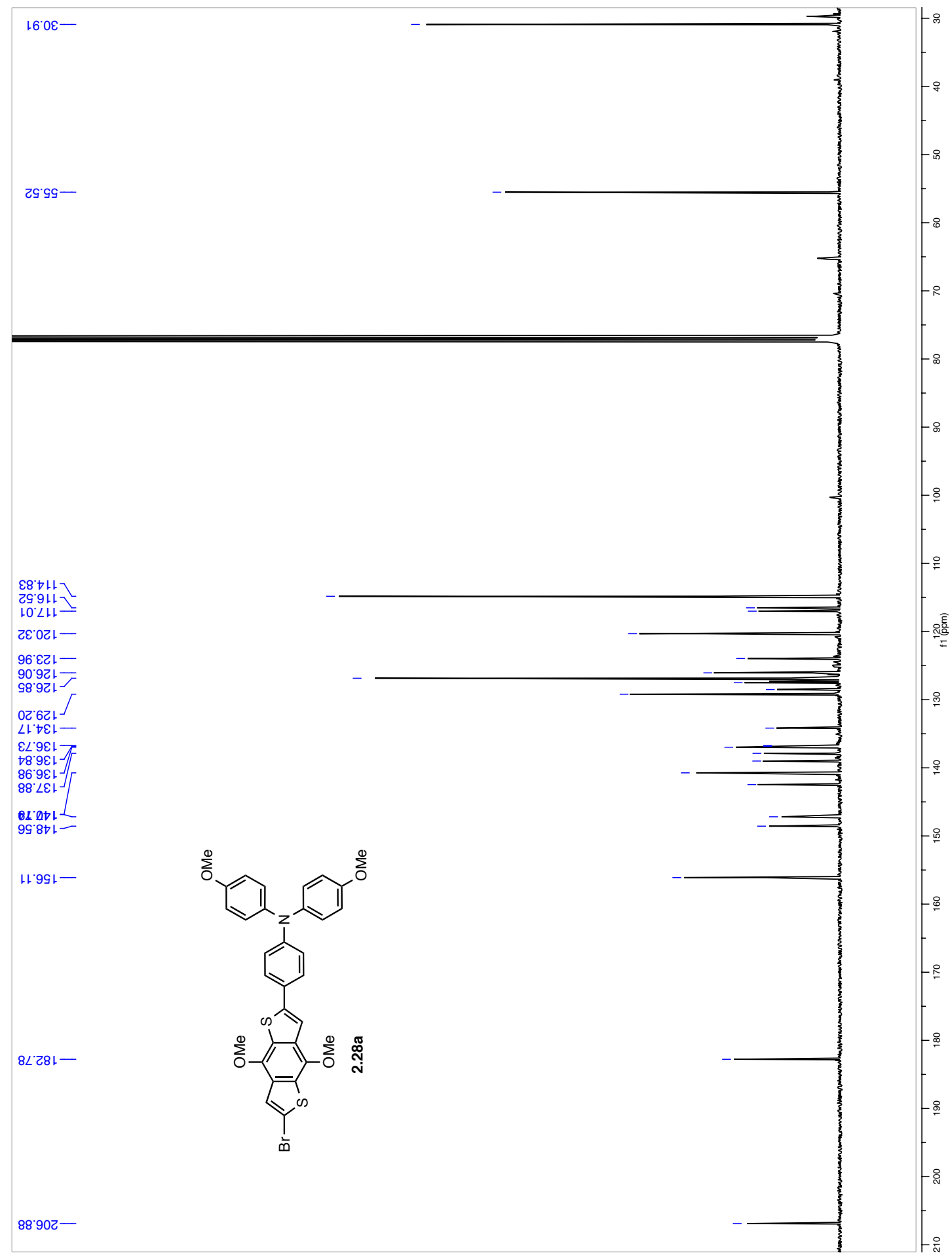




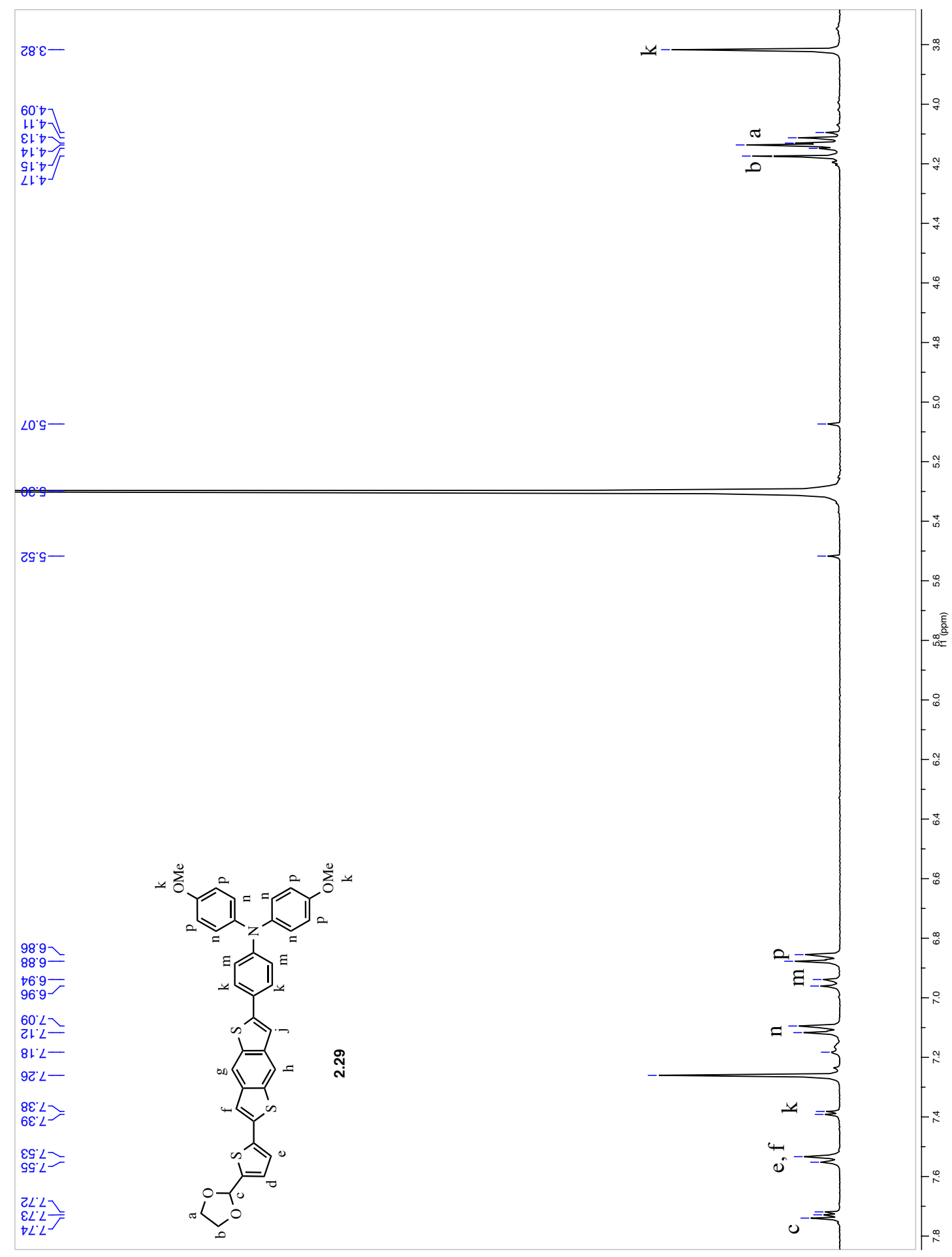




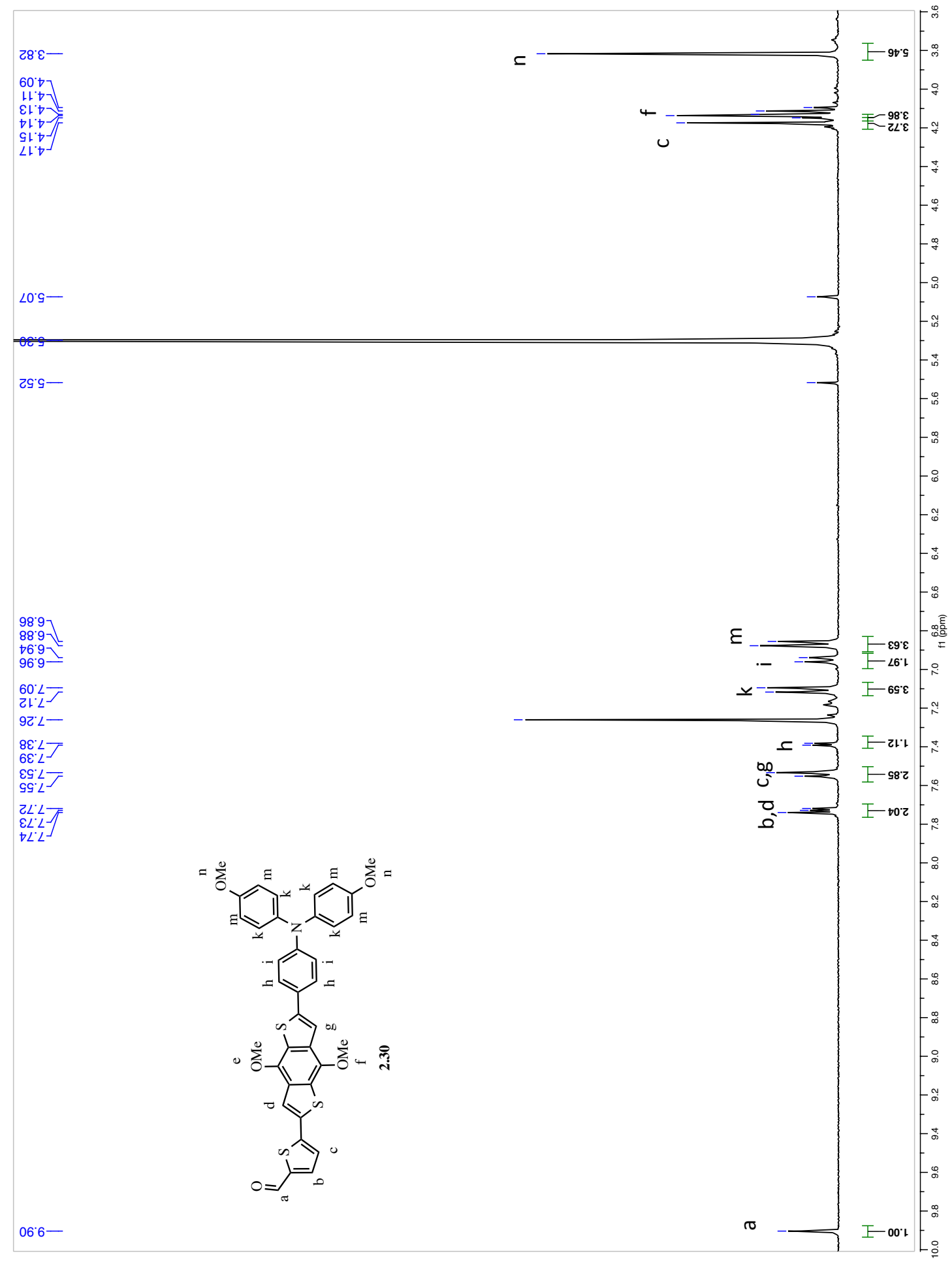




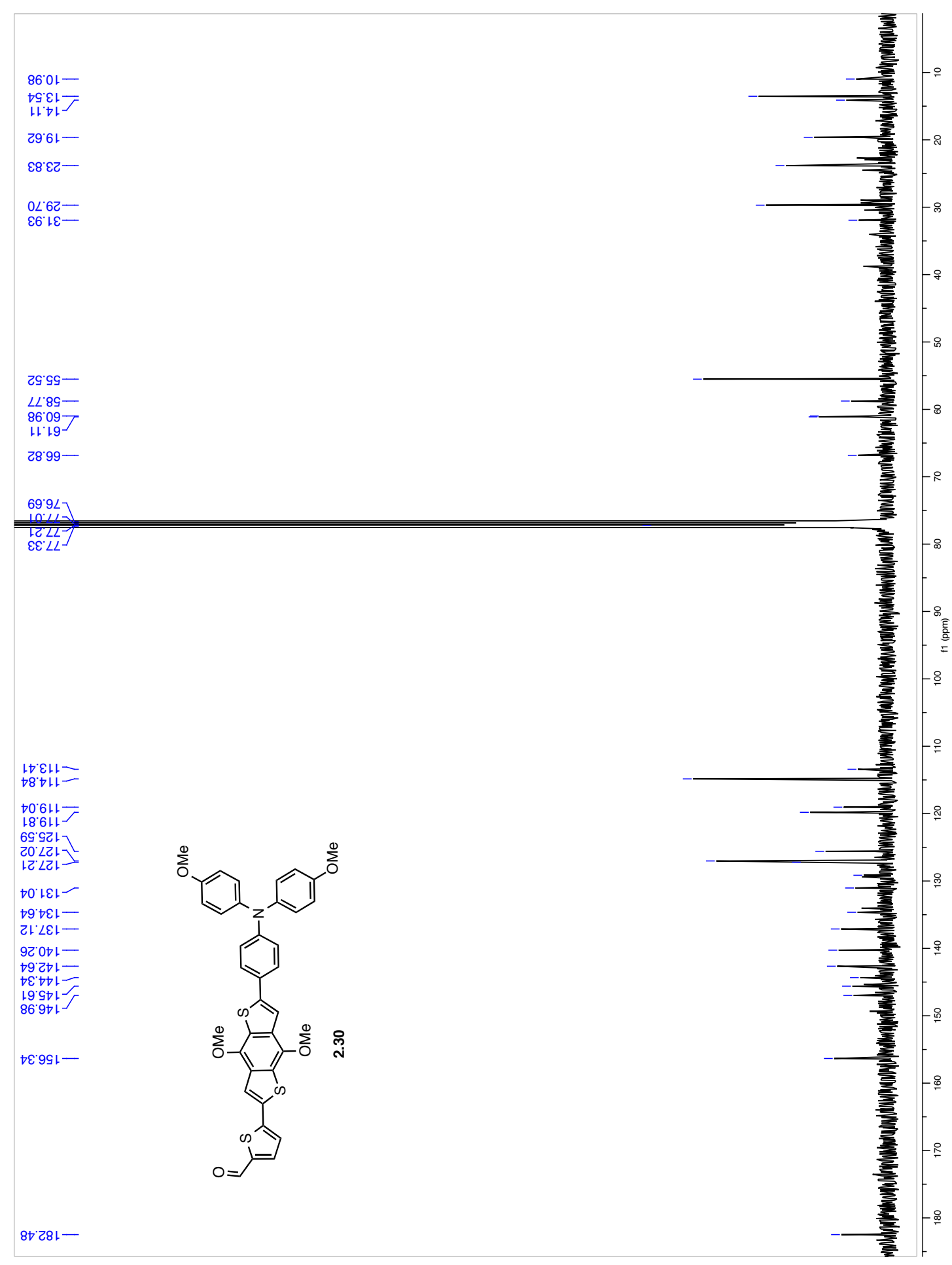




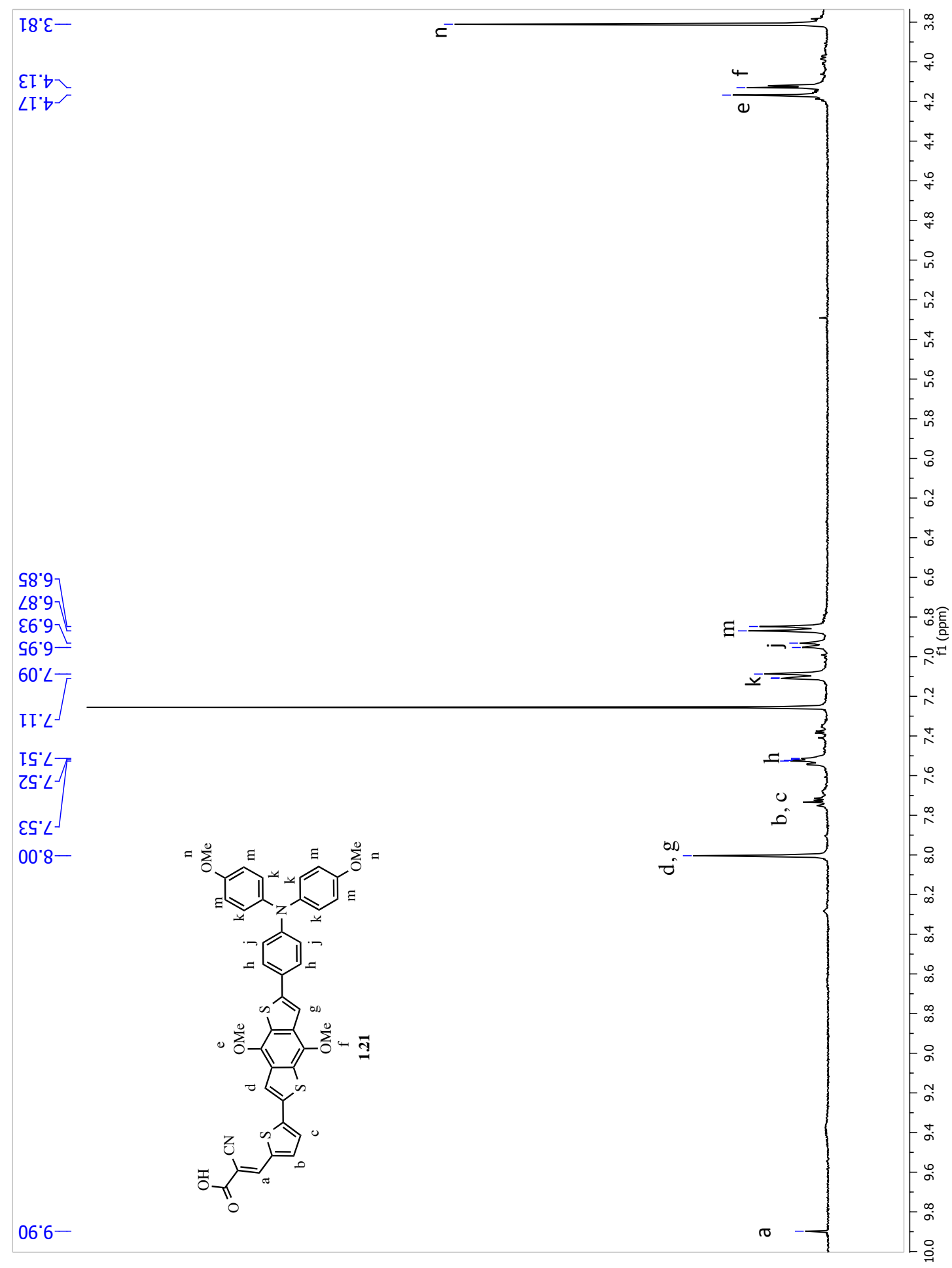




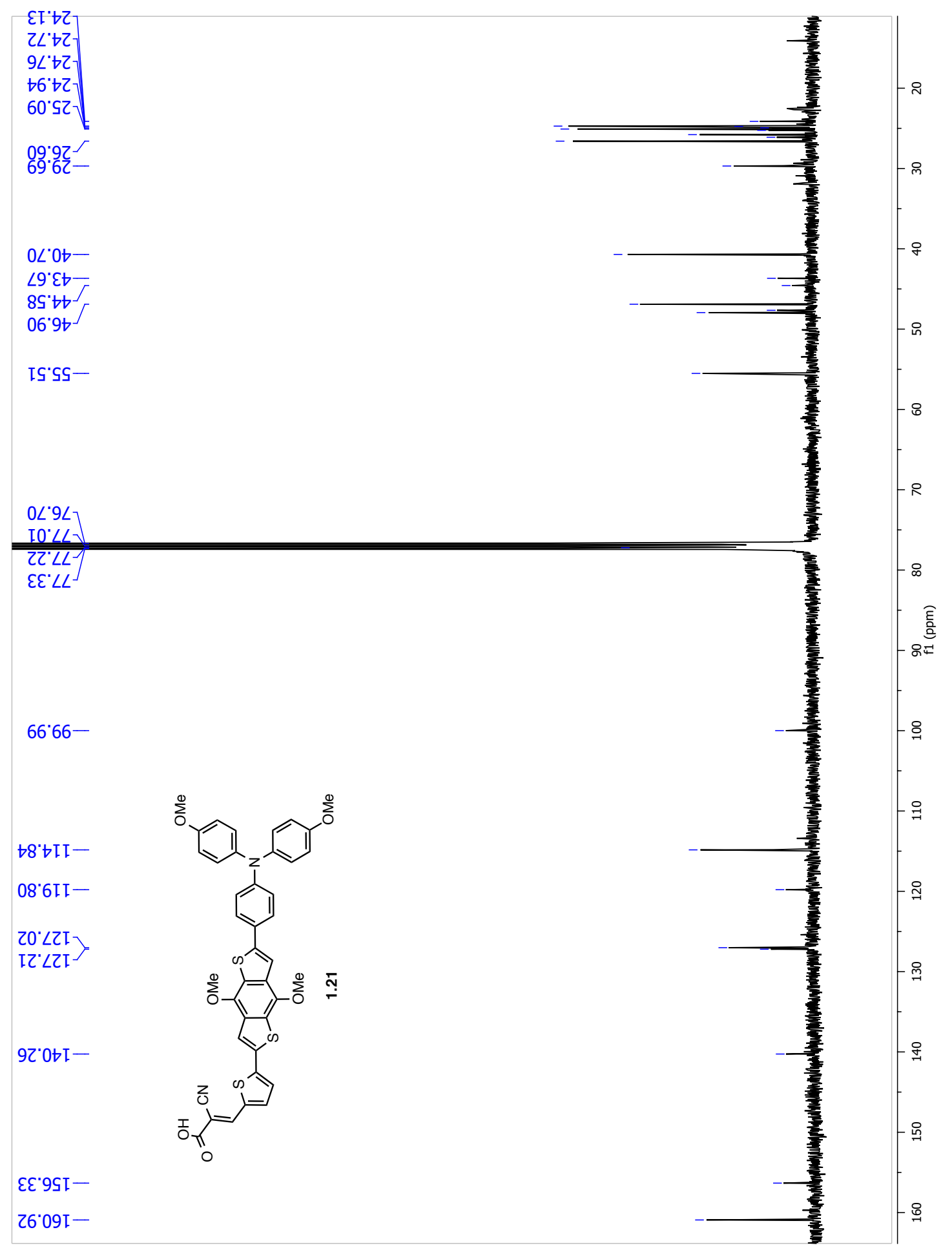




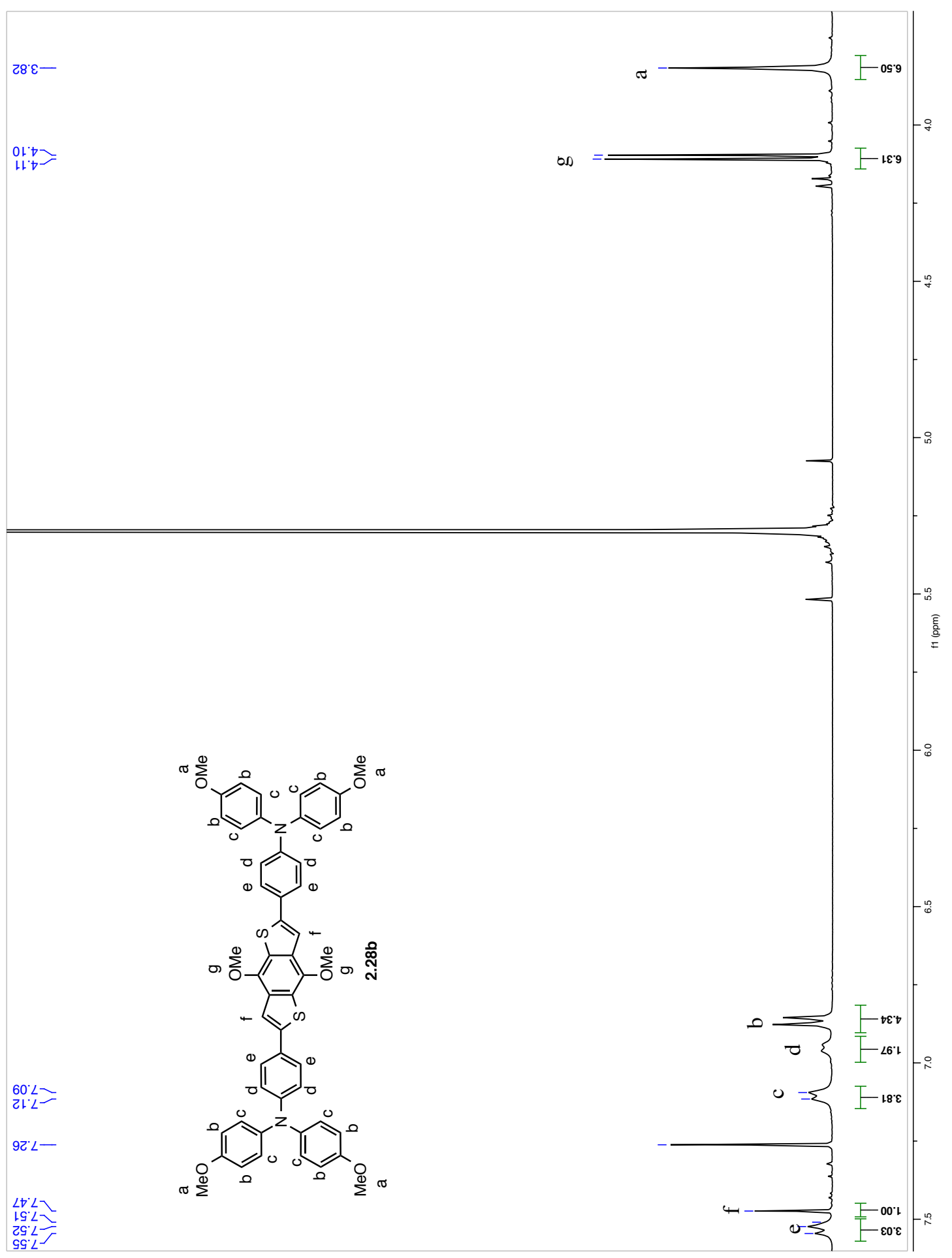




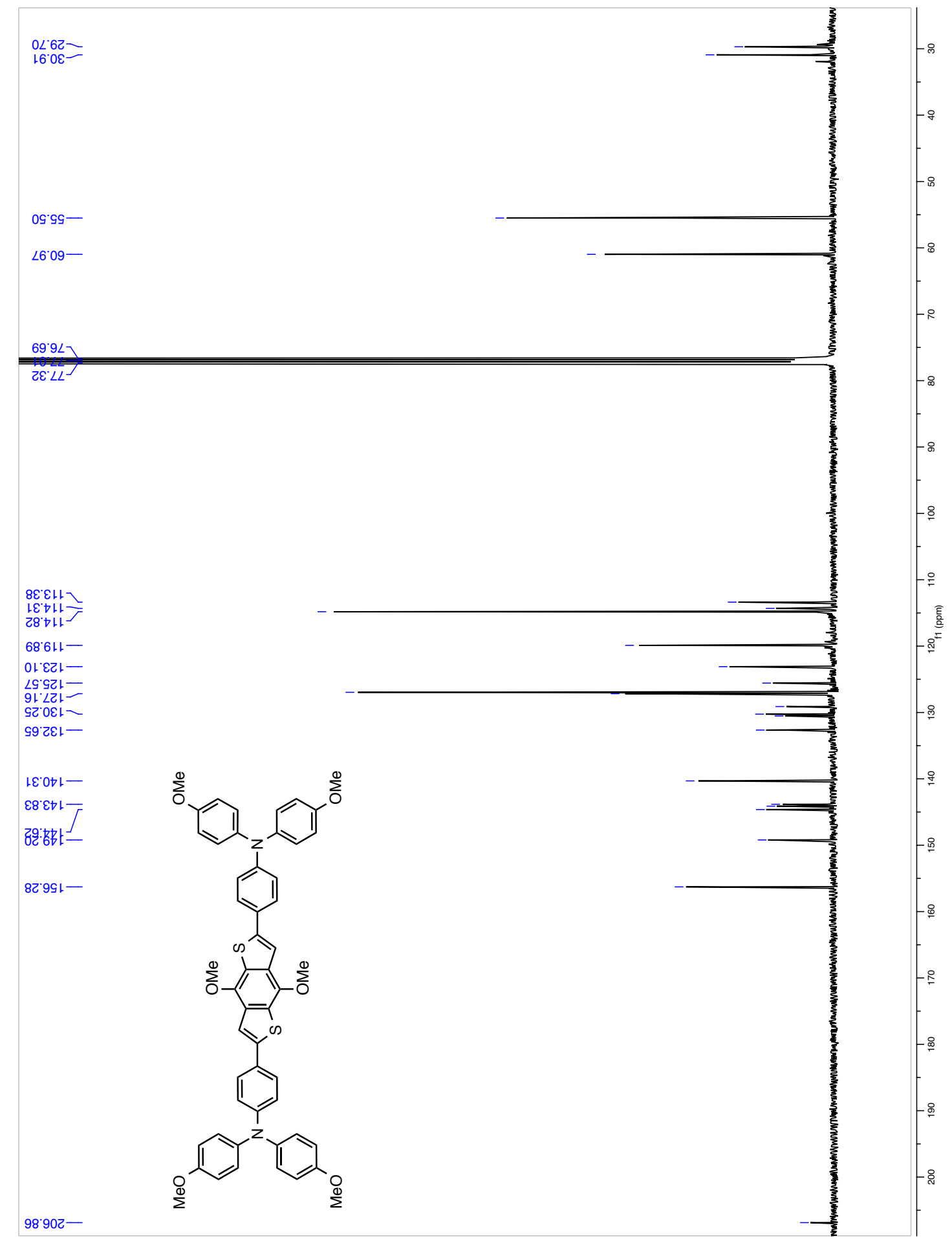




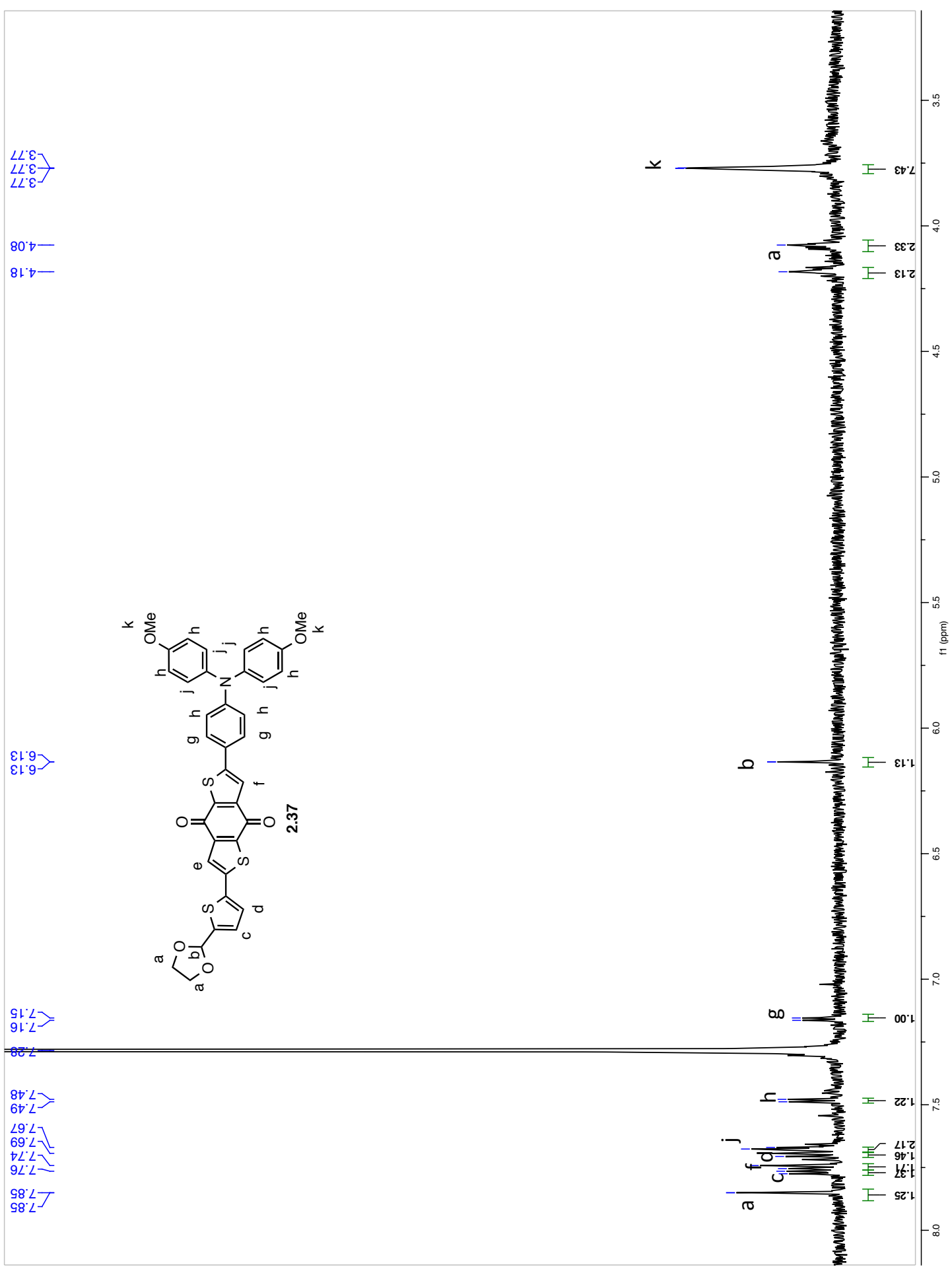




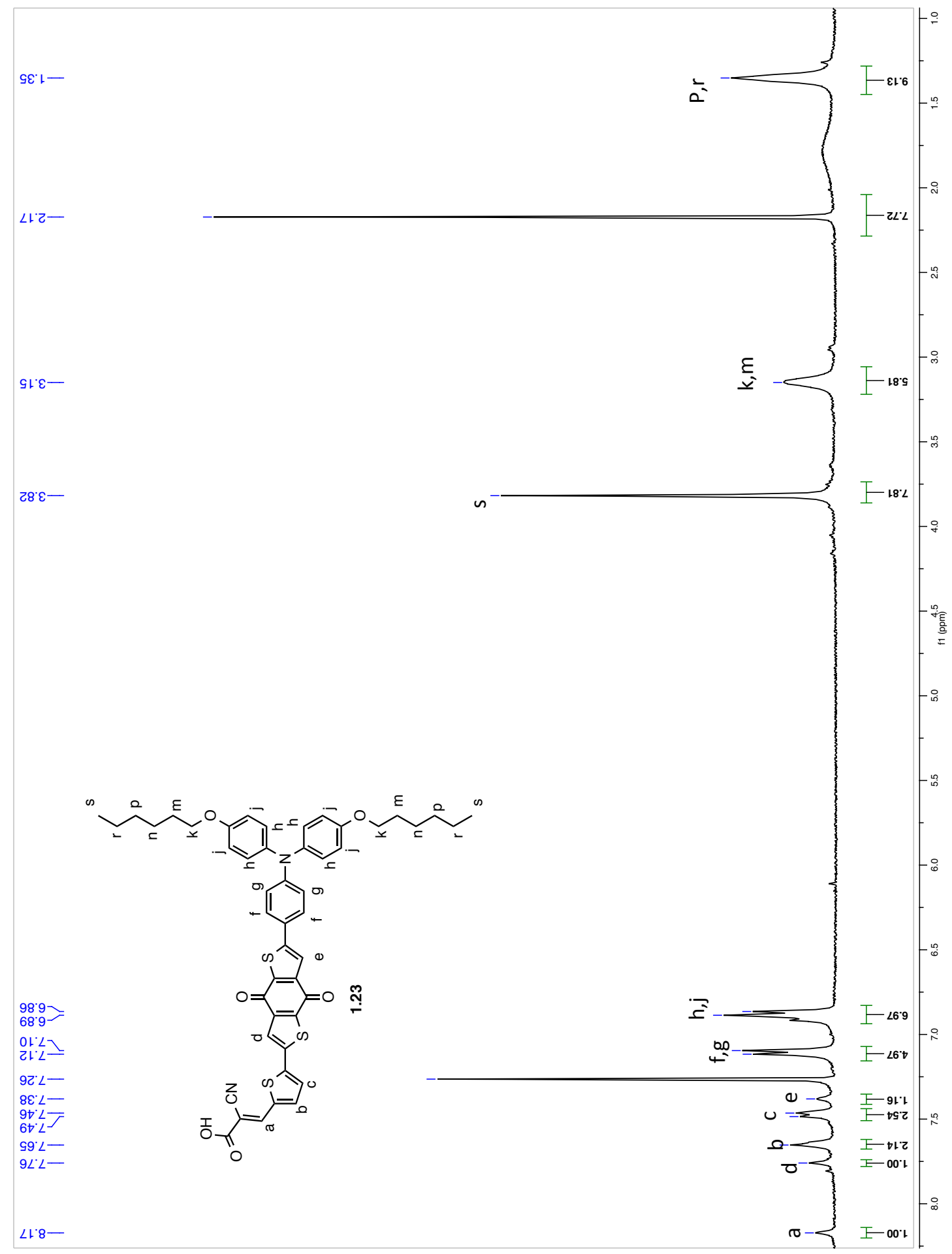

